




SPECIAL PUBLICATIONS

This series is a continuation of the Miscellaneous Series which was discontinued with number 294 . 


\section{Proceedings of a Symposium}

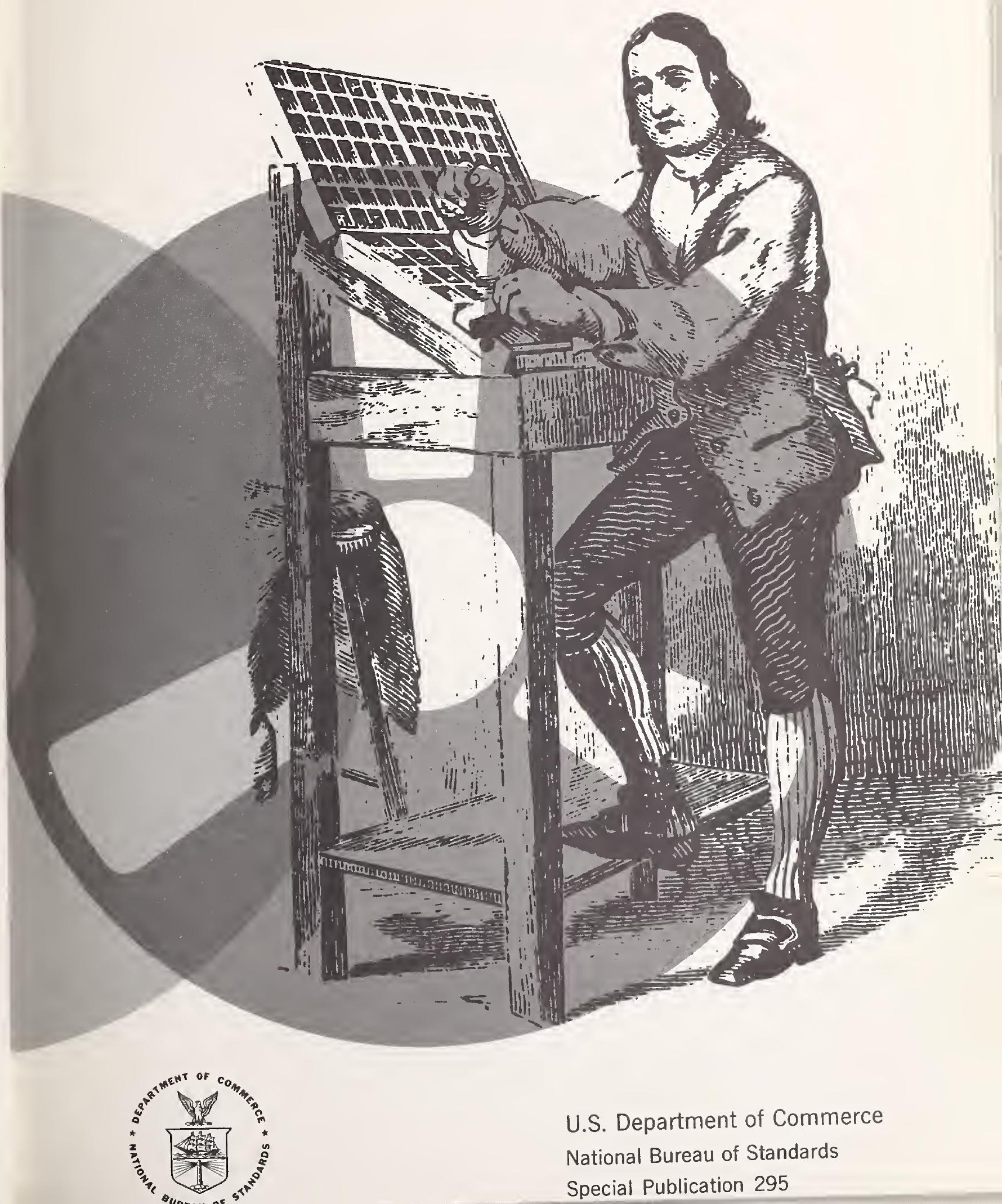





\title{
Electronic Composition in Printing
}

\section{Proceedings of a Symposium National Bureau of Standards June 15-16, 1967}

\author{
Edited by \\ Richard W. Lee and Roy W. Worral \\ Center for Computer Sciences and Technology \\ National Bureau of Standards \\ Washington, D.C. 20234
}

National Bureau of Standards Special Publication 295

Issued February 1968 


\begin{abstract}
A Symposium on Electronic Composition in Printing was held at the Gaithersburg Laboratories of the National Bureau of Standards June 15 and 16, 1967. Sponsored by the NBS Center for Computer Sciences and Technology, the symposium was a state-of-the-art review of a rapidly advancing field of computer application with great potentialities for increased efficiency and savings in the Federal Government.

Twenty-nine papers were presented and are published in this Proceedings. They include a diverse group by industry representatives reporting recent technological advancements in the field. Several papers define government policy and describe the new Linotron system of photocomposition at the Government Printing Office; another series is devoted to nongovernment applications and research; and a final group details specific applications within several Government agencies.
\end{abstract}

Key words: Character generation, composition language, computer technology, computerized text processing, electronic composition, electronic computer, electronic printing, GRACE, Linotron, MACRO coding, MEDLARS, microfilm, photocomposition, Photon, programming, text editing.

Library of Congress Catalog Card No. 68-60021 


\section{Foreword}

The National Bureau of Standards has been active in the field of electronic printing since the early 1960 's. In 1962 , pioneering work by W. R. Bozman of the NBS staff made it possible for the Bureau to publish the first production-line book printed entirely by computer-generated photocomposition. For several years NBS has been assisting other Government agencies to apply electronic printing techniques and, in October 1967, the Bureau established a section for the purpose of applying electronic printing to its own publication requirements.

Under the Brooks Bill (Public Law 89-306), one of the responsibilities of the NBS Center for Computer Sciences and Technology is to advise Federal agencies on the selection and use of computer systems to improve the cost effectiveness of their programs. In line with this responsibility, the Center sponsored a Symposium on Electronic Composition in Printing to permit a state-of-the-art review of this field of computer application which has great potentialities for increased efficiency and savings in the Federal Government.

The Symposium was held at the Gaithersburg Laboratories of the National Bureau of Standards June 15 and 16, 1967 under the general chairmanship of Richard W. Lee, assisted by Roy W. Worral and W. R. Tilley. The Bureau is pleased to have the opportunity of making the papers presented at the meeting available in this publication. Primary responsibility for their technical content must rest, of course, with the individual authors and their organizations.

A. V. Astin, Director. 
About these proceedings-

Although these proceedings deal with radically new printing techniques, they were produced by conventional methods because the limited NBS facilities for preparing machine-readable copy for photocomposition were fully committed to priority scientific programs.

The Editors. 


\section{Contents}

Welcome to NBS, J. P. Eberhard

Introductory Remarks, E. C. Marden

\section{Session I. State of the Art, Dr. L. H. Hattery, Chairman}

Technology of Electronic Composition: an Overview, L. H. Hattery $\ldots \ldots$

The Linotron System, D. H. Rollert__

Computer Image Drawing from Digital Data, M. V. Mathews

High-Speed 901 Zip, A. G. Bernardo

The Videograph Text Editor, G. T. Gerlach

The PhotoTextSetters, A. J. Smith

A Videocomp Systems Approach, A. H. Coleman _.

Micromation-Its Impact on the Photocomposing Industry, J. J. Kalagher

IBM's Position in Electronic Composition and Text Editing, H. E. Weiss_._.

\section{Session II. Government Policy, P. A. Ziemer, Chairman}

An Introduction, P. A. Ziemer

Transition on the Tiber-A New Look at the G.P.O., The Hon. J. L. Harrison

Present and Projected Policies of the J.C.P., J. F. Haley $\ldots$

Session III. Non-Government Applications and Research, Dr. G. E. Roudabush, Chairman

Introductory Remarks, G. E. Roudabush

Chemical Information-A Computer, and Photocomposition, B. G. Lazorchák

The Impact of Electronic Composition on Commercial Printing and Publishing, W. C. Lamparter_- 58

Computerized Typesetting Projections, K. B. Ludwig _

Classification in Computerized Text Processing, R. P. Wishner

System 70, J. W. Seybold

Session IV. Government Applications, S. N. Alexander, M. E. Stevens, Co-Chairmen

A Brief Overview, S. N. Alexander $\ldots \ldots$

Comments, M. E. Stevens

Electronic Composition within the Department of Health, Education and Welfare, E. R. Lannon $--\quad 84$

Electronic Composing System Applications, J. J. Boyle

Use of GRACE at N.L.M., R. E. Bogart $\ldots \ldots$

Computer Typesetting Program at NBS, W. R. Bozman

Typewriter-to-Computer Roster Publication and Maintenance, A. North

Implications of the Electronic Composition System for DSA Publications, W. J. Beran_._. 112

Conversion to Linotron, V. G. Kehler 


\title{
Electronic Composition in Printing
}

\section{Proceedings of a Symposium}

\author{
held at \\ the Gaithersburg Laboratories of the National Bureau of Standards \\ June 15 and 16, 1967
}

Welcome to NBS

John P. Eberhard, Director
Institute for Applied Technology
National Bureau of Standards

On behalf of the Institute for Applied Technology, I welcome you to the National Bureau of Standards.

I am pleased to note that your program includes provision for you to visit some of our facilities here. As we are located on some 560 acres, it will not be possible for you to see everything, but I hope you will take the opportunity to see what you can. One of the more exciting things to visit is a 100 -foot linear accelerator which produces one of the world's most intense electron beams. We also have a high-flux nuclear reactor for research on the properties of materials, and of course a great deal of work going on in various aspects of the computer field.

As I see it, this symposium addresses itself to the merger of two technologies.

- First, the technology that originally began the automation process: the reduction of the alphabet to the printing process.

-And now, the newest and perhaps the most revolutionary technology: the electronic computer.

I happen to be a humanist among the physical scientists here at the National Bureau of Standards. Therefore, I thought it might be appropriate in beginning this session (since I gather from your agenda that you will be filled with the technical know-how in this field in the next two days) that I enter a word from the humanist side of affairs. And this comes from a book that I presume many of you know by now-The Gutenberg Galaxy (University of Toronto Press, 1962), by Mar'shall McLuhan. In this book Dr. McLuhan tells a Chinese fable which I think is appropriate to this occasion.
According to the story, about 2,500 years ago the Chinese sage, Chon 'Tu, spoke of the danger of the machine. He said that as one Choo Chong was traveling through the regions north of the River Han, he saw an old man working his vegetable garden. The man had dug an irrigation ditch. He would descend into a well, fetch up a vessel of water in his arms, and pour it out into the ditch. While his efforts were tremendous, the results appeared to be very meager.

Choo Chong said, "There is a way whereby you can irrigate a hundred ditches in one day and whereby you can do much with little effort. Would you not like to hear about it?"

The gardener looked up at him and said, "And what would that be?"

Choo Chong replied, "You take a wooden lever, weight it at the back and lighten the front. In this way you can bring up water so quickly that it just gushes out. This is called a draw well."

Then anger rose up in the old man's face, and he said, "I've heard my teacher say that whoever uses machines does all his work like a machine. He who does his work like a machine grows a heart like a machine, and he who carries a heart of a machine in his breast loses his simplicity. $\mathrm{He}$ who has lost his simplicity becomes unsure in the strivings of his soul. Uncertainty in the strivings of the soul is something that does not agree with honest sense. It is not that I do not know of such things; I am ashamed to use them."

It is a long way from standards like the alphabet to standards like privacy with respect to the use of computers. But this range of standards is 
included in the kind of standards with which the National Bureau of Standards is concerned. We are not only concerned with nuts and bolts and screw threads or with the standards related to the phenomena of matter and materials. We are becoming increasingly concerned about man and about how man becomes a part of this measuring system.

When we begin to discuss, as we shall here today, matters like electronic composition in printing, I think we are talking about a new era. We are talking about a new stage in the development of technology and of man's use of technology-an exciting one, an important one - and I am sure it is going to make a great difference in our lives.

Let us be conscious, you and I together, not only of the kinds of things that it is possible for us to do, but also the kinds of impact that we are going to have with these new technologies. Let us be conscious of the differences that it is going to make, not only to your life and my life, but to our children's lives, and to those who in the next century are going to inherit from us the technologies of this century. 


\section{Ethel C. Marden}

\section{Center for Computer Sciences and Technology National Bureau of Standards}

In the space of little more than 15 years computer technology has grown until it commands a multibillion dollar annual expenditure. It is the most rapidly evolving and rapidly changing technology that the world has ever known. Originally used only in mathematical and scientific calculations, electronic computers now affect a whole spectrum of areas; one of the newer of these is printing.

It is a common observation that a change of an order of magnitude - that is to say, by a factor of 10 -in a technology produces fundamentally new effects. For example, modern jet planes fly from 400 to 600 or 800 miles an hour-about one order of magnitude faster than the Wright brothers' first flying machine, which flew at about 40 miles an hour. Another example is the automobile, which goes about an order of magnitude faster than the horse and carriage.

Each of these advances has produced dramatic changes in our way of life, both in war and in peace. The automobile and the airplane have made the world a very small place indeed. But these changes have occurred over a period of 50 to 60 years. By contrast, the first stored-program computer was completed only 17 years ago. Yet such computers have increased the speed of computation by more than 7 orders of magnitude orer hand computation. Today we can carry out computations 10 million times as fast as we could 17 years ago and this change has come about in a much shorter period of time than corresponding changes in other areas.

Initially some of the effects of the new technology were ignored. Computers were built to compute, so we used them for that purpose; but we still did things in pretty much the same way-we just did them on a larger scale and we did them faster. In the last few years we have begun to explore many new ways in which this technology can be exploited: in processing credit cards, in banking, in inventory control, in persomel record handling, in technical information handling and documentation, and in electronic composition for printing.

The Federal Gorernment spends more than 3 billion dollars a year in computer rental and purchase and in the application of information processing on computers. When this level of spending is reached, cost effectiveness becomes a very significant factor in operation. Cost effectiveness criteria must be applied not only to the cost of initiating a particular operation but also to the costs of error detection and correction in subsequent information processing operations. In data handling operations these latter costs usually represent the major part of the total expense of the operation. In a multistage information processing activity it is desirable to manage when possible with a single input and to generate subsequent ones. Cost effectiveness becomes significant in measuring different ways of handling multistage operations, particularly when manual handling is involved in any portion of the processing. It is easy to calculate orert costs but rery difficult to put a dollar value on the intangible cost of errors. This cost is a significant feature in many operations, but particularly in report and manuscript preparation. $\mathrm{By}$ means of electronic composition, it should be possible to reduce by a measurable amount the tangible costs of publication and to diminish dramatically those intangible costs associated with error elimination.

The National Bureau of Standards has been concerned with electronic computers since the early days of their derelopment. The first storedprogram computer in this country, the SEAC, was built by NBS in 1950. In 1965, the Brooks Bill (Public Law 89-306) gave NBS additional responsibilities for standards in both hardware and software, for rendering consultation and advice to other Government agencies in the use of computers, and for the innovation and extension of techniques for their use. Here an important area is the application of electronic techniques to composition in printing. In this connection we are very much concerned with the development of techniques to expedite the handling of textual information. It is therefore eminently suitable for the Bureau to sponsor this Symposium on Electronic Composition in Printing.

I should not like to predict what changes we shall see in the computer technology or in electronic composition in the next 15 years, or the next 10 year's, or even the next 5 . But of one thing I can assure youl changes - and dramatic changesthere will be. 



\section{State of the Art \\ Chairman: Dr. Lowell H. Hattery \\ Technology of Electronic Composition: an Overview

\author{
Lowell H. Hattery \\ Professor of Management and Public Administration, \\ American University
}

The electronics industry is at last turning serious attention to adapting its technology to printing processes. Printing plant customers are increasing the pressure for shorter delivery time and lower costs. The inevitable coupling of these two requirements is sparking a revolution in printing composition and production. We may expect major innovation in the next five year's.

Evidence of advancements already visible is found in the excellent review of the state of the art through 1965 in Automatic Typographic Quality Typesetting Techniques, by Mary Elizabeth Stevens and John L. Little. ${ }^{1}$ These advancements are updated in papers presented in the current National Bureau of Standards Symposium.

\section{State of the Art}

From Symposium papers several observations may be drawn:

1. The simple coupling of existing generalpurpose computers and related off-the-shelf equipment is not optimum for printing composition.

2. Extensive research and development targeted on printing needs are under way in major U.S. electronics companies and Federal laboratories and in Europe. It is apparent that this research is accelerating and beginning to bear fruit.

3. Development efforts are following different principles and design. This fact should accelerate the refinement of optimum machines and systems.

4. Hardware and software efforts are proceeding in parallel. In earlier years of computer development, development resources were skewed toward hardware development which resulted in serious lags in software development. Although a similar pattern has been observable in the develop-

1 M. F. Stevens and J. L. Little, Automatic Typographic Quality Typesetting Techniques: A State of the Art Review, NBS Mono. 99 (1967). Available from the superintendent of Documents, Washington, D.C. 20402, Price, 70 cents. ment of electronic composition systems, current programs are in better balance.

5. Whereas the special needs of printing are recognized in development efforts, there is a healthy and growing liberation from traditional concepts and methods which inhibit the effective application of new technology. An example of this is a more flexible approach to graphic arts standards.

6. The state-of-the-art papers are technical by invitation; yet there does seem to be too little recognition, either explicit or implicit, of the full information process of which composition and printing are segments. The nature of the total process or system affects the design of equipment and its application to any segment of the process.

The total information process is undergoing change. This renders the development of hardware and software all the more difficult. Department of Commerce printing industry specialist Harold F. Drury pointed to changes in process in a recent statement:

"Several factors are at work transforming the printing and publishing industries from a trade of craftsmen into units of broadly based communications facilities." 2

John W. Seybold, a pioneer in the concepts and application of electronics to composition, has presented a challenging frame of reference in which to view printing as an element in the information process which is affected by electronics and other developments:

"As the implications are understood and people begin to get insight into what can be done, incredible vistas are ... opened.

? H. F. Drury, The Printing and Publishing Indnstry-Where is it Headed in 1967, Inland Printer-American Lithographer, January 1967 , p. 37. 
So a total system encompasses the creation of knowledge, input, storage, updating, formatting, output, revising, reformatting, retrieval, reproduction, of the information, and ultimate classification of all knowledge in a comprehensible system." 3

Despite the favorable trend in the dedication of research resources to printing and publishing, there still is too limited spread of attention to the full spectrum. Even those concerned with the "big picture" on such a scale as national information networks give too little attention to the printing element. The need for total information process perspective and the active involvement of participants from each element of the system remain insufficiently fulfilled.

In summary, attention to advancing the art of electronic technology as reported in this Symposium is encouraging.

${ }^{3} \mathrm{~J}$. W. Seybold, Between Here and Someday, p. 153 in Automation and Electronies in Publishing, edited by L. H. Hattery and G. P. Bush (Spartan Books, Washington, D.C. 1965).

\section{Organization and Management}

Technological change often forces major adjustments in organization and management of enterprise. It is clear that such adjustments are already taking place in printing and publishing. Wo may expect a growing trend toward combinations of printers, publishers, educational services, communications, and electronics companies. Electronic typesetting is but one of the affective technologies. It is, however, an important development in itself and even more important when associated with new methods of reproduction, communication, and display.

The National Bureau of Standards contribution to the development of electronics science and technology in the past 25 years is outstanding. The NBS staff has been equally concerned with applications of the technology and has been interested in the system relationship of technology to functional and management processes.

Because of this ability to search for relationships, it is especially encouraging to note the sharpened interest of the National Bureau of Standards in electronic aspects of printing. 


\title{
The Linotron System
}

\author{
Donald H. Rollert \\ Section Engineer \\ Mergenthaler Linotype Co.
}

A year ago in another city, I made a presentation similar to the one being given here today. However, there was one major difference. Then we were talking about a machine that was under construction; today we are talking about a machine that is here! We have a film which describes the Linotron Photocomposer. Since this is such an important element of the Linotron System, it is best to show the film before describing the overall system.

A brief description of the Linotron Photocomposer follows: The Linotron consists of three main units: Control, Character Generation, and Display. Magnetic tape is the input for this machine. This tape contains all data characters and control codes required to operate the photocomposer. Four grids, each containing 255 characters, can be loaded into the Linotron. The character generator can position the required grid in one-half second and select any character on the grid at electronic speeds. (There are no shutters or other mechanical devices involved in character generation.) The output of the character generator is an electric signal which serves as an input to the display section. The beam of the display tube is positioned to the required $\mathrm{X}$ - and $\mathrm{Y}$-coordinates; then the signal from the character generator causes the character to be scanned out on the surface of the display tube. This character is projected through a lens onto the film. The beam is then positioned for the next character and this process is repeated until the page is complete. There is no mechanical motion of any kind while the page is being composed. The film is advanced only after the page has been completed. Because of this feature, it is possible to make the statement that the Linotron is an $\mathrm{X}-\mathrm{Y}$ plotter with a built-in character generator.

The Linotron is a slave machine, however, and its control tape must be generated via a software package on a general-purpose computer. The system that we have developed for producing the input tape to the Linotron will now be described in some detail.
A computer program which we call the Master Typography Program has been written so that formatted Linotron Photocomposer control tapes can be produced as output. The input to this program, however, has been kept very simple and flexible. We lave made every effort to keep as many codes unique to the typesetting process out of the input as possible. This has been accomplished by developing the program in such a manner that the specifications of each format which has been designed are stored on a parameter library tape. The specifications for the given format to be typeset are called into memory from the job card.

The Master Typography Program contains many routines which provide for a wide variety of textual and tabular typesetting. There are routines in the Master Typography Program that provide for justification, quadding, or centering of a line. There is, of course, a hyphenation routine. In addition, there are a number of automatic leadering routines which permit the format designer a wide latitude in formatting of this kind. The program also contains routines which allow the format designer to handle data that is tabular in nature. Tables containing a mixture of fixed and variable length fields can be accommodated. It is also possible to mix textual and tabular typesetting within the same format.

However, because the Linotron is an $\mathrm{X}-\mathrm{Y}$ plotter, it is practical and economically justifiable to incorporate into the Master Typography Program a great deal of sophistication in connection with the makeup of a complete page. There are routines which facilitate the justification of each column independently of other columns on the page. A wide variety of running, overlay, and first and last entry heading routines are included. The format designer has a great deal of latitude in the specifying of the folio. There are also elaborate footnote-setting and illustration area reservation routines in the program. The Master Typography Program is a dynamic thing, and as time goes on, we will continue to add greater sophistication, flexibility, and speed to this program. 
As I said before, we have concentrated on making the input to this program as simple as possible. Just how do we go about putting a new job on the Linotron System?

First, a printout of the job to be designed must be obtained. To date we have concentrated most heavily in the area of formatting jobs which are presently contained within a computer system on magnetic tape. Usually our starting point is a computer printout of the data to be typeset. From this printout and in accordance with instructions from the agency, the format designer designs the format. The type of individual who should design this format is one who has a typographic background. The economics of this system demand that the format be well designed. Paper is saved by packing data densely. In a well designed format, data are packed densely but readability is not hurt.

Once the format is designed, a dummy of a page or two is typeset. It is then possible to break the dummy into data elements or copy blocks. Once the copy blocks or data elements have been specified, input coding specifications can be determined. In many cases, in conjunction with computer-generated data, it is possible to take the tape which has been prepared for the computer printer directly as input to the Master Typography Program. No typographic codes of any kind need be inserted. In other cases, however, it is necessary to insert a few codes unique to the typesetting process. This is accomplished by writing an insertion program which takes as input the tape from the data processing system, and produces as output a tape which can go directly into the Master Typography Program.

The next step in design of the format is the preparation of the specification for each of the data elements or copy blocks. It is also necessary to prepare the specifications for the type of folio, running head, and other characteristics mique to the page and independent of the data on input. Forms that facilitate specification of data elements and page characteristics have been designed and instructions for their use have been written.

Once the specification forms for the data element and the page characteristics have been completed, they are sent to the keypunch room for keypunching. (Although he may not have realized it, the format designer has prepared the parameter card layouts for the keypunch.) Once the parameter cards are prepared, they are processed by the Parameter Maintenance Program. It is the function of this program to prepare the Param- eter Library Tape which was mentioned earlier. As each new format is designed, the cards are punched. These cards and the old Parameter Library Tape serve as inputs to the program. The program produces a new Parameter Library Tape which contains the new format in addition to all of the formats which were on the old Parameter Library Tape.

It is also very important to examine the typeset dummy very carefully to determine exactly the character complement that is required. Once this character complement is known, it is possible to select the grids containing these characters. In certain cases where the volume of the job is very high, it may be economically justifiable to specify a special grid containing the character complement. A system for the specification of a new grid has been developed, and instructions for its use have been prepared.

Perhaps I have made the design of a format sound too simple as I briefly described the steps required. I want to point out, however, that it is not a clerical job, and that the type of individual who should design these formats is one who has a knowledge of typography. The Government Printing Office has seen fit to assign men to this function who have extensive typographic backgrounds. The Government Printing Office has also decided to give these individuals training in computer programming. By training in computer programming $\mathrm{I}$ do not mean just a 2 - or 3-day indoctrination course on computers. These individuals have written some complex and ingenious insertion programs. They have also made many criticisms of the typography program as work on it progressed. They have contributed many ideas which have added to its flexibility and usefulness. It is important to emphasize again that the economy to be accomplished with this system is possible only because of clever format design; and this can only be performed by individuals with a great deal of typographic know-how.

The system that has been described is only one system possible for the Linotron Photocomposer. Improvements to this system will be made as time passes. However, I am sure that other Linotron systems will be developed in the future both by users and by us at Mergenthaler. Again, it is worth mentioning and stressing that the Linotron is a device which can place any character at any specified position in an area $8 \times 10 \frac{1}{2}$ inches. Therefore, the formatting is limited only by the imagination, ingenuity, and perservance of those developing the software for this system. 


\title{
Computer Image Drawing From Digital Data
}

\author{
M. V. Mathews, Director \\ Behavioral Research Laboratory, \\ Bell Telephone Laboratories
}

The basic process of computer image drawing is shown in figure 1. A cathode ray tube is photographed by a camera, both being controlled by a digital computer via a digital-to-analog converter. The four controls that one needs are an $X$-position control, a $Y$-position control, a brightness control for the electron beam, and a control of the film advance in the camera. The face of the oscilloscope is shown in the figure. We use an area composition in which a whole page appears on the face of the oscilloscope. The alphabet of drawing strokes from which all images are formed is very simple and consists only of two strokes: a straight line and a point. The point is specified by two numbers, an $X$-coordinate and a $Y$-coordinate, which come originally from a digital magnetic tape that provides information to the computer or from a memory within the computer. Specification of the line requires four numbers.

What determines the performance of this type of system? There are three main characteristics. One is the resolution of the oscilloscope, which can be measured in terms of the number of justtouching dots that may be put across the page. Resolution figures for currently available equipment go from about 500 to about 10,000. The

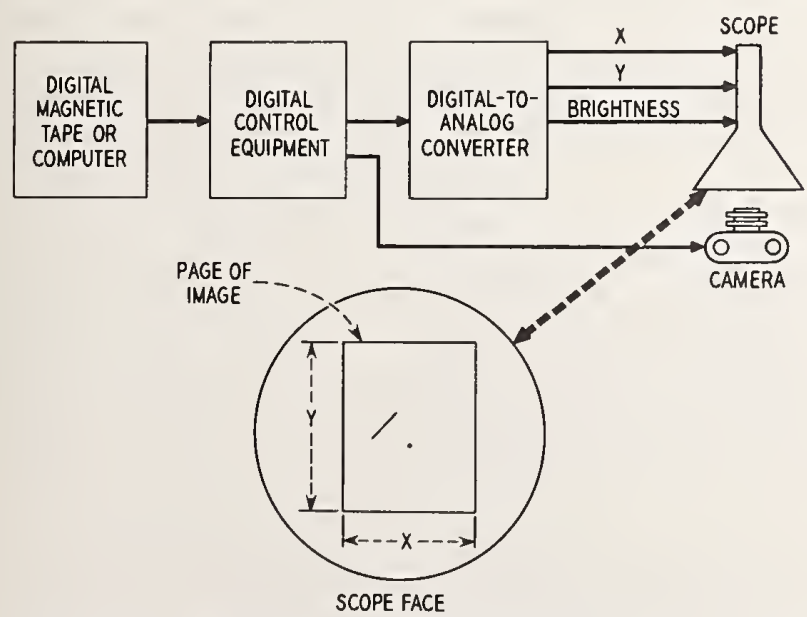

Figure 1. Computer controlled cathode ray tube for image drawing. second figure of significance is the size of the digital raster or the number of positions in the $X$ and $Y$ directions at which one may display a dot. Current numbers vary from 1024 up to slightly more than 16,000 . The last figure is speed which goes from about 500 characters per second up to 10,000 characters per second. We will be more specific about these figures for particular equipment later.

The second figure shows an example of the art of digital type design. It is basically a process of enlarging an image onto a Cartesian coordinate grid. In this particular encoding the image is represented by a number of short, straight lines or vectors. One numbers the coordinate grid 0,0 at
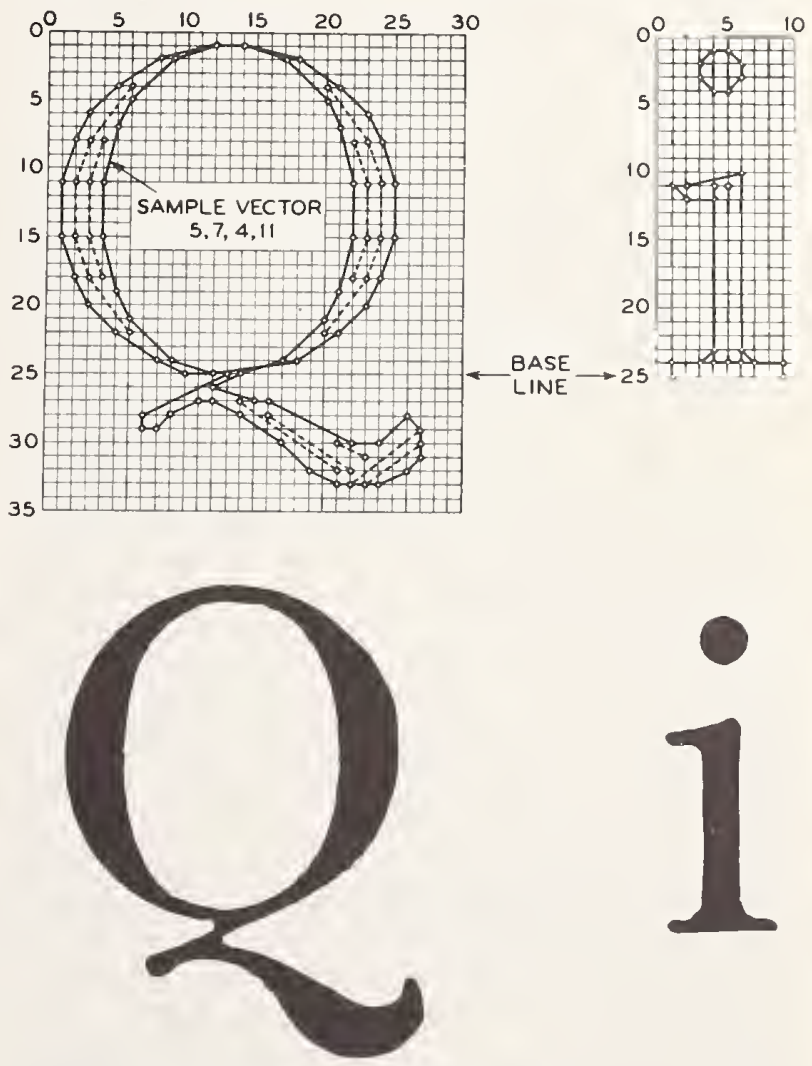

FIGURE 2. An example of digital type design. 
the upper left-hand corner and reads the coordinates of any given vector. For the sample vector, the upper end is at the coordinates 5,7 and the lower end at 4,11. All the vectors in the letter can thus be converted into numbers for the computer. This is a tedious process but must be done only once for a letter. Furthermore, there are ways of semiautomating the process.

It is possible to take advantage of the raster which is built into the computer and to adjust the shape of the letter so that the ends of the vectors fall exactly on raster points. This gains roughly a factor of two, in terms of the number of raster points that are required to get a given quality of letter, over randomly positioning the letter.

An example of this type of encoding is shown in figure 3. It is an alphabet which we designed and used at Bell Laboratories as an output for our computers via a Stromberg-Carlson 4020 microfilm printer. The resolution of the Stromberg-Carlson is a bit less than 500 points; the raster size is 1024 $\times 1024$; and the speed for this particular alphabet is about 100 characters per second. The Strom-

\section{A B C D E F G I JKL M N P Q R S $T \cup V W X Y Z$}

a bcdefghijkl m nopqrs

t u v w $x$ y $z$

\& 代 fif

$$
\text { [ ] \%/申@\#*0ø+\% }
$$

$\$ 1234567890$

, , : : ? ", “"

$\subseteq(\supseteq)$

$\leq<\geq>\neq \neq$

$+-= \pm \div \times \sqrt{ }$

$\int \partial \Delta \infty$

$\measuredangle 1 \equiv \|$

A B $\Gamma \Delta E Z H \Theta I K \Lambda M N \equiv O \Pi P \Sigma T$ $\Upsilon \Phi \times \Psi \Omega$

\author{
$a \beta y \delta \in \zeta \eta \theta \iota \kappa \lambda \mu \nu \xi \circ \pi \rho \sigma \tau$ \\ $v \phi \chi \psi \omega$
}

Figure 3. A sample font using vector letters.
berg-Carlson is a general-purpose computer output device not especially designed for printing purposes although it is useful to have an alphabet. This particular font includes upper and lower case, some ligatures, some special symbols, the numbers, punctuation, some mathematical signs, and upper and lower case Greek letters. It was selected for scientific applications. It is available in three sizes.

If one attempts to get better letter qualities than this, one must use scopes with higher resolutions, which are available. However, with a simple vector encoding, too much memory space to store the numbers that describe the shape of the letter may be required. One needs a more efficient encoding scheme, partly to save memory space and partly to allow speeding up the drawing process. An example of a more efficient encoding scheme called patch coding is shown in figure 4. It has been previously described, ${ }^{1}$ so we will mention it briefly.

${ }^{1}$ M. V. Mathews and J. E. Miller, Computer Editing, Typesetting, and Image Generation, AFIPS Conference Procedures, Vol. 27, Part 1, 1965 Fall Joint Computer Conference, pp. 389-398.

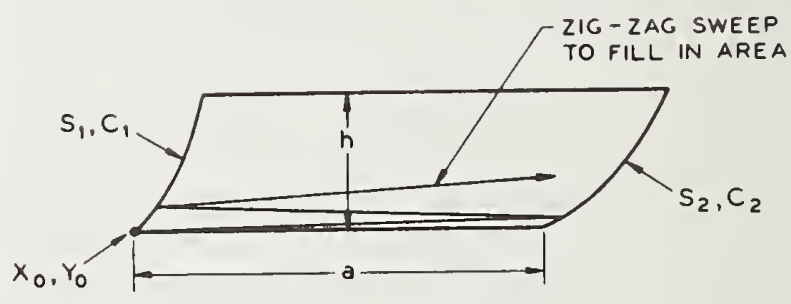

(a) PATCH

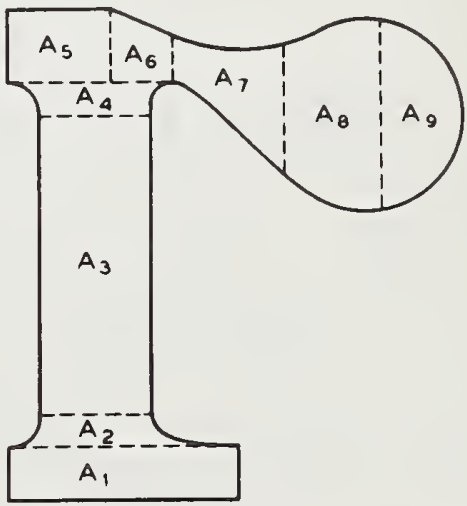

(b) FORMATION OF LOWER CASE " $\Gamma$ " BY PATCHES

Figure 4. Patch encoding. 


\section{An electronic system drew,}

\section{then set in words, sentences, and}

justified columns the letters you

\section{are now reading.}

FIGURE 5. An example of printing using patch encoded letters.

Each shape is decomposed into a number of subareas or patches (labeled $\mathbf{A 1}$ through $\mathbf{A} 9$ on the figure). Each patch is described by numerical paramaters so that the shape of the patch itself can be varied over a large range by changing these numbers. Each patch has two curved sides whose slope and curvature are specified by four numbers. The curved sides are suitable for matching the curved sides of letters (or images in general). Each patch has two flat sides which are suitable for stacking without leaving interior spaces. The patches can be also turned 90 degrees in case one wants to approximate curved upper and lower surfaces, as is usually necessary.

An example of some printing using the patch system is shown in figure 5. It is again done on the Stromberg-Carlson 4020 and, hence, is a demonstration since this instrument is not suited to production of this type. The resolution and raster are the same as for the previous example. The speed is 25 letters per second. A roughness in the shape of some of these letters is visible because the raster in the 4020 is too coarse compared to its resolution. The raster spacing is about one-half of the resolution distance; a raster spacing of one-quarter the resolution distance would be better. One-quarter the resolution distance is a good rule of thumb in designing equipment of this nature.

So far, our particular examples are all computer microfilm output. Let us next look at what can be done with a special piece of equipment designed particularly for printing. A number of companies are developing digital printing equipment. $\Delta$ s an example we will show a sample from Alphanumeric Incorporated. The particular cathode ray tube configuration is shown in figure 6 .

They have slightly amended the idea of area composition and use what we call slit composition. Images are drawn in a rectangular slit across the cathode ray tube which images to about $1 \mathrm{in}$. by $10 \mathrm{in.}$ on the film. The film is moved continuously

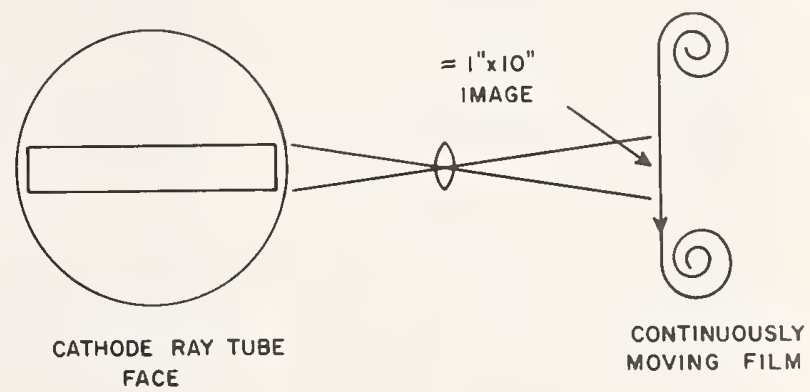

FIgURE 6. Cathode ray tube configuration for slit composition.

and the vertical position on the page is obtained by the movement of the film. In this way one can achieve higher resolution from a given cathode ray tube by a factor of at least the square root of two. Of course, it makes it more difficult to insert images that are wider than one slit. 'The slit is wide enough so that one could draw most mathematical equations that extend over several lines or put in subscripts and superscripts.

The encoding scheme which they use for characterizing letters is a proprietary scheme and we do not know the details. However, I think it is similar to the patch encoding. The font memory which contains the description of several on-line fonts is about $10^{6}$ bits. Figure 7 shows an example of their output. The resolution is greater than 5,000 points across the screen. The speed is impressive, somewhere between 3,000 and 10,000 characters per second for the small size characters. The speed depends on the size of the character and is, of course, slower for large characters. The higher speed is a proofing mode and the lower speed is for high quality.

What is the next step in the process of image drawing? One possibility is a direct electron 
GAMBITTA, ALFRED F. (M) (L), Retired, S. Fratello, GAMBLE,'BRICE, G. (M), Engr., Texas instruments,

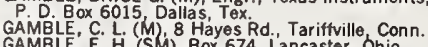
GAMBLE', E. H. (SM), Box 674, L'ancaster, Ohio GAMBLE, FRED D. (M) Radio Engr. Supvr. Dhio
Dept. of Highways, 1620 W. Broad St., Columbus GAMBLE, GEDRGE P. (F) (L), Executive V.P. Union GAMBLE, GDRDDN L. (M), Bell tel. Labs. 3B 192, Whippeny, N.J.
GAMBEE, S. (M) Box 537 Mt. Baldy, Calit.
GAMBLE, J. S. (M), 10700 Gregory St., Silverspring MAMBLE, JDHN L. (A), Technical Writer, Hewlett. Packard Co., Frequency \& Time Div., 1501 Page Mill Rd., Palo Alto, Calit.
GAMBLE, JDHN T. (M), EMCTT-1-RADC, GAMBLE, JDSEPHA. (M) Chief Engr., Columbus Broadcasting Co. Inc., 1350 13th Ave.. Columbus Goorgia
GAMBLE, LESTER (F) (L), Retired, W. 1012 23rd Ave Spokane, Wash. sell \& Associates, $6620 \mathrm{E}$. Washington St., IndianGAMBLlis, Ind. R. L. (A), W. Star Rt., Box 375, Fallon, Nev. Dakota'State Univ.. Brookings, S.D.
GAMBLING. W. ALEC (SM), Prof. of Electronics, Univ. of Southampton Southampton, Eng. communications, Post D ffice Bidg., 'Manila Philipgines
GAMBOA, GONZALEZ JAMES E. (M), Engr. TechnicalEconomical Dept., Asociacion Nacional De Empresa

GAMBDA, JDHN F. (M), USS Columbus CG-12, APD San Francisco Calif. etion, Lockhood Georgia Co., $86 \mathrm{~S}$. Cobb Dr., Mariette Ga

GAMGRELL, J.B. (M), Box 1971, Senta Ana, Calif. GAMBRELL, VERNDN'C. (M), Electronics Engr.
ITI Industrial Leb., 3700 . Pontiac St., Fort Weyne Ind. Leb., 3700 E. Pontiac St., Fort of Ships, Nav Dept. Washington, D.C., Bureau

Farm ington, Mich.
GAME, LEDNARD C. (M), Inspector, Canadian

Standard Assc., 178 Rexdale Blvd., Rexdale,

Dntario Can.
GAMEL, GAYNE D. (M), Engr., Westinghouse Electric Corp., East Pittsburgh Pa. Corp. 736 N. Beal St, Fort Walton Beach, Fla.
GAMERTSFELDER, GEDRGE R. (SM), Reseerch Con sultant, GPL Div, General Precision, Inc., 63 Bedtord Rd., Pleasantwille N.Y. (M), Project Engr.
GAMERTSFELDER, HDWARD E. (M), Dept. of Army ' Washington, D.C.
GAMES, KEITH' M. (M) Regional Mgr. James R Kearney Corp., 9433 Montgomery Rd., Cincinnati,

Dhio GAME, WILLIAM A. (SM), Sr. Elec. Mechanical Design Engr., Rocketdyne, NAA, 6633 Canoga GAME Ca TIAM, TAKVDR (M) Sr. Equipment Engr., West ern Electric Co., Inc., 898 Stewart Dr., Sunnyvale, Celif. GAMMELL, HENRY C. (A), District Mgr., National
Telephone Sales, Motorola, Inc., 2720 's. Birch, Denver, Colo.
GAMMELL, J. (SM), 3227 North 104 St, Milwaukee, GAMMELL, PAUL M. (M), Research Graduate Asst. Catholic Univ of America, Washington, D.C.
GAMMIE, JAMES (M), Member Technical Staff, Bell Te, JAMES (M), Member Technical Sta Andover, Mass.
AAMMDN, C. (M), S A M Box 4157, Brooks AFB Tex. P.O. Box 339 , Cambridge, Mass. NASA-MSC Houston, Tex.
GAMMDN, GEDRGE T.'(M), Engr, Alabama Power Co., $600 \mathrm{~N} .18$ th St, Birmingham, Ala.
GAMD, H. (M), Univ. of Rochester E Dept., River Campus Station, Rochester, N.Y. Campus Station, Rochester, N. Transmission Div. Illinois Bell Telephone Co., 20 ' W. Washington
St. Chicago lil.
GAMPHER W. G. (SM), S.W. Bell Tel. Co., 1010 PAMB St. Louis. Mo. (A) Staff Engr. MIT Instr Lab., 68 Albany St. Cambridge, Mass. GAMSDN. EDWIN R. (SM), V.P. \& Div. General Mgr.
Wyle Labs. Products Div., i33 Center St., El Segundo, Calif.

Svenska Radioaktiebol

Alstromergatan 14. Stockholm Sweden
GAMUS, ABRAHAM (M). Engr., international Systcoms, GAMW 4946 Bourg St. Montreal, Quebec, Can. GAMWELL, DAVID L. (A) Product Service Rep., GE,
Drdnance Dept., 100 Plastics Ave., Pittsfield, Mass. W. (M), 3225 Riverside Dr., Riverside, Dnt. GANAHL, PAUL J. (SM), Staft Engr., FMSAEG, Fleet Missiles Systems Analysis \& Evaluation Group, Cor. ONa, Calif. N (M) Project Leader, Telecom Dept. Canadian Marconi Co., 2442 Trentón Ave., Montreal, Quebec, Can.
GANARD, THOMAS (M), Div. Field Engr, Atiantic City Electric Co., 1600 Pacific Ave., Atlantic City, GANCIE, JDSEPH J. (A), V.P., ITT World Communications Inc. 1707 L St. N.W. Weshington, D.C.
GANDHI, CHANDRAKÁN D. (M), Managing Dir., Emco Transformers, Ltd., Ballard Bldg., Manglore St. Ballard Estate, Bombay, India
GANDHI, D. P. SM Engineering Pilani, India 310 A.RIVERA, LUiS (SM), Consultant, GANDIN, PAUL' (A), Engr., La Radiotechnique, 51 Rue GANDIN', R.A. (M), 1388 Bob white Ave., Sunnyvale, GANDLER, BERNARD R. (M), Staff Engr., IBM, Monterey \& Cottle Rds., San Jose, Calit GANDDLPH, ANDREW A.' (M), Staft Engr, Genera Telephone \& Electronics Infernational, Inc., 730 GANDDUR,'J.R. (M), 404 N. Page Ave., Endicott, GANDY, CHARLES L. (M), Branch Chief, Dept. of Defense, 7520 Creighton Dr., College Park, Md. GANDY, L. DOUGLAS (M), Teacher, York Township GANDY, W. H. JR. (A), Design Engr., The Boeing GANDY, WDDDRDW W. (SM), Chief, ECH \& M\&TC, General Dynamics, FW, Fort Worth, Tex.
GANE, CHARLES E. (M), Sr. Elec. Engr., Melpar Inc. Arlington Blvd. Falls Ch. Va. Vales Engr, GE, 1115 East Rd. St. Louis Mo.
GANG, RD'BERT E. (M), Electronics Engr., Varian Associates 611 Hansen Way Palo Alto, Calif. ANGADHAR K. A. (M), c/o The Post Master, Aerodromo P.D. Coimbatore 14, South India PSG College of Technology, Coimbatore 4, Coim batore, Madras india Ackerman Engravers, (nc., 43-22 36th St., L.i.c. N.YGANNA H.V (M) Karnatak Science College, Radio Physics Lab., Darrarr, Dharwar, Mysore, GANIIa WERE, LLDYD B. (M), Sr. Engr., Westinghouse

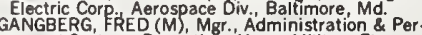
sonnel Systems Dperation. Heavy Military ElecGANGE, RDBEkTA.' (M), Member Technical Staff, RCA Labs. Princeton. N.J.
GANGEL, MARTIN W. (M), Application Engr., GE, 1 River Rd. Schenectady, N.Y. GANGER, GA'RY M. (A) Eloctronic Technician, U.S
Air Force, TDCET.ASD, Wright Patterson AFB, GANio ANTHDNY F. (M), Assoc. Prof., MIT, Rm. GANGL, ERWIN C. (M), 4313 Blue Rock Rd., Dayton Oh GANGNES, ALFRED V. (SM), Pres., Interstate Elect. ronics Corp. 707 E. Vermont Ave., Anaheim, Calit GANGNON, ROBERT' N. (A), Protection \& Control Technician, Dntario Hydro Elec. Power Comm., 200 Kipling Ave. S. Toronto, Can.

GANIAS, THEMISTDCLES E. (M), Task Mgr., Com. munication Systems, Inc., S.60 State Hwy. N. 17, GANIERE, HERBERT C. (M), Mgr., Eloc. Equipment Design, Centralab Div., Glove Union, Inc., $900 \mathrm{E}$. Keefe Ave. Milwaukee, Wis.
GANN, ALAN G. (M), Elec. Engr., Federal Power Commission, 441 G St. N.W., Washington, D.C. MASS. DDNALD A. (M), Elec. Engr., Hewlett-Packard, Boonton Div., Green Pond Rd., Rockaway, N.J. GANN, GRAHÄM D. (M), Sr. Dev. Engr. Standard
Telephones \& Cables, Ltd., Oakleigh Rd., London N11, England
GANN, WiLLIAM C. (M), 2115 Brookline Dr. N.W., Huntsville, Ala.
GANNAWAY, RDBERTSN R. (SM), Principal Engr. Raytheon Co. 6380 Hollister, Goleta, Calit. Hebron Dr. Hendersonville N.C.
GANNETT, ELWDDD K. (F) Dir., Editorial Services, IEEE, $345 \mathrm{E}$. 47 th St., New York, N.Y. GANNETT, G. L.'(M), 48 N. Main St.' Jordan, N.Y. EANglewoód, N.J. Charlotte N.C.
GANNDN, C. C. (M) 118 Homestead, Clarksville, Ind.
GANNDN, EDMUNB C. (M) Electronic Engr., USN Underwater Sound Lab., Ft. Trumbuil, New London, GANNDN, GEDRGE F. JR. (A), Electronic Technician, Westinghouse Electric Research \& Dev. Center, Pittsburgh, $\mathrm{Pa}$.

ANNON, J.' J. (A), Colonial Gardens, 1036 Kearney GANiNDN, JDHN W. (M), Engr., Boston Edison Co.,

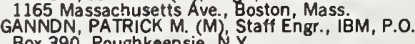
Box 390 , Poughkeepsie N.Y. 675 Howard St., San Francisco, Cali. GANO, ALFRED S. (SM), 88 N. Kensico Ave., White GAains, N.Y. AAND, JDSEPH J. (SM), General Mgr., Dynamic Con.
trols Co., 2225 Massachusetts Ave., Cambridge, Mass. Anes. Dept., R208 Med. Center, Stanford Calif. GANOBSIK NDRBERT J. (M), Elec. Engr., Cleveland Electric Jlluminating Co., Box 5000 , Cleveland. Dhio
GANOTE, MARVIN D. (M) Project Engr., USAF, AFLC Support Group, Box 1525 , vandenberg AFB, Calif. GANS, JOSEPH S. (A), Pres., Cable Equipment end Service, Inc. 217 E. '9th St.. Hazieton, Pa.
GANS, M. L. (M), 304 Ocean Ave., Ma ssapequa Pk., GANS, NATHAN (M), Engr., Partner, Gans, Kofman Assoc., Alpha Engineering, 1171 St. James St. W., Montreal, Que., Can.
GANSCHOW, DD C. (SM), Planning Engr., Pan AmeriGANSENBERG, VALEN Electronic Service Assoc., 28 Eastman Ave., Gorol Mass.
General JACQUES S. (M), Program Mgr.,
Genision, 150 Totowa Rd. Wayne, N.J. GANSSLE, KARL A. (M), Asst. V.P. Engrg., South western'Bell Tel. Co., 1010 Pine St., St. Louis, GANSTWIG, MAX (SM), Assoc. Mgr. TRW Systems GANT, bDNALD W. (SM), Engr. Commonweelt GANT, DDNALD W. (SM), Engr. Commonwee
Edison Co. 1319 . Ist Ave. Maywood III. GANT, JAMÉS C. (M), Sr. II Engr., Distribution,
Alabama Power Co., P.D. Box 211 , Montevello, GANT, RAYMOND C. (M), Russell Ditices, Royel Australian Air Force, Canberra A.C.T. Australia GANTHER, CHARLES E. (SM), General Super intendent, Elec. Div. The Cleveland Electric lluminating $\mathrm{C}$ GANTHER, J. R.' (M), Box 1454, Houston, Tex. GANTICK, NDEL A. S. (M), Engr., Collins' Radio Co., 5220 CAve. N.E. Cedar' Rapids, lowa
GANTNER, JDHN C. (M), Regional Sales Coordinator, Brown Boveri, Canada, Ltd., 4000 Transcanada Hwy. Montreal Can.
GANTSWEG, MARVIN (M) Sr. Design Engr., ITTFL, 15151 Bledsoe St, San Fernando, Calif.

GANTT, CLINTDN L'. (M), Sr. Mfg. Engr., Texas
Instruments, Inc., Semiconductor Div., P.D. Box
5012 , Dallas. Tex.

GANTI, E. D. (M) 8 Kings Rd., Lynnfield, Mass. GANTI, LEVON, JR. (M), Research Engr., Boeing, Astronant Blvd.' Cocoa' Beach, Fla.
GANTT, MELVIN S. (SM), District Engr., Southern Bell Tel. \& Tel. Co., P.O. Box 3158, Winston GANTZER, G.C. GRALD A. (M), Assoc. System Engr. IBM, 447 E. Broad, Columbus Dhio GANZ, DDNEL C. (M), Elec Engr., Martin Co.,

GANZ, GED'RGE D. (M), Sales Engr., GE, P.O. Box G2045, Houston, fex. ola Inc. 4501 W. Auqusta Chicago, III. Phillips, Inc., 3050 N. California St., Burbank,
Pand GANZER, RAYMDND W. (M), Protection Engr., San Diego, Calif.
GADN DAVID (M), Engrg. Writer \& Editor, 100 Hoyt GAPASIN, F. G. (M), 12864 Gilmore Ave., Los Angeles Calif. GARA, WJLInamics, Grants La., Fort Worth Tex. Oscar Mayer \& Co., 910 Mayer Ave., Madison, Wis. GARABEDIAN, ARTHUR (M), Member Technical Staff, TRW Systems, Dne Space Park, Redondo Beach, GARAFALD, JDSEPH J. (M), Asst. Dir., Field Service \& Support, Hughes Aircraft Co., Culver City, Calif.

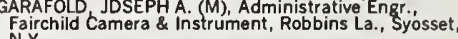
GARAFOL, JDSEPHR. (M) Sr. Engr. ARINC Research Corp., $1700 \mathrm{~K}$ St., N.W., Washington, GARANICH, RDNALD J. (M), Junior Engr., Pennsyl. vania Electric Co., 1001 Broad, Johnstown, Pa. GARASI, LDUIS A. (M), Engr. III, Electro Dptical
Systems, Inc., 30d N. Halstead Ave., Pasadena, GARASKY, JAMES T. (M), Elec. Engr., Hamilton Standard, Box 1000 , Windsor Locks, Conn.
GARAVANIAN, HAGDP G. (M), Engr, Sylvania Elec tric. Inc. 75' Sylvan St." Danvers, Mass.
GARBACIK, RICHARD J.'(M), Patent Examiner, U.S Patent Difice, Washington D.C. GARBACZ, RDEERT J. (M), Research Assoc., Ohio
State Univ. Antenna Lab., 1320 Kinnear Rd., Col

UmbBS, OhI,
GARBARE R. RDERT F. (SM), Dir. Engrg. Difice
Space Science \& Applications, NASA, 400 Maryland Space Science \& Applications, NASA, 400 Mary
Ave., Washington D.C.
GARBARIND. CHARLES L. (M), Superintendent GARBARIND, CHARLES L. (M), Superintendent,
Toiletries Div., Gillette Safety Razor Co., Gillette Park, Boston, Mass.
GARBARIND, HARDLD L. (SM), General Mgr., Engrg.,
Electro.Netic Steel, Inc., 459 Maple St., CerpenGARBATIO, SALVATDRE F. (M), Engr., Sperry Gyroscope Co.j, Great Neck N. Y.
GARBE, CARL J. (M), Mgr., Reliability Dept. The
Bendix Corp. Systems Div., 3300 Plymouth Rd., Bendix Corp Ann Arbor, Michstems Div., 3300 Plymouth Rd., Rd. Schenectady N.Y. Berkeley, Calif.
GARBER, ALAN M. (M), Silicon Transistor Corp. GARB ER, Rd., Garden City, Long Island, N.Y. Corporate Regulation Biv., Federal Power Commission,
Washington, D.C.

FIGURE 7. An example of printing by Alphanumeric Incorporated. 
writer, a device which moves film into a vacuum chamber with an electron beam and writes on the film by exposing it directly to the electrons, rather than using a cathode ray tube where the electrons impinge upon a phosphore and the photons from the phosphore focus with a lens onto the film. The direct electron process is more efficient. Films can be obtained which are very sensitive to electrons; in this way both a higher writing rate and a higher resolution can be achieved because the size of an electron beam is inversely proportional to the amount of current. The disadvantage of a direct electron writer is the problem of moving a film through a vacuum seal into a high vacuum container. However, it has been solved; we have obtained an experimental model of a machine produced by the Minnesota Mining and Manufacturing Co., whose working parts are shown in figure 8. The actual electron beam is vertical and impinges on the film at the bottom of the circular drum. The film itself comes from a cassette. The vacuum and light cover are shown open. The film moves continuously into the vacuum chamber and continuously out. The slit through which the film passes is very narrow and there is a sequence of pumping chambers which maintain the internal vacuum.

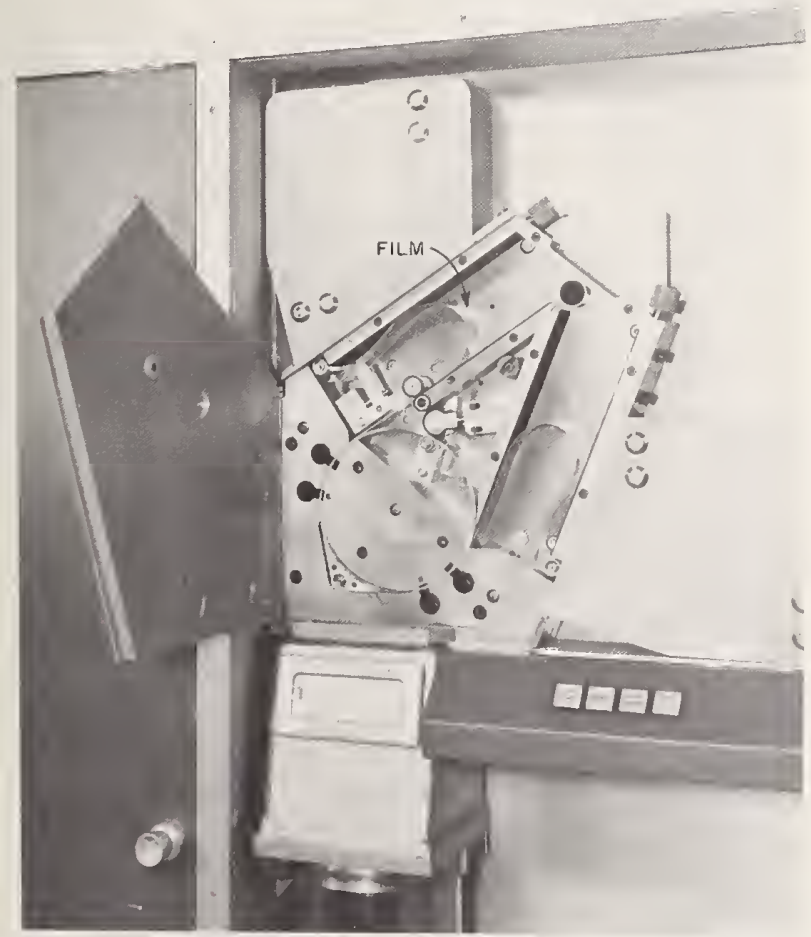

Frgure 8. Picture of an oscilloseope in which the clcetronic beam writes directly on film.
The whole device is only about the size of a large refrigerator. The cathode ray tube is assembled on precision elements and can be disassembled to adjust and replace elements. It is not yet operational but we hope to achieve a resolution of 5000 points across a frame. The speed and the raster are as yet unknown.

To conclude, let me contrast computer image drawing with analog image drawing in figure 9 . We will call the digital device a Cartesian machine since its entire geometry is a grid of Cartesian coordinates. Into the Cartesian machine we will put a digital magnetic tape. The first record contains a Cartesian description of the standard characters that we wish to draw. The rest of the tape contains encoded characters that are to be drawn, with the characters efficiently encoded as six or eight bits per character. Occasionally, we may have a character that is not in our standard set; here we can interpolate the Cartesian description of this special character. As long as it happens infrequently, it will not introduce a significant amount of additional input tape. If many special characters are needed, we are either using a poor selection of standard characters or we must enlarge the memory to hold more characters. An image is produced on film. The complete information, both the text and the shape of the characters, is on the digital magnetic tape; digital tape is complete in itself.
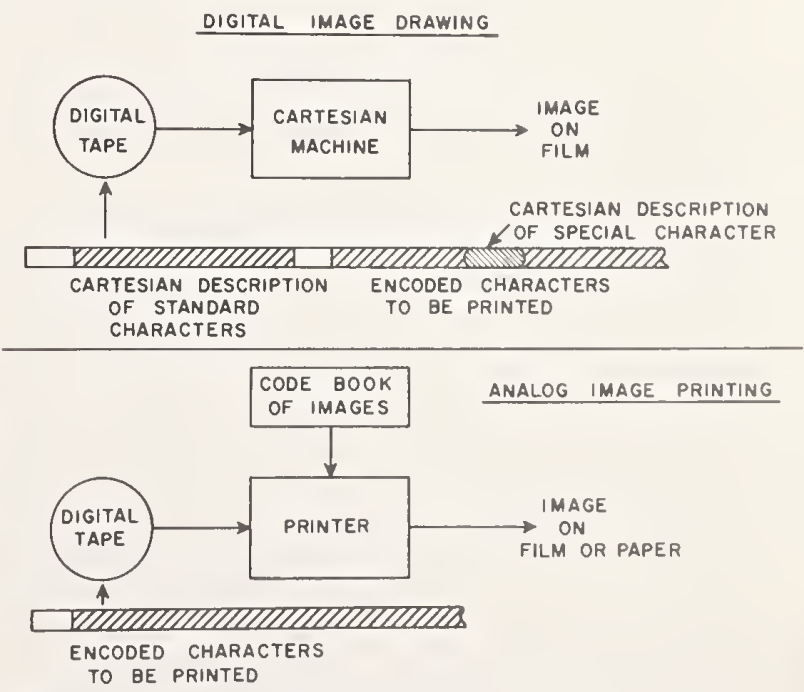

Figure 9. A comparison of Cartesian imagc drawing with typesctting by an analog deviee. 
Tape for the analog process contains essentially what is on the second record of the tape for the digital process - the encoded characters to be printed. The printer must have a code book of images, either in the form of a photographic plate or metal type or some analog form. The digital tape is essentially incomplete and is useless without the code book. The code book is an inherently nondigital object. Furthermore, it is impossible or very difficult to add special characters not in the code book.

We think that the advantages of digital image drawing will eventually prove to be overwhelming because of the completeness of the digital tape, because no extra code books are needed, because of the flexibility for adding special characters, and because of the direct extendability to line dra wings and to illustrations which do not involve a grey scale. 


\section{High-Speed 901 ZIP}

\section{Anthony G. Bernardo}

\section{Sales Representative, Photon, Inc.}

Some 15 or more years ago there was a thought that there must be a better, cleaner way of setting type. From this idea the Photon 200 was developed. This was the first step toward automated typesetting as we know it today. Its inventors, René Higonnet and Louis Moyroud, have been cited by the Franklin Institute as having made the most fundamental change in printing since Gutenberg's invention of movable type. Photon, as a pioneer in photographic typesetting, has progressed from the original 200 to the present highly sophisticated ZIP 901.

The Photon ZIP 901 comprises a control console and a high-speed photographic unit. The ZIP control unit receives one line at a time from the magnetic tape transport as it will appear in the printed finished product. ZIP, incidentally, is a computer slave operated off line, and driven only by computer-generated magnetic tape. This tape will very likely have been page-formatted.

The control unit performs a series of arithmetic and logic manipulations to put the characters on a single line into proper firing order for the photo unit. The ZIP photo unit does not fire a series of characters sequentially as they were originally presented to the control console. There is an excellent reason for this.

First, let us realize that the ZIP 901 is a line machine rather than a character machine. That is to say, our speed is calculated in lines per second; 3.19 to 2.15 lines per second, depending upon line length. Any speeds quoted in characters per second must necessarily be developed by extending the number of characters per inch to inches per line and lines per second. In this manner we can evolve speeds of 750 characters per second or more. Maximum line length that the ZIP can produce is 11 in, which incidentally is the longest in the industry. This is achieved without attachments or manual intervention of any kind, and without photographic enlargement of the output. Thus, 11 in is the output line length, attained by a tape signal generated within the computer.

I have referred to the ZIP as a line machine, and this is true not only with reference to speed but also as regards a formatted page or pages. For example, in the case of a telephone directory there may be three, four, or even five columns across a page. They are treated as one line by the ZIP.
Another example is a type page that has a line length of 30 picas or 5 inches; two pages side by side will not total the 11-in. line length of the ZIP, so why not format two pages side by side and treat the two lines across the scan area as one? This is exactly what is being done in some of our installations, and thus a scan of two pages is considered as one line.

A total of 264 characters is available at any given instant. These characters exist on three glass matrix plates mounted within the photo unit of the ZIP. They are accurately positioned photographically on the matrix plates. The plates are custom-designed for each user and are engineered to meet his particular needs. Any matrix plate can contain alphabetic, numeric, or special characters in a range of sizes from 6 to 14 points. Any character thus placed on a matrix plate can be mixed in a type line with any other character or characters contained in this set of three matrix plates. In short, it is possible to mix any and all of these characters on one line if this is desired. Photon has recently announced a ZIP capable of containing 9 matrix plates, thus making 792 characters available, but still limiting instant availability to 264 characters.

Situated immediately behind the matrix plates are xenon flash tubes, one for each of the 264 characters. The flash duration is approximately $3 \mathrm{mi}$ croseconds. Please bear in mind that a microsecond relates to a second as a second relates to almost two weeks in time. These xenon tubes are guaranteed for a minimum of 10,000,000 flashes, and based on the experience of nine machines in the hands of our users this seems to be a conservative figure.

Our next consideration is the optics within the photo unit. The lens travels on a horizontal plane parallel to the matrix plates and the photographic material, obviously situated between the two. The lens "gathers" in the flashed character, reduces it by four, and sends it on to its proper position in the line of type. One traverse of the lens gives us one full line of type. The lens photographs from left to right and returns photographing right to left. Operating in this manner there is no lost mechanical motion.

If you will, please visualize the matrix, the lens, and the photographic material on planes parallel to each other. The flash occurs as a ray of light, passes through the matrix and thereby becomes 
a ray of light carrying an image, then through the lens for its four-to-one reduction, and on to the photographic material in its proper position in the line. You are no doubt a ware that the reduction of the existing image makes for good typographic quality and resolution.

To explain further the logic that takes place in the control console, let us pursue the following: As pointed out previously, the flashing of characters for a particular line does not occur sequentially. A determination must be made, taking into consideration the position of the character on the matrix, the position of the lens, and the position in which character is needed in the line. The firing occurs when the three are in the proper relationship to each other. The result is a distortion-free, optically perfect letter, placed in a line within an accuracy of $0.001 \mathrm{in}$. The same degree of accuracy is maintained in leading between lines.

The Photon 901 is capable of handling the following photographic materials : standard film with a thickness of $0.006 \mathrm{in}$, thin-base film and stabilization paper, $0.004 \mathrm{in}$, and the much-discussed paper plate material with a thickness of 0.008 in. All these thicknesses are approximate and can vary from one manufacturer to another.

I would like to emphasize that the paper plate material is to be considered strictly experimental at this time. However, one of our users has had considerable success with this material on a dayto-day basis where they have been conducting trade tests for the manufacturer.

Their particular business requires that they compile and update certain information on a daily basis and incorporate it with information existing for all previous days in that period. This process is followed until the end of the period, at which time the updated file is merged with a master file and printed. It should be noted that this ZIP user is employing a five-column format for the daily publication, and a three- or four-column format for the annual publication. There is no faster way to handle this situation than a computer and ZIP in combination. It is interesting to note that $64 \mathrm{~K}$ is the maximum core needed for this operation, and it also represents the largest amount of core that has been used with ZIP to produce formatted pages.

The information for this daily updating is exposed on the experimental paper material in page format. After processing, the paper plate is mounted on a small offset press and up to a few thousand copies are printed. Incidentally, the paper plate is approximately in the realm of stabilized paper in that the dereloping chemicals are contained in the emulsion and the processing procedure contains activating chemicals.
Formatted pages come out of the ZIP in normal rotation-that is-page one, followed by page two, etc. Now, the next problem concerning paper plates for this user is the handling of imposition of these pages for the monthly updating and merging with the mastel file. Obviously, many more pages are involved here than with the daily procedure, so that the printing method has to be changed for both press and bindery efficiency. In order to achieve these efficiencies it is necessary to print many pages up, and herein lies the problem. A carrier has been devised so that the pages of plate material can be imposed in the proper order for binding. However, the edges of the material are susceptible to ink, and no method has yet been devised to prevent the edges from printing. This is not acceptable from a quality control point of view. There have been two or three systems devised to limit this inking, but a completely satisfactory method has not yet evolved. Once again, at this point in time the paper plate material is being used strictly on an experimental basis.

Our first installation was at the National Library of Medicine where they have been and are l'unning the Index Medicus. They have been known to run the approximately 6,000 pages without any "down time." Just recently they have run 3 shifts for over $11 / 2$ months without any time down.

We have two service bureau type installations, one in London, England-International Computaprint - the other, Sedgwick Printout, located in New York City. They have recently finished a 9,000-page l'un for a state library, running at the rate of 500 pages per day without an error.

The New York Telephone Company is on the air with the Staten Island telephone directory and also Rockland County. Their next endeavor will be the Bronx. They are producing telephone pages in 46 seconds, and it is interesting to note that they have dumped the hot metal for the previously mentioned directories. Photon will soon be delivering another ZIP to this installation. It has been estimated that the Manhattan white pages will be produced in $21 / 2$ days.

General Motors has produced the Oldsmobile parts price list and is planning several other tasks for the future. The price list contains a rather complicated configuration of type and rules (both horizontal and vertical), produced in one pass through the ZIP 901. There is no hand drawing of rules.

Recent deliveries have been made to two large printers who will undertake both telephone directories and other diversified applications. ZIP has also been installed at another Government agency doing classified work. 


\title{
The Videograph Text Editor
}

\author{
Glendon T. Gerlach, Manager
}

\section{Applications Engineering, Videograph Systems, A. B. Dick Co.}

Although more widely known as a manufacturer of duplicating and copying equipment and supplies, the A. B. Dick Co. has been active in the field of electronic data processing for more than ten years. Its engineering, production, and marketing activities in this respect are designated as Videograph Operations, and are conducted from the company's main plant at Niles, Ill.

The Videograph electrostatic printing process uses a special cathode ray tube (fig. 1) for creating alphanumeric characters on dielectrically coated paper at rates in the order of 10,000 characters per second. In electronic data processing systems, the source data are usually provided from computerprepared magnetic file tapes. The binary-coded signals from the tape are decoded in the Videograph system by means of an electronic character generator into the video signals necessary to modulate the printing tube and create the character shapes. The principal application of Videograph printers has been to produce address labels of the type used on magazines, newspapers, and direct mail. Printers such as the Model 910 Videograph Address-Label Printer, shown in figure 1, are capable of producing approximately 140,000 five-line labels per hour. Systems such as this one at the Subscription Fulfillment Department of Time, Inc., at Chicago are now in use by most of the large magazine publishers, as well as by many direct-mai!, catalog, and mail-order houses.

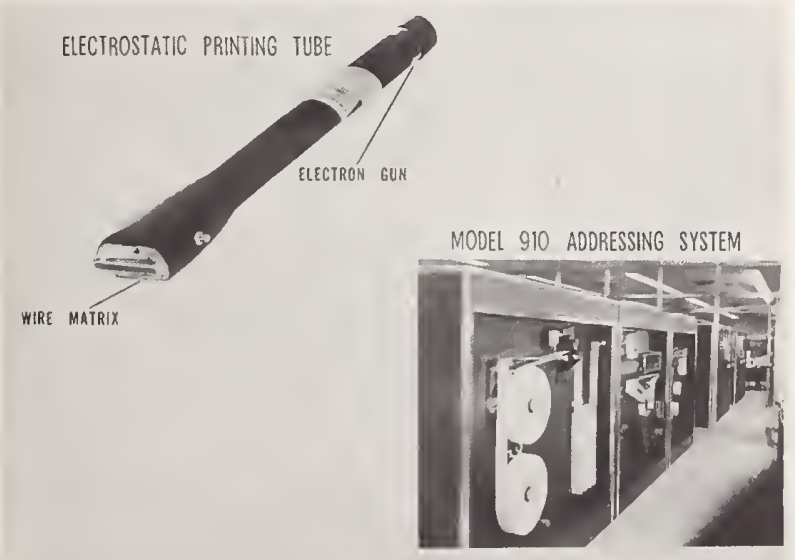

FIGURE 1. Videograph electrostatic printing tube and typical application.
While Videograph systems of this type represent the fastest computer printout equipment available, they are relatively expensive (in the order of $\$ 150,000$ per system), and require high output volumes to make economic break-even. For example, a Videograph label-printing system capable of turning out over 15 million labels per month on a one-shift basis, needs a minimum loading of about 2 to 3 million labels per month to be justified.

In 1964, A. B. Dick Co. initiated development work on a new computer-oriented printing technique capable of wider use in the EDP field, and specifically suitable to meet the price and performance requirements of the growing on-line ol time-sharing field. The specific applications of this new printing technique, designated as the Videojet process, to the publishing and printing fields have not as yet been comprehensively identified and studied. However, a description of this and parallel A. B. Dick Co. developments is presented on the basis that they may provide future contributions in these activities.

The Videojet process essentially employs a small metal chamber, about $1 / 8$ in. in diameter and $1 / 2$ in. in length, and having an orifice of 0.002 to $0.003 \mathrm{in}$. at one end. If such an assembly is connected to a source of pressurized ink, it will be discharged through the orifice as a nonuniform spray, very much like a garden hose, as shown in figure 2. However, if the assembly is energized

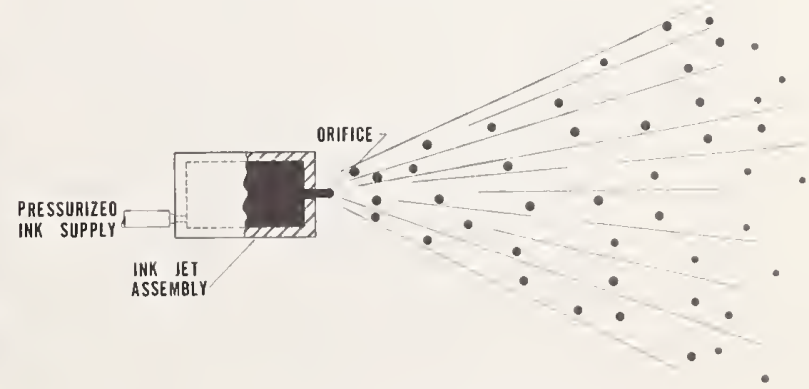

Figure 2. Uncontrolled ink jet. 


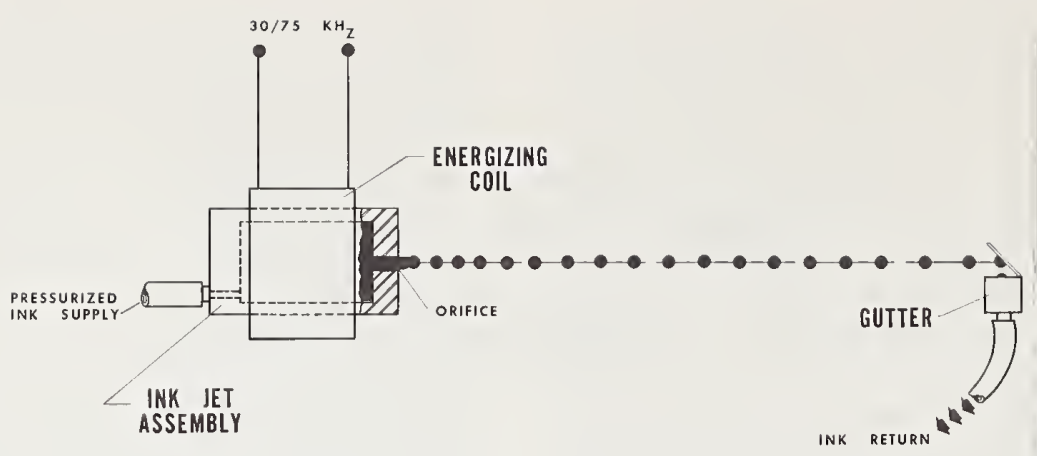

Figure 3. Controlled ink jet.

by a source of ultrasonic energy, such as a coil driven by an alternating current or a piezoelectric crystal, the ink will be discharged from the orifice as a stream of droplets of uniform diameter and at a rate equal to the frequency of the energizing signal, as shown in figure 3. For example, if the assembly is driven at $75 \mathrm{kHz}$, the ink stream will comprise 75,000 droplets per second. If the stream is generated through a $0.002 \mathrm{in}$. diameter orifice, the resulting spot on a piece of paper will be in the order of 0.010 in. in diameter. High-speed photos of the actual ink stream are shown in figure 4.
In such a system, the droplets break away from the main ink stream at a point slightly in front of the orifice. If a variable electrical signal is impressed on the ink jet assembly, each droplet will accept an electrical charge equal to the instantaneous value of the signal at the point of its break-away.

As shown in figure 5, a grounding tunnel is located around the ink stream at the point of break-away to complete the circuit through the conductive ink stream. The controlled droplets are then directed between a pair of fixed deflection

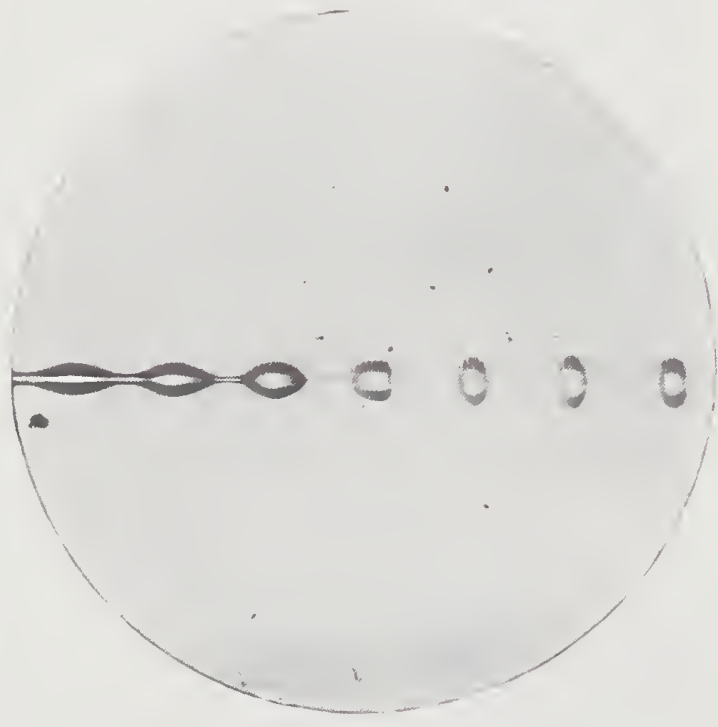

BREAKAWAY

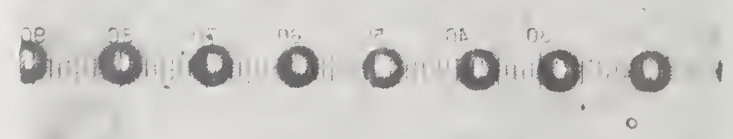

REGULATED STREAM

FIGURE 4. High-speed photos of "ink-jet" stream. 


\title{
The Photo'TextSetters
}

\author{
A. J. Smith, Manager \\ New Product Development, \\ Fairchild Graphic Equipment
}

\section{Introduction}

It is a pleasure to present to this large group a brief description of Fairchild's new PhotoTextSetters. These machines are the result of four years of intensive research and development by Fairchild Graphic Equipment, Division of Fairchild Camera and Instrument Corporation, and represent the talents not only of the Graphic Division but of many of the other divisions of Fairchild which are heavily involved in the development of optical, electronic, and small mechanical devices.

The Division recognized the importance of phototypesetting several years ago, due mainly to its familiarity with the market because of the Scan-AGraver, Color King, and News King presses and Teletypesetter products. A development program started which resulted in two completely different solutions for the problem of text phototypesetting, both of which are fully compatible with the Teletypesetter system. In addition, the current Fairchild service organization will be utilized so that prompt service will be available regardless of customer location. Customers with existing TTS perforators will be able to continue their use with the phototypesetting machines and existing counting magazines also can be utilized.

\section{Typographical Details}

Both PhotoTextSetters use a counting system similar to that used in the best hot metal systems. A font of type is divided into an 18 unit-to-theem variable set width formula. The only restriction is that the faces are similar to normal linecasting machine faces and the roman and italic are the same width. However, efforts are being made so that the italic will approach the more aesthetically pleasing faces as phototypesetting does not have the mechanical face restrictions of other systems. In other words, an italic " $f$ " can exceed the imaginary boundaries of the roman "f" and yet still not cause any counting problems either on the TTS perforator or PTS. It is expected that many of these "kerning" characters will be used in the type faces supplied.

\section{Font Program Boards-Width Boards}

Both machines utilize program boards to inform the machines of the typographical spacing of the fonts. The font program board interprets the character codes in the tape and assigns the character's into common groups. For instance: the " $a$ ", "e", "o" may be assigned to group 11 in one type face, but in a different face the "a" and " $e$ " may be in group 11 and the "o" in group 12. The size program board physically establishes the width of a group. This independent control permits higher quality typography when enlarging, as the white space the character occupies can be adjusted with this board independent of the black image of the character itself. With this system, different set values of a face can be obtained. For example: $81 / 2$ set from an 8 point image. More important, the relative white space of a font can be adjusted as the image itself is enlarged. On both machines, both unit and nonunit fonts are possible and wire service tape can be run directly onto the machines with no modification.

\section{Other Typographical and Machine Possibilities}

On both phototypesetting machines justifiable tape is the input. Both machines accurately determine the actual size of a word space before exposing the line to the photographic film or paper. The incremental fineness of this accuracy is $1 / 1296$ th of an inch.

On the PTS "2000" the word space expansion possibility for each word space is up to 2 picas. This permits added flexibility in keyboarding and eliminates the need for adding add-thin codes at the keyboard in order to obtain justification. On the PTS " 8000 " the word space expansion can be the entire line length, again easing the keyboard problem and permitting one more form of quadding. It is possible to quad left and right in the same line on the " 8000 " by first keyboarding the quad left information, then a word space code, then the quad right information, and the machine will automatically set the copy in that fashion. 
line. The flash tube is illuminated when the counting mechanism of the machine has reached the point in the line where the character belongs. Only three electric motors are used for the entire process of selecting and positioning the character in the proper position along the line. At the moment of exposure, two of the motors are completely stopped and the third motor, which is operating the second scan mirror, is moving at an extremely slow speed with only one "sweep" required for an entire line. The enlarged image is then deposited on film or paper in the camera section.

\section{Camera Section}

Figure 3 shows the camera assembly which is similar on both PhotoTextSetters. This assembly, when used with stabilization paper, permits complete daylight operation of the PhotoTextSetters. On the "2000" the line advance is set at the camera and offers primary leading in half point increments up to 18 point and in one-point increments up to 18 and 36 point. Because line advance is set on the P'TS, tape can be rerun for page justification if required. A secondary line advance is also possible from a code in the tape and, again, in the same increments for the primary. Secondary line advance is used for subheads, underlining and horizontal rules, and other such typographical functions.

There are two cassettes on the camera-one for the film or paper supply in which up to $100 \mathrm{ft}$ of paper or $50 \mathrm{ft}$ of film can be loaded. The same supply cassette can be used for $3-, 4-, 5$ - or 6 -in film or paper widths. 'The other, the takeup cassette, is self-threading and merely snaps into place. The entire cassette assembly was designed for minimum-interrupt operation. While one take is being processed, the extra supply cassette can be placed in position on the machine and continue in operation while the previous take is being processed.

When using stabilization paper, the supply cassette (fig. 4) can be attached to a Fairchild processor and the paper processed in normal room light to obtain a right reading paper positive for paste or waxup.

\section{Other Controls}

Figure 5 shows a closeup of the control cabinet on the PTS "2000." Included in the machine are automatic quad controls for center, flush left, and flush right from the appropriate code in the tape. On the top right are the typeface program boards mentioned previously. In the center is an indicator for the amount of film or paper remaining in the supply cassette with a fail-safe mechanism so that 


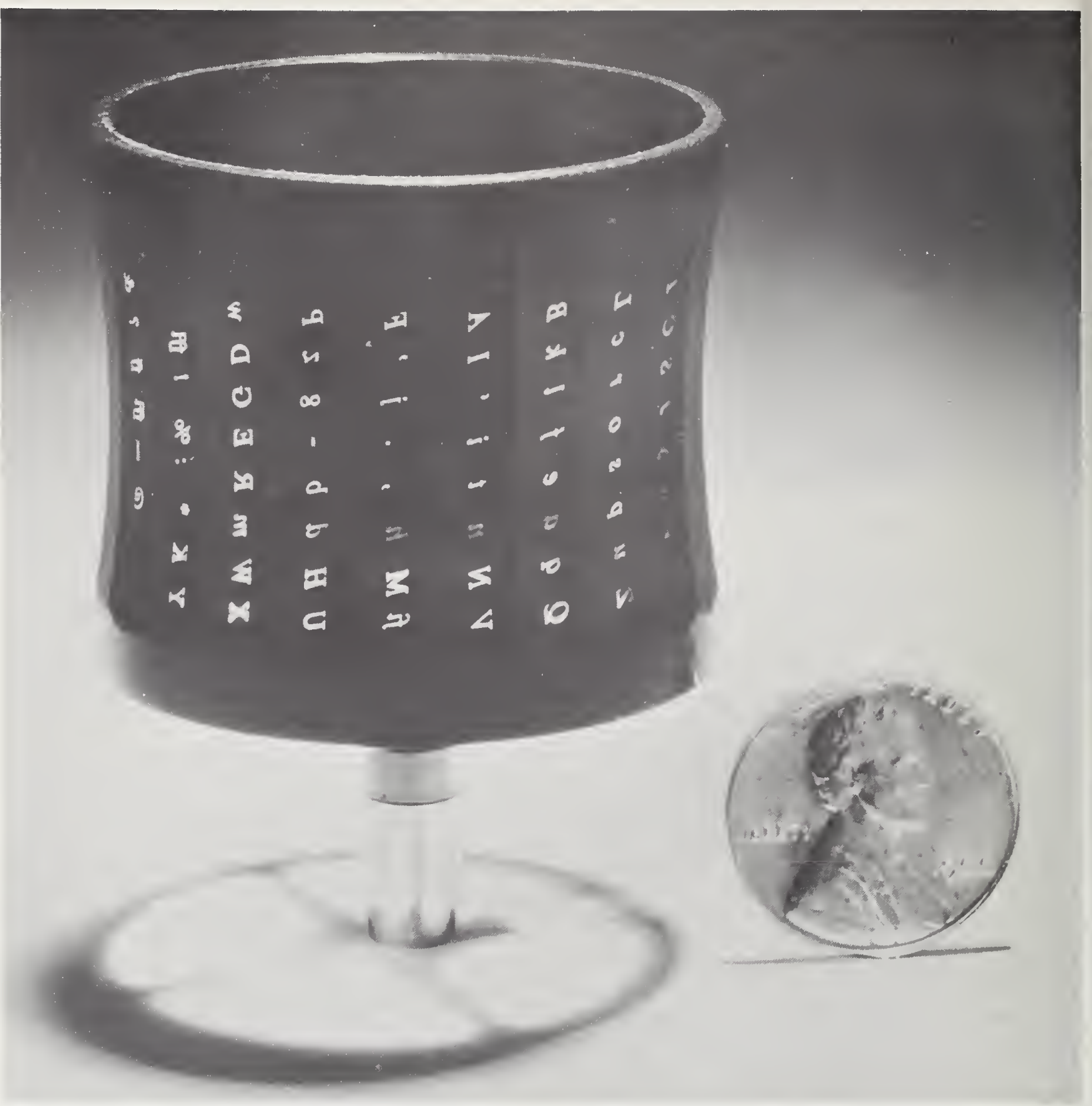

FigURE 2. The PTS "2000" hourglass matrix.

the machine stops when $2 \mathrm{ft}$ remains. When the cassette is empty the machine will again stop and will not operate unless the counter has been reset to $99.9 \mathrm{ft}$ or $49.9 \mathrm{ft}$. Also located in the top control panel is a line counter indicating the total number of lines set, off/on switches (one for a-c power and one to stop the tape at the end of the line being processed.)

Figure 6 shows an operator changing the line length for a new job. This control is in points and picas and does not require an operator to check any tables or convert into an unfamiliar counting system.

\section{Computer Control}

Both machines use the latest in electronic circuitry-integrated circuits-and Fairchild Micrologic elements are employed. Figure 7 shows one of the circuit boards on one of the computers. Each of the little "cans" on this board can have as many as seven transistors and related elements contained inside. This reduces the number of connections required and improves reliability. 


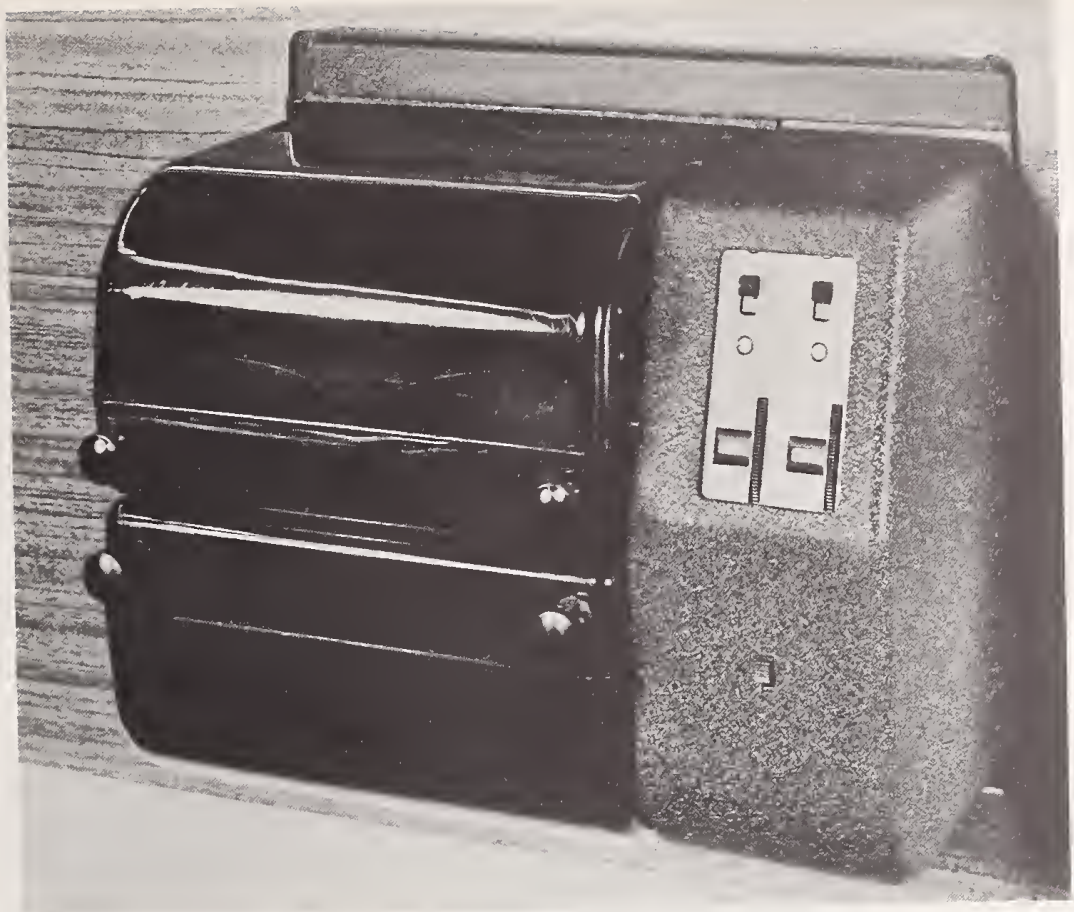

FIgure 3. The PTS “2000” camera section.

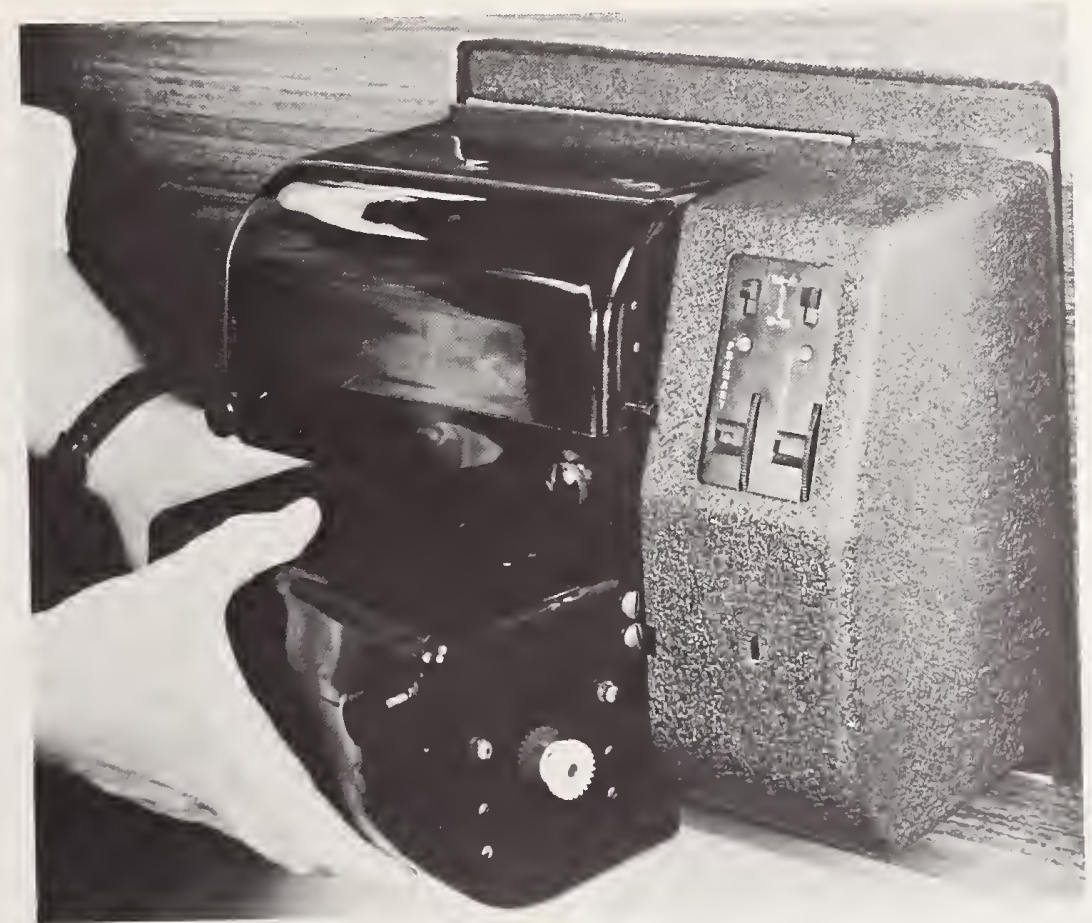

Figure 4. Cassettes of the PTS "2000." 


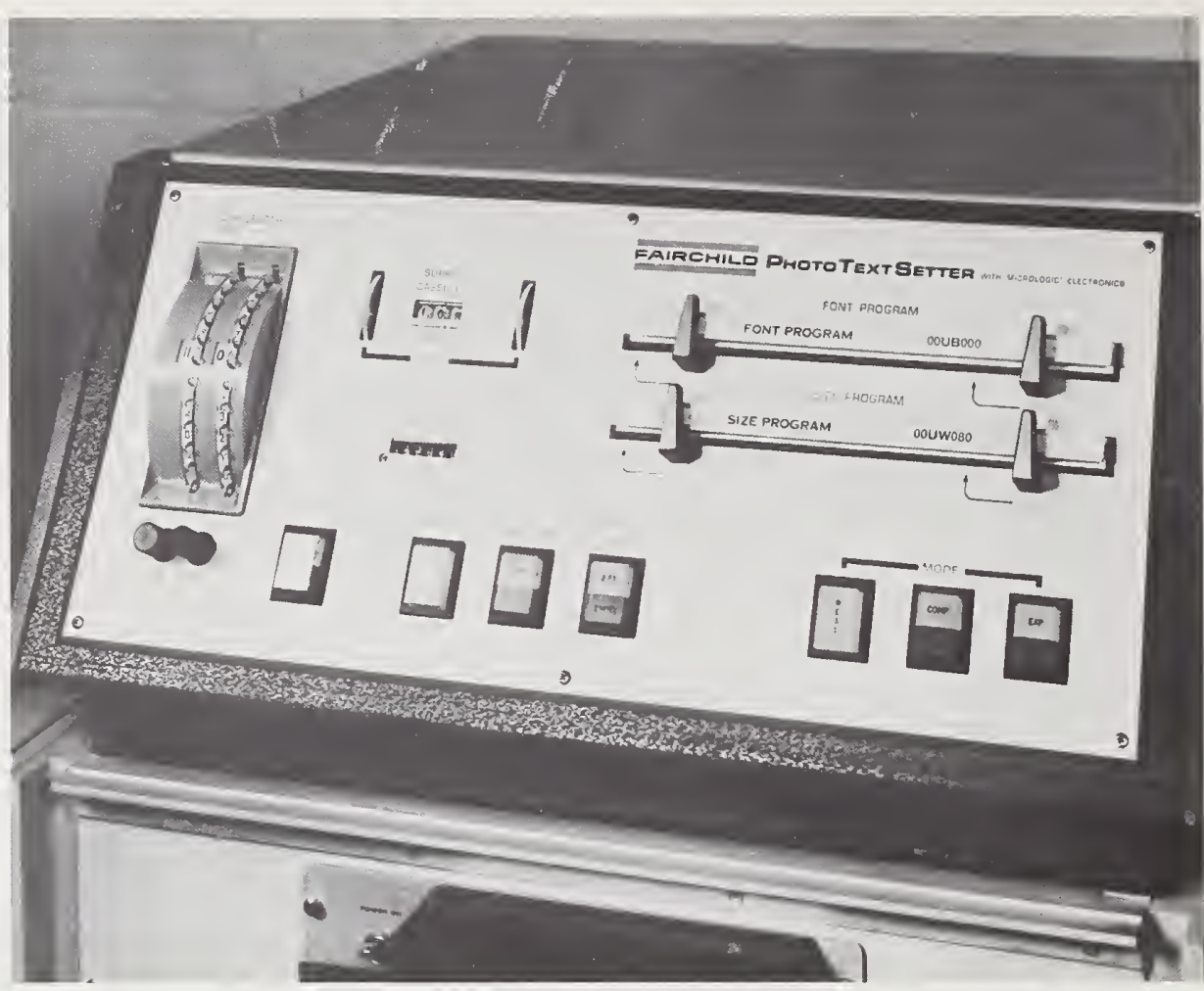

FIGURE 5. PTS “2000" eontrol eabinet.

\section{Other Specifications}
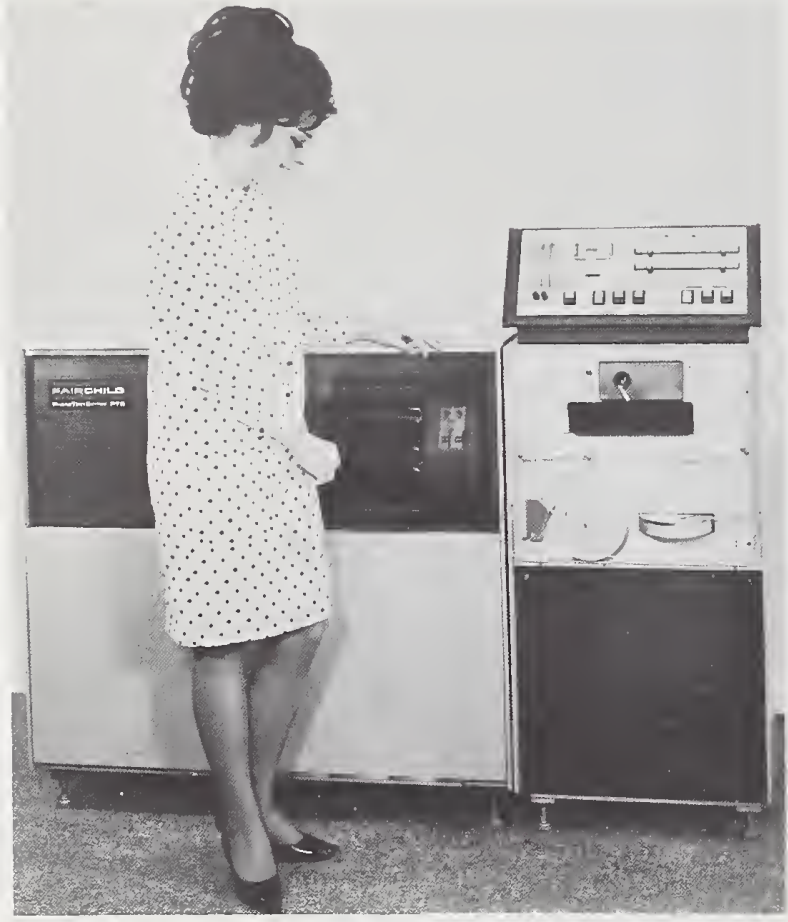

FIgURE 6. Changing line length on the PTS "2000."
The PTS " 2000 " will average 18 newspaper lines per minute, or 16,000 to $20,000 \mathrm{ems}$ per hour. It has been field tested for over nine months at a daily newspaper in Cleveland, Tenn. It will be available for delivery before the end of 1967 . Standard equipment includes quadding, full camera assembly with supply and takeup cassettes, tape reader, and spooling equipment.

\section{PhotoTextSetter "8000"}

The PTS " 8000 " differs from the " 2000 " in all respects. It uses a completely different principle which Fairchild calls "non-sequential font scanning." The machine is a true mixer; two sizes of two faces or two sizes of the same face in one line.

\section{PhotoTextSetter "8000" Type Matrix}

Figure 8 shows one of the 8 segments of a matrix. On the " 8000 " there are two complete 8segment matrices. Up to 288 different characters can be positioned along one 8-segment matrix. Six different sizes of a type face are also contained. Thus, a typical font could contain the roman and italic, small caps, ligatures, fractions, and other miscellaneous pi characters of a face. Up to 24 


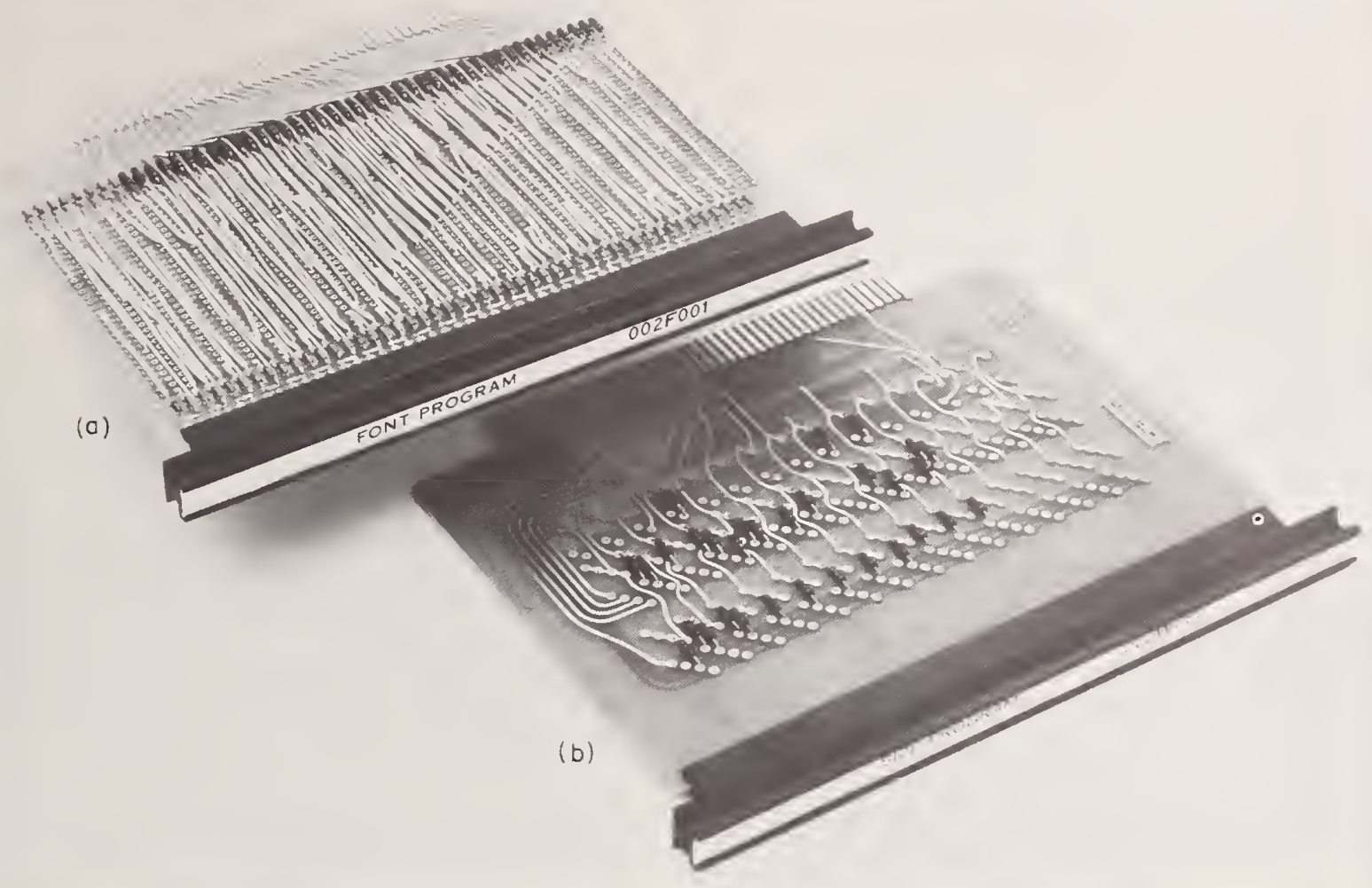

FIGURE 7. Circuit boards for computer control. A, font program; B, size program.
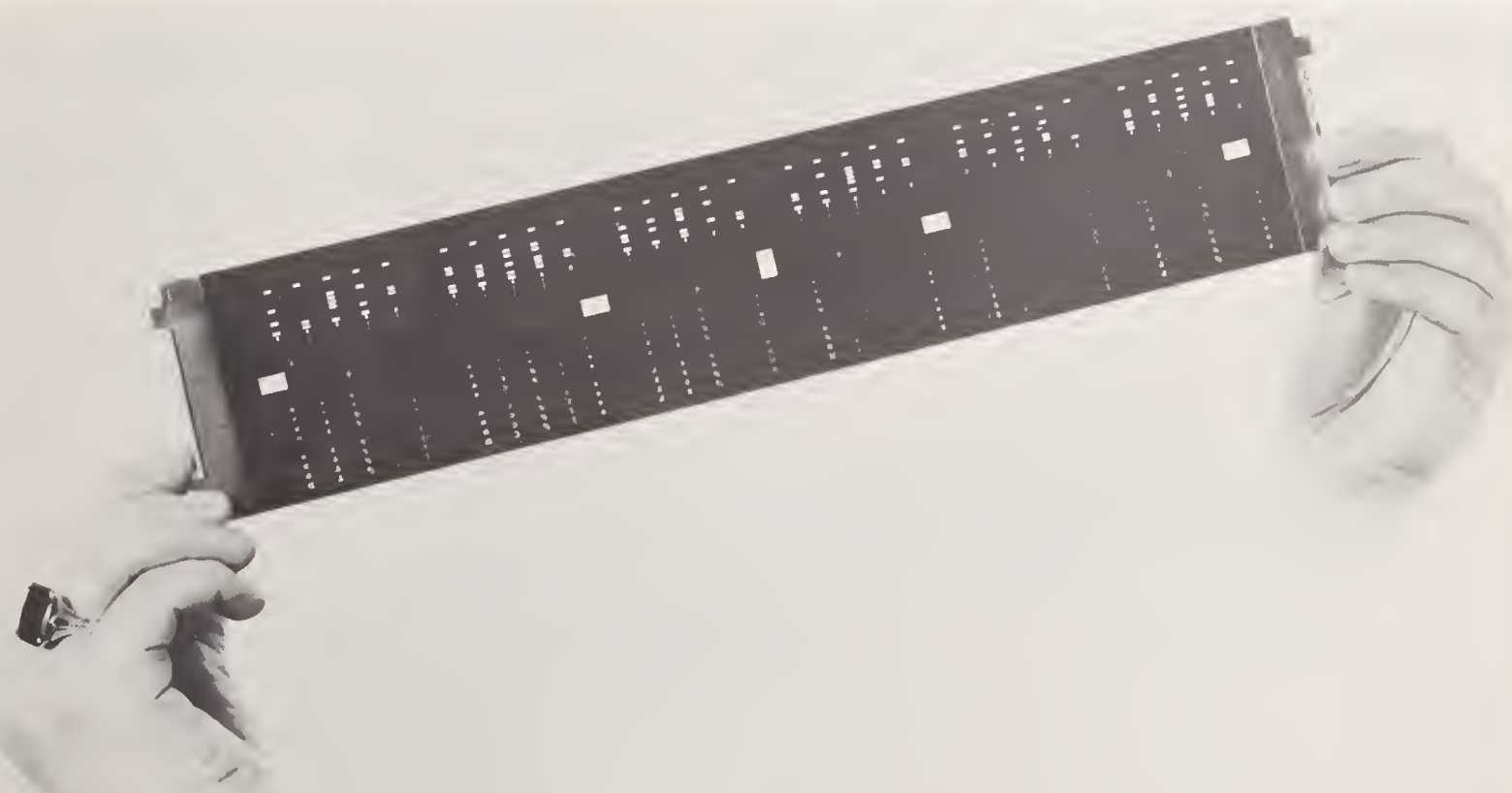

FIQURE 8. PTS "8000" typc matrix. 
fonts could be on the machine at one time. The segments are quickly changed on the machine and one face can be changed without disturbing the other. Also, a part of a face containing special characters for special jobs can be changed without disturbing the remainder of the face so that special characters, such as Greek and mathematical symbols can be interchanged for true pi character possibilities. Each size of the face has its own image on the segments.

The PTS " 8000 " has two speeds of operation and because of its non-sequential principle, these speeds are uniform regardless of the point size or number of characters in a line. For lines up to 15 picas the machine will average 80 lines per minute. For lines over 15 picas the machine will average 40 lines per minute. These speeds are possible because the machine does not set type like a typewriter, in other words, the first character in the line exposed first. It sets type as the characters appear on the font, so that if the first character in position on the font is the "e" that character" will be exposed in each and every position it is required in the line before the next character is exposed. Thus, in one revolution of a slowly moving wheel, all the different characters which a line would require can be exposed. By duplicating the font around the wheel, two lines can be set for every revolution but the lines cannot exceed 15 picas-thus the speeds mentioned. This principle offers three advantages - the first is speed, the second is reduced mechanical movements as the machine has no high-speed reciprocating motion. This also improves reliability and makes for extremely low machine error. The entire burden of selecting, positioning, and exposing a character to its appropriate place in the line is placed on optical and electronic components. The third advantage is that the machine is quiet in operation because of the small number of moving parts.

\section{Camera}

The camera assembly on the PTS " 8000 " is basically the same as the "2000" except that there are three levels of line advance-primary, secondary, and tertiary - which can be programmed by a single, double, or triple return code in the tape. Line advance is available in $1 / 2$-point increments to 32 points. The line advance on the machine is extremely fast, requiring only 2 milliseconds per each half point. The specifications on the cassettes for the " 8000 " are the same as the " $2000 . "$

We at Fairchild believe that these machines are the start of a product line. I am sure there are many questions from the audience which I will attempt to answer. I wish to thank you for your attention and this opportunity to discuss the PhotoTextSetters. 


\title{
A Videocomp Systems Approach
}

\author{
A. H. Coleman, R. F. Day, and D. G. Gerlich \\ Graphic Systems Division, Radio Corporation of America
}

\section{Introduction}

Graphic Systems Division was established as a major operating unit of the Radio Corporation of America (RCA) approximately $21 / 2$ years ago. Its mission is to provide systems, equipment, and services to the printing, publishing, and allied industries. These industries cover a broad spectrum of activities ranging from the creative processes of the author, editorial, and proofing functions, and layout and composition, to the printing preparation, production, and distribution processes. Initial RCA activities are focused upon electronic composition and color scanning.

This paper describes the RCA electronic composition system, the 70/9300 Videocomp Electronic Composition System. The system has been delivered, installed, and placed into commercial operation during 1967 for more than five customers.

\section{Typical First-Generation Photocomposition System}

A photocomposition system may be defined as a system which composes printed pages on photo- graphic film or paper from edited manuscripts which are entered on keyboard. A typical photocomposition system in use today, which includes a computer and photocomposer, is shown in figure 1. Several operators keyboard manuscript data and elementary typographic instructions for column generation onto paper tape. Paper tape is read into a low-cost computer which automatically justifies, hyphenates, and composes a column, punching an output paper tape. The output paper tape is then read into a photocomposer, such as Photon 713, Linofilm, etc., which generates the composed column of text on typesetting film or paper. The text is proofread and corrections are punched on paper tape by reference to line number. A tape-merging unit is used to combine the original paper tape with corrections for the purpose of obtaining an updated paper tape. The cycle is then repeated. When a satisfactory column has been composed, it is "pasted up" to form a page for use in printing plate generation. This type of photocomposition system has a low overall throughput speed and requires numerous manual operations. However, its original equipment cost is considerably lower than comparable linecasting systems.

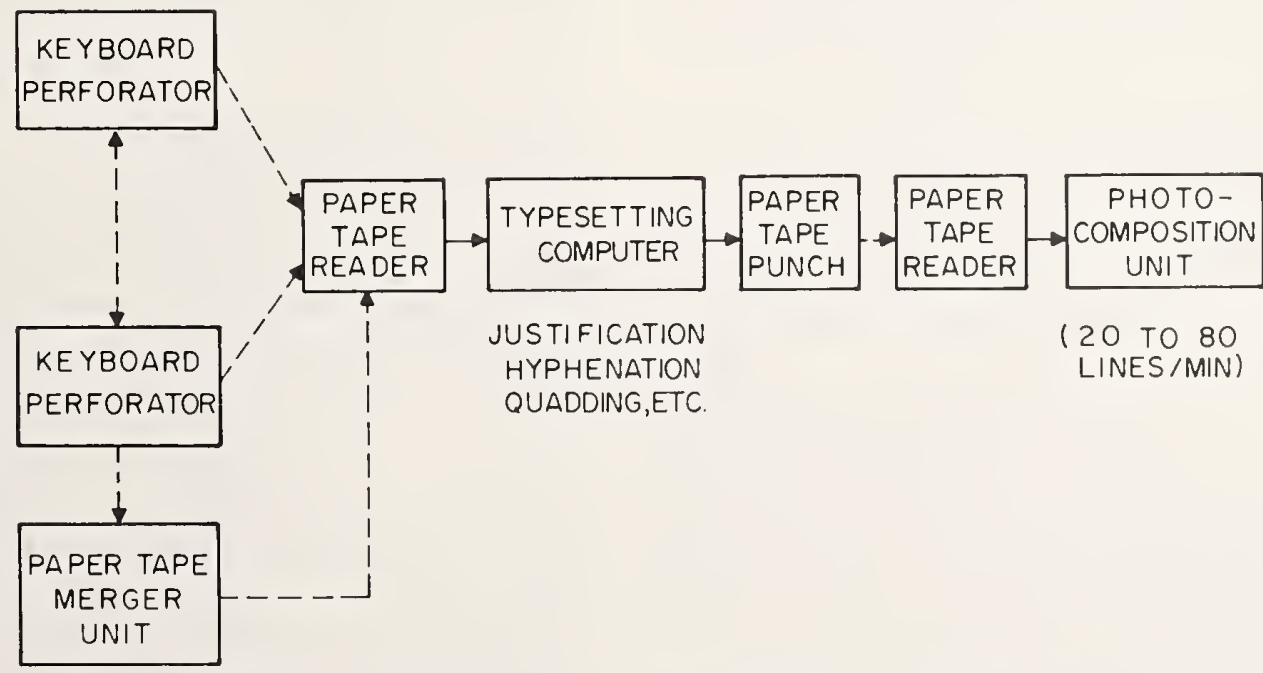

FIGURE 1. Typical first generation photooomposition system. 


\section{Definitions}

Videocomp is the generic name which RCA has given to electronic composition systems and equipments which employ high-speed cathode ray tube (or equivalent) photocomposing techniques. These systems and equipments are capable of greater speed and flexibility than first generation optical-mechanical photocomposers. The 70/822 Videocomp is the output subsystem which performs the actual photocomposition in response to magnetic tape data and control input. The 70/9300 Videocomp Electronic Composition System is an integrated system which includes the 70/822 Videocomp and executes the complete composition process from manuscript to final photocomposed page.

\section{Basic Functions}

To exploit fully the electronic composition capability, the functions performed in a typical photocomposition system were examined at RCA with the following objectives: reducing routine manual operations, increasing overall throughput speed, and decreasing significantly the ratio of price to performance. These basic composition functions are listed below:

(1) Keyboarding text and control codes.

(2) Acquiring and storing manuscripts.

(3) Performing typographic language analysis and page composition.

(4) Generating column and page proofs.

(5) Proofreading.

(6) Keyboarding proof corrections.

(7) Merging corrections and updating manuscripts.

(8) Repeating the proof-generating and correction cycle.

(9) Generating final photocopy in page format at high speed.

(10) Maintaining supervisory control and recording necessary production and other statistics.

These basic composition functions and the 70/ 9300 Videocomp Electronic Composition System which implements them, provide the answers to the following questions presented to RCA by prospective users:

Given a marked-up manuscript of a book chapter or newspaper article, how do we assemble the necessary equipment, computer programs, and operating personnel to convert a high volume of markedup manuscripts and corrections into final photocomposed pages which are ready for plate making?

How do we perform basic composition functions at high speed and efficiency?

A simplified block diagram of the $70 / 9300$ Videocomp Electronic Composition System for performing these functions is shown in figure 2. This system consists of four major hardware-software subsystems, as follows:

(1) Keyboard input

(2) Composition data processing (hardware)

(3) Composition data processing (software)

(4) Videocomp output

These subsystems operate to perform the composition process as described below.

\section{Composition Process}

Manuscripts are marked using typographic control codes which define both elemental and macrotypographic functions. The 70/9300 Composition language described on page 33 has been developed for this purpose. This language permits the book designer to communicate with the computer using a minimum of control codes and keystrokes while

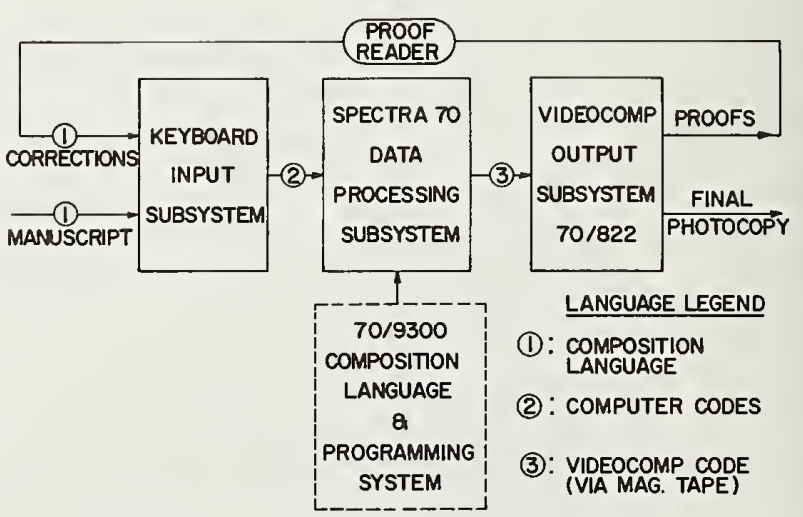

FIGURE 2. 70/9300 Videocomp electronic composition system. 
permitting a wide variety of complex typographic formats. The marked-up manuscript is keyboarded, and paper tape is perforated by a number of operators. The torn paper tape is read into papertape readers.

The Spectra 70 Composition Data Processing subsystem acquires and stores the manuscript, performs composition language analysis and typographic composition, and generates proofs at high speed through the 70/822 Videocomp. Proofs contain line-reference numbers in the margin, so that corrections can be entered on a line basis and merged with the previously stored manuscript. When no further corrections are required, a final high-quality print is generated which is suitable for plate preparation.

\section{Differences, Videocomp and Other Systems}

How does the Videocomp composition system differ from typical computer photocomposition systems now in use? The answer is fivefold:

First, new hardware and software has been synthesized on an integrated, general-purpose-systems basis. Prior photocomposition systems have evolved as an assortment or assembly of equipments provided by different manufacturers.

Second. a full-fledged composition language has been developed which significantly reduces book (and other printed products) designer and keyboard operator labor. First-generation systems are restricted to primitive composition commands for use by a skilled operator in column (rather than page) composition.

Third, manuscripts in process are stored digitally on magnetic tape or disk and are automatically updated by keyboarded corrections. In firstgeneration systems, manuscripts are stored as individual items or "takes" on paper tape and are merged off-line with a paper-tape merger unit. A complete manuscript in page format is assembled and stored only in the form of "pasted-up" pages or final photocomposed film.

Fourth, complete, multi-column pages with varied typographic formats are photocomposed, thereby reducing "paste-up" operations. Present photocomposition systems generate single columns which are assembled manually into pages.

Fifth, a high-speed electronic photocomposition equipment, the $70 / 822$ Videocomp, is driven by magnetic tape and generates both proofs (column and page) and final photocopy. Prior systems use relatively low-speed equipment driven by paper tape. Proofs are frequently produced with computer-type line printers.

\section{Keyboard Input Subsystem}

This subsystem is the same as used in present day first-generation photocomposition systems. Substantial improvements in this area may be expected as this subsystem becomes a limiting factor in the improvement of the cost-to-performance ratio.

\section{Spectra 70 Composition Data-Processing Subsystem}

This subsystem is a conventional third-generation data processing system, as shown in figure 3. The processor is a Spectra $70 / 35$ with a $65 \mathrm{~K}$ byte memory. Text input is through the $70 / 221$ or $70 / 224$ paper-tape readers which operate at 200 or 1000 characters per second, respectively. Magnetic tape is provided for manuscript files. $A$ disk is provided as the input data-acquisition buffer and for the storage of the Videocomp font library.

\section{0/822 Videocomp Output Subsysterin}

The 70/822 Videocomp is an electronic CRT photocomposition equipment which operates from magnetic tape input. It generates characters lineby-line on the face of the cathode ray tube (CRT). The CRT is imaged upon phototypesetting film or paper which is transported past the CRT face. A simplified block diagram of the 70/822 Videocomp is shown in figure 4. (A photograph is shown in figure 5.) It consists of three major elements: a magnetic tape unit, a digital-control unit, and a photocopy unit.

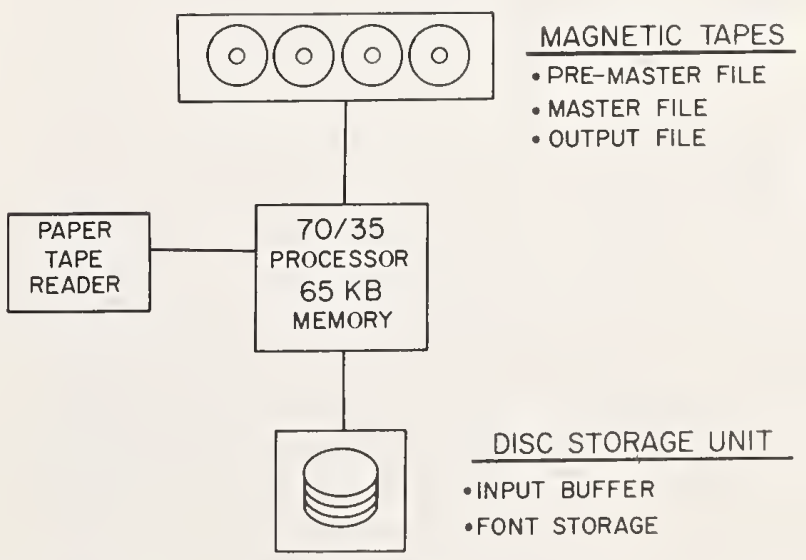

FIGURE 3. Spcctra Yo composition data proccssing systcm. 


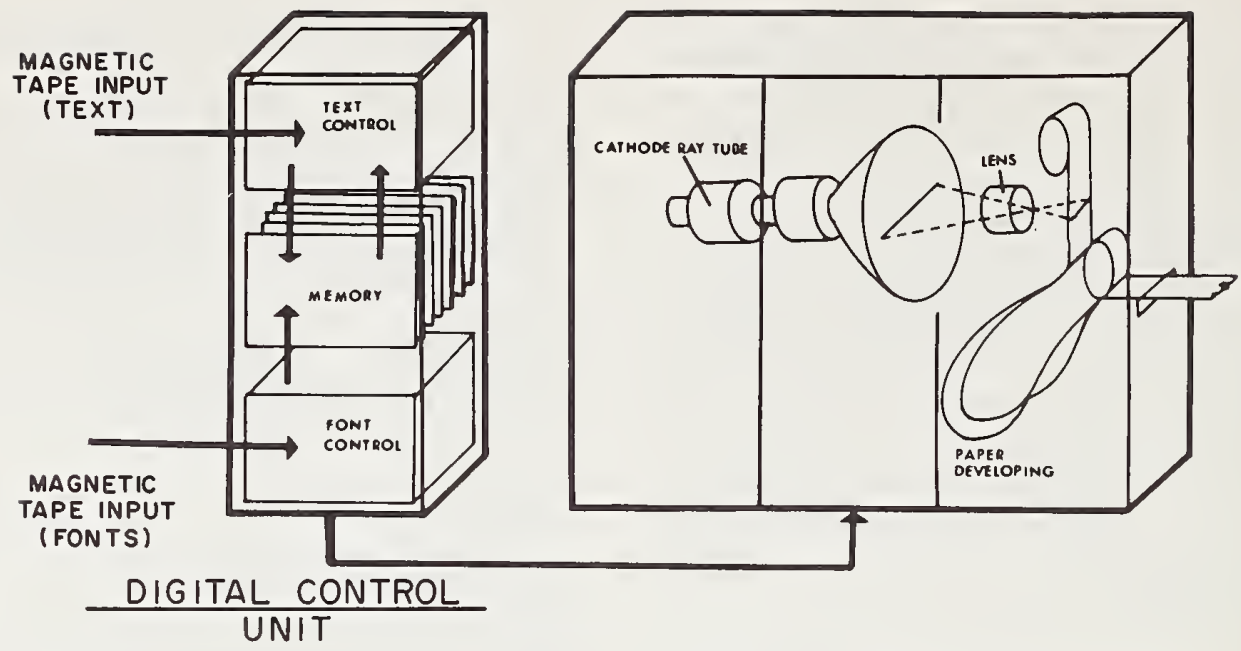

PHOTOCOPY UNIT

Figure 4. Simplified diagram of the ro/822 Videocomp output subsystem.

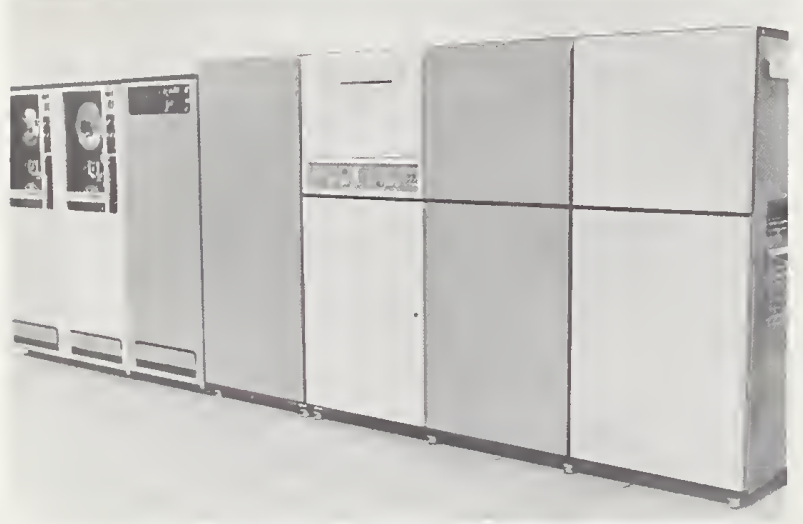

Figure 5. 70/822 Videocomp output subsystem.

\section{Digital-Control Unit}

The digital-control unit reads data from the magnetic tape, first loading font data into the selfcontained magnetic-core memory. The memory is divided into two sections, addressed by primary and secondary addresses. When text generation starts, the individual character codes from magnetic tape are used as primary addresses to interrogate the first area of the memory. The information obtained by the primary address is the secondary address or, in other words, the location of the actual character writing information for control of the cathode ray tube. This scheme of primary and secondary address is used to obtain the most efficient use of the memory space. Since each of the characters may require a different number of memory locations, it permits packing of characters adjacent to each other, regardless of the number or sequence of characters in the font.
Within the photocopy unit, character generation data are brought out of the font memory and are used to control the position and intensity of the cathode ray tube beam. Characters are generated by closely spaced vertical strokes with resolutions up to 900 strokes per inch. After each character is completed, spacing information is read out of the font memory to form the interletter spacing. Then, the writing of the next character begins. The characters are generated one at a time across the face of the cathode ray tube and imaged through the lens onto the photographic material in the camera assembly. At the completion of each line, the photomaterial is advanced by a command from the magnetic tape, and the beam is restored to the beginning point for the next line.

\section{Photocopy Unit}

The photocopy unit accommodates stabilization paper, which is phototypesetting film or paper in roll or sheet form. An on-line stabilization-paper processor is provided in each Videocomp photocopy unit to provide immediate proof output.

\section{Performance Parameters}

The major performance parameters of the 70/822 Videocomp are shown below:

Input Magnetic tape

Speed

Line Length Up to 32 picas

High-Speed 3.25 char $\mathrm{x} 8$ sizes

Typeface

Access
(32 K byte memory)

4 to 12 point, up to $650 \mathrm{char} / \mathrm{sec}$

18 to 24 point, up to 325 char $/ \mathrm{sec}$

650 char $x 8$ sizes 

(Approx.)
( $65 \mathrm{~K}$ byte memory) (Stabilization paper
Output Typesetting film/paper 2.75 , 4 or 6 inch width.
Mixing \{Complete flexibility all sizes and typefaces on one line.

\section{Technical Concepts}

The basic technical concepts embodied in the $70 /$ 822 Videocomp are listed and summarized below:

(1) Off-line character dissection

(2) Digital-font storage

(3) CRT character generation by vertical stroking

(4) Electronic magnification over limited size range

(5) Electronic $X$-motion (along line)

(6) Mechanical $Y$-motion

Characters are dissected off-line and converted into digitally coded representations of the vertical strokes and other parameters comprising the character. Fonts are stored digitally in computer magnetic tape or disc and in memory. These fonts are obtained by off-line scanning and digitizing under a precise system of quality control.

Once approved by the Art Director and Typeface Committee, a typeface is released into the master library as a set of digital information. Since no physical analog of the font characters are used in the equipment, time, dust, dirt, and the environment can lave no degrading effect on the character shape and appearance.

Digital storage of fonts provides twin advantages of flexibility and steadily decreasing costs as the computer industry continues its search for higher-speed memories at lower and lower costs.

Electronic $X$-motion under precise control of horizontal CRT deflection is used to position characters along a line. The CRT beam is maintained within a narrow, vertical aperture, so as to minimize effects of CRT geometric distortion.

$Y$-motion or leading is obtained by mechanical motion (transport) of the film or paper.

To minimize the digital memory required for font storage, electronic magnification is used over a $2: 1$ size range. $A$ single, stored font is used for eight point sizes within a size range. In addition, extended, condensed, or slanted versions of a typeface can be readily produced.

A 32 or $65 \mathrm{~K}$ byte memory is provided with the $70 / 822$ Videocomp to furnish high-speed access to approximately 325 to 650 characters, respectively, in eight point sizes.

\section{0/9300 Composition Language}

The goal of the 70/9300 Programming System is to produce complete pages with properly apportioned text and spaces for the insertion of graphics. It has been demonstrated in the past that a computer program could be written to generate a page of a specific format. When the desired page format changes, the computer program to generate it is changed. This can be costly and slow, depending upon the complexity of changes from one type of page to another.

To achieve the goal of the 70/9300 Programming System, the RCA 70/9300 Composition Language was developed. This language is a problem-oriented computer language based on the work of Dr. Michael P. Barnett at the RCA David Sarnoff Research Center. It is used to instruct the computer how to position text characters for electronic composition. The user of the 70/9300 Composition Language writes statements which describe the desired format of the finished copy. A program in the computer translates these statements into codes which are then executed, generating the output format. The results of this process are retained in the computer memory until enough text has been internally composed; then, the Videocomp Output Subsystem is directed to produce either paper proofs or film, ready for platemaking. The input to the computer composition system is the manuscript to be set (data) and the 70/9300 Composition Language format statements which tell the computer how to set the text.

The approach used in this language is to permit varied page formats by providing a means of describing a page as the sum of its parts, i.e., heads, body text, secondary text, footnotes, runarounds, etc. Each of these parts is specified by a series of format statements in the 70/9300 Composition Language. The computer builds a page from a collection of typographical parts. Any part of the page may be changed independently so that an entirely new page is created.

The classical problem of automatic pagination is the determination of the layout of a page, based on the contents of that page. Since the page breaks are unknown when preparing manuscript, the Composition Language permits the user to state rules for all alternative composition requirements. The computer selects the proper alternative format, in conjunction with its own results at that point in composition. For example, if a runaround is called for after a figure reference, the statements that 
specify the runaround test the space remaining on the page, and determine whether or not the runaround should be included on that page or its facing page.

The RCA 70/9300 Composition Language contains the following elements which are listed and described below :

(1) Control words or primitives

(2) Control word qualifiers or parameters

a. Absolute magnitude

b. General variable

(3) Control strings

(4) Format statements

(5) Job specification

The user of any language should be aware of the vocabulary (words), grammatical rules for punctuation (symbols such as ., : : etc.), and rules of constructing sentences (strings of words) for that language. These three topics are also included as they apply to the 70/9300 Composition Language.

\section{Control Words}

The vocabulary of the composition language is much smaller than that of a natural language. There are 78 control words, called "Primitives," in the Composition Language. These words are control words of the language because each one has a unique and positive meaning which causes the computer to execute a particular function. For example, the word "new line" will cause the computer to terminate setting in the current line and begin setting in the next line without justifying the current line. New line is spelled " $n$ "" in the composition language. All 78 words in the language are spelled by a unique combination of two letters. A few examples are listed below.

$\begin{array}{ll}\text { Page number } & \text { "pn" } \\ \text { Paragraph } & \text { "pr" } \\ \text { Point size } & \text { "ps" } \\ \text { Typeface } & \text { "tf" } \\ \text { Tabset } & \text { "ts" }\end{array}$

\section{Qualifiers or Parameters}

Many control words require a qualifier, or a parameter, in order to completely define their function. For example, the control word "ps" specifies point size for the text. However, until the exact point size is stated, the computer does not have sufficient information to perform its function.

Therefore, a user may write "ps, 10." The computer then can set type in 10 point until further instructed. The number 10 is the parameter of the control word "ps." It may vary each time the primitive is used. In this case, the parameter is simply a number or constant. For reasons that are explained later, the user may wish to write a control word, but may not wish to specify the value of the parameter at the moment. To do this a variable, rather than a constant, is used as the parameter. A variable in the composition language is the name of a location in the computer where the parameter is stored. There are 200 variables available at any one time. They are "gv 1 " through "gv 200." As an example, to use a variable rather than a constant to specify point size, the user writes "ps, gv 5." In order to make the general variable number five equal to the proper point size, e.g., 10 point, the user also writes "gv $5,10 . "$ When the computer executes the control word "ps," it notices that the parameter is a variable, seeks the specified value in location "gv 5 ," and sets the text in 10 point. The advantage in the use of variables is the elimination of rekeyboarding of instructions which are repetitive.

\section{Punctuation}

The first rule of punctuation in this language states that a control word is always separated from its parameter or variable by a comma (,). If a control word has more than one parameter, each is separated by commas. The second rule of punctuation states that a control word and its parameter(s) are separated from the text to be set by delimiters. Since the control word is spelled with letters from the same alphabet as used for text, the delimiters indicate which characters are data and which are control words to the translation program in the computer. The bracket symbol is generally used as a delimiter.

\section{Gontrol Strings}

An arbitrary number of control words may be strung together. For example, [ps, 10] [bl, 12] [tf, $6]$. To reduce keystrokes the composition language has made a semicolon (;) equivalent to a double delimiter. Thus, the above string could be written as $[\mathrm{ps}, 10 ; \mathrm{bl}, 12 ; \mathrm{tf}, 6]$. This example represents the method for building strings of words (sentences) in the composition language. Unlike most other languages, it is possible to build meaningful strings of words which are independent of their order. For example, the user obtains the same results whether he writes $[\mathrm{ps}, 10 ; \mathrm{bl}, 12]$ or $[\mathrm{bl}, 12$; ps, 10]. A similar example in the English language would either produce nonsense, or a legitimate sentence with a different meaning. In the composition language it can be said that generally the string of instructions (control words, parameters, and delimiters is legitimate if each individual control code is legitimate. There are exceptions where cer- 
tain codes must follow in a sequence. Each string has a specific meaning which results in a unique typographical event, such as a line of certain type set on a certain measure or a space of certain dimensions located on a printed page. For this reason, sentences which are written in the composition language are called formats.

\section{Formats}

Many formats are repetitive, that is, they are used with different sets of copy. In that case, the user enters the format into the computer only once, and thereafter refers to it each time it applies. Rather than keyboard it every time he wishes to "say the same thing," the composition language provides the facility of referring to a format by a "defined name" which consists of one letter followed by one digit, such as $\mathrm{C} 8$. Using the 26 letters of the alphabet and 9 digits, there are 234 unique names available for formats.

To use this technique for a repetitive format, a mark-up man may follow a three step procedure:

(1) Define the output format desired by writing a string of control words.

[ps, gv $1 ; \mathrm{bl}, \mathrm{gv} 2 ; \mathrm{tf}, \mathrm{gv} 3]$

(2) Assign a name to this string.

F2 [ps, gv 1; bl, gv 2; tf, gv 3]

(3) Instruct the computer to store the format and its name, with a format statement code "fs."

[fs, F2[[ps, gv 1; bl, gv $2 ; \mathrm{tf}, \mathrm{gv} 3]]]$

The format is stored by the system using a noncomposition or system-update program. It is available for use with any composition job. To use this format a markup man or copy editor simply writes the name [F2] delimited by brackets, at each point in the copy that he wishes the equivalent string of codes to be executed. This format would be available without rekeyboarding for every job that is composed on the computer.

\section{Job Specification}

Each job may require different parameter values. For this reason the use of variables is required in the format statement. The markup man specifies the value of each variable by writing a job specification. This is a list of general variables and synonyms and their corresponding values. This is entered into the computer as the first "take" of a job. A synonym is a format used exchusively by a single job and is entered with the job itself during composition input. A synonym may also be a string of repetitive text, such as a chapter title to be used as a running head.

\section{The 70/9300 Programming System}

As shown in figure 6, the $70 / 9300$ Programming System which exercises the composition language is divided into two cycles that are overlapped in time, namely, System Input and Composition.

\section{System Input}

Data prepared on paper tape are read and stored in a random-access buffer. These data may represent a number of independent composition jobs, such as titles or stories. Each item, or take, is identified by a job number and a sequence number. As the data are buffered, the program maintains a directory of all inputs by identification number. This allows data preparation and system input to be scheduled independently of the compositionprocessing cycle.

\section{Composition}

The second and main cycle, composition, is divided into three phases. The cycle is initiated when the operator enters the identification of the next job to be composed.

The Phase 1 program then selects all the inputs for that job from the input buffer and places them in order of sequence number. It merges alterations by line with the existing Master File for that job. It then performs language analysis, that is, the format names are replaced by their equivalent strings of control codes and variable parameters are replaced by their appropriate constants. The results of the Phase 1 program are stored in an intermediate file, called the preliminary Master File.

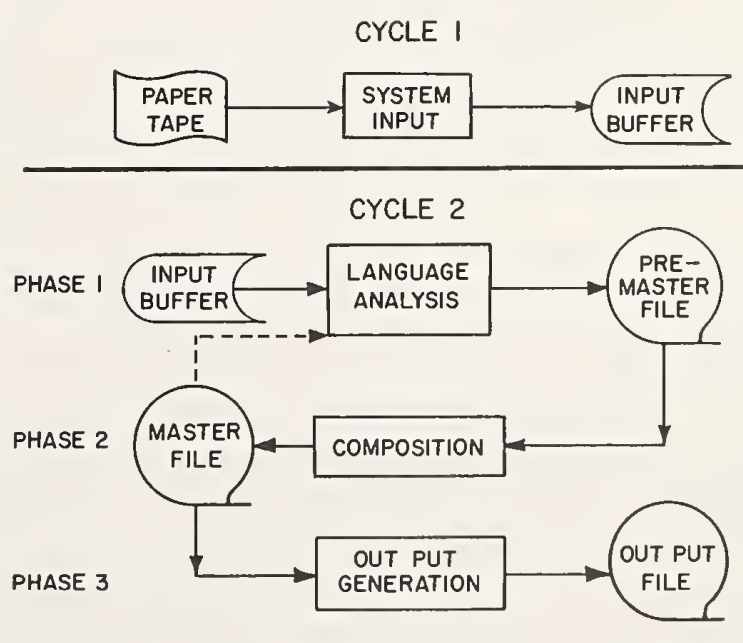

HIGURE 6. 70/9300 programming system. 
The Phase 2 program is automatically initiated at the conclusion of Phase 1 . This program executes each composition language control that appears in the data and justifies each line through word-spacing and hyphenation techniques. The result of Phase 2 is an updated Master File which is automatically passed on to Phase 3 and also saved for subsequent processing of that job.

At this time the Master File is in the order that data were inserted. This may not col'respond to the required order of the final page. The Phase 3 program reads the Master File and sorts the lines to correspond to the required Videocomp output. That is, heads, footnotes, multicolumn text, etc. are properly apportioned. Vertical justification is performed by the Phase 3 program. Finally, all composition controls are translated into Videocomp machine code. The results are stored on the magnetic tape Output File. The Output File contains character codes, machine commands, and digital font data, in a form suitable to drive the Videocomp and produce pages on either photographic paper or film.

It seems reasonable to assume that future electronic composition systems, such as the $70 / 9300$ Videocomp Electronic Composition System will move in two major directions : lower overall system cost and increased performance capability and versatility. Lower system costs probably will be achieved by more thoroughgoing system synthesis of the major subsystems of an electronic composition system and by the advent of substantially lower-cost, higher-speed, random-access memory systems. The latter, of course, is a goal which is being pursued by the entire computer industry. Recognition of this was a major influence in the $\mathrm{RCA}$ decision to employ digital font-file storage. Increased performance capability and versatility may be expected to result in increased printed line widths, perhaps up to newspaper broadsheet width. The efficient, low-cost photocomposition of full pages, complete with alphanumeric text and graphics, may be anticipated as a major competitive element in the second or third generation of high-speed electronic photocomposition equipments.

Simultaneous with the photocomposition hardware developments will be parallel developments in composition programming systems and languages for use in the high-speed processing of many printed products from newspaper, magazines, and books to manuals, parts lists, directories, and varied commercial printing products. Improved methods of entering text and control data into a computer system are inevitable as a direct byproduct of similar activity in the entire computer industry.

By describing our first electronic composition products and systems, and predicting some future directions in this field, we have presented a picture of RCA Graphic System Division concepts and results in the field of electronic composition. We have emphasized the importance of the fruitful marriage between the graphic arts and associated technologies on one hand and the electronic computer, communications, and CRT display technologies on the other. 


\title{
Its Impact on the Photocomposing Industry
}

\author{
John J. Kalagher, Manager \\ Federal Government Marketing, \\ Stromberg-Carlson Corporation
}

The Data Products Division of StrombergCarlson Corporation, a subsidiary of the General Dynamics Corporation, is engaged in the design, engineering, manufacturing, and marketing of an extensive line of equipment and systems, with particular emphasis on the technologies of electronics, microfilm, and cathode ray tube recording.

In November 1966 at the Fall Joint Computer Conference held in San Francisco, Calif., Stromberg-Carlson Corporation unveiled its MICROMATION Technology equipments. These equipments and systems, based as they were on over 15 years of technological experience in cathode ray tube recording had an immediate impact upon the data processing industry. It is natural that the data processing industry would accept MICROMATION because, for the first time, the paper bottleneck that has plagued computer users was eliminated through high-speed output printing directly onto microfilm. The throughput speeds of an electronic data processing system were now brought into balance by providing printing speeds 15 to 20 times that presently obtainable by mechanical printers, the operating and storage costs were reduced by a factor of 10 , and access to the information thus generated on microfilm was made faster, more timely, and less cumbersome.

If all of the above be true, one may logically ask why Stromberg-Carlson is discussing the same systems and technology at a seminar the specific concern of which is electronic composition in printing, a related but not identical field.

Many of you are aware that the twin technologies of data processing and graphic arts have come closer together in sharing equipments and their capabilities. The key in the past has been "electronics" and the resultant speed and flexibility it brought to both technologies. The introduction by Stromberg-Carlson of Micromation-or microfilm directly produced from a computer, bypassing the paper stage-has brought about, paradoxically, a better way of mass-producing paper. The key is Stromberg-Car'lson's "Microfilm Generating Equipment" and the microfilm itself, from which photographic plates can be prepared.

\section{The S-C 4060 Stored Program Recording System}

We wish to highlight in our discussion today the most powerful of these Micromation equipments-the S-C 4060 Stored Program Recording System. The S-C 4060 is a system which translates digital data into alphanumerics and graphics and then records the results directly on microfilm and, optionally, on paper. The S-C 4060 is a unit which has given to the printing industries a new means by which it may be possible to cut costs and improve the quality of their product. The $\mathrm{S}-\mathrm{C}$ 4060 was practically "user designed." Members of UAIDE, a society for Users of Automation Information Display Equipment, recommended the features they wanted in the next generation of data recording equipment and most of their ideas have been incorporated into the S-C 4060. In addition, the basic techniques used have been proven by UAIDE members who utilized the S-C 4020 Computer Recorder, another product of Stromberg-Carlson.

The S-C 4060 is designed on a "building block" philosophy so it can be introduced into a center gradually and expanded whenever desired. The S-C 4060 accepts input from a variety of sources. It can operate "off-line" from magnetic tape transports; it can also accept data from the most modern, third generation computers.

The basic components of the S-C 4060 System are four in number:

1. The I/O Control Unit. The input/output section is designed in modular fashion, and signals from almost any data source can be converted for use. The system is capable of accepting data at rates up to 250,000 bytes per second.

2. The Product Control Unit. This unit is a buffer with an internally stored program. It has a capacity of 8,192 words. As it is programmable, no rigid data formats are required.

3. The Display Head. In this section digital codes are converted to alphanumerics or line graphics 
and displayed on the face of a CHARACTRON® Shaped Beam Tube. Characters are formed by passing an electron beam through symbols etched in a tiny matrix in front of an electron gun. The characters are then reproduced on the tube screen. The cathode ray tube on which characters are displayed produces characters of exceptional quality. Both upper and lower case characters are etched into the 116 character matrix and four distinct character sizes are available under program control.

4. The Recording Section. Recording can be accomplished on $35-\mathrm{mm}$ or $16-\mathrm{mm}$ film. The microfilm camera automatically records the data displayed on the tube face. Perforated or unperforated film can be produced. Standard formats which do not vary with each frame, such as company symbols, forms or maps, may be superimposed over the frame by a built-in forms projector. This system saves valuable computer time by relieving it of the task of providing data for the drawing of standard formats. Optional equipment in this unit provides for the automatic production of output on hard copy white paper, as required.

\section{The Product Control Unit}

Let us examine more closely these system components. As was mentioned, the Product Control Unit, or PCU, is a stored program buffer. Electronically, it is manufactured from integrated circuits, with a resultant high degree of design life. A memory cycle time of less than one microsecond provides high-speed data processing. Its core storage consists of 8,192 computer words, each 16 bits in length. A standard item of input/output equipment which provides for operator/machine communications is an ASR-33 Teletype Printer. This assists the Product Control Unit in the operation of the system and provides operator communications. The unit provides two-way communications with operational programs.

\section{The Display Unit}

The Display Unit is characterized by the utilization of an advanced version of the CHARACTRON® Shaped Beam Tube, providing not only exceptionally high quality character output, but also providing selectable character size, increased character repertoire, higher resolution, improved line generation, as well as providing for rotatable characters under program control. A stroke generation system is provided for creating special characters by joining short line segments. Resolution of drawn lines has been increased through the use of four line weights and 12 plotting point sizes. Another improvement is the capability of changing character orientation by program control. This proves extremely valuable in annotation of charts and graphs.

\section{The Recording Section}

The Recording Section provides for recording on $16-\mathrm{mm}$ or 35 -mm camera, with options available for on-line developing or processing of film, online viewing, and on-line hard copy, thus permitting instant and valuable access to the data recorded and printed. Another adjunct to the system is the ability to produce strip charts-one continuous length of data in charted alphanumerical and/or graphic forms. This on-line hard copy costs less than 2 cents a sheet and is available in three different sizes, either cut and stacked. $n \boldsymbol{r}$ rolled, as selected by the operator.

\section{Characters Available}

There are 116 characters available within this system. The character repertoire provides for 54 special symbols as well as the standard alphanumerics in both upper and lower case. The quality is such so as to exceed high-quality typewriter output, specifically, exceeding the quality achieved on the latest models of electric typewriters. Two character orientations are available with four character heights, each with upper and lower case characters. The recording speed is greater than 60,000 characters per second. As a matter of note, tape drives reading and/or' writing at 90,000 characters per second are acceptable to this system.

\section{Stroke Generator}

As was mentioned earlier, a stroke generation system is provided for creating special characters by joining short line segments where desired. Instructions for generating the strokes are stored within the Product Control Unit. The benefit achieved via stroke generation is the providing of smooth integrated lines beyond the four character sizes provided as standard.

\section{Line Generator}

Straight lines, solid or dashed, can be drawn from any one address of the matrix point to any other point. Four different line widths can be used. It is significant to know that the plot points, or addressable points available, are over 12,000,000 on a matrix 3,072 points times 4,096 points. This is over 12 times the capability provided with the S-C 4020 which had a 1,024 by 1,024 matrix. 
Two basic classes of software are provided with the $\mathrm{S}-\mathrm{C}$ 4060. First, IGS (Integrated Graphic Software) is a series of computer-independent routines designed to enable the operations programmer to use more efficiently the S-C 4060. The IGS System is designed to operate in time-sharing and other multiprocessing environments. IGS is written in ASA basic FORTRAN and is intended to be added to the system library of the user's main computer. The second class of software consists of the MCS (Master Control System) and several library programs. This software operates entirely within the S-C 4060. The library programs contain an IGS processor, an S-C 4020 simulator, a general print tape program, a typographical composition program, and translators to enable the $\mathrm{S}-\mathrm{C} 4060$ to simulate several other graphic units. Users of the S-C 4060 may become members of UAIDE and share programming experience and services with other members.

\section{S-G 4060 Optional Equipment}

The extreme flexibility of the S-C 4060 is apparent when one considers the optional equipment which can be easily added to the basic system.

\section{On-Line Film Processing}

The on-line film-processing option provides a built-in system that develops microfilm at a rate of approximately 3 feet per minute (more than one full page per frame every 2 seconds) and requires no external plumbing connections.

\section{On-Line Viewer and On-Line Hard Copy Option}

The on-line viewer, used in conjunction with the hard copy option, makes available each frame of film by having it displayed for several seconds on an 11 x 14 in. viewing screen. The operator may manually interrupt the system and hold a given frame in the viewing station for checking and/or interrogation purposes.

The S-C 4060 uses an electrostatic printing process that prints on a white paper; either $81 / 2$ × 11 in. or $11 \times 14$ in. reports can be produced and the paper output automatically cat and stacked; a roll take-up system is available.

\section{Special Interfaces}

Unlike all the other data-recording systems, which were designed to interface with a single data source, the S-C 4060 is designed for multiple sources of input. Special tape units can be supplied with the S-C 4060 or it can operate with units already installed in the computer center. The standard system can operate with one or two tapes, simultaneously, either 7 or 9 track, and up to eight tape units may be controlled. Tape-write equipment is optionally available.

\section{Cameras}

A $16 \mathrm{~mm}$ or $35 \mathrm{~mm}$ microfilm camera, equipped for either perforated or unperforated film, can be selected as part of the basic equipment.

\section{Film Coding}

Film coding for retrieval systems can be accomplished automatically with the S-C 4060 on $16 \mathrm{~mm}$ film. Line indexing marks, image count blips, and Miracode or Kodamatic retrieval codes can be imprinted on the film at electronic speeds.

\section{The S-C 4060's Impact on the Photocomposing Industry}

In summary, the S-C 4060 converts computer output (either directly from a computer or from computer-generated magnetic tape) into precise graphic and alphanumeric page output onto microfilm and paper. The S-C 4060 System offers four character sizes, each with upper and lower case letters and proportional spacing for masters of high quality and handsome appearance. The unit produces not only page copy, but also ultra-high resolution graphics, plots, vectors, curves, Boolean diagrams, global maps, PERT charts, even frames suitable for animated film. The printing rate is up to 90,000 characters per second, with a median graphics print rate of 30,000 characters per second, including variable character spacing.

Because the S-C 4060 is a stored program graphic system, programmable via standard and common programming languages, extreme flexibility is achieved. This is not all: two elements have not been mentioned which are of extreme interest to users-speed and cost. We have available for handout sample output from the S-C 4060. This output was produced at a print rate of 30,000 characters per second.

Truly Micromation has brought new dimensions to the photocomposing industry. Electronics, now married to microfilm, proves once again that it is a more efficient and economical way to get the job done. 


\title{
IBM's Position in Electronic Composition and Text Editing
}

\author{
Hans E. Weiss \\ Printing and Publishing Systems Engineer, \\ Data Processing Division, International Business Machines
}

As you know, the very foundation of the success of the computing industry, dating back to the inception of manually powered punched card systems as envisioned by Dr. Hollinth in the 1890's and extending to the present world of microseconds and multiprocessing, has been the continuous growing need for information gathering and information dissemination. While we regard with pride the leadership that our company has established in the application of computers to this information explosion, it has been relatively recent in this evolution that the data processing community, in general, has extended its interest beyond applications directed toward manipulation of information content to applications of information presentation-or electronic composition.

IBM's initial efforts in this field began in 1962 with the development of basic hot-metal typesetting programs at several locations across the country. These were primarily joint IBM/customer efforts which utilized the IBM 1620 or 1400 series computers. All of these programs, with minor variations, were directed toward improving the process of transcribing pre-edited text into the proper form required for operation of paper tape driven hot-metal linecasting equipment. The next year, IBM announced the 1620 Type Composition Program, which incorporated into a single application programming package the experience gained with the earlier individual efforts, with some extensions-mainly in the paper tape allotting and distribution functions.

At the same time, several customers interested in film composition and the potentially greater payout to be gained through the use of computers in that area were developing composition programs for most of the photocomposition devices then in existence. These programs, similar to the early efforts in hot-metal composition, were mostly done by individual customers working with local IBM systems engineers assigned to their accounts.

As more and more programs were undertaken in this manner, two things very quickly became obvious: (1) text composition was becoming a fertile area for application of computers, and (2) the need for specialized systems knowledge in this new area was exceeding the capability on the local level. As a result, in late 1965 , two new groups were formed in IBM to concentrate on printing and publishing applications-one group in our Data Processing Division oriented primarily toward development of application programs and sales support for existing programs, and another group in our Systems Development Division whose activities are directed mainly toward development and integration of new systems hardware applicable to the printing and publishing environment.

One of the first products of the Data Processing' Division's application group was the 1130 Type Composition Program. This system, utilizing one of the lowest priced computers that IBM has to offer, was developed not so much to provide capabilities a great deal different from previous composition programs, but primarily to reduce the cost of the computerized text composition function, thus making it available to a broader range of potential users - especially for those installations utilizing dedicated text composition computers. This 1130-based system offers an integrated hot-metal and/or film composition capability for approximately one-half to two-thirds the cost of the lowest previous IBM offering on the 1620 system.

For purposes of this state-of-the-art discussion, several other IBM programs and products deserve mention that have come into being over the past couple of years and which enable the computer to facilitate the transcription of text from its origination point into a final printed form. Most of these systems, like the 1620 and 1130 Type Composition Programs, have been specifically oriented toward providing a solution to a rather restricted segment of a larger total text processing problem. The number of different systems and different approaches, perhaps better than anything else, attests not only to the lack of any previous unified examination of the problem, but also to the variation in functional emphasis on the part of the users. The capabilities of some systems have been designed to aid primarily in source data entry, some for text revisions, some for print for- 
mat control, and others for composition and page layout functions.

One such product is the IBM Magnetic Tape "Selectric" Typewriter which is offered by our Office Products Division. This is essentially a typewriter which records data onto a small magnetic tape cartridge and permits you to perform edit functions on previously prepared cartridges, as well as to obtain printouts of the stored text. The production of clean copy can be handled in two ways. One is to let the manuscript typist proofread from the typed byproduct as the text is being recorded. The typist can backspace or erase entire lines when an error has been made. Another approach is to key the original copy continuously and perform a separate proof/edit run using the original hard copy and magnetic tape cartridge. While this system, when used in conjunction with the recently announced IBM Magnetic Tape "Selectric" Composer to obtain graphic quality final printing, does provide a functionally complete composition system for low-volume operations, the system cannot be used for computer text input preparation since IBM does not have a device that allows the tape cartridge to be read into a computer. However, I do know of at least one customer who has had a device built by another firm especially for him that will permit the content of the MT/ST cartridge to be transferred onto a standard computer magnetic tape, which is then read into the computer.

Another IBM system being used in the data entry and text editing environment is the $\Lambda$ dministrative Terminal System. This system consists of typewriter terminals attached directly to the computer via communication lines, which permits the computer to capture and store operator keystrokes as the text is being keyed on the typewriter. The information is stored by the computer on a random access device where it can be retrieved for correction or updating purposes via the terminals, or formatted printouts obtained on the system's printer. Each of the typewriter terminal stations can be in operation simultaneously on different documents. ATS is not widely used in applications which require eventual graphic quality printouts because output is presently restricted to the nonproportioned spacing printers and typewriter terminals attached to the computer.

Although each of the previously mentioned systems and approaches provide measurable benefits to their users, several trends are beginning to influence a general reevaluation of the computer's role in a text processing environment :

1. The origination of input data that eventually require printing is not always under complete control of a specialized text-processing system. The economy of being able to capture and process data from a multiplicity of sources is becoming more and more evident.

2. The eventual form of printed text or its disposition is not always known at initial processing time. Not only is there an increasing requirement for variations in output media and format, but also an unpredictable variance in the elapsed time period between processing activity on either the text or the information it represents.

3. New composition devices and computer systems devices that enhance the role of the computer in a text processing environment are becoming available as advances in technology are combined with a better understanding of the problem by computer users and manufacturers.

4. The computer's functions as an aid in the composition of text are becoming secondary to its utilization in processing the informational content of the same text. Printing and composition functions are being increasingly considered as implied byproducts of having the text in computer-processable form.

5. The scope of computer applications relating to text processing is enlarging, thereby increasing the requirement for additional computing power to handle them. For economic reasons, this trend has dictated a requirement to utilize the text-processing computer system for nonrelated data processing functions, especially during periods of low text-processing activity.

The logical tendency for the users of current text-processing systems who desire to extend the capabilities of their systems into additional related functions, and thus attack more of the total problem, has been to inodify and augment their existing programs. In almost every case, however, it is inevitable that some factor in the original design or approach of the basic system being modified eventually presents a major stumbling block to further advancement.

The evolution of most of the IBM text-processing systems just discussed tends to confirm this point. These experiences seem to make it apparent that no single systems design which locks in on a specific set of input/output facilities or composition media can possibly meet the needs of the full range of text-related applications-not only because of the wide divergency in functional application requirements between technical publishers, commercial printers, newspapers, and other users, but, more important, because the user himself rarely knows at a given point in time what the next application will be.

We think the trends just enumerated will dictate a definite change in the design objectives of future text-processing computer systems, espe- 
cially in terms of programming design. Avoidance of system obsolescence is going to become more and more a factor as return on programming investment dollars is considered in light of new composition and computer systems development. Flexibility and adaptability are becoming premium considerations.

As an example, earlier this week at the American Newspaper Publishers Association meeting in Kansas City, IBM announced an application programming package for System/360 called S/360 Text Processor. It actually consists of two program modules-Composition/360 and Hyphenation/ 360 - which must be combined with user-writer systems I/O and composition device-dependent routines to produce a functionally complete system. In fact, the most striking difference between this system and those previously offered by IBM is that the user must tailor the system to his own requirements by adding his own programs. The intent of this program is not to offer one arbitrary systems approach to the user, but to provide the basic ingredients of the foundation for a comprehensive text-processing system which can handle both current and future requirements with maximum adap- tability. The underlying philosophy is that regardless of the variations in application requirements or the complexity of application extensions, one function is common to all systems - the calculation involved in translating systems-resident data representing text into a format that conforms to the specific visual characteristics desired by the user. That is the function we are attempting to supply with this programming package.

While this effort by no stretch of the imagination represents any major breakthrough in computerized text composition-in fact it is only a reorientation of old ideas-it does represent the first fruits of a unified approach to the problem and perhaps a little more awareness of the problem on our part. We, too, are enamored with the possibilities of high-speed photocomposition devices, full page proofing and final printouts, visual display terminal editing, and on-line data entry systems. In fact, the implications of these very things on traditional text-processing approaches have been the primary motivating force behind a temporary pause on the part of the data processing industry to reevaluate the role of the computer in the evolution of electronic text composition systems. Hopefully, we will all mutually benefit. 


\section{Government Policy \\ Chairman: Paul A. Ziemer}

\section{An Introduction}

\section{Paul A. Ziemer, Deputy Director \\ Office of Publications, U.S. Department of Commerce}

It is a pleasure to be here and to see so many persons interested in the subject "Electronic Composition in Printing."

My first reaction as I look at the program and see one hour allocated to the "Session II, Government Policy" is to wonder what can be said in such a short time on such a broad subject as Government policy in printing and publishing.

Electronic composition in printing is now making only a slight impact on the Government's printing and publishing program. From what you have heard this morning, what you will hear this afternoon, and what you will hear tomorrow, I am sure you will agree that the impact in the future will be tremendous. So, before we take a "New Look at the GPO," I would like to talk very briefly, particularly for the benefit of those in the audience who are not in the Government or who are not in a position in the Government directly related to printing or publishing, about a few salient points in the Government's program.

Publishing is "big business" in every agency of the Government. In the Department of Commerce alone, over $\$ 12$ million is spent annually on printing and publishing. Yet, despite the large volume and the complex structuring of Government agencies, it never ceases to amaze me how simply a job can flow from the author's manuscript through the pipeline or chain-of-command to the finished printed publication.

Let's look for a moment at this pipeline, at how a manuscript flowed to the finished product "before electronic composition," and then at what happens "after electronic composition."

Basically, in Government publishing there are three main points of control. First, almost every Department or major agency has a centralized point of control or processing point through which all jobs flow. Second, we have the Government Printing Office, which by law produces or procures all printing for the Government with a few exceptions-more about that from Mr. Harrison later. And third, we have the Joint Committee on Printing, which sets out the rules and regulations for the name of the game and how it shall be played.

Back to the manuscript. Before computers were invented, a researcher, an economist, a statistician, or an author wrote out his manuscript or report, or compiled his statistics. He then prepared his copy for the printer and sent it through his departmental headquarters for review, approval, and perhaps further editing, then to GPO for typesetting and printing.

Today we find more and more data emanating from computers. Not only statistics, directories, and bibliographies, but also manuals, texts, and reports.

The advent of electronic composition has changed the flow of manuscripts. In fact, in many cases there is no manuscript per se. It now is necessary for the printed publication to be planned before the information which will generate the data to be printed is programmed into the computer.

So, to make it possible for the "author" to take advantage of electronic composition we need to bring into the picture the computer people-the programmer and the systems analyst. While this at first glance may sound like an added channel, another step in the procedures, and thus a time delay, the direct reverse is true. Computers in the printing pipeline are a new element in the process but an element designed to improve the speed and improve the quality of the finished product.

To make this possible - to speed up the composition process to improve the quality of the product and to utilize the newest technologies available-is the purpose of this Symposium and must be the purpose of the personnel involved both in 
publishing and in data processing. If we want to improve the quality of our printed material and effect increased efficiency and savings in the Federal Government, we must get together for such an exchange of ideas as this.

At the departmental level most printing and publishing personnel are now working with dataprocessing personnel in preparation for this new era. The GPO and the JCP have been in this program for several years.

It is interesting to note that the many different exporiments and ideas leading to what we now consider electronic printing began in 1961, the same year that President Kennedy appointed a new Public Printer. On March 16, 1961 the Honorable James L. Harrison was confirmed by the Senate as the new Public Printer and he has been at the helm of the GPO throughout this experimental period leading to the new era in printingtypographic quality via electronic composition.

Before his appointment as Public Printer, Mr. Harrison served for 12 years as staff director of the Joint Committee on Printing. In this position he not only gained a thorough knowledge of Congresssional activities, the operation of the GPO, and the operation of the executive agencies, but also became deeply involved in the printing, publishing, and distribution problems of all the agencies. He had the opportunity to obtain an overview of the Federal Government's organic printing capability and to analyze the strengths and weaknesses of supplying its sizable needs.

Prior to his appointment as staff director of the JCP, he was president of a wholesale electronics company which he owned and organized. He served as liaison officer of the Office of Price Administration from 1942 until 1947 and before that he held various positions in the Census Bureau of the Department of Commerce. The fact that Mr. Harrison began his government career in the De- partment of Commerce always gives us a feeling of pride and joy. I know that it adds to our pleasure in having him back here today. I have never met with Dr. Eckler, the present director of the Census Bureau, that he doesn't ask about "his good friend, Jim Harrison."

After Mr. Harrison became Public Printer in 1961, the GPO gross volume jumped from $\$ 97$ million to $\$ 122$ million in one year. By 1966 the rolume had risen to $\$ 170$ million. Despite this tremendous increase in volume with which Mr. Harrison had to cope, he found time to inaugurate a series of employee-oriented programs directed toward improved working environment; he was responsible for the revitalization of the apprentice-training program; and through his efforts he so improved the safety program that in 1965 he was awarded the President's Safety Award for outstanding safety record for Government departments under 10,000 employees.

Mr. Harrison is co-chairman of the Joint Printing Foundation of Metropolitan Washington and a member of the Foundation's Board of Trustees. He was awarded the Medal of Merit by Rensselaer Polytechnical Institute in 1965 . He is a life member of Printing Industry of Washington, D.C. and holds honorary memberships in the Graphics Arts Association Executives, the Washington Litho Club, the Washington, Chicago, and Los Angeles Clubs of Printing House Craftsmen, the GPO Alumni Association, and the Franklin Technical Society.

Mr. Harrison has spoken to numerous organizations from Maine to California and a few places like Japan and the Philippines. Suffice it to say that I feel highly honored and I know we are all pleased that he is able to be here this afternoon to address this audience. I give you the Public Printer of the U.S.- the Honorable James L. Harrison. 


\title{
Transition on the Tiber- a New Look at the Government Printing Office
}

\author{
The Honorable James L. Harrison
}

\author{
Public Printer of the United States
}

I am pleased to have been invited here to participate in this symposium on electronic composition. My remarks will be both brief and general, and will be aimed at acquainting you with what the Govermment Printing Office can now do for you, and what we hope to be able to do for you in the foreseeable future.

I selected the rather theatrical title, Transition on the Tiber, to dramatize the quiet revolution in methods and procedures going on in our agency. For those of you who fail to appreciate the connection between the Government Printing Office and the fabled Tiber River, let me explain that our buildings are located on the site of the original Wendell printing plant purchased in 1861 as the first Government printing establishment. The plant was only half a block away from a stream which drained the many bogs typical of the Swampoodle area. This drainage ditch was named Tiber Creek by some classicist with a twisted sense of humor. The cesspool went underground in 1876 and now flows beneath North Capitol Street, between the bottom of the roadbed and the top of the tunnel connecting our warehouse with the main plant.

Briefly stated, our mission at the Government Printing Office is to provide a printing service for the Federal establishment. Last year the Government Printing Office produced in the central office more than 20 billion $8 \times 101 / 2$ equivalent units and set more than three billion ems of composition. But the demand for printing far exceeded our capacity. Today, slightly over half of our annual printing volume is procured from commercial printing houses throughout the United States. We have more than 2200 firms on our list of active suppliers -and their capabilities range the full spectrum of processes from xerography to gravure.

In handling more than a thousand individual orders each day, the Government Printing Office has acquired a know-how unequalled in the printing field. Despite this volume, our policy is totally centered on providing you-our customers-with the best possible quality in printing, in the best possible time, for the least possible cost. With minor exceptions, the service you are getting is consistent with this policy.

In the past few years, we have seen a remarkable increase in demand for printing and a steady decline in the "put-through" time. In 1960, our business volume was just below $\$ 100$ million-this year we expect it to reach $\$ 210$ million. In 1960 , commercial printers did 40 percent of the total and this year will do 55 percent. My reason for giving you these figures is to demonstrate that with virtually the same workforce, and in virtually the same space, we are meeting a ballooning Federal requirement for printing. The answer is, of course, our growing dependence on new technologies and devices.

Two innovations, as far as the Government Printing Office is concerned, loom large in the assessment of our future plans-offset and electronic composition. Today, for the first time in our history, we are producing more impressions by offset than letterpress. This, I note, follows the nationwide trend in production as reported by Commerce's Business and Defense Services Administration in their excellent publication, Outlook. Improved efficiency and better quality camera work, automatic film processing, steadily declining plate costs, and swifter press rumning speeds have all contributed to this trend. But perhaps foremost in the picture has been the move to web equipment in the offset pressroom.

While conmercial experts were spreading the doctrine of long runs for profit, our offset division demonstrated the soundness of producing even modest runs on web equipment. We now have two offset webs in the $6 \times 9$ inch 32 -page family, and one in the $8 \times 101 / 2$ inch 64-page family.

The large web is equipped with a utopasters. Our Modernization Committee is eurrently conducting studies on various types of oftset web equipment to angment our present web capability. Such matters as press size, web speeds, pasting, folding, and drying options, and antomated control devices weigh very heavily in our decisions to recommend purchase to our Board of Directors-the Joint Committee on Printing. 
Now since this Symposium is chiefly taking place in order to review progress in electronic composition in printing, let me turn to the Government Printing Office's activities in this area. Here again, we have kept the practical interests of our customers foremost in our minds.

In 1962, the Joint Committee on Printing put their foot on the stern of our little expeditionary force and pushed us out into the forbidding and relatively uncharted sea of computer-oriented composition. Our exploratory group-now dignified with the title of the Federal Electronic Printing Committee-consists of a leader-the Staff Director of the Joint Committee on Printing, and hardy representatives from Army; Navy; Air Force: Commerce; Health, Education and Welfare; CTA; the Bureau of the Budget; and the Government Printing Office.

This Committee's findings formed the basis on which the Government Printing Office has acted, and were instrumental in moving us to the forefront in the search for a suitable electronic composition system. We are now on the threshold of realization-expecting delivery of the highly sophisticated Linotron system in a few weeks.

But back four or five years ago when the work of the Committee gave substance to our estimates that 20 percent of all Government printing was being composed entirely-or in part-on EDP equipment, we realized that a temporary or interim solntion was needed-and quickly. So the Government Printing Office seized the initiative and installed a system which we felt would provide much-needed experience, information, and training in this field. At the same time, we were confident that such a system also would provide important savings to our customers on certain types of work while we were fixing our sights on the ultimate answer to our composing problems.

This first essay into computer composition took the form of two Linofilm keyboards, a Linofilm photo unit, prototype-paper-to-magnetic and magnetic-to-paper tape-converters, three Justowriter perforators, and three Electron tape-operated slug casting machines. Two IBM 1401 computers were already in service in our accounts division.

WVe now have five photo units and the old 1401's have been replaced with an IBM $360 / 40$ and a $360 / 50$. This computer setup will serve not only the composition requirements but also accounting, payroll, inventory, and some production functions.

I am sure that by now you are familiar with the proven advantages of this system-chiefly a dramatic reduction in the overall bulk of work produced in this mode over conventional production of printout copy. Using magnetic tape as input, we have achieved a bulk reduction of nearly 40 percent in some publications. When the cost of paper and ink, and the allied savings in production, handling, and mailing are considered, the results are quite worthwhile.

Where bulk cannot be reduced on a publication because it has already been compacted and reduced to the minimum size, we have been able to upgrade the typographic quality of the product and make it more useful for the reader and at greatly reduced costs over manual rekeyboarding and proofreading by traditional methods.

The Library of Congress Subject Headings was converted from 1400 pages of standing type to magnetic tape. The quarterly supplements to this basic edition are also produced by computer and Linofilm. Each supplement is input to the computer to keep the basic edition master file constantly up to date. Future editions of this massive publication will be produced at only a fraction of hot metal cost and in much less time. It also might interest you to know that this entire publication is now stored on three reels of magnetic tape, while the type stored in the Government Printing Office for previous issues weighed seven tons.

Defense Documentation Center and Commerce Clearinghouse for Scientific and Technical Information were two of the agencies who saw the possibilities in this system very early, and we have been producing their semi-monthly announcement journals from magnetic tape for nearly two years.

Regularly scheduled publications are being composed for the Departments of the Army, Navy, Air Force, Commerce, and Transportation. Many other agencies are in the process of preparing programs to place work on the system.

But our work with this interim equipment configuration is merely a shadow of the promise held by the coming high-speed system. Increased flexibility will make production practical on many jobs that exceed present capabilities.

The prospect of working with this space-age printing tool is exciting to contemplate. But here I must pay tribute to the vision of the Federal Electronic Printing Committee-and the conviction of my own staff.

With the approval of the Joint Committee on Printing, we wagered a sizable chunk of money on the Linotron concept-and gambled that a system designed to the broad specifications laid down by the Committee could be built. Your agencies are about to become beneficiaries of this program.

Tomorrow you will be treated to a "nuts and bolts" presentation by Jack Boyle, Government Printing Office's highly qualified expert in electronic composition, so I am confining my remarks to generalities so as not to steal his thunder. 
But here again I want to emphasize that our electronic printing policy is not designed to hypnotize or fascinate the lovers of abstract electronic gadgetry-it is a down-to-earth effort to bring you savings in printing costs. To this end our classes at the Government Printing Office for preparation of magnetic tape are aimed at acquainting you with our needs, and at the same time allowing us to assess your requirements in terms of the future. The entire program is slanted toward a team effort, for the greatest effect in highspeed electronic composition, and will be felt only when our customer agencies are an integral part of the total production pattern-from raw copy preparation to product delivery. We are in a position to help you realize the full impact of this system on Government printing. But without your complete cooperation and your intimate familiarity with the unique characteristics of this system, your agency will derive only superficial benefits.

Computer photocomposition will not solve all of your typesetting problems. Some jobs will not be practical for this system for various reasons and will continue to be set as in the past. Each publication must be judged on its own merits by our people who are experienced with equipment limitations.

So I invite you-no, I urge you-to work closely with our staff through your printing and publications office to give this program the added thrust of cooperation needed to bring it to maximum effectiveness.

The future may, as Demosthenes said, be hidden from all men, but this I feel no qualms in predicting - that the principle of service by the Government Printing Office to its customer agencies will endure. We are structured and equipped to be totally responsive to your printing needs-whatever they may be-now, or in the future. Our electronic composition posture is first rate. Some less cautious than I say it is years ahead of the industry in some applications. One thing experience has taught us is that we have just scratched the surface in this field. The state of the art, despite today's complex and sophisticated systems, is in its adolescence. We know, for example, that straight keyboarding of copy, regardless of the high-speed systems following, is handcuffed to manual operator speeds. While we are learning ways to improve manual keyboarding somewhat, increases are not significant. Optical readers and scanning devices offer hopes of freeing input speeds and sending them soaring.

But whatever the future brings in the way of innovation, or improved printing technology, you may be sure the Government Printing Office will put it to work for its customer agencies. We are committed to a policy of progress, quality, and economy. The printing service we offer is eclipsed by no service elsewhere obtainable, and I might add we have few peers. We have the know-how and the capacity and stand ready to serve your every need. Yes, the Government Printing Office is a facility in transition - and the transition is focused on giving the Federal establishment better printing, faster printing, and less costly printing. 


\title{
Present and Projected Policies of the J.C.P.
}

\author{
John F. Haley, Staff Director
}

\section{Congressional Joint Committee on Printing}

Permit me, please, at the outset, to state that I felt myself quite taken with undeserved importance when I was asked to participate in this Symposium-and wish to express my gratitude to my friend and colleague, Paul Ziemer, and to Mr. Lee, the general chairman, and his able assistant chairman, Roy Worral. I shall direct my remarks to many items that should tinkle with familiarity to most of you. Please bear with me, and be certain it is not my intention to be penalized for ambiguity. I will serve up no predigested ideas or slogans, recognizing that such a practice disturbs most mental climates. Let us depart from the inverted conventions and try to see everything quite plainly as the verbal smokescreen lifts.

Allow me to lower the historical backdrop and take you back to another day a little more than five years ago. It will be a spoonfeeding process-fully analyzed for reality-and, I hope, no solid lumps that may have you swallowing with any difficulty.

During the course of this Symposium you will hear from my friends in the Department of Health, Education, and Welfare about their efforts in the field of electronic composition. Notwithstanding the significant advance made by the National $\mathrm{Li}$ brary of Medicine of that Department, I believe it is essential to put it into context.

First, the output system of MEDLARS was designed around the typographic requirements of a single publication, i.e., Index Medicus, with very limited needs in terms of type styles and sizes.

Second, the speed requirement was also built on the desired publication cycle of this single publication.

Third. the move to electronic composition on the part of the National Library of Medicine was not so much prompted by the typographic imperfections of the preexisting system (which was a Listomatic system), but rather because of the need to automate the data base from which Index Medicus was derived.

Keeping these three major factors in mind, it becomes clear that the development of the MEDLARS system did not meet the generalized needs of the Federal Printing Program.
Dating from the installation of the first highspeed line printer in the Bureau of the Census, an increasing number of Federal publications were being composed either in whole or in significant part on the line printers of the computers in use in the Federal service.

In 1961 an analysis of the Federal publications crossing the desk of Mr. Lou Shomette, then the Staff Technical Assistant of the Joint Committee on Printing, indicated that approximately 20 percent of those publications were being composed on some form of automatic data processing equipment. Further analysis of these publications indicated that compromises with legibility, bulk, and printing and binding costs had been made for the sake of pure speed in composition and dissemination of the end product.

After discussions with the major publishing agencies of the Executive departments and staff of the Government Printing Office, a policy determination was made by the Joint Committee on Printing to give a mandate to the Public Printer of the U.S. to develop a program designed to give proper balance to the use of computers in the printing field. All of us concerned with this effort are fully convinced that this was an epochal event in the history of electronic composition. The Joint Committee's policy letter is reproduced in the illustration.

To assist the Public Printer in fulfilling his mandate, the Federal Electronic Printing Committee was formed. We believe it highly significant that this committee was truly interdepartmental in nature, and indeed interbranch, when one considers that GPO is part of the legislative branch. This band of hardy pioneers was composed of the following men :

Mr. Ed Forbes (now Mr. Jack Boyle)-Government Printing Office

Mr. Bill Gill-B Bureau of the Budget

Mr. Harry Aldridge-Department of the Army

Mr. Ted Maynard-Department of the Navy

Jt. Col. Angie Elmo-Department of the Air Force

Mr. Bob Pearson-Central Intelligence Agency 
CONGRESS OF THE UNITED STATES

Joint Committee on Printing

WASHINGTON

Honorable James L. Harrison

The Public Printer

Government Printing office

Washington, D. C.

My dear Sir:

The Joint Committee on Printing has noted the growing amount of material produced from high speed printers on automatic data processing equipment which is submitted to the Government Printing office for printing. A majority of this copy lacks legibility and when printed results in significant waste of paper, presswork, folding, and related operations. In addition, the bulkiness of the finished product, together with the difficulty of reading, provides generally unsatisfactory results.

Because of the need for improving the legibility of this class of copy, and to reduce the bulk with its attendant waste, the Joint Committee on Printing, in compliance with law as provided by section 4, title 44 , U. S. Code, requests the Public Printer to institute in the Government Printing Office a research and development program in order to improve the quality of the copy emanating from automatic data processing equipment and make greater utilization of such process in printing production.

The Public Printer is authorized to obtain, subject to approval of the Joint Committee on Printing, necessary equipment to provide printout service from tapes or other media furnished by Government agencies when it is in the public interest.

The Public Printer is requested to make periodic reports to the Joint Committee on Printing covering developments resulting from operation of the requested program, and to make recommendations for the consideration of the Committee.

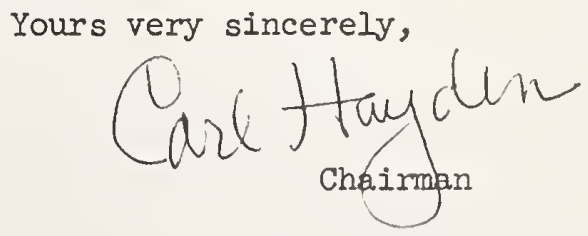


Mr. Ray Lannon-Department of Health, Education, and Welfare

Mr. Paul Ziemer-Department of Commerce Working to bring about a solution to the conflicting needs for speed in composition and desirable printing practice, this group also analyzed and integrated work that had begun in the various agencies on this problem. In particular, a draft set of specifications developed in the Department of the Navy was used as a departure point.

A subcommittee, composed of representatives of the GPO, Army, Navy, and HEW, drafted a set of specifications for the approval of the whole committee which, in turn, submitted them to the Public Printer for his consideration.

After approval of the Joint Committee the specifications were released to the industry on July 17, 1963. A pre-bidder's conference was held on August 12, 1963 at which the subcommittee responded to questions from a wide segment of the industry. On October 15, 1963 a total of six proposals was received from the following firms: IBM, Harris Intertype, A. B. Dick, Alphanumeric, Photon, and Mergenthaler.

I subcommittee of the Electronic Printing Committee, composed of the representatives of GPO, Navy, and HEW, assisted by Mr. Ralph Mullendore of the Bureau of the Census, undertook the difficult and sometimes thankless task of evaluating the paper mountain of proposals received. Each firm was requested to supplement its written proposal with an oral briefing and to answer detailed questions on various aspects of its proposal. After a complete and exhaustive analysis, the subcommittee recommended that the contract be awarded to Mergenthaler.

This recommendation was endorsed by the full committee and submitted to the Public Printer on January 27, 1964. On March 11, 1964 the Joint Committee on Printing approved the request to purchase two high-speed phototypesetting machines known as Linotrons. The contract was awarded on March 11, 1964.
Even as I stand here today, the first of the Linotrons is being prepared for shipment to the Government Printing Office where, after meeting contractual requirements pertaining to performance, it will usher in a new era in composition.

Why, one might ask, do I say that the Linotron will usher in a new era in composition?

First, I would say that we have bridged the gap that had existed in the speed imbalances between computers and composing devices. While the bridge may not be as wide as we might like, the fact of the bridge is there.

Second, I would say that we have introduced a new technology to composition by means of cathode ray tube outputs. Some said it could not be done, but it seems that the history of progress is built on the bones of those who said it could not be done.

Third, we have brought together within the Federal service the practitioners of two arts; namely, the art of data processing, and the art of typography. Recognition of each other's problems has been and will continue to be an essential element in the exploitation of this new era in composition.

I trust that an examination of what I have had to say will disclose nothing unsubstantial and illusory. Rather, I hope it has contained a message of official attitude. I am not asking that we cling to wholly conventional practices merely to give support to our components of realism. Let us not mock the rules of logic and create possible doubtbecause doubt is self-dest ructive.

In concluding, I must confess that the finer technics of computerized printing live in the stylish suburbs of my thinking. But the associations I have had in conducting such a Congressional printing program are treasureable highlights of my life. Being here in this wonderful company adds a shining page to my diary. Thank you very much for programing me today. 


\title{
III. Non-Government Applications and Research
}

\author{
Chairman: Dr. Glenn E. Roudabush
}

\section{Introductory Remarks}

\author{
Dr. Glenn E. Roudabush
}

Assistant Director, Computer Center, University of Pittsburgh

The typesetting project at the Computer Center of the University of Pittsburgh was started in early 1965. Its genesis was haphazard and came about through three converging conditions. First, in late 1964, we asked for and received from NIH, the Photon S-560 phototypesetter that Michael Barnett had used at MIT to develop his PC6 system of computerized typesetting programs, along with the programs themselves. Second, we had some staff and monetary support under an ongoing Department of Defense Advanced Research Projects Agency grant that could be applied in this area. And third, we were able to generate some interest in the project among some able staff members. All of these conditions, including the existence of an exceptionally able staff at Pittsburgh, were the direct result of the efforts of William B. Kehl, who then directed the Center.

I became involved in the project in the early summer of 1965 at about the time we decided to program our own system from scratch. For a number of reasons, the project fell short of full development but several important components of the system were completed. These included the IBM 7090 program which provided for a computerized typesetting capability and the PDP-4 text editor program. Because these programs, along with our overall plans for the system, have been described elsewhere, I will only briefly characterize them here.

The typesetting program was designed to be as general as possible so that it might be used with a wide range of materials to be photocomposed. The emphasis was on format flexibility. It operates on a system of text markers, which are quite arbitrary strings of symbols included in the text or which may be part of the text to be photocomposed itself, and several kinds of parameters which specify actions to be taken when the markers are encountered. These actions specify the appearance and format of the output. Formatting is done by the page. A full page of material is retained in core storage, manipulated there, and output one line at a time only after it is in its final (symbolic) form. The parameter "language," though in appearance quite distinct, is similar in operation to the system being developed by RCA. Both have developed from the early work of Barnett.

The text editor program was written for a Digital Equipment Corporation PDP 4 computer which includes a CRT display and light pen. The text editor continuously displays text on the CRT with a set of stationary "push button" symbols beneath it. The "push button" symbols indicate operations to be performed on the text and are activated by the light pen. Positions in the displayed text are marked by light pen with a left delimiter, right delimiter, or a curser. Portions of text can be moved or deleted, corrections can be made or additions inserted, and so on. This program, written by Charles R. T. Bacon, has been very useful to us.

The autopublication system which we designed was placed in the context of first secondary, then primary, scholarly publication. It was to become the processing component in a total information system for one scientific discipline, namely linguistics. Our planning toward this goal was aided in many ways by Alfred Pietrzyk and his staff at the Center for Applied Linguistics through a number of fruitful discussions and exchanges of working papers. 
As the design of the system unfolded, it became increasingly apparent that, when implemented, such a total information system must radically change the nature of scholarly publication. Scholarly publication is directed at disseminating information to peers in the form of journal articles, monographs, technical reports, theses, and so oll. What I have to say here has been said many times before, by myself and by other's, most recently perhaps by Miodrag Muntyan in the June 10 issue of the Saturday Review. It is simply this: that publication on paper in this field must in time certainly cease to exist. For a scientist or scholar, publication will simply become a matter of making his report available to a computer and thereby to his peers. His work will be indexed, abstracted, evalu- ated, and displayed to any appropriate interested parties quite automatically.

Such gross changes in the way information is handled within a discipline imply not only substantial technological developments but also fundamental changes in the behavior of individuals and in the social organization of the sub-society of which the individuals are a part. Changes of this kind are evolutionary, not revolutionary, in nature, and implementation is stepwise. These changes must certainly take place in time, but the time is typically on the order of at least one full generation. The first and perhaps most important step in this sequence of change is the subject of these meetings. 


\title{
Chemical Information, a Computer, and Photocomposition
}

\author{
Bernard G. Lazorchak, Assistant Director \\ Graphic Arts Research, \\ American Chemical Society
}

These demands on information are constantly being heard: "Give me a greater amount, cut the time span between availability and release, and package it in a form that will satisfy my use." The demands are coming from all walks of life, but especially from the scientific community, where research results generally predict the competitive position of an organization.

Today, a large volume of information is available but the user must generally rely upon the distribution of a printed page before he can become informed of its availability. And if he is to use this information in another form, he must duplicate the procedures required to obtain the original. But for tomorrow, based on a concept that is beginning to evolve today, we see a change in the means by which information can be distributed. This new means is evolving around coded information, which can be manipulated by a device such as a computer at great speeds and transmitted to many locations through communication devices. It does not mean the elimination of the printed page, but suggests that this is but one use for information, instead of its main source.
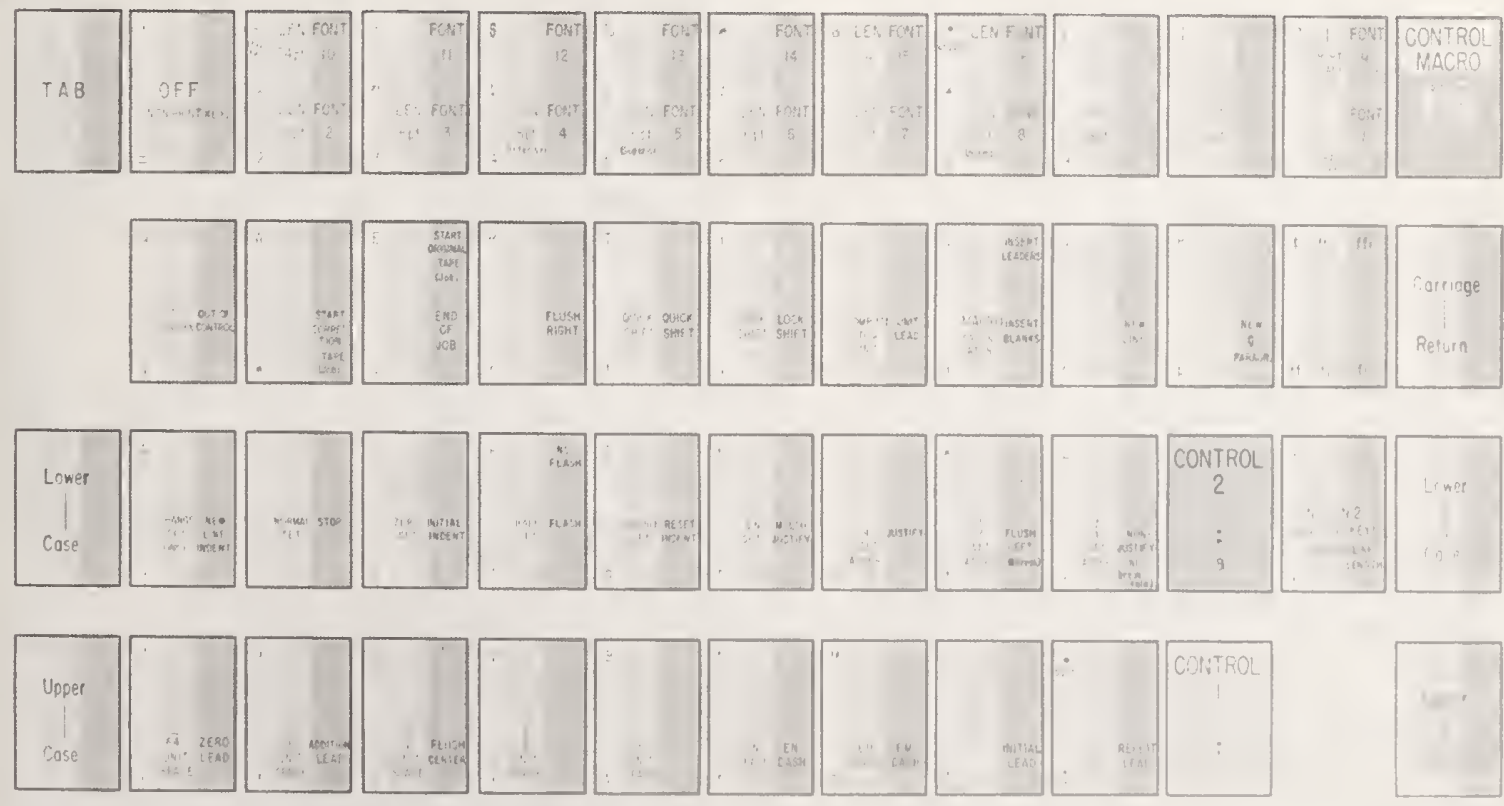

FIGURE 1. Sehematic layout of Friden Flexowriter as used for input to computerized typesetting. 
Let us look at what the American Chemical Society (ACS) is doing today and try to visualize the usefulness of such a capability for information processing in the future. ACS has developed an input procedure that is referred to as MACRO coding. ${ }^{1}$ MACRO, in effect, is a flag procedure which permits the identification of information and the association of parameters with that identity. In addition, MACRO coding simplifies the input procedures and reduces keystrokes.

The keyboard layout illustrated in figure 1 has been designed to accomplish three specific purposes: text character production, MACRO identification, and printer control language input.

1. Text character production: Forty-two key positions are assigned to character information to produce unique codes in the tape. The key positions are doubled when using the upper case shift, thus permitting the assignment of 84 characters of information. However, for those who desire to avoid the use of the standard shift keys, a function is available in the printer control language that can be used to have the computer programs automatically generate the shift.

2. MACRO identification (classified as permanent. temporary, and special): Permanent MACROs are identified by the alphabetical characters $A-Z$ and are defined as those sections of information that generally appear in all manuscripts. These are such items as the title, author, abstract, main items of text, mathematical formulas, tables, figures, etc.

Temporary MACROs are identified by numerical characters and are defined as information for a specific manuscript. These may consist of such items as key words, reference indicators, chemical terms, quoted data, etc.

Special MACROs are identified by punctuation symbols and are used to define specific conditions, e.g., the end of a sentence.

3. Printer Control Language: This consists of functions that are used to vary the standard text character mode and to define controls in reference to MACRO identification. With this language, a person trained in printing applications can manipulate information using terms that are familiar in his everyday work.

For the past two years we have been using MACRO coding for live manuscript copy of articles which appear in the Journal of Chemical

\footnotetext{
${ }^{1}$ B. G. Lazorchak, Coded Manuscripts for Computer-Aided Typesetting and an Information Handling System, TAGA Proc., pp. 114-125 (1966).
}

Documentation and the Journal of Chemical and Engineering Data. MACRO coding is used to handle text, tables, and mathematical formulas. The implementation of the system begins with a phase called copy analysis. Here an individual scans the copy to determine all sections of information that should be identified by temporary MACROs. These sections are identified by a mique number and are labeled at each point of occurrence in the copy. Permanent and special MACROs are repetitire in nature and are not required to be marked on every manuscript. However, a listing is available at every input station for reference by the input operator. In addition to identifying sections, MACRO instructions are created using the printer control language. These instructions are coded by the input operator previous to the point of first reference within the copy.

Information is coded by an input operator, read into the computer, and stored on magnetic tape. When all the information relating to a specific manuscript has been coded and stored in the computer, a request is entered to receive a computer printout of the total manuscript. The computer printout is proofread and then corrected at an input coding station. The coded corrections are read into the computer, merged with the original information, and a corrected master file is obtained.

What have we accomplished through the use of MACRO coding? We have generalized the input coding procedures to a point where every condition that can be predetermined is coded using a variant that can be changed depending upon the requirement of a user. For example, the MACRO identification can be ignored and only raw text character's reproduced; or MACRO identification can be searched to locate a specific section of the manuscript; and any of these identifications may be associated with any combination of characters or control functions. To evaluate the degree of the potential of such a coding procedure, the ACS Publications and Chemical Abstract Services are working on a cooperative effort to exchange coded information between both operating systems. This is expected to broaden the understanding of the interchange that can take place between the primary and secondary literature and its related advantages to the user.

Now we have coded information, stored in the computer, that can be manipulated in a manner defined by our use. At the present time this use is a published journal. Thus a request is entered to the computer to select specific information, process it through the typesetting program, and produce a coded tape to operate a Photon photocomposition machine. 
Galleys of information are produced on the Photon, copies of which are forwarded to the editor and author for verification and/or alterations. The proofs are returned, corrections are coded, information is updated in the computer, and once again we have corrected information stored on a master file. Upon release of the information to a printed publication, the master file will be stored as part of our permanent records.

In addition to the ACS MACRO coding procedures, an auxiliary system has been developed to handle chemical structures. This system has been programmed to read coded information produced by using the Army Chemical Typewriter ${ }^{2}$ and to punch a coded tape to operate a Photon phototypesetting machine.

The Army Chemical Typewriter produces a coded tape which can contain alphanumeric characters, special characters to represent the chemical bonds, and reference data expressed as $X-Y$ coordinates. The alphanumeric and special characters are coded by pressing special keys on the keyboard, while the $X-Y$ coordinates are punched automatically by the typewriter platen movement being changed.

¿A. Feldman, D. B. Holland, and D. P. Jacobus, The Automatic Encoding of Chemical Structures, J. Chem. Doc. 3, No. 4, 187-189 (Oct. 1963).
The ACS system reads the Army Chemical Typewriter coded information and converts it to a standard format-character data are represented along with an $X-Y$ pointer reference, while the $X-Y$ coordinate data are represented in a separate table. Input data are continually accumulated until an end-of-job code is found. At this time the $X-I$ coordinate table is searched to locate the lowest value and is then used to gain a starting position on the grid. The information in the grid is then analyzed and translated to Photon control codes. At the completion of this operation all input data are preserved and stored for possible future use.

The Photon is equipped with an eight-channel tape reader and a specially designed disk containing the characters required to build the chemical structures. These special characters consist of angles that are made up of a variant of four conditions (fig. 2).

The choice of variant selected by the computer program depends on what exists in the upper right- and lower left-corners of the bonding character (fig. 3). Alphanumeric characters contained within a structure are originated using standard text characters. Size, set, and baseline adjustments are calculated by the computer programs in order to position these elements in their proper perspective in relation to the bonds.

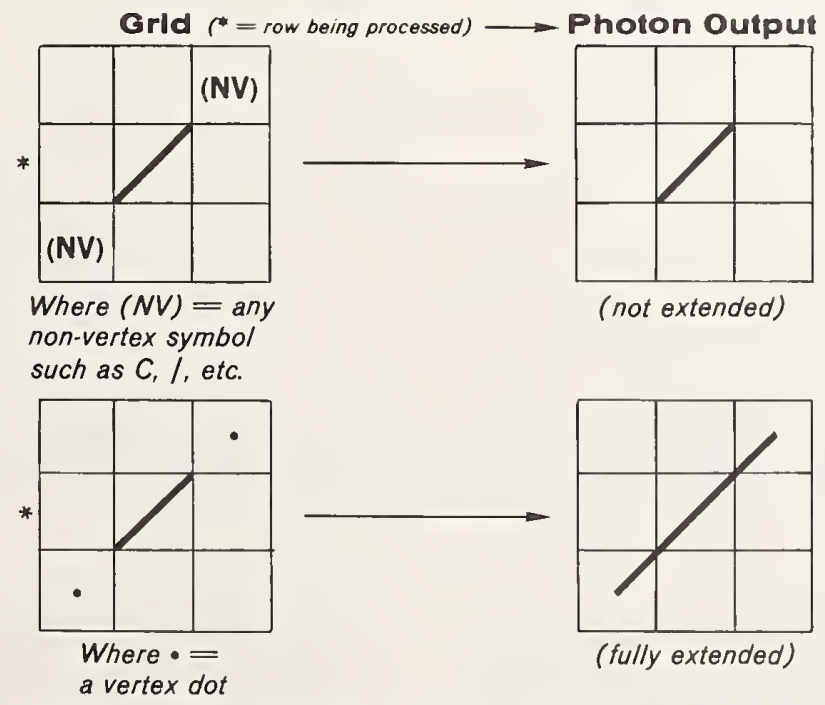

FIGURE 2. Four variants used to build chemical structures. 

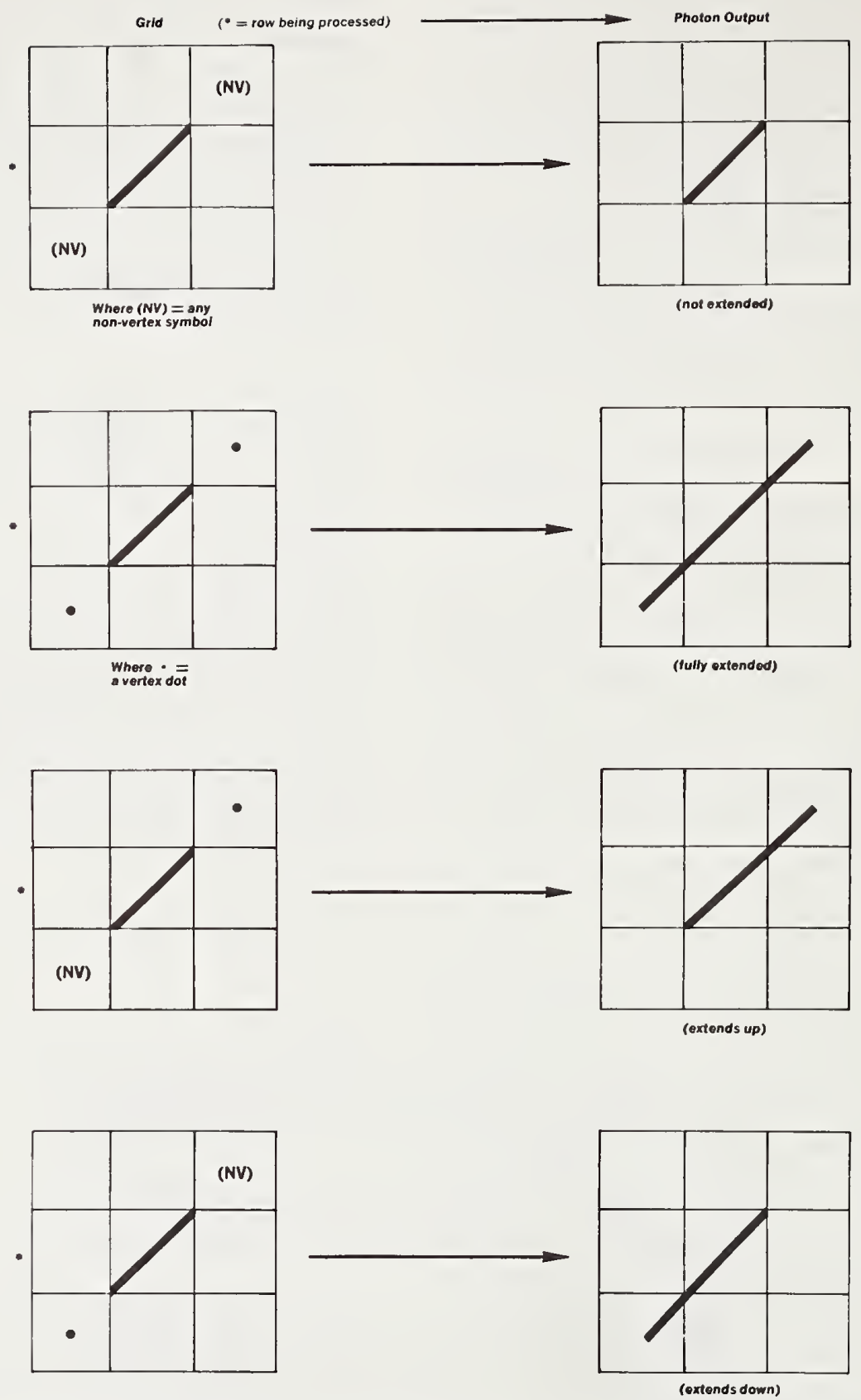

FIgURE 3. The choice of variations depends on what exists in the upper right and lower left cells adjaccnt to the variant in the center cell. Examples of input and the resultant output are shown.

The ACS programs have been tested using coded information supplied from the Army Chemical Typewriter operated by Herner \& Co. for the Walter Reed Institute for Army Research. This same coded information used by ACS can be used as input to the Army Information System. (See figs. 4,5 , and 6. .)

Along with the ACS 1460 system, Chemical 


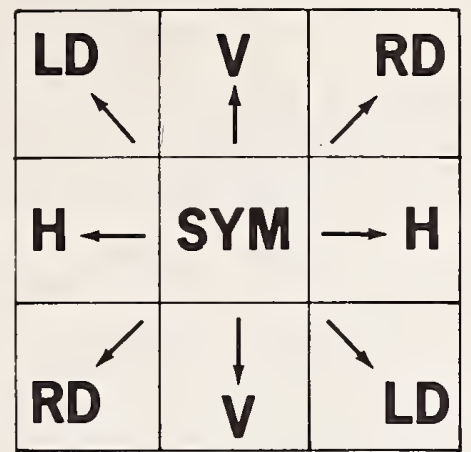

$H=$ Horizontal bond

$V=$ Vertical bond

\section{$\angle D=$ Left Diagonal bond}

\section{$L R=$ Right Diagonal bond}

Figure 4. This figure demonstrates the possibilities for special characters.

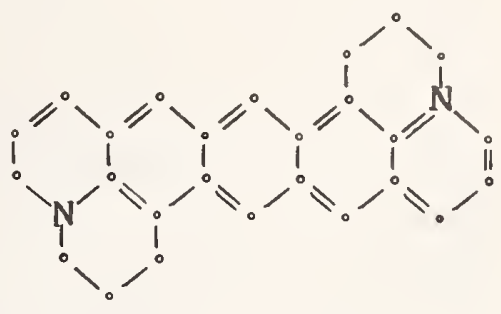

$\mathrm{J}$

RI 9590

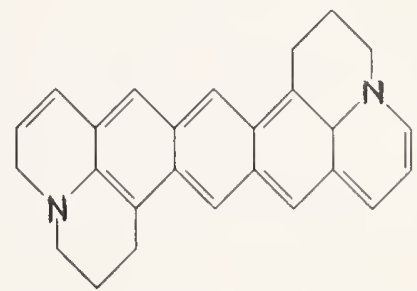

FIgURE 5. Sample of hardcopy, showing a structure produced on the Army Chemical Typewriter (top) and its film results produced on the Photon (bottom).
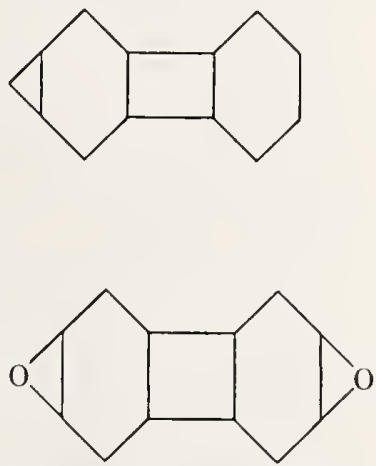

FIGURE 6. Examples of results using Photon output.
Abstract Services, another division of the ACS, has developed a system for handling information using an IBM 360 computer that reads coded information supplied from the Dura Mach 10 and the Mohawk 1181. It then translates and manipulates the information as defined by its specific use. For output, they have recently installed an IBM 2280 character generator.

These are but a few examples of today's research using and developing tomorrow's concepts. It is giving us the awareness that if we treat information as a coded medium, a computer, with its power to translate and manipulate at great speed, can effectively present information to a user" in a man- ner that can serve his demands for information. We must remember that information by itself is simply raw data, and until it is placed at a source where it can be absorbed by the human mind, which can contribute understanding to the information, elaborate on its concepts, formulate principles, and make evaluations, we have no knowledge.

We wish to express our appreciation to the National Science Foundation for its support and encouragement of this work under NSF Grants GN-140 and GN-426. 


\title{
The Impact of Electronic Composition on Commercial Printing and Publishing
}

\author{
William C. Lamparter \\ Senior Graphic Arts Economist Battelle Memorial Institute
}

\section{Introduction}

Thus far in this seminar on electronic composition, we have heard quite a bit about specific pieces of hardware and how this hardware might be used in various Government applications and largescale data- and information-handling systems. It is appropriate that we take a few minutes in a meeting such as this to assess the impact of electronic-or computerized-composition on the commercial printer and publisher.

Everyone knows what a commercial printer or publisher is - that is, until wo try to define him. Then, as is the case with much terminology in the graphic arts, we find that not everyone means the same thing. Let me explain what I mean by a commercial printing and/or publishing company.

As the word commercial implies, such a company is in business to make money. This is an important consideration because it means that the utilization of new concepts, such as computerized composition, must either immediately improve the profitability of the business or at least offer some hope that greater profitability can eventually be realized.

The many thousands of small job printers located in virtually every city, town, and hamlet in this country are prime examples of commercial printers. While many of these operations are small businesses of less than 10 employees, the category also includes medium-sized businesses that, in a few cases range up to 250 employees. Also included are the handful of large companies that make up the "giants" of the producing-printing industry. Although graphic arts is one of the top 10 industries in the United States, even the largest companies in the industry are small, as compared with the industrial giants found in electronics, chemicals, and heavy manufacturing. Therefore, we are talking about small- to medium-sized firms consisting of general or job-shop printers that must make a profit to survive.

Our definition of commercial printers also includes a number of the specialized segments of the printing industry such as the business-forms printer, the greeting-card manufacturer, the book and periodical printer, as well as the specialist in items such as direct mail, catalogs, and directories. Particularly important for inclusion in this list is the trade composition house.

Not included in the definition are the graphic arts service operations that are not concerned with composition or press work, such as a book binder. Because of their highly specialized situation, we have also excluded newspaper. Operations that exist primarily to manipulate data-probably by computer-are not considered to be commercial printers, even though they may at times be concerned with printing. Government operations are also outside of our definition as are those organizations that are not profit oriented.

Publishers - those who really pay the bill for the automation of commercial printing-might more accurately be defined as the buyers of printing. Book and periodical publishers, as well as the industrial publisher (or buyer of printing) are within our definition of commercial publishers.

As a part of Battelle's research activities, we have been conducting almost continuous field interviewing of the group of commercial printers and publishers just described. During the past five years, wo have been particularly interested in photocomposition-or as it might more properly be called, phototypesetting-and the application of the computer throughout the graphic arts industries.

\section{Battelle's Role in the Graphic Arts}

A word about Battelle and its research activities is in order for those of you who are not familiar with the Institute. This background will help to put in perspective our qualifications to comment on the impact of computerized composition. Battelle is not a commercial printer or publisher, but it has made substantial contributions to the graphic arts industry through its research.

Battelle Memorial Institute was founded in 1929 in Columbus, Ohio, and is the world's largest independent not-for-profit research institute. Today, 
Battelle is a worldwide organization that does contract research in a wide variety of fields. We have been particularly active in the graphic arts during the last 20 years and have been associated with significant technical innovations in virtually every phase of printing. The Institute is currently active in information research, operates specialized information centers for the Government and others, and is working on the development of new imaging technology.

Battelle is also active in marketing, management, and economics research and business planning activities for printers, publishers, packaging companies, equipment manufacturers, and the producers of expendable supplies such as paper, film. and printing plates. Automation in the graphic arts-including, but not limited to, computerized composition-has been the subject of a number of research projects. Also, the area of computerized composition has been of personal interest to me over the years, both during my career at Battelle and elsewhere. In investigating this field I have interviewed a lage number of printers and publishers. Some of these companies are producing computerized composition, some have investigated the field and have equipment on order, and some have looked into the field and decided not to enter it.

The results of our discussions with publishers and printers indicate that the attitudes in the industry toward automation of the composing room are varied and often contradictory.

We have heard many stories of both the successes and horrendous failures experienced in converting from conventional typesetting methods to computerized composition. At least a few of these stories are fictitious and many of them-both successes and failures-were exaggerated. However, the free circulation of these stories has tended to draw the attention of potential customers for computerized composition.

We did find that there was considerable opinion regarding the markets and production technology associated with computerized composition-although many of these opinions were based on few or no data. The repetitive nature of some opinions made us suspicious of their validity, and a little detective work resulted in tracing some of these "opinionated facts" to the same sources of information-frequently trade magazine articles and convention speeches.

As is unfortunately the case in many areas of the graphic arts, there is a lack of comparative data for computerized composition and its reasonable alternatives. The little factual information available is all too often misused by both the printer and printing buyer in the formulating of conclusions. For example, information applicable to newspaper work has been used to draw general conclusions regarding the applicability of computerized composition for all types of composition work. Another common misuse of data is the comparison of information regarding computerized composition to similar information that concerns completely manual methods. This has the net effect of making computerized composition look more attractive than it really is.

While many publishers and other printing buyers indicate that they are using or plan to use computerized composition, it was also found that these publshers are extremely reluctant to commit a specific piece of work, such as a catalog or a dictionary, to the computerized approach. One of the objections is that the initial typesetting job for a publication like a catalog or a dictionary is almost inevitably more expensive when done by computer than by conventional methods. Some publications or printing buying organizations operate on an annual budget. In other cases, a particular issue of a publication must make a short-term profit. This situation makes it difficult to convince the buyer to spend more money now in order to improve his publication, obtain greater flexibility, and save money at some indeterminate point in the future.

While certain portions of the graphic arts labor force present a progressive image, there seems to be a general reluctance on the part of labor to accept and actually permit the application of the computer in an economical manner in the graphic arts industry.

However, despite the problems and the negative aspects of computerized composition, within the publishing and printing industry there is intense interest in the potentials of computerized composition and considerable optimism that this methodology will improve communications and help the industry grow in the future.

\section{Computerized Composition Today}

The interest and controversy associated with computerized composition are as much the result of fantasy as fact. The fact of the matter is that, of the vast volume of material set in type by the commercial printer or publisher, precious little has been set on a computer. There are few publishers who have achieved a tamgible reduction in their production costs as the result of utilizing computerized composition. There are few printers who can point to black ink on their balance sheet and say that it represents a profit achieved from supplying computerized composition services. 
During the past few years, automation of the graphic arts and computerization of the composition function has been the subject of many seminars, conferences, and articles in the graphic arts trade press. Superficial review articles are appearing with increasing frequency in both the business publications and the popular press. Unfortunately, this outpouring of information has too often been incomplete and oversimplified. This mass of fuzzy communications has led some in the industry to believe that computerized composition will somehow turn typesetting into a painless, push-button procedure.

There are two versions of the painless-procedure stories - the first goes something like this: Lowpaid help, which requires only the barest minimum of training, perforates simple tape (or as it is called by some, "idiot" tape) from original copy. The simple tape is then run through a computer, which does all of the real composing-room thinking and produces a tape that can be used to actuate some type of composition device. This tape can also be used to produce a standard computer printout type of proof. The proof is furnished to the publisher or author, who has been educated to make only a minimum number of changes and Ad's. The correction manuscript is given to the lowpaid help, who perforate another simple tape that, along with the first tape, is fed into the computer to antomatically produce a corrected tape. The corrected tape is used on a composition machine to produce type. The second and updated version of about the same story substitutes for the low-paid help an optical character reader to produce the simple tape, or now magnetic tape. The tape is then fed into a computer that will do the composition oriented "thinking" and furnish impulses to an electronic-character generator which, in turn, will produce complete pages ready for press. Variations on this story detail the utilization of a cathode ray tube display and the use of light pens for editing purposes.

Unfortunately, at this point in time, the picture of push-button ease is punctured with pain and sweat necessary to get the "blankety-blank computerized monster" to do anything well and right and, for our profit-oriented commercial printer and publisher, to do it economically.

These comments are not intended to imply that the computer is not and cannot in the future be practically used in the composition function. But these comments are intended to bring us back to earth and recognize that, in so far as commercial printing and publishing is concerned, the computer has barely scratched the surface and that there are many problems to be solved before wide. spread implementation is indeed practical.

It should be recognized that there may be situations, or most probably will be situations that will never be amenable to computerized composition just as there are situations today that are more suitable for the utilization of hand foundry type than the hot-metal line-casting machine.

We certainly feel that there is a place for the computer in the composing room. Without a doubt, the power of the computer can be applied to the entire pre-press preparation function. But it will be the "hard facts of economic life" that will determine the extent to which computers can be realistically applied to composition in commercial printing and publishing.

Computers are being used by the commercial printer. There are approximately 100 to $125 \mathrm{com}$ mercial printers, publishers, and trade typesetters utilizing the computer for the composition function (estimate of commercial computerized typesetting installations based on a survey published in October 1966 by Composition Information Services of Los Angeles, California). Although this is a small percentage of the total graphic arts installations now setting type, a printing buyer can purchase computerized composition with hot metal or photocomposition output in virtually every city in the United States. Some of these computers are located in the facilities of conventional printers, publishers, and trade typographers. They are coupled with both photocomposition and hot metal output and provide composition for catalogs, directories, and books.

A number of these computers are associated with a new kind of typographic service firm in the graphic arts. Although one of the principals of this new type of company may be an "old hand" in the graphic arts, perhaps even a compositor, these companies are characterized by their utter disregard of industry traditions and taboos. They are new companies and, therefore, are not faced with the problem of utilizing old equipment on hand as is the entrenched printer and publisher. They are data processing specialists who can look at the requirements for composition from a fresh, new viewpoint. They do not have established labor contracts with the traditional graphic arts craft unions, and are free to hire labor at the true skill level required and pay a wage that is in direct relationship to these skills.

These companies are often located in areas that a conventional printing executive would describe as the "sticks." Sales coverage is obtained through representation in the important graphic arts centers. 
In an effort to keep costs to a minimum, some of these new service houses have made arrangements with local housewives to perforate the input tape in their homes. This approach takes a leaf out of the book of many direct or strike-on, or typewriter-type cold composition operations that have used part time "at home" labor for many years. Thus, in this era of real-time computers we see at least a small return to the age-old concept of a cottage industry.

I do not want to imply that these new installations have solved the problems associated with computerized composition. They have not, and in some instances they have created new problems. They are significant, however, because they can bring a new unfettered view to the composition problem and they are able to use low-cost labor when it is appropriate.

Despite the problems, computers are being used by commercial printers and publishers to produce composition. One might well ask, "Why?"

Some composition jobs are computerized because the need for rapid output-speedy service to the customer-overrides conventional cost considerations. When unusual speed requirements are not a job condition, the kinds of composition work that can be economically produced on a computerized composition system are limited. Standard straight matter that requires keyboarding, hyphenization, and justification can rarely be done economically on a computer. When the setting of composition can in some way be combined with data manipulation functions, total production costs drop sharply and the computerized approach becomes economically feasible on a total product production-cost basis.

Utilization of the computer becomes attractive when a significant number of keyboard strokes can be saved. Of course, the ultimate in saving keyboard strokes is when a secondary publication can be produced without any keyboard strokes. Thus we can get the output tape for a secondary publication at a minimum cost.

A similar situation exists when an existing publication is to be updated. By merging corrections and new material with old material, the computer can be used to eliminate rekeyboarding the unchanged older material. When information is already in the computer for some other purpose, keyboarding is sharply reduced or eliminated for the production of tape. Any time that maximum use can be made of the data-processing capability of the computer, the composition function becomes economically feasible. This is an important consideration because most commercial printers are not in the data manipulation business. They are more accustomed to following copy out the window than they are in making any changes or manipulating customer-supplied information.

\section{The Future}

It appears that the printer must change his thinking and become involved in data manipulation if he is going to earn a profit in the computerized composition business. There is also considerable question from the customer's viewpoint of the desirability of having a printer become a data manipulator. The printer's customer, be he a commercial publisher or an industrial printing buyer, may well want to do his own data manipulation.

In the future, the compositor may become merely the operator of photocomposition or charactergeneration equipment. The equipment would be activated by tapes supplied by the customer. This approach will, of course, reduce the value added to the final printed product by the printer. The acceptance of outside produced tapes is a practice that is prohibited in many labor contracts. This may cause considerable problems in the traditional graphic arts shops.

In the future it does seem probable that there will be: (1) some composition jobs that cannot be computerized economically, (2) some that can be computerized, (3) some that require the printer to become involved in data manipulation, and (4) some where the customer prefers to do the data manipulation and furnish the output tape to a composition specialist to be run through his photocomposition or character generation equipment.

The road to computerized composition is difficult and, despite manufacturers' claims and glamour talk to the contrary, much pain, blood, sweat, and tears are necessary to put computerized composition on an economical basis.

In the commercial world, printers, publishers, buyers, and users of all varieties will do well to remember that there still are significant problems attached to computer hard ware. Maintenance costs and equipment "down time" are frequently more than is expected.

The software associated with computerized composition frequently leaves much to be desired. Programming must be accomplished by the producer of computerized composition. Specialized work cannot be handled without substantial programming capabilities. Composition jobs computerized for the first time are almost never less expensive than conventional typesetting approaches. Even on subsequent runs of the same material. computerized composition must frequently be sold on the basis of a savings in total preparation costs. 
Unfortunately, customers frequently do not know what their total costs really are.

\section{Conclusion}

Although there are many problems, commercial computerized composition can be economical for many types of directories, indexes, bibliographies, and other material that require manipulation of data. Computer composition can be economical when the nature of the work permits savings in keyboarding.
Commercial computer composition is barely out of its infancy. Its development may well precipitate changes that improve the flow of communications even though these changes may upset traditional functions and patterns of operation in the graphics.

Like many of the commercial printers and publishers that Battelle has been interviewing, we are optimistic that computerized composition will find a siginficant place in commercial printing.

Progress will not, cannot, and should not be held back-but progress in commercial electronic composition will also be difficult to achieve on a sound economical and profitable basis. 


\title{
Computerized Typesetting Projections
}

\author{
Kenneth B. Ludwig, President
}

Photo Data, Inc.

Starting as a sequential card, Varityper, and Justowriter cold-composition house handling typesetting for publications such as the Department of Defense Telephone Directory and the Post Office's National Zip Code Directory, Photo Data would seem to be a healthy expanding segment of the typographic business. Unfortunately, however, after seven years of this growth at Photo Data, we found our best and biggest customers switching to more advanced methods, leaving us to again cultivate the small jobs, but in effect hoping they wouldn't grow too big.

Our entry into computers and photo composition has been quite recent, both taking place early this year and consequently our experience at this time is quite limited.

Having selected the IBM 1130 Computer, Mergenthaler (4 grid) Linofilm Quick with TTS perforators, my discussion will necessarily be limited to applications with this hardware. Comparisons will be to Justowriters and sequential card equipment and related costs.

Briefly, we operate with the "torn tape" system. Hopefully we will have the Tabmatic feature on our "Quick" very soon and a specially written software program to update or maintain tapes as well as special conversion programs to convert standard Justowriter output tape to computer input tape.

Let us analyze some comparative figures.

\section{Quality}

There certainly is no question in my mind that the typographic quality of the Linofilm Quick equals or exceeds any competitive photo or hot metal typography with which I have had the opportunity to compare it. Kodak Stabilization S paper is used, processed in a Foto-Rite processor, and while this system was approached very much with tongue-in-cheek, so to speak, we have beeu able to match type quality (or print density) from day to day or week to week with an uncanny degree of success. Corrections and authors' alterations set at a later date simply cannot be detected.

\section{Versatility}

The Linofilm Quick has the complete mixing capability within a line or a "take" of any four grids each with two sets of 88 characters including a normal and rail font, or regular type with a matching italic or bold. These grids are all "base line" alined characters making complete mixing possible.

\section{Speed}

We look upon our hardware as the poor man's entry into computerized typesetting, and necessarily recognize that some sacrifices had to be made. We were not willing to sacrifice quality and we felt that it would be foolhardy to limit ourselves with anything less than a general purpose computer that could not be programmed for most if not all of our needs, including accounting as well as typography.

Keyboard perforating has been increased by 50 percent as compared to Justowriter perforating and substantially greater increases as compared to Varityping which requires a double (repeat) manual keyboarding for justified copy.

Perhaps you feel as I did that your typists are not capable of physically operating the keys at a speed 50 percent faster than their previous rate, but there are many advantages that are not obvious at first. In addition to the absence of operatorrequired line ending and hyphenation decisions there are no more overset lines requiring a complete retyping. Hyphenation is completely computerized as a nonoperator function with a greater degree of accuracy than that of my best prerious operator. Format statements enable the operator to perforate repetitive material with single computer command codes.

Computer processing time is the faster link in our hardware system. The IBM 1130 computer with Teletype CX readers and a BRPE punch operates at 110 characters per second. This effectively handles in about three hours per day the total output of eight pertorator operators. 
While the speed of the Linofilm Quick by many comparisons is slow, its speed per dollar investment and quality is exceptionally good. Its actual measured speed is somewhat dependent upon magazine changes, but measured with the conventional yardstick of newspaper lines, its speed is approximately 20 lines per minute.

\section{Personnel Training}

While, in general, we took our best operators from Justowriter, IBM, and Varityper departments, we have also experimented with new trainees and find that conversion to the new system and training has been greatly reduced, considering all aspects. All copy is premarked by a copy marker so that the typist simply keyboards the marked manuscript in front of him. Special instructions are spelled out in computer language to designate type fonts, column widths, special indents, format statements, etc.

\section{Cost Comparisons}

While computers and photo equipment are still relatively expensive, there are presently at least six major manufacturers producing typesetting systems. Recent price and utilization considerations indicate that the value of these systems has substantially increased while their costs have decreased to such a degree that small companies now find computer systems practical. I feel certain that as time goes on, these installations will increase to such an extent that computers will eventually provide the major source of all typesetting.

General trade shop composition jobs do not, at this time, offer cost reductions for computerized typesetting; however, there are offsetting advantages of quality, speed, updating capabilities, etc.

A large cost advantage also lies ahead in our ability, as programs are written, to convert existing tape or card keyboarded material into TTS coded tape to drive a photo unit.

\section{Limitations}

While there are limitations to the capability of the computerized system, we are now most generally reevaluating our views and taking the position that almost anything can be done for which there is justification and funds available to write the required program. However, programs are both expensive and difficult to create. Experienced programmers are virtually nonexistent and manufacturers' program libraries are woefully lacking, if not entirely absent, beyond basic standard requirements.

\section{Software}

Our standard package IBMTCP (Type Colıposition Program) has proven to be quite versatile for most routine and even semicomplex jobs. It handles normal formatting for hyphenation, justification, indents with up to four parameters, hanging indents, four grid interline font mixing, leader dot or white space line expansion, rail, no rail, ligatures, tape visuals, and almost any format requirement. The TCP program accommodates character width information for 99 type fonts stored on disk for automatic call at all times. Operator statistics are a valuable byproduct of the TCP Program, furnishing character and line counts as well as computer instruction coding errors for each of up to 32 operators.

$A$ very important facet of TCP is the ability for each of 32 operators to store 16 personal format statements which are simply entered or changed by the operator in any given tape. There are also 83 "common" format statements available to all operators. These statements must be entered from the computer console keyboard. They constantly lemain in computer storage until eventually replaced by a new statement.

A format statement consists of any repetitive text and/or computer instructions that would normally be keyboarded throughout a job. An example of the utilization of format statements is a Question and Answer publication which we recently produced which called for a 14 pt capital letter $\mathrm{Q}$, period, followed by a hanging indent, 10 pt "Question" text followed by a $1 / 2$-line space, then repeat with a 14 pt $\mathrm{A}$, period, hanging indent, italic answer, etc. Since this format repeated itself a single operator instruction perforation achieved all perforations necessary to accomplish the following: quad left the last line, give $1 / 2$ line blank space, change to the 14 pt magazine, shift to upper case, type the letter A period quad space, define the hanging indent position of the following text and shift to a rail position. Other utilization of format statements would be running heads, chapter heads, frequent reference to long association names, etc.

The hyphenation capabilities of the TCP program are exceptional. Hyphenation is accomplished first by rules of logic and grammar, but then this result is checked against an exception library stored on disk. In three months' use we have found only nine words that have been mishyphenated and each of these has been added to the exception library so that they will not be repeat errors. Certainly, hyphenation accuracy exceeds that of our best operators. 


\section{Future Software}

We are presently writing, and expect to have available by July 1 , programs to update perforated tape. This will enable us to update directories, rosters, biographies, etc., from edited computer printout on a line-for-line basis, computer merging the update tape with the primary tape for a purified tape. This updating may be repeated as necessary to obtain final changes before running through the photo unit. Another program soon to be operative will convert existing Justowriter tapes into computer input tapes for processing through TCP.

Future programs not yet started include page formatting for multicolumn pages. This will eliminate much manual work presently done at the boards and light tables. We also expect to have a payroll, job cost, work in process inventory control program available to replace the current external purchase of this service from a local computer service bureau.

\section{Hardware}

Our hardware also consists of an IBM 1442 card $\mathrm{read} /$ punch, an 80 line-per-minute computerprinter which can list directly from paper tape or punched cards while generating sequential numbering for each line. At the present time there is no I/O capability for magnetic tape processing through the 1130 computer. This is not viewed as a severe drawback, however, since perforated paper tape input or output would still limit the speed of magnetic tape to the 110 character-persecond paper speed if the operations are conducted simultaneously.

\section{Computer Service Bureau}

Since our present utilization of the computer is less than three hours a day, we plan to offer a computer service bureau, tape processing service to other firms that are presently using tape-operated hot metal or photo units. Existing programs, modifications of TCP, are in use in other areas of the country for line casters and most photo units and this programming is available to all IBM users. Additional time will be offered and has been sold to firms outside of the graphic arts industry.

In summary, from a very brief entry into computerized photo typesetting, we at Photo Data feel that the potential is unlimited, the profit possibilities are good, and the challenge is enormous. It has been expensive and unprofitable at the outset but our "Computerized Type Projections" for the future include unlimited profit and growth potential. 


\title{
Classification in Computerized Text Processing
}

\author{
Raymond P. Wishner
}

\author{
Senior Consultant, \\ Documentation, Inc.
}

\section{Introduction}

The abstract journal of the Geological Society of America, Bibliography and Index of Geology Exclusive of North America, has been produced in its entirety by a computerized publication system since January 1, 1967. This system is an instance of Documentation Incorporated's Text Processing System (TPS) and was created by Doc. Inc. as a subcontractor to the American Geological Institute. Figure 1 shows the generalized computer input form from which the elements of three sections of the book are extracted. In the figure some of the common elements of the citation, subject index, and author index are related.

\section{Basis for System Architecture}

The design for the generalized structure of Text Processing System resulted from Doc. Inc.'s past experience, not all of it good, with computerized photosetting.

In 1961, Doc. Inc. won the NASA Technical Information Service contract, in which a major product was to be an abstract journal. A Photon 200, a keyboard photosetting device, was purchased and phased into production. When direct keyboard capacity was exceeded, a method for the remote keying of paper tape was devised, and a paper tape reader was added to the Photon 200 . At this juncture it was thought that the same paper tape used to drive the Photon could be used to bring elements of the citation into a computer. The attempt failed, basically because of the ambiguous mixture of typographic function codes in the data stream and the fact that the data were proofed after photosetting and not from the typescript copy. The lesson was clear : keep the textual file free from typographical functions and clean up the data once, not for each separate operation. Needless to say, Doc. Inc.'s Text Processing System now produces NASA's abstract journal from a file free of typographical functions.
One of the early requirements of the NASA Technical Information Service contract was the rapid production of indexes with numerous entry points. Initially these indexes were produced with an ordinary upper case computer chain printer and later with an upper-lower case chain (fig. 2). With the advent of the Photon 900 (GRACE) at the National Library of Medicine, NASA decided to convert the publication of nonconfidential indexes from computer printer to this photosetting device. As shown in figure 3 , the change from a two- to a three-column format reduced the number of pages without impairing readability of the indexes. One of the more difficult elements of this conversion procedure was that the index was filed on computer tape with a fixed line length corresponding to the requirements of the computer printer. In order to reformat for the GRACE photosetting device, we had to reshape these lines, resulting in ambiguity in information. Lesson : textual data must be stored independent of the format requirements of a particular publication.

Thus the architectural requirements for a computer-based publication system were clear when the construction of Doc. In'c.'s Text Processing System began. Data must be capable of being inputted independent of any output printing device or any particular output publication format. Figure 4 depicts the architecture of the System. Note, as shown in the figure, that the type of input device has not been specified. We have successfully introduced input into TPS from Flexowriters and from typewriters equipped with a stylized upper and lower case font for optical scanning. The figure illustrates that very little of the input module is dependent upon the input device. On the output side at present, we have a Photon 713 output program and are writing an output program for Zip (Photon 901). We anticipate writing output programs for the RCA-Videocomp and the CBSMergenthaler Linotron.

The concept of preclassification of data elements and encountered conditions has been given 


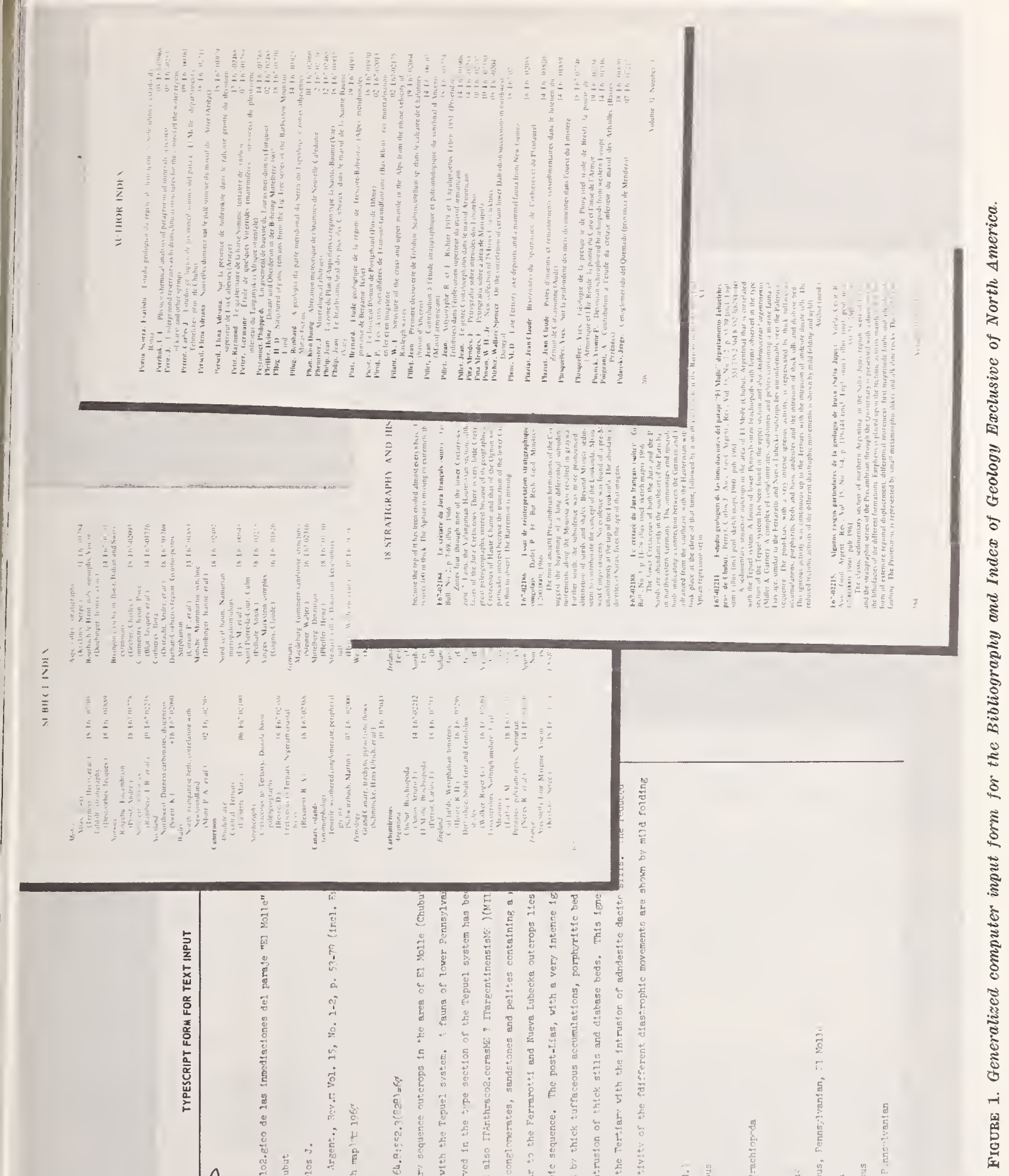


CNEA- 169

Constralned of nimization problem solution applied to chemical equilibrium theory using linear prograning RM-4657-PR

CHEMICAL EXPLOSION

Photographic method of scaling chemical explosive detonation dust cloud dieensions T1 D-22266

c20 N66-23250

Electrostatic probe and photomultiplier techniques used to measure conduction, velocity, and luainosity of lonlzation shock wave from chealcal explosion AFOSR-65-2209

c25 N66-23870

CHEMICAL KINETICS

Thermal decomposition kinetics of phenyi sllanes ARL $-65-215$

Chemical kinetics of atmospheric gases AFCRL-66-1 c06 N66-22631 CHEMICAL PROPERTY

Properties of calcium oxide refractories for use at high tenperatures in alkaline metal vapor FT D-T T-65-1396/1+2+4 c18 N66-22539

Structures and dynamics of molecules by electron diffraction AFOSR-65-2231

Alloying effects on physical and cheilcal properties of $n$ loblum FT D-TT-65-915/1+2+4 $06 N 66-22544$ (hanum hexaboride cathode material for electron tubes c06 N66-22973

Physical and radiochenical properties of fallout debris USNRDL-TR-899

c 24 N66-23245

CHEMICAL REACTION

Chemical reactions and energy. distributions in electric discharges and Infiuence of pressure, flow, burner size, and copposition on enlssion Intensity of hydrocarbon-oxygen flame AFOSR-65-2723

c 33 N $66-22387$

Chemical reactions for $N$-monosubstituted hydroxylamines for application to sookeless solid rocket propellants $A D-624300$

c06 N66-22489

Reactions of free radicals containing nitrogen AF OSR-65-2886 c06 N66-22491

Tritium beta ray induced exchange reaction mechanlsa of deuterlua with methame and ethane in gas phase $A D-624657$

c06 N66-22707

Ruby lager temperature-jump relaxation kinetic studies of rapid reactions UUCD-2-64

c06 N66-23078

Chenical process for study of thermodynanic and kinetic behavior of electrically activated reactions

NASA-CR-74510 c06 N66-23594

Organic cyanine dye for detection of protein in trace amounts - dye reaction mechanisum, aethods of eliminating Inorganic compound reaction with dye, and detection of humic acid NASA-CR-466

CHEMILUMINESCENCE

Chenlcal kinetics of atmospheric gases AF CRL-66-

c04N66-23620

c06 N66-22692

Biological ultraweak chealluminescence analysis FTD-TT-65-1144/1+4 c04N66-22711

CHEMOTHERAPY

Isoniazid therapy for tubercular chimpanzee ARL-TR-66-1 c04 N66-22674 CHIMPANZEE

soniazid therapy for tubercular chlapanzee ARL-TR-66-1

c04 N66-22674 CHINA

Chinas physics research, spectroscoplc weosurement of nioblue using resorcinol, synthesis of nickel ferrite single crystals, and diethyl-aminothiazolylazo-phenol sensitivity agent of niobiue JPRS-34589

Communist Chinas physics research progran c23 N66-22977

CHLOR 1DE

Ion association contants of sllver with chloride iong in molten metallic nitrate electrolyte NYO-2873-7 c06 N66-23119 CHOLESTEROL

Properties of temperature sensitive cholesteric liquid crystals for large area colored display screens
RADC-TR- $65-274$

c23 N66-22695

CHORUS PHEMOMEMON

Observations of whistlers and VLF evissions at Godhaun and Narssarssuaq, Greenland and at Tromso, Norway

REPT . -19

c13 N66-22456

CHROMIUM ALLOY

Titaniua and chromiun alloy, and glass protective coatings, with batch mounting and

Interconnection technique for lou cost ilicon integrated circuit

REPT. -1

c09 N66-22744

Chroulum-nolybdenum-vanadium high strength steel sheet

ARC-CP-811

c15 N66-2278?

Oxidation resistance of chromlum base alloys at high temperatures ARL/MET-23

17 N66-22879

Effects of electroslag welding paraneters on notch-strengths and alcrostructures of reactor steels and chromiun-molybdenue alloys EUR-2367. D

17 N66-23693

Vacuum denosited cermet chromium-silicon oxide resistors fabrication and evaluation NAF $1-T R-688$

c09 N66-23884

CHROMIUA COMPOUND

Paramagnetlc electron resonance spectra of chemical bonds in chromium III complexes TR-8?

c06 N66-22590

CINEMATOGRAPHY

Siou motion cinematography by electronic sultiple spark camera

CIRCUIT I SL-T $-8 / 64$

c14 N66-22829

Unt functions and Laplace transforas used to obtain solutions to silicon control rectifier circuits in case of single phase half-wave rectifleation

c 10 N66-22948

Unit functions and Lapiace transforms used to obtain solutions to silicon control rectifier circults in case of polyphase half-wave rectification c 10 N66-2295?

Modular electronic circuitry - power supplies 1NR-629/IA/PL c09 N66-23332

Properties of multielectrode RC distributed circuits NASA-CR-74180

c10 N66-23717

CIRCUIT RELIABILITY

Feasibility of magnetic circuits for high reliability computereswitches NASA-CR-7 1749

$\operatorname{co9} N 66-23769$

CIRCULAR CONE

Longltudinal and lateral directional aerodynamic character istics of raked-off circular and eli Iptical cones at Mach 20 in hellum NASA-TN-D-3401

c0 1 N66-23454

CIRCULAR CYLINDER

Measurement of vortex separation about two-dimensional circular and elliptic cyilinders using hydrogen bubble technique for flow visualization TR-114

c12 N66-22464

Edge effect of axlsymmetric loading of onlsotropic circuiar cylindrical shell by trangverse pressure and axial forces c32 N66-22991 CIRCULAR ORBIT

Gravity gradient torque effect on spin axis motion of asymatric vehicle in precessing elrcular orbit of oblate earth NASA-CR- 433

c30 N66-22909

CIRCULAR SHELL

Buckl Ing problem solution for thin circular cylindrical shells heated on axial strip using orthonormal functions SUDAER-234

c32 N66-22622

Beam column model for theral buckling behavior analyses of thin circular cylindrical shells SUDAER-226

c32 N66-22678

CIRCULAR TUBE

X-ray generator for radiographing circunferential welds in saall diameter tubes LA-DC- 6977

c22 N66-23376

CIRCULATORY SYSTEM

Influence of welghtlessness on mans circulatory function in space flight c04 N66-23064

CLASSICAL MECHANICS

Classical cross section for energy transfer in In two particle Couloeb collision NASA-CR-74137

FIGURE 2. Index page reproduced from Scientific Technical Aerospace Reports published by NASA-2-column format produced with computer chain printer. 
[CLOR-47/D]

PROPULSION

Neutrallzatlon of positive and negative ions for electrostatic propulsion c26 N67.13692
ELEMENTARY PARTICLE

Symmetry princlples in physics - history, effectlveness in quantum mecbanles, symmetries in elementary particle physics, and $C, P$, and $T$ Invarlances [BNL-956/T-397/] and T invariances Maximum llkellhood method applled to Maximum ilkellhood method appled hlgh energy elementary particles
[DESY-66/17] [DESY-66/17]
EMBRITTLEMENT

Cleaning, plckling, and electroplating processes to minimize hydrogen

embrittlement of uItrahlgh strength steel [NASA-CR-60690] c15 N67-13569 Determination of embrittlement of pressure vessel steels after Increasing neutron radlation doses Plastlc fatlgue embrittlement of reactor vessel steels

vessel steels

c17 N67-14095 Cadmlum plated notched blgh strength steel speclmens load tested to determin slze effect on embrittlement

[RAE-TR-66166]

c17 N67.14116

EMSSION

Stars of T-Taurl and uv Cetl types, and phenomenon

of continuous

EMISSION SPECTRUM

Emission spectrum analysis of marine plankton ashes

[EUR-2771.D]

c04 N67.13439

during emission spectrum analysis during combustlon from electric discharge
[NASA N67.13794

EMITTER

Caplllary emitter of ceslum tons, and application to thermlonlc

converters

EMOTIONAL FACTOR

Major causes of alrcraft accldents and recommended tberapy

[AM-66-6]

c03 N67.13664 ENCODING

Small sclentific satellite PFM telementry encoding system evolution

[NASA-TN-D-3757] evolution c07 N67-13761

Encoding algorithm for processing dat

from space experiments

[NASA-CR-60630]

ENERGY ABSORPTION

c07 N67-14213

Impact energy absorptlon propertles of crushable materlals

[RM-315]

NERGY CONVERSION

Thermionlc energy propulsion

c32 N67-1366

ENERGY DISSIPATION

Theoretical basis for using energy dissipation pattern to predict ground wate potentlal distrlbution in beterogeneous porous media

ENERGY DISTRIBUTION

Multinucleon transfer reaction, and energy distrlbutions of fluorine is reaction products

[J1NR-P-2613]

c24 N67.14022

\section{EXRY EXCHANGE}

Exchange of vibrational energy between components of alr behind normal sbock wave fron

ENERGY LEVEL

Low nonrotational states and complex structure states in deformed odd mas actinide nucle!

[J1NR-E-2657]

Energy levels of simple mole for posslble molecular laser materla [NASA-CR-60632]

Uranlum fueled reactor experlments for checking nuclear data on uranlum 235 and 236 over 10 to $500 \mathrm{keV}$ energy range [AWRE-R-5/66] [ C22 N67.1396 Detectors and techniques for obtaining energy spectra of high energy accelerato radiation

[UCRL-16769]

c14 N67.14033

Energy spectra reduction of nonstable particles according to particle decay

[JINR-P-2797]

c24 N67.14074 NERGY TRANSFER

Proton transfer reaction on carbon al uminum, vanadlum, sllver, tantalum, and nloblum target nuclel

c24 N67-1405
NGINE DESIGN

Deslgn, development, and qualfication testing of Castor 11A rocket engine for second stage Scout Launcb vehlcle application

[NASA-CR-66250]

c26 N67-13570

Overall performance of stator component of cold alr turblne determined for destgn

[NASA-TN-D-3751]

c26 N67.13719

ENGINEERING

Engineering and metallurglcal evaluation of Irradlated control rod

[WCAP-6074]

c22 N67.13390

Role of education in clvil engineering applications of remote sensing c34 N67-13515 University bybrid computer faclittea and Instruction program for engineering students

ENGINEERING DEVELOPMENT

Engineering development problems in two high performance repetitively pulsed neutron sources - advanced pulsed fast

reactor, and accelerator-booster system
[CONF-660914-1] [CONF-660914-1]

Mixing of two flows witb different stagnation entbalples in supersonic efectors [TP-411]

ENVIRONMENTAL CONTROL

Electronic package environmental control systems and vebicle thermal systems Integration for space missions to 180 days duration

[NASA-CR-60771] c31 N67-13674

Environmental and attitude control

problems of manned spacecraft

[NASA-TM-X-1325]

c31 N67.14243

VIRON MENTAL INDEX

Emplrical method for correcting alrborne

Infrared radlation thermometer readings for environmental factors

c14 N67.13466

ENVIRONMENTAL SCIENCE

Uses and limitations of multispectral

remote sensing c14 N67-13472

Proceedings of sclence assoclation

conference on remote sensing c14 N67-13504

Environmental analysis, remote sensing, and education c13 N67.13516 Proposals for solving educational needs in remote sensing c14 N67-13517

ENVIRONMENTAL TESTING

Environmental effect on creep and tenslle

behavior of metal single crysta'ls and
polycrystalline metals polycrystalline metals

AOYME ACTIVIT

Adaptlve propertles of enzymatic reactions with enzyme forming system c06 N67-13451 EQUILIB RIUM

Lquid equilibrlum conflgurations and disturbances of vehicle motion due to liquid sloshlng in space c12 N67.13644 Equillbrium and stabllity of toroldal plasma screw plncb

Phase equilubrla and spectelc 25 N67.14004 llquid metals and alloys

[N YO-2731-7]

Plasma equillbrium in confined toroldal magnetic fleld conflgurations

magnetic
[1AE-1151] fleld configurations
c25 N67-14076 ERROR

DIfference methods for asymptotic estimates of errors at numerical integration of systems of ordinary differentlal equations [NASA-CR-60650] c19 N67-13537 Long perlod errors of Doppler and Inertlal navigation systems

[RAE.TR-66064]

c21 N67.13959

\section{ERYTHROCYT}

Application of cybernetics and

mathematical statistics to determine state of erythrocytes in chronlc leukoses

C04 N67.13457

Cathodlc etchlng using argon lon bombardment for cleaning radloactlve metal samples prior to oxygen determinations
[UCRL-14959]

EXCITATION

c17 N67-14136

Applicability of nonlinear differential equation with discontinuous coefficlent to development of mathematical model for excltation of nerve tissue c04 N67-13446 Relatlve quantum yleld dependence of spontaneous zinc oxide luminescence on excitation wavelength

[NASA-TT-F-10390]

c28 N67-13765

Excited states of arsenlc 75 following

decay of selenlum 75

c24 N67-13598 Nonrelativlstic tbree-quark model of potential group theory

[INR-733/V11/PH]

XOSPHERE

Large semlannual varlation in exospherlc density confirmed by analysls of orbit of Caispbere 1 satellite

EXPANDABLE STRUCTURE

c30 N67-13980

Stay time extension module shelter structure to support 2 men for 6 days on lunar surface

EXPANSION

Two-dimenstonal flow in laminar wake studies

[REPT.-66-6]

EXPERIMENT DESIGN

c12 N67-14115

Response characteristics of lonization cbamber and spectrometer experiments

aboard Orbittng Geophysical Observatory

/OGO/

[CR-87]

c31 N67-13710

Characterization and classification of learning and psychophysical experiments as asymptotlc or nonasymptotic

AD-636216

Experlment- design to obtaln 04 N67.13911 Information about 19 rod fuet transfer

[R1SO-124]

c22 N67-13973

Dlsturbance envelope and experiment requirements for Apollo missions used to determine optimum control-moment gyro-jet system

EXPLORER XXII SATELLTE

Electron content measurements from

Explorer XXII satellite recordings of Faraday

[RPU.S26]

XPLOSIVE FORMANG

c28 N67-13815

High energy forming studles metal shock hardening, dynamlc deformation, high veloclly displacement measurements, and

high Intensity short duration pressures

[CR-65-77]

XPLOSIVE GAS

Mathematical model for gas shock wave interaction witb plane metallic uner [EUR-3157.E]

EXPULSION

Elghteen-Inch expulston dlaphragm

recycleablitty and fabrication from stalnless

steel and titanlum

[NASA-CR-60770]

EXTRACTION

Process of extracting polyacrylonitrile flbers and modification of polypropylene flbers, tIssues, and textures by using acrylonitrile

[FTD-TT-65-1897]

c16 N67-13361

Process of extracting polyacrylonitrile fibers in aqueous dimethyl formamide c16 N67-13382
baths coefflclent of uranlum in system with varlous diluents

[REPT.-490/C] 


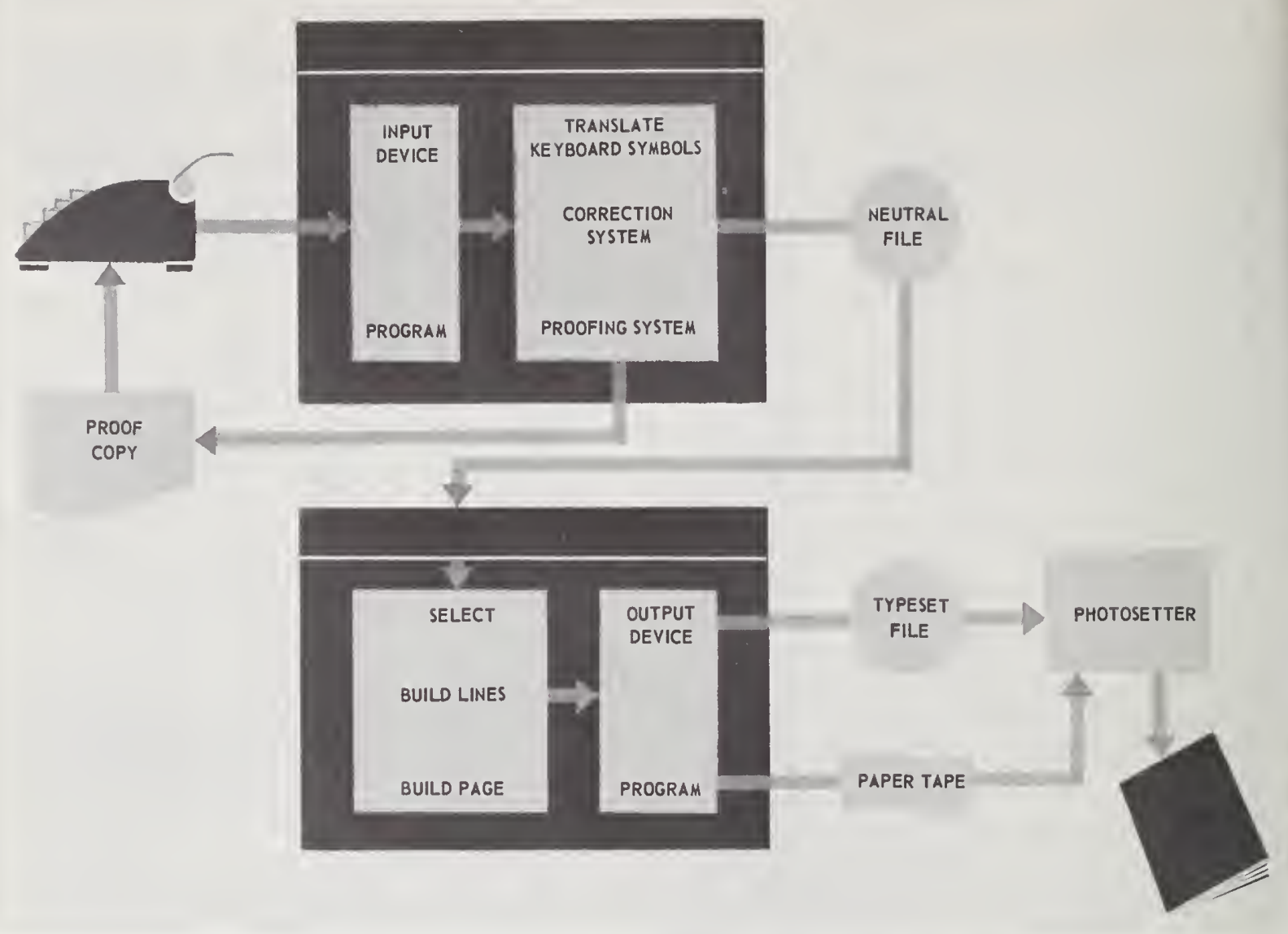

Figure 4. Diagram shonving Text Processing System architecture.

in a previous paper of mine. ${ }^{1}$ But to repeat its thesis, it is the systematic classification of input data elements that permits a later computer program to insert function codes for the form of a symbol (i.e., bold, italics, medium), the size of a symbol, and its spatial position (i.e., superscript and subscript). Further, the classification scheme permits an explosion of the data for many different publication embodiments. Data classification permits the isolation of input and output functions.

\section{Text Processing System Features}

A typescript produced by the American Geological Institute on a Flexowriter is shown in figure 5. Note the following features:

\footnotetext{
${ }^{1}$ Raymond P. Wishner, The Role of Paper Tape and Optical Scanning Computer Input in Textual Data Processing, Proceedings of the 1965 Congress, International Federation for Documentation (Spartan Books, Washington, D.C.).
}

1. The typescript number at the top is a control number used to locate information for correction and to produce production control reports.

2. On the lefthand margin you will see numbers followed by a blank space created by striking the "tab" key. These are data field tags which at the time of file extraction are used for typographical encoding. Tag " 3 " which is a title could just as well have been spelled "title".

3. A word that will not fit on a line is indicated by a single hyphen at the end of the line. See Example $\mathrm{A}$ in figure 5. Obviously, this is not hyphenation in the usual sense.

4. Characters which are beyond the display capability of the input device are indicated in redribbon shift with a string of symbols which are mnemonic in nature. Thus, "GA" is used for an upper case Greek alpha. In optical scanning input, left and right brackets serve the same purpose as a red-ribbon shift. 
Q2] srug $\mathbf{s}$

o prirode khloridnykh glubinnykh rassolov

Kapchenko, L. N.

Sovv Geol.a No. 3, p. 96-1877 1962

Int. Geol. Rev.! Vol. 5, No, 9, p. 1137-1146! 19633

$553.774: 553 \cdot 232: 552.113=\not 33.82=2 \varnothing$

H ighly mineralized sodium-chloride type brines in deep artesian basins are similar $\checkmark$

in composition to the mineralized abyssal hydrothermal waters of present day volcan regions and to the material impounded in liquid inclusions of minerals. It is also established that present brines are veyry similar to hydrothermal ore-forming soluti Some highly concentrated brines $c$ an be explained by derivation from salt basins but there is no adequate explanation for the worldwide distribution of concentrated brin Exchange reactions rmerely change composition, not concentration. Some hydrocarbons

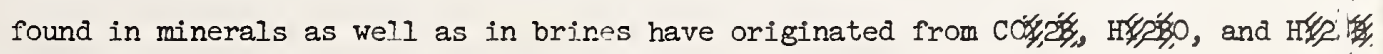
liberated from volcanoes and magma chambers. The abyssal brines may , be the product of magmatogenic hydrothermal activity or the brines themselves may be the source of ore-forming hydrothermal solutions. If the latter is true, there is still no explan ation of the high mineralization of brines.

I.G.R.

Brines

Genesis

Abyssal, hydrothermal solutions

Mineral deposits, genesis

Ore-forming fluids

Brines, genesis and distribution

Magmas

Differentiation

Hydrothermal solution, abyssal brines

FIGURE 5. 'T'ypescript form illustrating input techniques of the 'T'ext Processing System. 


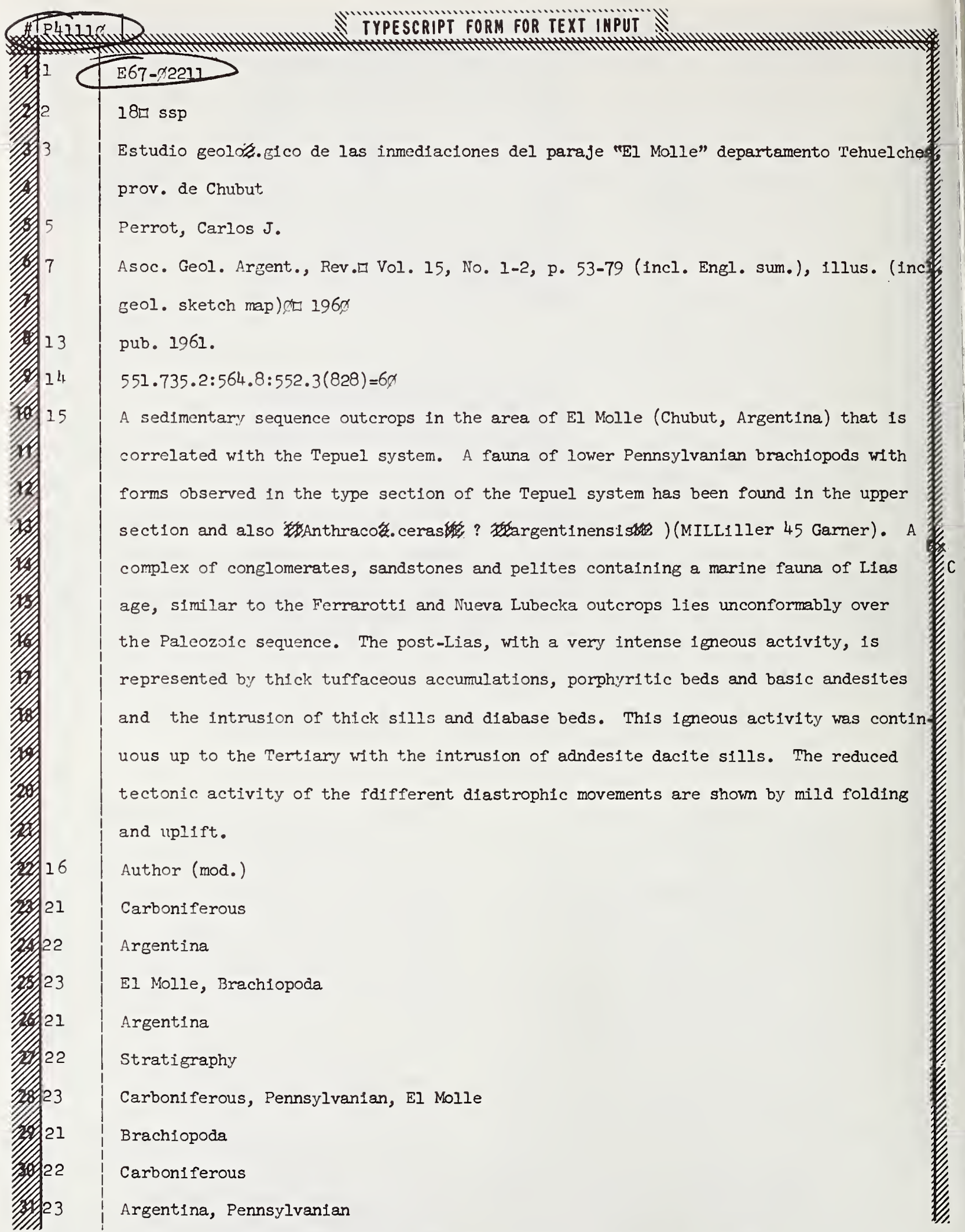

FIGURE 6. Typescript form of TPS showing input for changes in font style. 


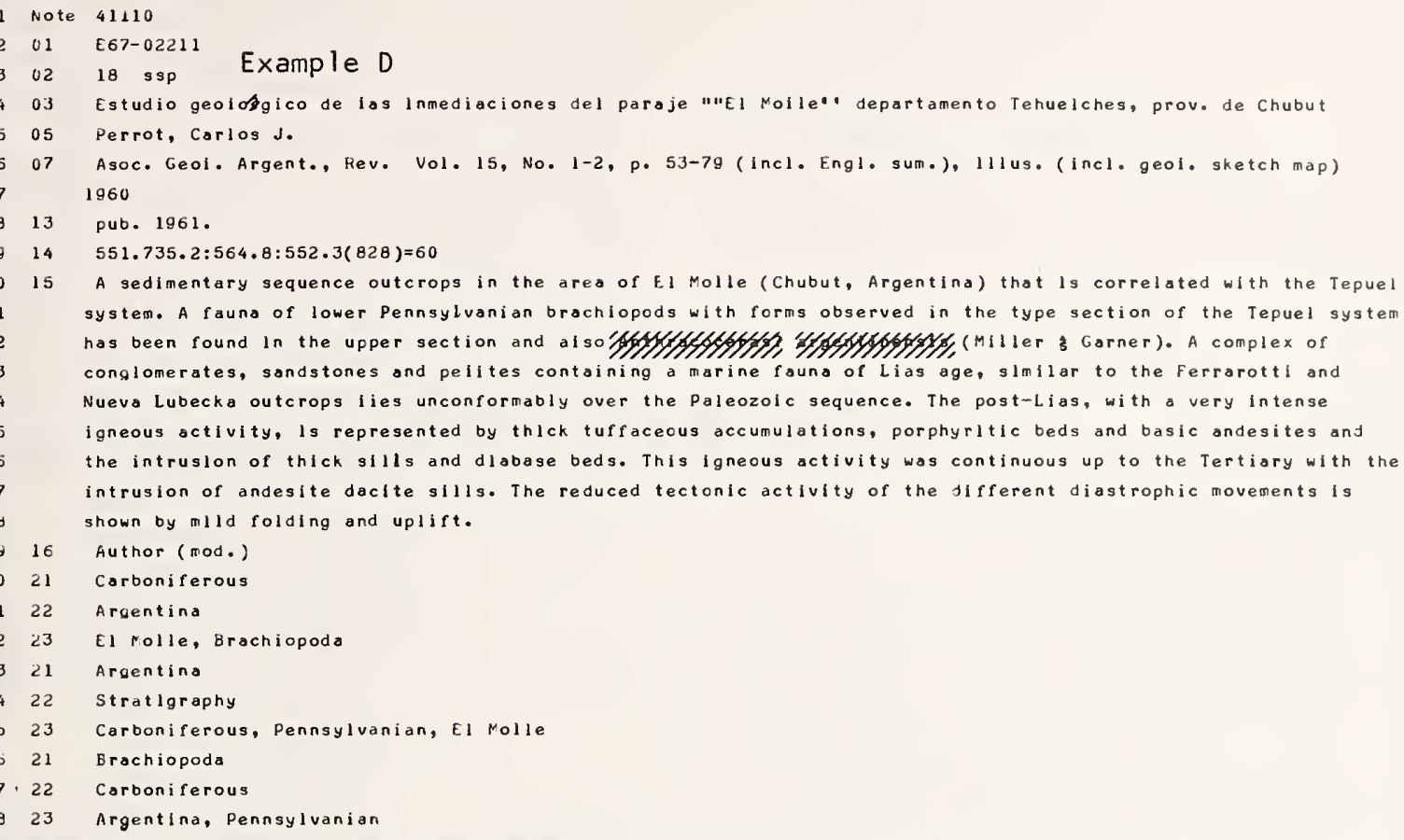

Froure 7. Proof copy of input typescript shown in figures 5 and 6 . 
5. Functions such as shift to super and subscript are also indicated by a red-ribbon shift. See Example B in figure 5.

6. A particularly interesting function is a change in font style. Since the input operator does not know the context of an item, it is meaningless for her to indicate bold, italies, or small caps. We permit an operator to classify four fonts of typenormal and three types of emphasis. See Example $\mathrm{C}$ in figure 6. At output time, depending on the context, font shift functions are introduced to create the desired emphasis.
Proof copy of the previous two input typescripts is shown in figure 7. At present we are printing proof copy on an upper-lower case chain printer. This was an economic design choice in that our Photon 713 is not capable of printing proof with fast enough turn-around.

On the proof copies, note the following features:

1. The display of the original input tags in the margin.

2. The extension of the character set of the chain printer by over-striking characters. Example D in figure 7 shows an acute accent.

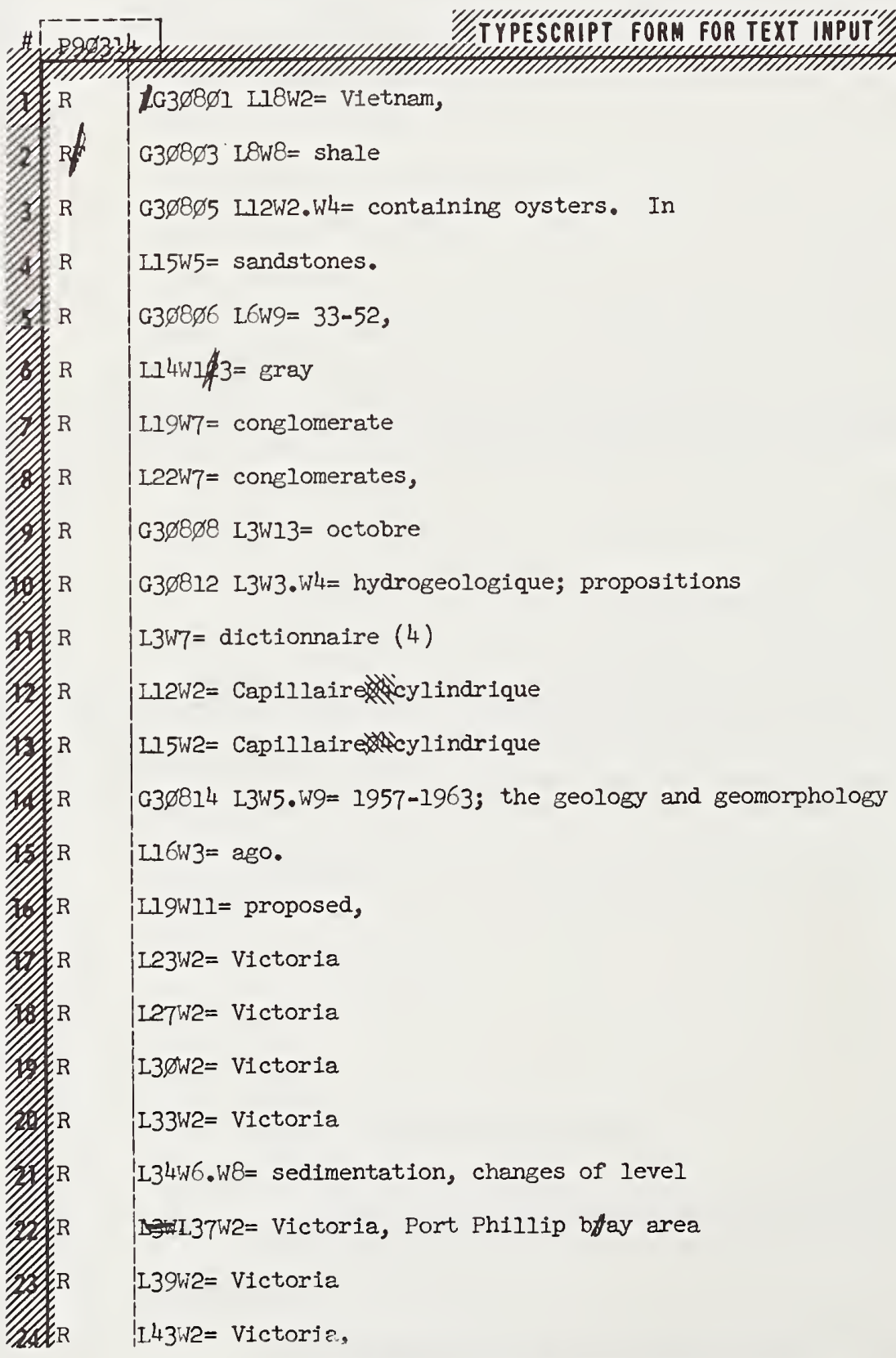

FIGURE 8. Typescript form illustrating options for correction. 
3. The display of super and subscript characters displaced from the base line. See Example E in figure 7.

4. Emphasis types are displayed by the boldfaced effect produced by double striking the characters. See Example $\mathrm{F}$ in figure 7.

The Text Processing System offers many options for correction:

1. An operator may immediately "kill" a letter, a word, or a line by special reserved input keys.

2. Outside of this capability, an operator may delete, replace, or insert any string of symbols, by referring to the line number and word number of the typescript or computer proof. In fact, the only distinction between a typescript and computer text are "G" for galley and " $F$ " for file. Corrections may be made either in the original typescript or in a separate typescript. See figure 8.

3. A correction may be superseded in an input batch by repetition of the same line and word number used on the correction to be superseded.

\section{Line End Decision}

The AGI abstract journal is set with 8-point type on a 5-inch line. Naturally, one could agree that the 5-inch line was selected in order to avoid hyphenation. Figure 9 displays the same material set on 5, 3, and 11/2-inch lines. The Text Processing System makes every attempt to avoid hyphenation, but, when it becomes necessary, the program hyphenates with nearly perfect accuracy. This effect is achieved by a careful blending of line balancing, letter spacing, and dictionary look-up hyphenation.

\section{Computer Page Makeup}

In closing, I would like to display figures 10, 11, and 12 from the three sections of American Geological Institute abstract journal: the citation section, subject index, and author index. These pages illustrate the complete automation of the publication process because they were constructed wholly from logical rules in the computer. Each paragraph, when extracted from the textual file, has been given a class identifier. Tables have been entered into the computer specifying widow rules for breaking lines within paragraph classes. Further rules have been entered for breaking columns and pages between paragraph classes.

\section{EXAMPLES OF LINE JUSTIFICATION 8 PT. TYPE}
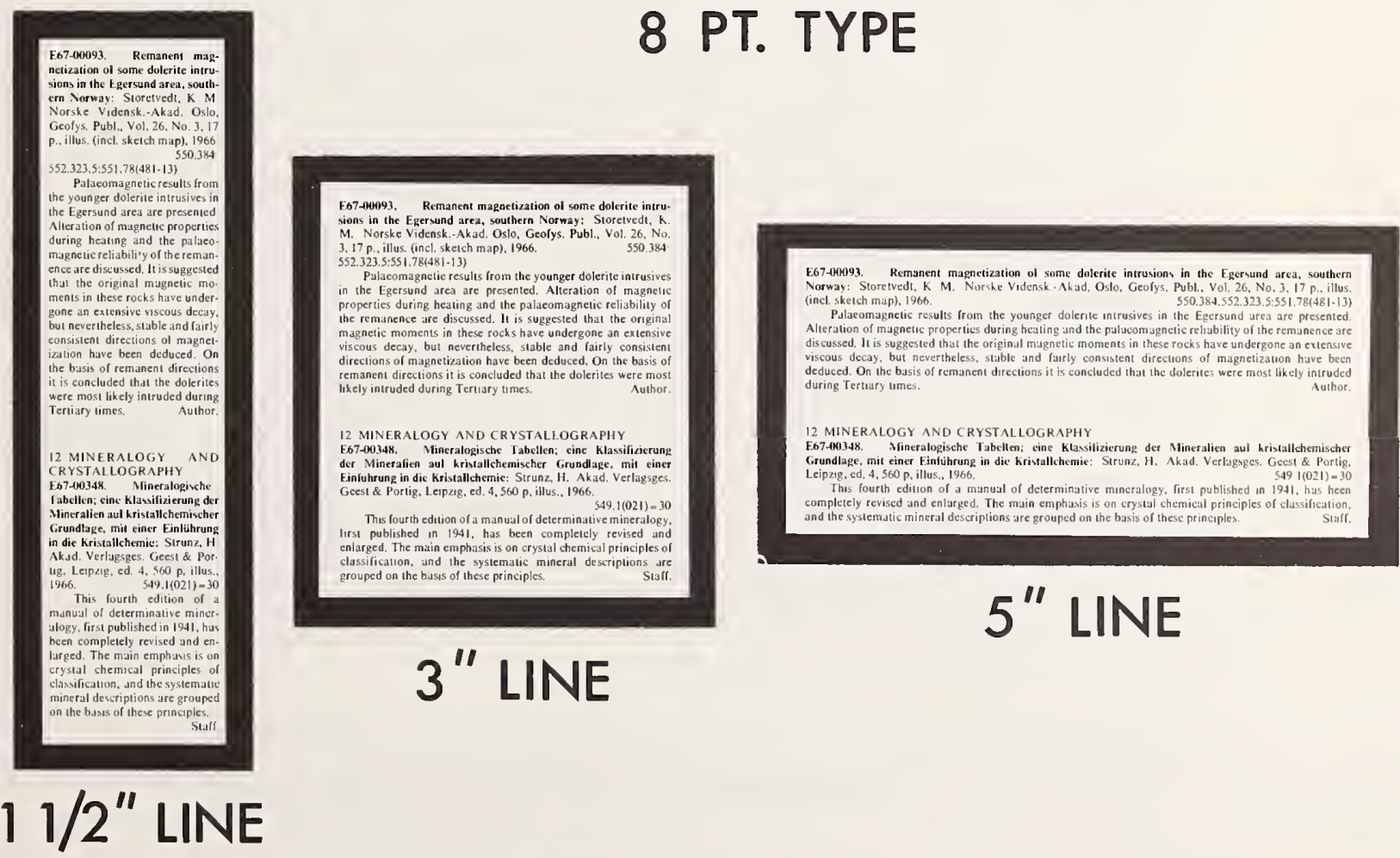

FIgure 9. Examples of line justification in TPS. 
Cretaceous metamorphic basement. An unbroken sequence of Barremian(?) to Maestrichtian rocks in the Coast Range basin shows declining metamorphic grades both southward and upward in the section. Upper Cretaceous conglomerates contain lower Cretaceous fragments that were metamorphosed prior to erosion. Metamorphism occurred gradually. Metamorphic grade in the Coast Range basin seems to relate more to relative position in a zone of abnormal temperature gradient than to diastrophism punctuated by uplift and erosion.

J.P.F.

E67-02162. Geología del área de Barquisimeto, Venezuela: Bushman, Jess R. Venez., Div. Geol., Bol. Geol., Vol. 6, No. II, p. 3-107, illus, (incl. geol. map 1:100,000), 1965.

$55(87-18) 551.763 / .79: 551.24: 552.3 / .4=60$

The mapped area is situated at the junction of the Andes and the Coast ranges, northeastern Venezuela. The oldest rocks range from Cretaceous to Paleoçene. They are overlain unconformably by scattered outcrops of late Tertiary and Quaternary rocks. The Barquisimeto strike-slip fault divides the area into northern and southern provinces. Cretaceous sedimentary rocks in the northern province resemble those in other parts of western Venezuela. Downwarping at the end of Cretaceous time was responsible for the boulder bed facies at the margins of the depositional basin. Subsidence recurred during Paleocene and Eocene time. Miocene or Pliocene clays and sands provide evidence of brackish water conditions. Widespread alluvial gravels testify to the uplift and erosion which has persisted from the close of the Tertiary to the present. Unfossiliferous metamorphosed rocks in the south seem to be lithologically and stratigraphically equivalent to the less metamorphosed Cretaceous rocks in the north. Metamorphic grade increases from west to east on both sides of the Barquisimeto fault. Very low-grade regional metamorphism is evident in the north; serpentinized ultrabasic igneous rocks and greenschists occur in the south. Compression produced considerable thrusting in the west. Principal fold axes trend within 15 degrees of the Barquisimeto fault. Movement along the fault affected the orientation of regional structures.

J.P.F.

E67-02164. Geología del área de El Tinaco, centro norte del estado Cojedes, Venezuela: Menéndez, Alfredo. Venez., Div. Geol., Bol. Geol., Vol. 6, No. 12, p. 417-543, illus. (incl. geol. map 1:100,000), 1965. $55(87) 552.3 / .5: 551.7: 551.243=60$

The pre-Cretaceous El Tinaco complex consists of gneiss, schist, and younger igneous rocks, including an east-trending belt of trondhjemite plutons along a wide intrusion zone characterized by isoclinal folds. Within the zone the fold limbs dip steeply, but dips are shallow outside. In the north the complex is overlain unconformably by upper Cretaceous rocks, and both are overthrust by lower Cretaceous strata. The same metamorphic facies is apparent throughout the Cretaceous rocks though the grade decreases gradually southward. Both lower and upper Cretaceous formations lie discordantly on the complex in the south but an apparently conformable relationship exists between successive formations from Cretaceous to Paleocene. Eocene strata are locally unconformable on the lowermost upper Cretaceous formation but were overthrust by younger Cretaceous and Paleocene rocks, resulting in klippe. Two periods of folding are recognized in the area; the first is represented by structures in El Tinaco complex, and the second by folds and high angle reverse faults involving both metamorphosed Cretaceous and unmetamorphosed Cretaceous-Tertiary sequences. Movement assisted by gravity developed bedding plane faults prior to this deformation, probably as a consequence of northward regional uplift.

J.P.F.

E67-02382. Regional geology of the Spanish Sahara: Querol, Ramon. In Bassins sédimentaires du littoral africain, symp., Ire partie, Littoral Atlantique (New Delhi, 1964), p. 27-38 (incl. Fr. sum.), illus. (incl. sketch map), 1966. Union Int. Sci. Géol., Ass. Serv. Géol. Afr., Paris. 55(648)551.7:551.243

The northwest Africa geosyncline developed on the border of the Atlantic Ocean and the stable African shield at least as early as the late Precambrian. Following the deposition of Paleozoic formations, the Hercynian orogeny developed a fold belt now partially exposed between Semara and Ausert. A thick sequence of Mesozoic and Tertiary formations was deposited west of the Hercynian fold belt in what is now termed the Aiun basin. These formations dip gently westward, and overlie metamorphosed sedimentary Precambrian (?) and Paleozoic (?) rocks exposed in several places west of Ausert. The Tinduf basin, next to the southeast, is occupied by Paleozoic formations resting upon a relatively stable Precambrian basement. The northwest Africa geosyncline and Hercynian fold belt extend far beyond the limits of the Spanish Sahara.

Staff.

Volume 31 Number 3

Figure 10. Page of Citation Section, Bibliography and Index of Geology Exclusive of North America, illustrating the complete automation of the publication. 
General description, Italy, Mola limestone (Azzaroli, Augusto, et al.)

18 E67-01522

Geochemistry, Germany, Muschelkalk (Seidel, Gerd.)

$05 \quad \mathrm{E} 67-02303$

Geochemistry, Marshall islands (Gross, M. Grant, et al.) 05 E67-02037

Petrology, Cambodia, Permian (Fontaine, Henri.)

16 E67-01507

Petrology, England, Devonian (Braithwaite, C. J. R.) 16 E67-02099

Petrology, Italy, Eocene, Sicily (Broquet, Paul, et al.) 18 E67-01670

Petrology, Italy, Piz Boè, Triassic (Bosellini, Alfonso, etal.) 16 E67-01501

Petrology, Vietnam, Rhaetian-Liassic

(Fontaine, Henri.)

18 E67-01503

Petrology, Wales, bryozoan, Carboniferous (Nichols, R. A. H.) 16 E67-02091

Provenance, Ireland, Gweestin valley, chalk outliers

(Walsh, Peter Thomas.) 18 E67-01931

\section{Lithofacies}

England, Derbyshire and Devon (Walker, Roger G.)

16 E67-02431

France, Jurassic

(Tempier, Claude.)

18 E67-0249l

Ireland, Donegal, Dalradian correlations (Pitcher, Wallace Spencer, et al.)

$18 \quad \mathrm{E} 67-02537$

Morocco, Atlas

(Termier, Henri, et al.) 18 E67-02505

\section{Lutite}

Mineral composition, Red Sea

(Gevirtz, Joel L., et al.) 16 E67-02096 Methods

Heavy minerals, polished thin sections (Chatterjee, B. K.)

16 E67-02105

Shape index, pebbles, one parameter (Williams, Elizabeth M.) 16 E67-02084

Size analysis, arithmetic and phi transformations

(Sahu, Basanta K.)

16 E67-02089

Size analysis, weight and number frequency transformation

(Sahu, Basanta K.)

16 E67-02087

Size analysis, weight and number frequency transformation (Dixon, Mark A., et al.) 16 E67-02088

Petrology

France, uranium content, Tertiary (Steinberg, Michel.) 16 E67-01738

Phosphate rock

Provenance (Slansky, Maurice.) 02 E67-02014

Physical properties
Bed thickness, correlation with cleavagefan angle in chevron folds

(Bayly, M. B.)

19 E67-02285

Grain interpenetration, sedimentary quartzites, Norway

(Carstens, Harald.)

12 E67-02200

\section{Sandstone}

Japan, Kii peninsula, Muro group

(Tokuoka, Takao.)

18 E67-01515

Petrology, England, Coniston grits, provenance

(Furness, R. R.)

16 E67-02286

Physical properties, England, Shale Grit (Walker, Roger G.) 16 E67-02094

Provenance, Guyana, Precambrian, lapilli bands

(Bateson, J. H.)

10 E67-02262

Structures, Scotland, depositional indicator (Hubert, John F., et al.) 16 E67-02103

Structures, Wales, quartz microfracturing (Roberts, J. C.)

19 E67-02267

Sandstone, Maizuru zone

Provenance (Shiki, Tsunemasa.)

16 E67-01513

\section{Sandstones}

Fabric, France, Caen (Poncet, Jacques.)

16 E67-01625

Shale

Physical properties, England, Grindslow shales

(Walker, Roger G.)

16 E67-02094

Physical properties, England, Wenlockian graptolitic mudstones

(Llewellyn, P. G.)

16 E67-02290

Structures, compaction, conical slip marks (Wood, Alan.)

16 E67-02085

Size analysis

France, Tertiary

(Blondeau, A., et al.)

18 E67-01629

Tillite

Antarctica, late Paleozoic

(Crowell, John C., et al.) 16 E67-02029

Fabric, England, Lowestoft glaciation (Banham, P. H., etal.)

19 E67-02274

Tonstein

General description, England and Wales, Carboniferous, significance (Hoare, R. H.)

$16 \mathrm{E} 67-02298$

\section{Turbidites}

France, Vosges (Gagny, Claude.)

16 E67-01826

Sedimentary structures

Bedding

Scotland, Silurian sandstones, groove molds (Hubert, John F., et al.) 16 E67-02103

Channels

England, Derbyshire and Devon (Walker, Roger G.)

$16 \quad \mathrm{E} 67-02431$

Figure 11. Page of Subjeet Index of the Bibliography and Index of Geology illustrating eomplete automation. 
Sarcia, Jacqueline A. Place de la géochronologie en gitologie prévisionnelle. Utilisation directe possible en prospection extensive.

Sarkar, Satya S. Procymatoceras mazardrikense nov. sp.: nautile jurassique du Baluchistan.

14 E67-01916

Sass, Louis C. Review of 1965 petroleum developments in South America and Caribbean area.

02 E67-02472

Sassi, Sassi B. M. Etude préliminaire des argiles éocènes, mio-pliocènes et actuelles de la région de Metlaoui-M'Dilla et du cap Bon (Tunisie).

12 E67-01777

Saugy, Luc. Observations lithostratigraphiques nouvelles sur la série de base (ordovicien inférieur) des nappes de Cabrières, région de Gabian-Glauzy (Montagne-Noire, Hérault).

Saul, John M. New collection of 75 Ivory Coast tektites.

18 E67-01874

Saurin, Edmond. Foraminiferes namuriens de Tan-Lam (province de Quang-Tri, centre Viêt$\mathrm{Nam})$.

05 E67-02041

Sawkins, F. J. Ore genesis in the North Pennine orefield [England], in the light of fluid inclusion studies

02 E67-02042

Scarth, A. The physiography of the fault-scarp between the Grande Limagne and the Plateaux des Dômes, Massif Central.

07 E67-02376

Schad, Albert. Abtragungserscheinungen an der Grenze Jungtertiar I/Jungtertiär II im Inneren des mittleren Rheintalgrabens.

18 E67-02413

Schallreuter, Roger. Zur Taxonomie und Phylogenie der Ostracodenfamilie Ctenonotellidae Schmidt, 194.l (Paleocopina, Hollinacea).

14 E67-02306

Scheube, H. G. An evaluation method for geomagnetic deep sounding, its derivation and practical use.

08 E67-02353

Schlegel, Gerhard. Über Mandelfüllungen in ostthüringischen Diabasen.

10 E67-02312

Schmidt di Friedburg, Paolo Contribution à l'étude structurale du groups du groupe Judica (Sicile orientale)

Schmidt, Kurt Eberhard. Fossile Bodenbildungen der Eem-Warmzeit im Raum Juterbog Dahme-Luckau.

18 E67-01672

Schmincke, Hans Ulrich Secondary flowage features in welded pyroclastic flows, Grand Canary, Canary islands.

10 E67-02043

Schoeller, M. La concentration des eaux souterraines en chlore.

09 E67-02170

Schopper, Jurgen R. A theoretical investigation on the formation factor permeability-porosity relationship using a network model.

08 E67-02349

Schürmann, K. Stability of metamorphic amphiboles; the tremolite-ferroactinolite series.

Schuiling, R. D. Residual cipolino, end-product of calcareous rocks in regional metamorphism; a reply

12 E67-01922

Schulz, Werner. Helpter Berg. Schmooksberg, Hohe Burg; ein Vergleich dreier Stauchendmoränen Mecklenburgs.

11 E67-02240

Schwarzbach, Martin. Bemerkenswerte Konglomerat-Verwitterung. Beispiele von "Hohlkehlen"Verwitterung aus Teneriffa, NW-Australien und Tasmanien. $\quad 07$ E67-02000

Schweinfurth, Ulrich. Uber eine besondere Form der Hangabtragung im neuseeländischen Fjordland.

07 E67-01998

Scolari, Georges. Contribution à l'étude géologique et métallogénique du Nivernais septentrional (région de Chitry-les-Mines, Nièvre).

02 E67-01959

Scolari, Georges Le précambrien de la chaine congolaise du Mayombe; état des connaissances géologiques, le problème des orogénèses.

18 E67-01994

Scott, K. M. Composite nature of Silurian flysch sandstones shown by groove molds on intrabed surfaces, Peeblesshire, Scotland.

16 E67-02103

Scott, K. M. Sedimentology and dispersal pattern of a Cretaceous flysch sequence, Patagonian Andes, southern Chile.

Seidel, Gerd Zur Geochemie des Muschelkalkes in Nord thüringen.

Seiders, Victor M. Geología de Miranda central, Venezuela.

Semenza, Edoardo. La tettonica del fianco sinistro della valle del Piave fra Lozzo e Pieve di Cadore.

16 E67-02138

$05 \quad \mathrm{E} 67-02303$

18 E67-02163

19 E67-01499

Sergeyev, V. O. Metodika perescheta magnitnogo polya v verkhneye poluprostranstvo na primere zapadnoy chasti Sibirskoy platformy.

$08 \quad$ E67.01724

712

Volume 31 Number 3

Figure 12. Page of Author Index of the Bibliography showing complete automation.

Based upon its experience in working with computerized publication systems, Documentation Incorporated has created a Text Processing System in which the input keying process has been made independent of the output machine and format rigidities. Data classification techniques permit text to be retained in digital files without complex input and output typographical codes. 


\title{
System 70
}

\section{John W. Seybold, President}

\author{
Rocappi, Inc.
}

I wish to compliment all of those who have played a part in the planning and carrying forward of this most successful conference on electronic composition. The large turnout is eloquent evidence of the escalating interest in this subject.

A preliminary comment I would like to make is that this meeting points up the fact that insufficient attention has been paid to the interrelationships between the computer processing of information generally, and the typesetting application. What conventions can be established to make it generally possible to take data from computers, wherever situated, and create a typeset product, by means of all-purpose typesetting software? What conventions can and should be established to represent format instructions and to access the wide variety of typographic characters now available? This is a matter in which the National Bureau of Standards should concern itself, if it has not already done so. The adoption of specific code structures is more or less irrelevant, but the establishment of related "families" of type characters is a minimum prerequisite to effective interchange of information when there is a possibility that the end product will be photocomposed.

Not only must type-family conventions be agreed upon, but ways of signalling for these must be specified. Where information is described in fixedfield format it will not be difficult to precede this field with whatever relevant format and typesetting instructions are required, but it will also be necessary to provide for midfield flags. This is really not very difficult, but it will be necessary to modify standard programming applications so that such flags, and uppercase identifiers, will be ignored in normal data processing runs. The editinsert programs which the Government agency users of the Linotron are expected to provide are of this character. Formatting for typesetting is not difficult where the information to be typeset is very limited in its typographic requirements and character set. But we should not permit ourselves to be constricted by unimaginative adaptations.

Let me turn, now, to my topic: an exposition of Rocappi's System 70. System 70 is so named because we conceive of it as a valid solution to the problem of computerized photocomposition until the early or mid-1970's. It represents the third major rewriting of our basic programs since we came into existence in 1963. System 70 is the product of many minds, including those of us now with Rocappi and many who have gone before. Former key staff members are now with Rocappi, Ltd., with IBM, with the RCA Graphic Systems Division, and with Alphanumeric. We derive some satisfaction from the fact that some of our ideas and visions are becoming a reality not only in our own company but also generally throughout the industry.

System 70 is first of all a complete operating system with its own diagnostic routines, table-generating capabilities, its own assembly language, and its own sort procedures. It consists of more than 20 separate but related programs, many of the major ones, all of which are read into memory from the same program library tape, which usually remains mounted on its tape station for the entire day of research and production activity.

System 70 differs from our earlier System 65 in the following major respects:

(1) Its table-generating capabilities.

(2) Its ability to handle complicated tabular matter (up to ten columns across the page).

(3) Its ability to move into and ont of justification and hyphenation-that is, to substitnte ragged setting for justified composition at any point in text processing.

(4) Its recovery capabilities.

(5) The fact that the system nses its own unique language, which is different from common machine language. But at least four different code structures are required for the processing of each job.

(6) Its command over five different levels of hyphenation accuracy.

(7) Its IIYCOR or hyphenation varification procedures.

(8) Its ability to nest indents within indents (up to 5 combinations) and to handle indents of a definite duration. Left, right, center, hanging, and variable indents are possible with a predetermined duration or until further notice. 
(9) Its ability to incorporate nontypesetting information at any point in the text, bypassing this information for purposes of typesetting.

(10) Its castoff and pagination procedures (Phase III and Phase V), including the ability to correct pagination parameters following inspection of the proposed pagination solutions.

(11) Its treatment of justified lines of composition as if they were slugs (Phase IV), thus permitting merging of lines for multicolumn setting, and rearranging line sequences, or line substitutions, at the last minute.

(12) Its magnetic-tape-to-paper-tape procedures for producing paper tape output for a variety of different typesetting devices, including ways of keeping track of output on a galley-by-galley basis, starting and stopping the punching-out process at any designated galley, and controlling the length of each "take."

(13) The corollary programs which

a. provide keyboard shorthand facility and the use of generalized macros which may be interpreted in a variety of different ways;

b. make possible extractions for further data manipulation: abstractions, explosions. permutations, etc;

c. permit indexing, with page references.

It is evident that System 70 consists of a comprehensive set of modular, interrelated programs which make up a total system. These programs are input-oriented, as indeed the entire system is; that is, they seek to simplify the problems of keyboarding and try to take into account the capabilities and limitations of keyboard operators. The System is operational without complicated markup and instructional procedures.

Let me digress to observe that I believe keyboard operators are not unskilled people, but re- quire a high degree of skill. They should be well paid. For the most part, at least for the kind of business we do, they are creating a permanent file or data-bank, and it is worth any amount of pains to get this file correct. It will be used for reiterative typesetting, explosions, and updates for many years to come.

Our System is also based upon a keyboard philosophy which seeks to separate input from output so that there is in no sense a one-for-one correspondence of codes; we do not believe in "position" keyboarding.

All photo-units activated by our System are used as slaves. We do not permit any photo-unit to do its own justification. Complete flexibility is thus afforded, which usually goes beyond the normal capabilities of these typesetting devices.

It is possible to use the same input for any typesetting device capable of coping with the requirements of the job, whether or not the same font or grid configurations obtain. If ligatures are called for they will be generated. If accents are desired they will be accessed, either as floating accents or as distinct characters. If no accents exist the unaccented equivalent characters will be produced.

We are still working on more elaborate pagination solutions, but we are also planning to move as quickly as possible into the development of an entirely new series of programs for third generation computers. Some of the things we do now we will keep because we believe our solutions are generally valid. Some of the features will be changed. At present all programs operate within $20 \mathrm{~K}$ (6 bit) core memory with a minimum of overlays. We have four tape stations but no disk storage.

We do not plan to write our third generation programs so tightly. Nevertheless, we think they must be written for a computer configuration which can justify its installation solely for a typesetting and related data processing application. 


\title{
IV. Government Applications
}

\section{Co-Chairmen: Samuel N. Alexander, Mary Elizabeth Stevens}

\section{A Brief Overview}

\author{
Samuel N. Alexander \\ Senior Research Fellow, Office of the Director: \\ National Bureau of Standards
}

I have a few words that I would like to inject. First, I would like to point out that the Government's stake in this new and growing technology is very high. If the Government has a characteristic output that can be clearly identified it is printed matter in large quantities, amply supplemented by multilith and mimeograph output. It is a bit of government lore that a man with a mimeograph machine is a force to be reckoned with; it follows then that if he has access to a printing press-watch out!

My contact with this field over the last couple of years has been a continual source of amazement to me. I did not have a prior appreciation of the extent of the Government's dependence on and the variety of its activities in the printing and graphic arts areas. I presume there are some exceptions, but it seems as though the Government is involved in printing and graphic arts activities in practically every form in which they are known today. As a consequence, the Government will very likely become the proving ground for a wide variety of innovative practices because of our pioneering in the application of these new tools.

I would hope that in these activities there will be a better balance in the proportions of accomplishments reported versus advance publicity on "good intentions" than was the case with the introduction of automatic data-processing techniques into our Government practices. Here publicity consistently tended to run well ahead of accomplishment. Many of us saw ten years of hard work ahead glibly being implied as current accomplishment in administrative reports and press releases, wherein the tenses seemed to have become garbled. The "is-to-be" was all mixed up with the "are-now!" I hope that this community will exercise a little more restraint in reporting its progress and that there will be a careful distinction made among "what-we-are-planning-to-do," "what-we-are-about-to-do," and "what-we-havedone." Therefore, I am urging the speakers today to set a good example in the "tense straightening" that I so strongly recommend.

In view of the day-to-day dependence of most activities of Government upon the steady flow of products based upon the printing and graphic arts, it is only reasonable to expect that the introduction of the novel techniques covered by this Symposium will have to be evolutionary in character. There is so much at stake that we cannot afford to take excessively large steps and have temporary failures, backups and start-overs. This is a prudent attitude that may, however, become overemphasized. Consequently, I would like to urge at this time that somewhere there be commissioned a group or two that will be responsible for pushing the frontier just a little faster than it would progress by the normal process of evolutionary replacement which is required to at least "break even," if not be a "profit maker," in each fiscal year.

Just how to accomplish this laboratory approach within the present budgetary structure and budget review procedures of the Government is a difficult question. Even so, I feel that there is a definite advantage for some sort of "trail-blazer" operations in which people are commissioned to push hard and fast enough that one must accept the risk of making mistakes. Moreover, these people should be in such a position that they are free of administrative embarrassment in recording and reporting their mistakes so that those who come next with an operational requirement can aroid at least those pitfalls which the pioneers found and duly recorded and reported. This is a different environment, I hasten to note, than the one in which I understand most of you must carry on your operations. You must get your products out on reasonable schedule; you cannot absorb a loss arising 
from an experiment that failed; you cannot carry such losses from one fiscal year over into the next where they may be offset by subsequent successes.

There are a number of untidy little problems associated with my proposal, but I do hope that somehow and in some way we can explain to the "powers-that-be" the inherent effectiveness and potential for long-term efficiency that make this approach a desirable one to foster. Everyone should not have to fall into similar traps during the "start-up" periods for developing proper techniques with new tools because of the onus associated with analyzing and reporting on initial poor starts. We will fall into plenty other traps because of differences in the character of our work and in the requirements and restraints on us. Still I observe enough items that are going to be common to all of us to recommend this course of action.

TVe should not each separately have to find ont about the common "booby-traps," and disa rm them one at a time, each unaware of the other's experience. This implies a more formal sort of reporting for this special trail-blazer activity than is present practice for such innorations. It present, information of this kind is mainly transmitted by a "graperine" procedure. One must often depend entirely upon the supplier of the equipment for information on the booby-traps that he has observed in his contacts with other customers. While this is a useful source, I do believe that it ought to be purposefully supplemented with a more formal way of sprea ding the word.

I related point I would like to make is that the techniques here under discussion are raising expectations that we may soon achiere a new economic balance point in the creation of publications. The relationship I have in mind is between the costs of preparing the material for publication and the follow-on costs of printing and binding. These may be brought into balance at a much smaller number of copies than is presently feasible. I've seen some analyses and estimates to support this position, and while I must admit that they had optimistic overtones, they certainly were not unrealistic. The indications are that in the not distant future it will become feasible to justify quality type for runs as small as 2,500 and perhaps tho break-even point may be pushed as low as 2,000. 'This implies that many reports needing only moderate distribution, normally thought of as practical to produce as office-machine reports, could now have the benefit of quality appearance, with high legibility and readability. This is a very attractive prospect and I hope that it comes to pass.

One of the purposes of the proposed trail-blazer operations is to derive firm information about some of these "trade-off" points. The other objective that the trail-blazer operations ought to try to achieve is to examine the total package of skills complements that will become associated with these new techniques. This is needed so that the Civil Service Commission, the Wage Boards, and other personnel policy groups may be properly advised with respect to the shifting demands that surely will arise from this new technology. The data processing area is in a rather unhappy state in this respect because of the lack of a purposeful effort to systematically obtain this kind of information in advance of urgent need and in a form that is useful to these personnel policy groups. I do hope that we can avoid going through similar umecessary experiences, but rather find a more effective way of identifying and specifying the skills complements needed all the way from originating the publication to its output and distribution.

The concluding point I would like to make is one that I always plug for. I believe that an extraordinary amount of material of transitory interest is printed and put on unnecessarily good quality paper. This enhanced appearance tends to give the publication an unjustified aura of permanence and makes people very reluctant to dispose of it. Now that we may be aggravating the prospects of such poor practices, I would like to see wider consideration of the uso of the "comic-book" quality publication which soon falls apart. In fact, it might even be wise to investigate a paper-andink combination with built-in chemicals which, instead of retarding deterioration, would actually induce it in a year or two! 


\section{Comments \\ Mary Elizabeth Stevens \\ Center for Computer Sciences and Technology, \\ National Bureau of Standards}

I would like to comment very briefly on two points where I think we can see some convergence of interests in different fields with respect to this new technology of electronic composition in printing. Earlier in these sessions we heard some differences of opinion as to the probable role of optical scanning in the whole process. While I am not now taking sides on this matter in regard to the preparation of new text material, I would like to remind you of the millions and millions of printed pages that are already in existence and for which we have no capturable machine-form versions. There are similar problems with the continuing flood of publications from all over the world. In many cases we will have access to neither the manuscript preparation nor the typesetting tapes. If we wish to process this great bulk of information by machine, then optical character recognition techniques may prove to be the only economic means of input.

If this proves to be the case, we will need to know certain things. Thus, at a symposium on mechanized abstracting and indexing held in Moscow last September under UNESCO auspices, one of the recommendations that was submitted to
UNESCO related to these needs. This recommendation was that all printers of books, periodicals, journals, and the like, be asked to provide in each issue in a special place a full set of all characters and symbols in any font or fonts used in that particular book or journal. The implications for the development and use of OCR techniques are obvious.

My second point also relates to automatic data processing of printed text, but in a slightly different sense. Those of us who use computers for language and text and bibliographic data processing have, like other computer users, asked you who are members of the graphic arts industry to give us back high typographic quality and still keep compatibility with computer speeds of output. And this, I think, you are well on the way to doing for us. However, some of us would now like to ask you to back off just a little on the typographic quality on one minor point. Please be sure you give us, even with variable spacing, some means of differentiation between the period used to end a sentence and the symbol used to indicate an abbreviation or as a decimal point, whether by special spacing or by new symbols, and whether or not this produces "rivers" of white on the page. 


\title{
Electronic Composition Within the Department of Health, Education, and Welfare
}

\author{
Edwin R. Lannon
}

\author{
Assistant Commissioner for Administration, \\ Food and Drug Administration, HEW
}

I should like to address myself to two elements of work underway within the Department of Health, Education, and Welfare.

Since Mr. Bogart of the National Library of Medicine (NLM) of the Public Health Service will cover the GRACE system in some detail, I will confine myself to the historical development of that system and the reasons why the first truly electronic composing system came about. Secondly, I should like to describe a venture being undertaken in the Food and Drug Administration inrolving the use of the IBM MTST Composer.

Going back to topic one, figure 1 shows a page from the predecessor publication to Index Medicus, namely, the Current List of Medical Literature. The entries were typewriter composed and "slingled" into a page. The process was a torturous one and the product about as bad as it appears in the figure. Extreme dissatisfaction with this product led in 1957 to the Index Mechanization Project of NLM which was partially financed by the Council on Library Resources. This study, which I should point out was one of the best pieces of analytical work I have been exposed to, culminated in the installation of sequential card system employing the Listomatic camera and Justowriter inputs. The system became operational in 1960 and figure 2 shows an example of the output. I believe you will agree that a significant difference exists between the two samples. By no means, however, is the product in figure 2 completely acceptable from a typographic point of view. Note the wandering register of individual entries.

While the sequential card system was a major improvement over the shingled card system, it lacked retrieval capability. The coding on the card was essentially limited to instructions pertaining to the sequencing of the card through the camera. The space available could not tell much about the printed entry on the card.

The knowledge acquired by the Index Mechanization Project led in 1961 to the initiation of the MEDLARS contract. The General Electric Company was put under contract
(1) to establish the preliminary design of such a system,

(2) to go to detailed design, and

(3) to operate the system on a "turn key" basis. Preliminary research on composing technology had been conducted for the NLM under contractual arrangements. This assessment of the state of the art indicated that phototypesetters offered the most promising methods of meeting composition requirements.

Since there was a real sense of urgency in developing MEDLARS an early decision was reached to use only "off-the-shelf" equipment to fulfill the requirements of the system.

In 1961 for costing purposes it was assumed that two photocomposition devices operating in the range of 12 characters per second would be adequate. With 20-20 hindsight we can say that this was ridiculous. The fact is, however, that in 1961 we really did not know any better.

As work progressed on the preliminary design effort a point of decision was reached in October of 1961. It had become quite apparent that given two basic requirements, namely, (1) typographic quality and (2) a composition cycle of two days for Index Medicus no existing typographic system could meet this time factor realistically.

Facts were beginning to force a decision to waive typographic nicety and go to the only "off-theshelf" device that could produce copy at high speed, i.e., the line printer of the digital computer which would be the heart of the system. At this juncture I made perhaps my only real contribution to the MEDLARS project by asking the simple question, "Have we considered total time to the press?" The consultants, while being expert computer people, had forgotten that camera copy was not a plate. When phototypesetters and the line printer were timed to comparable outputs it was apparent that even a mechanical monster banging out 1,760 characters per second dropped to 200 characters per second when the film cycle was considered. Indeed GE, after consulting the production staff of the Government Printing Office, 


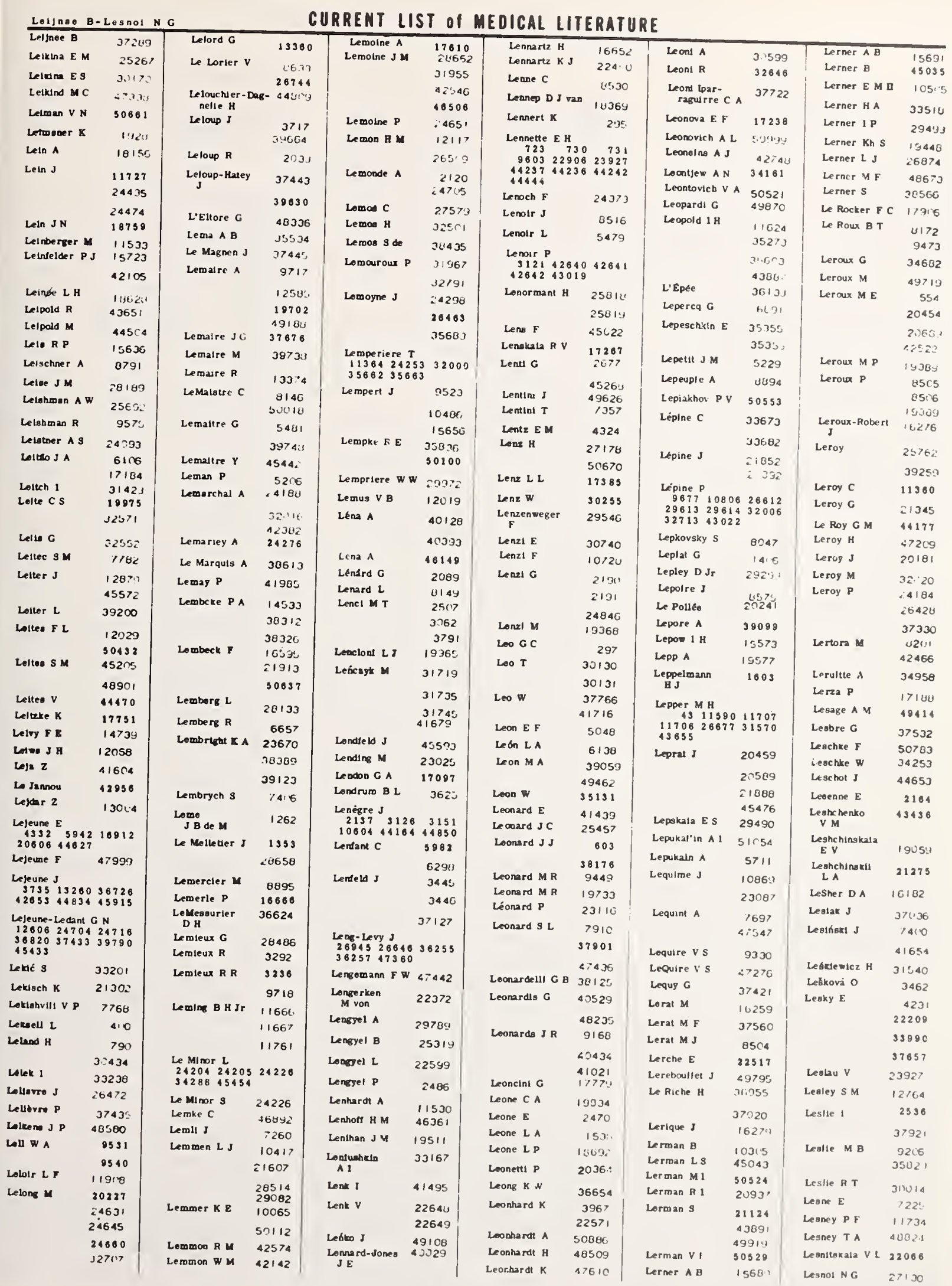

FIGURE 1. Sample page from the Current List of Medical Literature, predecessor to the Cumulative Index MIedicus. 
Lepra! J see GENNES L de

LEPRI G, PARDUOC] F: [5-lodto-2'-deoxyurdine in exper-1mental vaccinal keratitis] Ann Otral $88: 443-7$. Oct 62 (it) LEPRI G, PARDIICCI F: [The Qutck test and Owren's thrombotest in the control of anticosgulent therapy in ophtha! mologyl Ann Ortal 88:117-24. Apr 62 (It)

Lepsik J see FRIC $P$

Lepsik J see HERF()RTK

LEQUESNE M: [ In what order should one use the different treatments for lumbosclatica'] Gaz Med France

$69: 2497-504,25 \operatorname{sep} 62$ (Fr)

Le Quesne LP sce HOHE CT

LEQUESNE M, CDULOMB R, KAHN MF: (Longtrudinal "faugue" fracture of the tibla] Rev Rhum 30:30-1, Jan-Feb 63 (Fr)

Leouesne $M$ see PORESTIER F
Lequesne $M$ see SEZE S de

LEQUIME J, CLEEMPOEL H: [Cardlological applications of radlolsotopes| Mal Cardlov 3:3-16, Mar 62 (Fr)

(heart dies

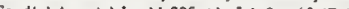

Cardiol angelol int 11:205-11. Jul-Sep 62 (Fr)

LEQUIME J: The circulatory dynamics in coronary thromboa!s. J Ass Physlclans India 10:591-5. Nov 62

LEQUMME ]: [The discovery of clrculation in the Renals-

sence era] Bruxelles Med 43:391-401. 7 Apr 63 (Fr)

Lezuln see SAUBiER E

Lequin $L$ soo VURD $H$

Lequiln P see REVOL

Leouln $A$ see MOURGUES $C$ de

Le QuIre VS see STAHLMAN MT

LERAAND S: Principles of pressure measurements, Acra

Anaesth Scand Surol 11:115-33, 1962

Lerand S see INGEBRICTSEN $R$

Lerat see GIROIRF

LerAt see HER VOUET F

LERAY C, CARLON N ! OOn the presence of a duality among

eynophilic cells of the edenohypophysis of Mugit cephalus

L. (Teleastea, Mugllidae)] C R Soc Biol (Parls) 157:572-5, $10 \mathrm{Jul} 63$ (Fr)

LERAY C: [ $A$ sandy of the incorporation of cysteine labelled with sulfur-35 Into the hyporhslsmo-hypophyslal system and more particularly Into the adenahypophysis in a teleost Mirgl cephulus L] C R Acad Scl (Perls) 256:795-8, $14 \operatorname{Jan} 63$ (Fr)

LERAY C: IEvalustion of the gonadotroplc propery (type FSH) of the plutitary gland of teleosts, particularly Cyprime carplo L.] C R Acad Scl (Paris) 256:474-7. 27 MaY 63 (F r)

LERCH H, RONCKE HC, WISCHMANN H: (On Haffs's knee

Jolnt disease] Chinung 34:269-73, Tun 63 (Cer)
LERCH ]: [Provisions of the construcd on (Codex for public health adminlstration] Nepegeszsegugy $43: 345-8$, Nov 62 (Hus)

LERCH V. OKACAID T, ALSTIN JH, KEVORUAN AY, YOUNCE PA: Cytologtc findings in progresslon of enaplase (dysplasia) to carcinoma in sto: a progress report. Acta Cyrol (Ptila) 7:1 83-6, May-Jum 63

Lerche D see NEUHAUSC

LERCHE W: [Eloctron microscope raulies on the differentas. ton of the plgmented eplitheltum and external granular cells (sensory cells) in the buman evel Z Zellforsch

$58.953-70,1963$ (Cer)

LeTe see LAURENT

TER Reheller A AA AI TRFRTIN F [Blood alcohol curves. Its vartadons] Bull Aced Nat Med (Per1s) 147:79-86, 22-29 Jan 63 (Fr)

LEREBOULLET ]: [Polygiobullsm. intractuction] Rev Pret 12:2353-6, 1 Sep $62(\mathrm{Fr})$

LERE BUULLET J, BENUIT $P$, LEDUUX $M$ : ! The anxiolyd action of chlordiazepoxide] Therapie 17:1005-9,

Sep-Oct 62 (Fr)

LEREBOULLET J: [Delitum tremens]

Rev Prat 12:3293-304, I Dec 62 (Fr)

LEREBOULLET J, POLSSON M: [The current Incidence of sulcide artempts; the problems which it poses in hospital sulctde artempts: the problems which It poses 3-10 May 63 (Fr)

Lereboullet J see LEVILLAN R

LERENMAN ML: [Role of some leboratory methods in the diagnosls of Botkin's disease] Med Zh Uzbek 9:50-7. Sep $k 2$ (Rus)

Mla see MUSABAEV IK

Le Reveller see BESSIERE E

Lergler $M$ see VOGLER $K$

LE RICHE Wit: University and hospltal training of public health phystclans In Canada, Ganad Med ASS J 87:1 322-5, $22 \operatorname{Dec} 62$

LERIQUE A, MISES J, MISES R: [A new hypnotic, Optanox.

Study of correlations berween clinical aspects and FEG]

sem Ther 38:925- - . Der 62 (Fr)
Lerqque J see LEFEBVRE J

LER IQUE JL: [The current contribudion of electrology to peripheral neurology] Bull Soc Med Hop Parls 114:337-42, 8-15 Mar 63 (Fr)

LERMAN H: Ovestions of valldiry raised by an adfectlve check list :echnique, J Clin Psychol 19:198-9, Apt 63

LERMAN J: Hypothyroldism: physlology and treatment, New Yort J Med 63:248-56. 15 Jan 63

ERMAN LS: The structure of the DNA-ucridine complex. $15 \operatorname{Jan} 63$

LERMAN MI, MARDASHEV SR: [Synthesls of OL-asparagine suttable for the product on of labelled $N-15$ and $C-14$ come pounds] Blokhd milla 27:904-6, Sep-Oct 62 (Rus)

LERMAN ML MARDASHEV SR: [Transaminadon of dica To boxylic amino acld amldes in myocardial preperadons] Vop Med KhIm 8:431-2, Jul-Aug 62 (Rus)

Lerman MI see GEORGIEV GP

Lerman MI SEe MARDASHEY SR

LERNAU $H$, SOMPOLINSKY D: Bovlne mastlets due to dwarf-colony varlants of Staphylacoccus aureus.

Cormell Vet 52:445-51, Oct 62

LeTner A see DREYER MS

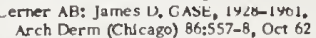

Lermer $A B$ aee $A X E L R O D$ J

LeTner AB seee BRAVERMAN IM

Lemer $A B$ aee LEE TH

LeTTer $A B$ see MCGULRE JS

LERNER AM, CHERRY JD, FINLAND M: Hemagglutination whth reoviruses. Vtrology 19:58-65, Jan 63

LERNER AM, CHERRY JD, KLEIN JO, FINLAND M: Inlectlons with reovlruses. New Eng $\mathrm{J}$ Med 267:947-52, 8 Nov 62

LERNER AM, CHERRY JD, KLEIN JO: Vrologlcal sudles of summer exanthems. Arch Intern Med (Chlcago) 110:687-92, Noy 62

LERNER AM, SHAKA JA: Coxsackle A9 myocardltss In aduit mlce, Proc Soc Exp Blol Med 111:804-8, Dec 62

Lemer AM ree CHERRY JD

Lerner AM see FEDERICI EE

Lemer B see CARTURIGHT RD

Lerner B see KARLSON KE

Lemer $B$ see XTSSACK AS J $r$

LERNER HJ, THOMPSON JC: Heparin suppression of gastric acld secretlon, Pro Soc ExD Blol Med 112:730-2. Mar 63 Lemer $H]$ see THOMPSON JC

LERNER J: Disability evaluation of psychiarslc illness in

Marvland. Marvland Med $111: 643-6$. Dec 62
LERNER J: Meatal health of the aging population in relatlon to soctal securlty benefits. J Amer Gerlat Soc 11:551-7, Jun 63

LERNER KL, FIDEL 'MAN MM: [Activity of carbonic anhy. drsse in the blood of newborn intent s under different condltlons] Pediat Akush Glinek 1:10.1, 1962 (Uk)

LERNER LJ, YLCAS E, BORMAN A: Blological acuvites of the 2-acetofur an derlvative of $16 a, 17 a-d$ lhydroxyprogesterone. Proc Soc Exp Blol Med 113:663-6, Ju! 63

Lermer $L J$ see HILF R

Lerner LI sलe SINGER FM

LERNER M, MILLS AL, MOUNT SF: Nareodics anatysis--A slmple apprasch. J Forenslc Scl 8:126-31, Jan 63

LERNER MJ: The coheslve small group in the treatment of chronlc schizophrenia, J Nerv Ment Dis 136:579-90, Jun 63

LERNER NV: [Use of prednlsolone in a pattent wth a severe vemporary insulln-resistant form of diabetes melluas assoclated with the development of an allergic reaction] Ter Arkh 34:121, Nov 62 (Rus)

LERNER S: [Respiratory insufflelency. Clinleal a spects, diegnosls, trearment. Ceneral conslderatlons for the genera! practidoner] Sem Med (B A Ir) 121:467-76, 2 Aug 62 (Sp)

LERNER S: [Persistence of Koch's beclill "sensitive" to the ent blogram. Clinlco-experlmental study

Sem Med (B A Ir) 121:1155.61, 17 Sep 62 (Sp)

LEROUX-ROBERT J, VANDENBROUCK C: [Ep!dermal epI-

thellomas of the ivula and adjacent portlons of the sof palate! Anr Otolaryng (Parts) 80:275-89, Apr-May 63 (Fr)

LE ROUS BT: intrathorsclc duplication of the foregut.

Thorax 17:357-62, Dec 62

LEROUX GF, MASY P: [Deo-ceco-collc Invagination on lymphoblastoma of the cecum] J Belg Radiol 45:531-3, 1962 (Fr)

LEROLX M: (The obstetrical future of women operated on by cesarean section. Problems posed by immediate risks and their remote outcome] Matermite 11:77-89, Apr-May 62 (Fr)

LEROUX ir TARR Hil: Glveose and ribose oxddation by Pseudamonas irapi Canad J Blochem 41:1023-34. Apr 63 LEROUX ME, SAMAMA M, BEASLAY Y, PROSTRJ:[Thrombadynamography in the functional exploration of platelets] Transfusion (Paris) S:169-78, 1962 (Fr)

Leroux ME see MAUP NN B

LerOUX ME SE MARCHAL G
LEROUX MP, JARROUSSF, J, LEMONE P, LEROUX P, HAROUSSEAU $H$, HERMDUET L, ALBFRTM DAVY JM:

[Plerre Robln syndrome\} Bull Fed Gines Obstet Franc
15:283-9. Adr - May 63 (Fr)

P. HERMOUET L MACRE J [Hemorrhagic syndrome complicated by retro-placental hematorna in a woman treated for chronic alcohollsm, heving mental dlsturbances and hyperirophtc cirrhosis of the IIver]Butl FedGynec Obstet Franc 15:114-9, Jan-Mar 63 (Fr)

Leroux $P$ see LEROUX MP

Le Roux PL see SEALY R

LEROUX-ROBERT J: [Indications and results after 5 years conservative surgery of concers of the larynx and hypopharynx] Blbl Otorhlnolaryng 9:44-130, 1961 (F r)

LEROUX-ROBERT J, VANDENBROUCK C: [Treatment of epldermal epltheliomas of the uvula and adjacent portlons of the soft palate] Ann Otolaryng (Paris) 80:101-2, Jan-Feb 63 (Fr)

LEROUX-ROBERT ]: (Spectacul ar action of cyclophosphamide (Endoxan) in a case of recurrence of an eplthelloma of the superlor maxdllary previously reated wlth surgery and r diat onsl Ans Orolarvne (Parls) 80:106-15. lan-Feb 63(Fr) LEROUX-ROBERT J, FORETTE B: (Acti on of cyclophospha mide in the treatment of $O R L$, and cervico-maxdllom acial eplethellomas) Ann Otolaryng (Paris) $80: 5-12$.

lan-Feb 63 (Prl

LEROUX-ROBERT J, BRUX J de: [Cranio-cervical chordomas (apropos of 4 recent cases)] Ann Otolaryng (Paris)

79:663-79. Sep 62 (Fr)
Leroux - Rohert J see ANCLA

Leroux-Robert J see MOULONGUET A

Leroy see MACENDIE

Leroy see POUYANNE

Leroy SE POUCHOL-HAUMONTE I

Leroy $\mathrm{C}$ see BFLEY A

Leroy $E$ see COIGNET J

LEROY F: [Cyrological analysis of in vitro cultures of the

human endometrium and its isolated constituents]

Bull Soc Roy Belg Gynec Obstct 32:483-503, 1952 (F r) Leroy $F$ sec MULNARD J

Leroy $G$ see POILLEUX F

LEROY GV: The American cummuntry looks at clvil defense. New York J Med 63:1574-7, is May 63

LEROY JP: Case report: infectious mononucleosls with essoch isted encephalopathy. J Amer Coll Itealth A ss

11:397-400, Apr 63

LEROY JC, COLLE Jl: Prolonged apnea following the use of succinylcholine. Acta Anaesth Belg 14:141-8, 1963 LEROY JG, VAN DER SCHOOT J8: 5-hydroxytryptamine an noradrenaline levels in brain of mice after nialamide, Ro-4-1530 and Ro-4-2308. Arch int Pharmacodyn $140: 374-9$, I Oec 62

Leroy JP SSe EGGERMONT E

Leroy JP see CORDONNIER Y

LEROY M: [Cure of a gub-capleal fracture o: the neck of the

lett femur by continuous exrension] Borde aux Chir 3:143-5, Jul 62 (Fr)

LEROY M: [The budgetary balance of hospltals]

Zlekenhulowezen 36:103-7. Apr 63 (Fr)

Leroy $N$ see BISERTE $G$

LEROY P: [Plumage changes obtained after injection of gutnea-fowl blood into hens of genetically controlled stock Blol Med (Parls) 52:402-12. Pul-Aug 63 (Fr) Blol Med (Paris) 52:402
Leroy P see MACENDE I

Lerov P see DARMAILLACOR

LERRICK A: Hashimoto's disease and carcinoma of the thy rold. Conn Med 26:639-41. Nov 62

LERTORA AC, PALEO MJ, PETTDA L, SCHROOER E:

(Objectlve evaluation of the ant/-alcoholic condtioned reflex] Sem Med (B Alr) 121:1612-3, 25 Oct 62 (SP)

LERU Y, RAYNAUD P: [Etfect of different amino acld combinations on rumen bacterla cuitures] Arch Scl Physlol

LER $\angle A H$, M(I)XI L: [Color percepton in the evaluabon or work adaptabillty] Rass Med Industr 31:187-93, M ay-Jun 62 (It)

Lerza P SE FARRIS $C$

LESAGE MA, SEALYWC, YOUNG WG Jr, LEE JM: Expermental studles on profound hypothermla Induced and reverted with a pumpoxygenator. Ann Surg 156:831-44, ^ov 62 LESAGE MA, TSUCHOKA $\mathrm{H}$, KOIE $H$, YDUNC WG $\mathrm{Jr}$,

SEALY WC: Studles on tolerance to prolonged deep hypo

thermis. Trans Amer Soc Artif thtern Organs 9:230-7, 1963 Lesage $R$ see SAANS $G$

Lesage $R$ see WAROT P

Lesage $R$ see WAREMBOLRG $H$

Lesbars G gee RTVIEREM

Lesbre see MIRAIL LET P

Lesbre IP see BAISSET A

Lesbre JP see REGNIER C

Lesbre P see SOREL R

LESHCHINSK AIA NP: IOn functional conditions of the thyrold gland determlned by the method of radloactive indleators in patients with sequelae of closed ccrebrocrarual traumit Zh Newropat Pslkhiat Korsakov 62:1326-8, 1962 (Rus) LESHCHINSKII LA: [On the effectveness of treatment of padents with elrculatory insufficiency with the glycoside korkhorozld] Sovet Med 26:133-5, Mar 63 (Rus) 
Leoni E: La mononucieosi Infettiva Gazz Int Med Chir 66:2209-21, 15 Nov 63 (65 ref.) (It)
Leonl GC, Taglleri G: Rlllevl slero.epidemiologlci in un camplone delia popolazlone deli Asmara (Eritrea).
Ricerca degii antlcorpi anti-O-streptolisinici.

Arch 1tal Scl Med Trop 45:189-96. Apr 64 (It)
Leoni L. Tecce G: Azione deila rifamicina SV sulle reazionl deila sintesl protelica in vitro.

Chemotherapla (Basel) $7: 194.9,1963$, 1963 (It)
Leoni R: Un nuovo farmacoa largo spettro di azlone per ii trattamento delie vaglnitl.

Leoni $R$ see Battaglia GB

Leonida D see Bashe WJ Jr
Leonoris SM: Slmpilicity: key ingredient of a successful

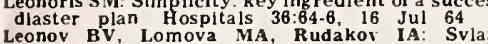

Leonov BV ' Lomova MA, Rudakov IA: Svlaz'
radiochuvstiviteinosti krys s antiokislitel'noi

aktlivnost'iu kostnogo mozg a i soderzhanlem

neesterifitsirovannykh zhirnykh kislot $:$ ikh krovi pri
sostoianil "stress". Radioblolog iia 3:518-22, 1963 (Rus)

sostoianil "stress". Radioblologlia 3:518-22, 1963 (Rus)

Leonov BV, Lomova MA: 1zmenenle soderzhanila
obshchlkh zhirnykh klslot v kul'ture tkanel posle

gamma-obiuchenlia. Radiobiologifa 4:72-5, 1964 (Rus)
Leonov VM: Osnovnoi obmen 1 likhoradka pri

Leonov VM: Osnovnoi obmen 1

Arkh Pat
Leonov VM:
25:75-61, 1963 (Rus)

venoznoi krovi u cheloveka.

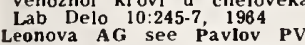

Leonova EV see Kravtsova EE

Leonova LA: Kozhnye temperatury I potootdelenie u

shkol'nlkov, obuchalushchikhsia professll tkacha.
Glo Sanit $28: 43-7$ (R)

GLg Sanlt 26:43-7, Sep 63
Leonova NA see Burobin VA

Leonova NA see Burobin VA
Leonova VG: Prenatal'nala dinamika kachestvennogo

sostava krasnoí krovt cheioveka.

Pedlatrlia 42:3-9, Oct 63 (Rus)

Leobsicheskikh reaktsliakh pri primenenll

antibiotikov.

(Rus)

Vestn Otorinolaring 25:63-7, Sep.
Leonovich AL see Krasnikova EIa

Leonovich AL see Markov DA

stradalushchlkh khronicheskoi pnevmonlei

bronkhlal'noi astmoi.

Vop Okhr Materln Dets 8:40-3, May 63 (Rus)

Leont'eva GR see Govyrin VA

Leont'eva KA see Kogurova MI
Leont'eva NS, Pokrovskif O funktsional'nom sostolanii

Pochek pri koarktatsil aorty
Ter Arkh 35:45-50, Nov 63

Leonteva NS, Pokrovskif AV: O pechechnom

krovoobrashchenli I mechanizme glpertonil prl

koarktatsll aorty. Sovet Med 27:31-5, Sep 63 (Rus)

Leontluk LA: Obrazovanie dopolnitel'nykh istochnikov

krovosnabzbenlla lachnlkov v èksperimente.
Zdravookhr. Beloruss 9:32-5, Dec 63

Leontovlch TA, Zhukova GP: The specificity of the

neuronal structure and topography of the reticular
formatlon in the brain and spinal cord of carnivora

formatlon in the braln and spinal cor

Leopardi G: Associazlone di dorso curvo ed aplasla

congenita del pettorale e della ghiandola mammaria

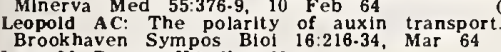

Leopold D see Kandler H

Leopold HC. Godwin B: LE celis in chronic bronchlal asthma. JAMA 186:945, 7 Dec 63
Leopold IH: Drug therapy in uveitis.

Leopold IH, Sery TW: Epidemiology of herpes slmplex

Leopold IH: The contribution of pharmacology to

cllnicai ophthalmoiogy.

Amer J Ophthal 57:936.43, Jun 64
Leopold IH: Capllary shunts in the pathogenesis of

dlabetic retinopathy. Dlabetes 12:349-50, Jul-Aug 63

Leopold iH See Hallett JW

Leopold it see Labson PR

Leopold IH see Mutlu F

Leopold J, Valtr Z: Use of preformed Asperglllus nlger

mycellum for determining the presence of
stlmulating cltric acld fermentation.

Folla Microblol (Praha) 9:36.8, Jan 64

Leopold $P$ see Bonnet JL J

Leopoldt H: A German psychlatrle hosp
Nurs Times $59: 1127,6$ Sep 63
Leotard $R$ : Interet et indications de

l'électromyographle.
Bruxelles Med 44:69-72, 19 Jan 64
Leoutsakos BG: He chelrourgike therapela tes

thyreotoxlkoseos. Analysls 362 perlptoseon. (Gr)

Leovey A see Szegedi G

Reo G: Neurooftalmologia.

Lepadatu C C see Munteanu-Ivanus $N$. Aborto septico e Insuflclencla renal aguda

Lepage C: Aborto septico e Insuficlencla renal aguda
Rev Obstet GInec Venez 24:165-78, 1964 (Sp)

Lepage C: Del post aborto molar.
Rev Obstet GInec Vencz 23:493-50I, 1963 (Sp)

Lepage C see Brunelle JP

Lepage F, Boeswillwald M, Bígey L, et al: La mortallté

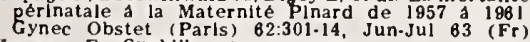
Lepage F: Syphllls el grossesse.

Rev Prat 14:1677.62, 1 May 64
Lepage F: Etude din test lmmunologlque de la

grossesse: essai d'appreciation quantitative.
Bull Acad Nat Mcd (Paris) 147:549.52, 8.15 Oct 63 (Fr)

Lepage $F$, Langevin.Droguet $G:$ La preparation psycho-prophylactique à l'accouchement.

Lepage F, Michelon B: Incidences obstetricales (Fr)

Med 1nfant (Paris) 70:413-6, Aug-Sep 63 Fr)

Lepage $\mathbf{F}$, Sureau C, Gaiula M: De La sterilisation

temporalre Maternite 13:67-95, Apr 64 A

Lepage $F$ see Michelon $B$

epage G, Grondin P: Le sang et ses substituts en

chirurgie cardlaque.

(Fr)

Lepage $G$ see Grondin $P$

LePage GA: Basic biochemical effects and mechanism of action of 6-thioguanine.
Cancer Res $23: 1202 \cdot 6$, Sep 63

LePage GA see Brink JJ Lepage M: The separation and identification of plant
phospholipids and glycolipids by two-dimensional thln-layer chromatography.
Chromatogr $13: 99103$, Jan 64

Lepage $M$ see Paquin $R$

Le Pecq JB, Bourgoin D: Etude

d'utilisation de la vlscosimétrle pour la détermination de l'activite Blochim Biophys Acta 60:173-62, 17 Feb 64 (Fr) Le Pecq JB see Le Tataer JY

L'Epée P. Lazarini HJ: Le problème de la mort pendant Le travail. Arch Mai Prof 25:245-6, Apr-May 64 (Fr)
L'Epée P. Lazarinl HJ, Campet L: Armes a feu dangereuses d'un type Inatendu. L'epée P, Lazarini HJ: Quelques problèmes relatifs a la syphills en medecine légale et en médecine sociale. $J$
L'E Med Be Bordeaux 140:1431-4, Sep 63 cutanées, a type de kératodermie palmaire, voisines

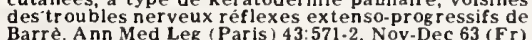
L'Epée P see Dervillee P $P$ Peltier: 17 lésions artérielles fèmoro-poplitées traltées par reconstruction immediate.
Bull Soc Med Milit Franc 57:251.6, Jun 63 (Fr) Leperchey F, Gaultier M: Interét du cyclarbamate par
vole rectale en pratique courante chez l'adulte.
Vle Med [Med Ther] 45:635-6, Apr 64 (Fr)
Leperchey F see Gauler Mater. Lepeschkin E: The Gaulectrocardiog raphic diagnosis of bilateral bundle branch block in relation to hear
block. Progr Cardiov Dis 6:445.71 Mar 64 Lepeschkin E, Surawicz B: Correlation between the potential and the electrocardiogram in electrolyt

Arch Inst Cardiol Mex 34:163-96, Mar-Apr 64

Lepeshinskli NA see Misluk NS
Lepeshkina AS see Dashevskaia RSh

Lepeshkina GN see Rossolimo oK

Lepets ME: AKTG I kortikosteroidnye gormony terapil ekzemy u deter grudnogo i rannego vozrasta.
Vestn Derm Vener $37: 29-34$, Sep B3
(Rus) Lepeuple A see Thibier $\mathbf{R}$

Leplavko AG, Glukhen'ki1 TT: Gerpetiformnyr

dermatoz Diuringas porazhenlem vnutrennikh
organov. Vestn Derm Vener $37: 71.2$, May 63 (Rus)

Le Plerres Y see Le Brland-Lohyac Y

assotslirovannoi immunizatsil protlv stafilokokkovo

infektsil, stol" stolbnlaka, briushnogotifa i paratifa B
1. Zh Mikroblol 40:116-22, Nov 63 (Rus)

Léplnay $\mathbf{B}$ see Degos $\mathbf{R}$.

resplratoire. Un Med Canada 93:666-6, Jul 64 (Fr) Léplne E: Nécrose ascpllque primitive de la tète Un Med Canada 93:693-9, Jun 64

Lépine J: Dlagnostic des alopécles.
le Med 45:1035.40, Jun 64

Leplne $\mathbf{J}$ see Degos $R$

Lepine $P$ : Vacunaciones y vacunas contra la poliomleiltis. Indlcaclones y resultados de tas vacunas

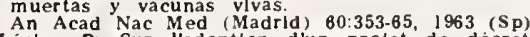
Léplne P: Sur l'adoption d'un projet de déc

obligatolre (au nom de la Comm!ssion de la Vaccine Bepline $P$ : Applleations of lactoglobulins in (Fr) Lexermental immunology. Trianglc 6:145.56, Ja
Léplne P: Appllcations des lactoglobullnes a

I'lmmunologie expérimentale.
Triangle [French\} 6:145.56, Jan 64 (Fr)
Léplne $P$ : Vacclns lnterfércntiels contre les matadles a

vlrus: unc nouvelle methodc d'lmmunisation.

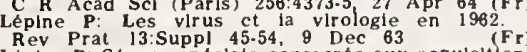

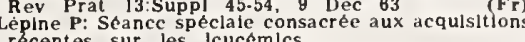
Nouv Rev Franc Hemat 3:617.30, Nov-Dec 63 ( 43 ref.

Lépine P, Rudder J de, Maurin J, et al: Essal dc therapeutique de Therpes recidlvant par un vaccin preparé en culture cellulalre ct lnactlve par les rayon
ultra-vlolets. 1. Preparation du vacein ct cssais d'immunlsation sur l'animal

Lépinc P, Zourbas J, Maurin J: Vaccinoprophylaxl antipollom yelltique par volc buccale dans une creche Infcetee par le virus de type 1.
Bull Acad Nat Mcd (Parls) 146:457.68, 30 Jun 64 (Fr) Lepine P see Atanaslu
Lepintre J see Seringe P

poiyethylene tubing. Amer J Ophtha i57:666-70, Apr 64 Lepkovsk y S, Naibandoy AV, Dimick MK, et aL: Growt and reproduction of depancreatized

Lepkovsky s see Han Pw

tonow slyszalnych przy badaniu audiometrycznyen przewodnictwa kostnego.

Lepkowski M, Turski C: Leczenie chirurgiczne chorob

Leplat G: Leo Weekers (1661-1962) Apr 64 (Pol)

Ann Oculist (Paris) 196:965-6, Sep 63

Leple y D Jr, Bormes W, Ka yser K: An electronic device

for accurate identification of the cardiac conduction

surgery. Amer J Surg 106:933.7
Lepley D Jr see Dawes RB

Lepley D Jr see o'Connor T

Lepoire J, Montaut $J$, Bouchot $M$, et al ( $F_{r}$ )

artério-veineux intrafrontaux vascularisés par

l'artère elhmoldale antérieure. A propos de trois

Neurochirurgie 9:159-66, Apr-Jun 63 (Fr)

retention chloro-sodee avec hypertonie osmotique en

neuro-chirurgie.

Lepoire J. Montaut 3 , Renard M: Méningites

répétition par fistule ostéoméningé congénitale de

l'étage antẻrieur révélée par un traumatisme.

Lepoire J, Montaut J, Renard M: Hematome sous-dura

Ann Med Nancy 2:1246-56, Sep 63

Lepoire J, Montaut J, Medot A: Lep 63 (Fr)

spontane. Maroc Med 42:676-65, Nov 63 (Fr)

carotide interne chez une enfant de deux ans
Arch Franc Pediat 20:1234-6, Dec 63 (Fr)

Lepoire $J$ see Chalnot

Lepoire J see Kissel P
Lepoire J see Neimann

Lepoire M: La circulation extra-corporelle et
I'hypothermie profonde dans le domaine de

neuro-chirurgie.
Transfusion (Paris) 6:413-7, 1963 (Fr)
Lepore PD, Siegel PB, King KW: Proximate and amino

acld composition of eggs and chicks from

Life Sci 6:564.93, Aug 63
Le porj R see Balestra E

Leporinskif IN see Volkova IN

epoutre L: Coprecipitatieef fekten biy de bepaling van

neerslagmetoden.

Arch lnt Physiol 71:636-9.

Lepow IH see Haines AL

Lepow IH see Ratnoff OD

immunization levels after an oral poliovaccine
program in Cleveland. JAMA 167:749-57, 7 Mar 64 Lepow ML see Warren RJ

Lepp A. Wagle SR, Oliner L: Effects of $L$ and D-thyroxine on cholesterol synthesis and turnover in
the chick. Proc Soc Exp Biol Med 115:517-21, Feb 64 Leppanen MK, Jalava E: Micturition
urethrocystography compared with cystometry as

gulde of bladder function.

Leppard LB see Schmidt

Lepper MH, Ost feld A: Preventive medicine and menta

health. Epldemiology of sociopsychologic varlables Lepper MH: Opportunistic gram-negatlve rod

Lepper MH, Chomet B, Karklys E: Experimental mixed

infections in mice

Arch Environ Health (Chicago) 6:570.63, Apr 64

Lepper MH see Devetski R
Lepper MH see Dowing HF

Lepper MH see Dowing H

Lepper $\mathbf{P}$ see Mehnert $\mathbf{H}$
Lepplen $\mathbf{R}$ : Das open-door

Nottingham/Engtand, selne Voraussetzungen und Auswirkungen Nervenar

Leprat J, Laudat P: Les tests non Isotoplques d l'exploration fonctlonnelle thyroldlenne.
Bulf Soc Med Hop Parls 114:747-57, 31 Hay 63 ( Fr) hypercortlelsmes melabollques
Cah RMF 79:73-6, Feb 64

Leprat J: Le syndrome de Chlarl-Frommel. (Fr) Vie Med 44:1627.6, Nov 63

Leprl G, Cappelil L: Farmacl ipotonizzantl oculari d lipo osmotfo. L'azlone del mannitolo per vi.
cndovenosa sull'occhio deil'animate (conlelio) normalc c con ipcrtenslone oculare provocata.
Ann Ottal 69:551.65, Oct 63 Leprl G sec Focosi M

ceprleur A sec Legault-Demare

cepukal'n Ai: Prlmencnie clektrofizlologichesklkh dlagnostikl dliti progressivnyk myshechnykh atrofi

FIGURE 3. A page from Index Medieus produeed with the GRACE system. 
established that composition of Index Medicus through to film would take as follows:

$$
\begin{aligned}
& \text { State-of-the-art phototypeset- } \\
& \text { ters } \\
& \text { 1,000---1ine per minute printer-- } 3.5 \text { days }
\end{aligned}
$$

The desired composing time was two days. Thus it was that a basic decision was made to advance the state of the art by going to composing equipment that was not "off the shelf." I believe that if this decision had not been made in 1961 this Symposium might well not be taking place today. Figure 3 shows the input of the existing system.

I would like now to turn to some efforts we in the FDA will undertake, having received the blessing of the Joint Committee on Printing to do so. I must hasten to point out that we are not attempting to develop another MEDLARS nor to compete with the Electronic Composing System of the GPO. Rather we are attempting to set up a system that, while input based, will permit us to produce publications from magnetic tape outputs of the computer.

When the IBM MTST typewriter was first introduced I was bitterly disappointed that its tape was not computer compatible and that its code structure was a nonstandard notation. It seemed to me that in the area of information processing and in preparing bibliographic materials we were losing a bet. The attraction of magnetic tape byproduct of a typing operation is as old as the Unityper of Univac I days. The attraction has existed since 1951 but achievement has been difficult.

Thanks to Yankee ingenuity (if Marylanders can in truth be called Yankees), a bridge to the IBM MTST has been perfected. Also, a bridge between the computer and the fairly recently announced IBM MTSC has been developed.

The coupling devices developed by the DigiData Corporation of Bladensburg, Md., will permit input to the computer on magnetic tape and output from the computer on a magnetic tape which can be used as input to a 15-character-persecond relatively low-cost composer.

This system is a major modification to the design effort initially undertaken by IBM. The input device is a standard IBM MTST IV Recorder. The Digi-Data 1670 Coupler is cable-connected to the MTST. The coupler accepts data from the MTST and records it on seven-track computercompatible tape. The density of writing on computer tape can be either 200 or 556 characters per inch. The coding conversion must be done on the computer at which point the density may be increased to the maximum available on the tape drives of the system.
Some of the keyboarding advantages we see from use of the MTST are as follows:

(1) familiarity of typist with standard keyboard,

(2) the ability to correct errors by magnetic erasure,

(3) the ability to type at draft speed since corrections may be easily made,

(4) visual hard copy,

(5) an error free tape, and

(6) a reusable medium with supply cost implications.

Point 3 is close to my heart. Keypunch speeds range in the area of 4,000 to 5,000 characters per hour with inherent error possibility of up to 3 percent 80 -column record. Correction typically requires repunching an entire card even if but one column is mispunched. The MTST should be able to achieve a speed of 8,000 to 10,000 characters per second. Only the specific characters mistyped must be rekeyed.

Figure 4 illustrates how the input system will facilitate author's revisions with a minimum of rekeying and reproofing.

AUTHORSHIP REVISIONS

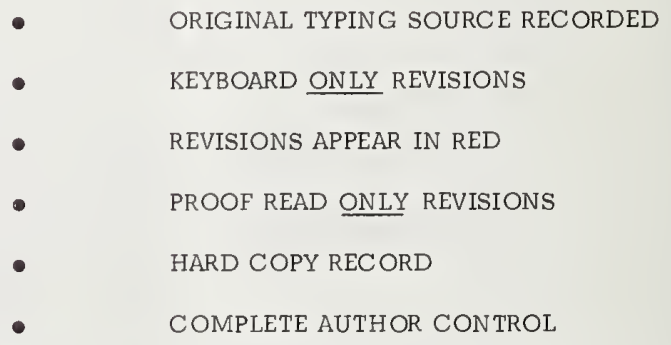

FIGURE 4. Features of GRACE for author's revisions.

Figure 5 brings together the components in the system. As will be noted we have three ways to go to output. The first way is as IBM originally designed the equipment. For data that are not going into the computer for storage, retrieval, or manipulative purposes we will go this route. For major publications that will be on the computer and meet the volume requirements for composing on the Linotron, the system will produce magnetic tape for input to the GPO computer and the Linotron. 


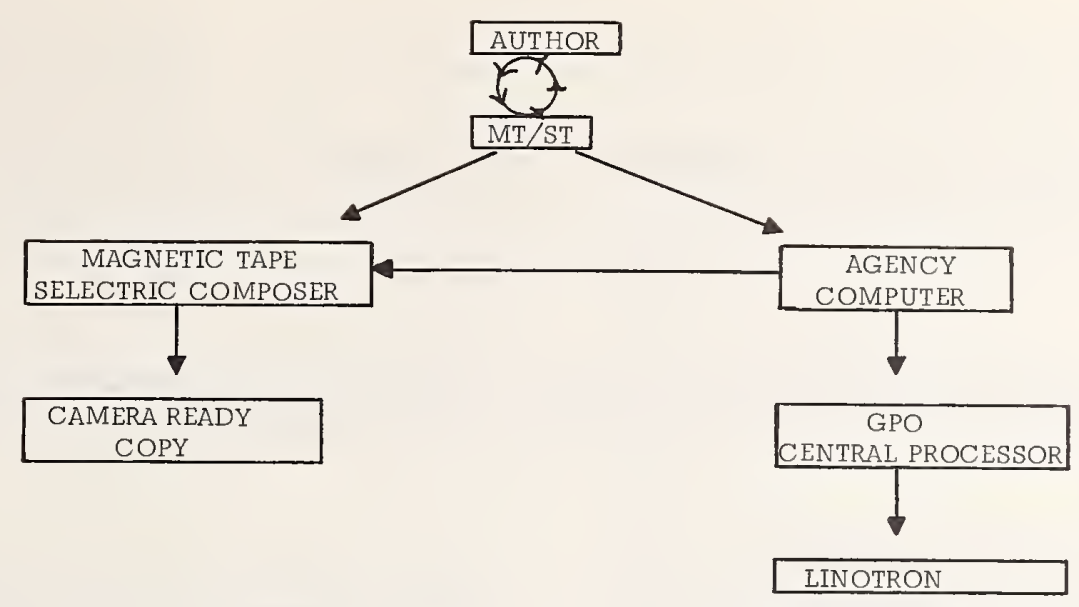

FIGURE 5. Components of the GRACE system.

For publications which are not of volume, e.g., internal issuances, but which may be more economically produced by typographic quality techniques, we will produce camera copy on the MTSC output device shown. A coupler to the MTSC which permits computer-compatible tape to be translated to the notation and tape of the MTSC makes this feasible. At this juncture we do not profess to have the data requisite to make decisions on break-even points. We believe that there will be logical break-even points that will dictate the most economic method of production.

The general characteristics of the input station are

(1) automated revision typing,

(2) automated general typing,

(3) tape cartridge storage,

(4) input to the composer, and

(5) input to the computer.

Below are summarized some of the features of the total system:

1. It may be used to prepare input for the GPO system at significant savings in keying time and time required to get a fast machine-processible medium.
2. It may be used as designed originally as a cold composition system with considerable flexibility.

3. It may be used directly for editorial insertions in cold composition processing.

4. We have the ability to convert files hitherto prohibitively expensive to magnetic media.

5 . We can store data in various forms of computer storage, e.g., disks and cells as a byproduct of typing operations.

6. Our investment in supplies will be minimized by having a reusable medium.

Still another advantage, which I feel strongly about, is that we will be freed of the tyranny of paper tape.

The purchase price of the total system from Federal Supply Schedule, FY 1966, breaks down as follows:
Couplers
$1 @ \$ 4,600$
Couplers
$1 @ \$ 8,500$
Total
$\$ 13,100$
MTST Recorder Model IV \$9,535
MTSC
$\$ 12,700$

Total cost for a three-way system would be $\$ 35,335.00$. 


\title{
Electronic Composing System Applications
}

\author{
John J. Boyle
}

\section{Special Assistant to the Production Manager for Electronic Printing, U.S. Government Printing Office}

You have heard the Public Printer and the Staff Director of the Joint Committee on Printing explain how and why the Gorernment Printing Office entered the field of computer composition.

This afternoon I would like to talk about some of the accomplishments of the past four years. What have we learned? What type of work appears to be most practical by this method? What are some of the problems that were encountered and what problems do we see in the future?

Four years ago, there were no available composition programs for the IBII 1401 computer. We had on our staff trained 1401 programmers, and computer time available to do a limited amount of composition, so a decision was made to write computer typesetting programs for Linofilm and linecasting machines utilizing available computers.

Mergenthaler at the time had started to write a Linofilm program and we used this as a nucleus to adapt to the specific needs of Government publications. IBM had a typesetting program for the 1620 , and with their help, the logic was used to write a 1401 hot-metal composition program.

We supplemented our programming staff with four compositors and trained them in computer programming so that they could work and communicate with programmers unfamiliar with printing problems and printing terminology. This approach proved to have merit and we believe the Printing Office has a team of programmers for printing with a knowledge of Government publications, typsetting machine limitations, and program adaptability that will prove invaluable as we advance into the area of electronic composition.

Our feeling was that typesetting programs should be written so that any style or format could be produced by the computer, within the limitations of the typesetting machine, by very simple changes in the instructions or parameters, or by codes introduced into the input.

This is the ideal. In practice this theory does not always work. Regardless of the knowledge of composition and its variables, each new job will create problems in a master composition program that require additional programming and debugging. In order to get into production we decided to find a publication that had an application and solve the problems one at a time.

The Library of Congress Subject Meadings, Seventh Edition, was our pilot project in computer composition. This 1400-page book, containing 326,000 lines, had for many years been produced by hot metal or Linotype, corrections being inserted into standing type. Additions and changes to the previous edition had been issued monthly as cumulative supplements and this type was also held in storage.

When the Library of Congress decided that it would be necessary to print a new edition of this book with all of the cumulative changes of the previous six years inserted into the basic edition, we were faced with the job of removing 1,368 pages from type storage and manually inserting 86,000 lines of additions, corrections, and deletions.

We felt that this job was a natural for a computer system and with the cooperation of the Library of Congress the necessary programming was started so that we could convert the material to magnetic tape files.

The sixth edition was used as basic copy and all of the cumulative supplement material was keyed into its proper place to create manuscript copy. In our study of the type style we identified 29 variations in line indentions, type faces, or type sizes. Each of these line styles was assigned a specific code which the computer could later identify.

The manuscript was converted to paper tape in TTS code on the Justow riter perforators. The line identifier, which consisted of a precedence code and an alphabetic code, preceded the actual data. This paper tape was converted to magnetic tape on the converter.

Each batch of magnetic tape, which for ease of handling was held to 100 galleys, was processed 
through the computer using a file organization program written specifically for this purpose. The file organization program translated the TTS code to $\mathrm{BCD}$, blocked the data in suitable record lengths, and assigned a line identification number or locator to each entry. The file was then listed on the computer printer to create a proof. This proof was read, corrections were keyboarded on the perforators, corrections were converted to magnetic tape, and the locators on each correction were used by the computer to correct, insert, or delete a line in the original magnetic tape to create a clean tape.

This magnetic tape was then processed on the computer which had been programmed with the Linofilm composition program to produce a new magnetic tape written in the language of the phototypesetter.

The Linofilm magnetic tape was converted to 15-channel paper tape which was used to drive the photo unit and produce galley paper positives. The positives were pasted up into 3 -column pages for camera, negatives were made, and the Seventh Edition was printed from offset plates.

All of the comparatively short reels of magnetic tape were consolidated in consecutive order upon completion of the composition so that the entire book is now on 3 reels of magnetic tape.

Supplements are produced by the same method, that is, paper tape perforation, computer file maintenance and composition, and photocomposition. The cumulative supplements are maintained as a separate file and will be used to update the basic edition when it becomes necessary to print a new volume.

Now I have described this system very quickly and simply. Several computer programs in addition to the composition program are involved. The cost of converting the data to machine readable language is comparable to resetting in hot metal type. So where is the payoff? How do we save the agency money on this job?

We have 3 reels of magnetic tape instead of tons of metal to store. When we are ready to print the next edition the magnetic tapes of the supplements will update the basic edition at much higher speed and lower cost than a craftsman manually inserting type slugs. The updated magnetic tape will be processed through the Linotron Master Composition Program and the Linotron will produce the new publication in film pages ready for platemaking. Manual composition, some of the proofreading, and manual page makeup will be eliminated. The publication will be produced on a much shorter time schedule and the data will be more current.
Let's look at another early example--the classification index of the Patent Offce Weekly Official Gazette. This index contains the class number, subclass number, and patent number of each patent issued in that week. In addition to appearing in each weekly issue, this index is consolidated and reappears in an annual index. A total of 68,409 patents were issued in 1966.

Prior to computer composition, the weekly index was set on the Monotype, proofread from copy, corrected, made up into pages, proofread again from copy, and corrected. It was then ready for press.

Now where did the copy come from? Back at the Patent Office as a part of the issuance procedure, a keypunch operator punched an 80-column tabulating card which contained the information we wanted to set, plus other information necessary to the Patent Office. The tab cards were listed on the printer and the three fields of information became our manuscript copy.

So what did we do? We duplicated the keystrokes on a Monotype that the operator had already accomplished on the keypunch. We made keyboard errors which had to be corrected and revised. In addition, the 52 issues of weekly indexes were not practical to merge and consolidate by hand and in order to produce the annual index we reset the entire job.

Here was an ideal subject for computer composition. Machine readable data already available. Why reset a job already set? Again with Mergenthaler's help, programs were written so that we eventually were able to put the weekly cards into the computer which assigned column identification to each entry, sorted the lines into columns, and wrote a magnetic tape for Linofilm to produce completely made-up pages ready for offset printing. This sounds like a lot of work for the computer but it takes only a few minutes each week. There is no composition, no proofreading, and no makeup performed manually on this job. At the end of the year the cards are written to magnetic tape, tape is sorted, and the Printing Office reruns the job for the annual. Page costs are less than one-third of the hot-metal rate.

An interesting sidenote to this job is the addition of a new index of patent classifications by State which appears in the weekly Official Gazette. This index by State is produced by simply resorting the cards on a State code which is on 2 columns of the card. Last year for the first time the annual classification index was resorted to produce a cross-index. It is very doubtful if these valuable additions would lave been considered if we had not been able to reduce the cost far below previous methods. 
While we were working on these jobs another very important series of publications was brought to our attention. The Department of Defense Technical Abstract Bulletin and the Commerce Department U.S. Government Research and Development Reports are announcement journals that contain abstracts of documents available in the Defense Documentation Center and the Clearinghouse for Scientific and Technical Information.

The abstracted information was being keyboarded on paper tape perforators for input to the computer to create a base fol information retrieval. As a byproduct of computer input the perforator produced a typescript proof which was pasted up to use as camera copy for offset production.

It was desired to improve the typographic quality of these publications so that they would be easier for the reader to use and, of greater importance, reduce the number of pages because they were getting quite bulky and expensive to print and distribute.

Again, programs were written to edit the material and assign typesetting information which had not been keyboarded in the original perforation. Modifications were made to the composition program to handle this job. We now produce both of theso publications in graphic arts quality, in nearly 40 percent fewer pages over typewriter copy, on a fairly tight schedule every two weeks. There is no rekeyboarding and no proofreading. It would be nice to say we had no trouble in converting these jobs to computer photocomposition but that wouldn't be very interesting. Actually, from the time of the initial study and decision to proceed, it was nearly one year before we were in full production.

I have purposely selected these three publications to point out the flexibility of the input. The Subject Headings was produced from paper tape keyboarded in the Government Printing Office specifically to create a master file for future printing. The Classification Index was produced from an existing tabulating card file without any printing or typesetting information. The Technical $A b$ stract Bulletin and the $U S G R D R$ were produced from a magnetic tape generated by a Univac 1107 computer. We have in regular production a large publication for the Department of the Army which comes from an RCA 301 computer. Magnetic tapes are received regularly from the $\mathrm{Na}$ tional Bureau of Standards IBM 7090 computer at Boulder, Colo.

Some very important work is being done by the Naval Observatory and the Navy Oceanographic Office. We have produced on our Linofilm from furnished magnetic tape some of the most difficult composition that is set. All of the programming, including the Linofilm composition programming, is done by our customer agency. Magnetic tapes are ready for conversion to paper tape when received.

Last year for the first time the Directom of Post Offices was composed on the Linofilm from furnished magnetic tape. This is another illustration of the elimination of standing type and manual correction. The existing master magnetic tape file contains all of the information on each of the city post offices. From this master file we produce a state list of post offices, a county list of post offices, an alphabetical list, and a zip code list, all by resorting on the computer. The 1967 Directory of Post Offices is now in production. The National Zip Code Directory was in part produced this year from the same data. Next year we hope to produce the Zip Code Directory in its entirety on the Linotron.

I could go on for quite some time about specific jobs, each slightly different and each just as interesting as those we have mentioned. Much of the credit for the success we have had is due to those agencies who see the potential and who assign people with the dedication to overcome the early obstacles.

The Linotron hasn't been mentioned up to now because the problem is not that different. If we can produce the right kind of work economically on comparatively slow equipment, this should be sufficient proof that we can show dramatic savings on a machine that is 100 times faster. $\mathbf{A}$ whole new area of computer composition will become feasible with this added spced and reduced character cost.

In summary, I would like to point out that computer composition is not going to solve all of your composition problems. There are many factors involved in assessing the feasibility of any publication for this method. A precise set of rules is impossible to set down at this time. The determining factor must be the cost of conversion from the present method to the new method and the determination whether that cost can be recovered in a reasonable time by savings in other areas.

It has been our experience that considerable time elapses and considerable sums of money are spent before a publication becomes an actuality. Take advantage of the Public Printer's invitation to refer likely publications to us for an evaluation. The chief of your publications division will help you and I know he is interested in using the new processes. Our Electronic Printing Planners have been specially trained to recognize the problems in 
any new job. All they need is information which is readily available in every agency.

Keep these goals in mind and use them as guidelines for the selection of suitable work:

1. Reduction in cost by reduction in bulk of computer printout.

2. Reduction in cost by elimination of rekeyboarding data already in machine-readable language.
3. Reduction in cost by elimination of manually correoting standing type on recurring publications.

4. Improved schedules and more current publications.

5. Improved quality and upgrading of Government publications. 


\title{
Use of GRACE at NLM
}

\author{
Ronald E. Bogart \\ Information Systems Division, \\ National Library of Medicine
}

GRACE (Graphic Arts Composing Equipment) is a high-speed magnetic-tape-driven phototypesetter in use at the National Library of Medicine (NLM) for the production of Index Medicus, NLM Current Catalog, and other recurring bibliographies. GRACE is a prototype developed as a part of MEDLARS (Medical Literature Analysis and Retrieval System), a computer-based pub. lication storage and retrieval system in operation at the Library since January 1964. MEDLARS was developed to apply computer technology to the problem of providing effective bibliographic access to the ever-increasing volume of biomedical literature for the growing number of workers in the health professions.

Currently over 13,000 citations to articles appearing in over 2,300 biomedical journals are added to the MEDLARS computer files each month. These citations are input to the Honeywell 800 computer via punched paper tape produced on Friden Flexowriters. The MEDLARS files can be searched to produce demand bibliographies on highly specific subjects for physicians, scientists, librarians, and research workers as well as to produce the Index Medicus and other recurring bibliographies. MEDLARS uses coordinate indexing and Boolean equations to provide a greater capability than is possible by reference to a printed index or catalog. Currently the Library and its five decentralized search centers are processing approximately 600 searches per month against the file of over a half million citations on magnetic tape. Output for these is printed on tabulating paper or $3 \times 5$ cards rather than on GRACE since they are intended for individual use.

In addition to the MEDLARS citations, over $15,000 \mathrm{new}$ acquisitions cataloged by the Library since January 1966 have been entered into the computer system. These data are not used in the MEDLARS search or publication programs but are used in a separate set of programs known as the Interim Catalog Module to produce the NLM Current Catalog, a bi-weekly listing of the $\mathrm{Li}$ - brary's acquisitions. This publication is cumulated quarterly as well. These same catalog data are used to produce GRACE copy for the production of the $3 \times 5$ cards for the Library's card catalogs.

The output subsystem of MEDLARS is used for the production of Index Medicus and other publications intended for wide dissemination. Among the initial objectives of MEDLARS were: (1) to improve the quality of the Index Medicus while increasing the number of journals indexed for it. (2) to reduce the time required to produce printerready copy for the monthly issues of Index Medicus. (3) to provide for the publication of bibliographies similar to Index Medicus in form but devoted to specialized subject fields.

To meet these objectives, output requirements for publications were specified during the initial design phase. It was decided that an expanded character set would be required, one larger than was available on a standard computer printer. The Library decided that both upper and lower case characters, as well as different fonts and point sizes, were required. Quality of print was important, and there was a definite requirement for volume reproduction. Over 6,000 copies of the $I n$ dex Medicus are printed each month.

In addition, it was desired to minimize the page requirements for each issue. A monthly issue of Index Medicus runs about 600 pages on GRACE, whereas the same publication produced on the computer printer, which was used prior to the installation of GRACE, requires about twice that number of pages, even with a reduction to approximately 68 percent of original size. Needless to say, the quality cannot be compared.

The General Electric Company's Information Systems Operation, under contract to the Library, prepared most of the detailed specifications for the phototypesetter. It was determined that nothing commercially available at that time (1961) would satisfactorily meet the requirements. A decision was made to support the development of a magnetic-tape-driven phototypesetter that would meet these requirements. 
Initial specifications called for a speed of 2.5 lines per second. This requirement was not met. The operating speed of GRACE is approximately 13/4 8-inch lines per second, or for an average sixpoint font, about 300 characters per second. At this speed the 12-inch Index Medicus page takes approximately 1 minute to compose. In addition to speed, the character set, physical size of the equipment, performance requirements, maximum allowable error rates, and various special features were specified.

These specifications were opened for bidding, and an award was made to the Photon Corporation for construction of the prototype machine which they had previously designed and which we call GRACE. This equipment was a developmental model and is therefore unique. The equipment was delivered approximately 1 year later than scheduled, and it was installed at the Library in May 1964. After a period of acceptance testing, this prototype equipment was used for the production of the August 1964 issue of Index Medicus and it has been used since then for various Library publications.

The character set for GRACE consists of 226 printing characters. Each character is represented by an 8-bit code, the other 30 codes being used for a variety of blanks of different widths and control characters related to the software requirements of the system. The output medium is positive film or paper, up to 9 inches in width.

The 226 printing characters are divided between four fonts in three point sizes. The page headings are printed in 14 point upper case bold face. This font is limited to the 26 alphabetics and the period and hyphen. Subject headings are printed in 10point upper case bold face. In addition to the alphabetics and the numbers, a small number of additional special characters are available such as parentheses, hyphen, and comma. The largest segment of the character set is 6-point with both upper and lower case characters in both regular and bold face. A number of special characters are available in the 6-point font, including a small set of diacritical marks that are required for certain languages that are printed in the Library's publications.

The input mechanism is a standard Honeywell magnetic tape drive. The tape is a 9 -channel, $3 / 4$ in width tape, with eight data channels and a parity channel. The density is 400 frames to the inch, with each record on tape representing one line of print on the output. Since the page is printed upside-down, i.e., the last line is printed first, etc., the data must be recorded on the tape accordingly.

GRACE consists of two major components, a control console and a typesetting unit. The control console itself has three major elements. An input converter accepts the signals from the Honeywell tape drive and converts these to the internal codes required for the typesetter. The converted data are stored in a core storage area. Finally, a series of solid state electronics compute the timing of flash signals for the typesetting, or optical unit, where the photographic process itself takes place (fig. 1).

The optical unit houses several major sections. Each of the 226 printing characters is etched onto a glass matrix, the characters on the matrix being four times as large as they will appear on the printed page. Behind each character is a highfrequency flash lamp with a condenser discharging system for firing it. The lamps include a highspeed bulb with a 6 -microsecond flash time. At the opposite end of the optical unit is the film handling assembly, which advances the film from magazines, one line at a time. Between the plane of the film and the matrix of characters is a reciprocating lens assembly. Here a lens sweeps back and forth at a speed of approximately $13 / 4$ sweeps per second, making one sweep for each line to be printed. Between the lens and the film is a set of mirrors to compensate for the optical placement of characters on the matrix. After passing through the lens, the character image is reflected from the two alinement mirrors a number of times depending on the row in which the character appears on the matrix.

Leading is controlled by a manual switch on the control console. This can be varied from 1 to 18 points. In addition there are controls which provide tape searching features. Each record on tape has a report and a page number. 'This allows the operator to dial in this information through a series of knobs on the console. Composition will then begin with this page when in the search mode. Composition of a single page can also be selected. Error indications such as flash errors, parity errors, end of film, etc., are also displayed on the control console.

Input to MEDLARS and the Interim Catalog Module is prepared on Flexowriters which produce an 8-channel paper tape. Upper and lower case indicators and field indentifiers arc input with the data. All of the formatting, selection of type size, selection of regular or bold face, etc., arc controlled by the computer programs. A given data element always appears in a fixed font. The system was designed to meet the specific requirements of the Library's publications, and we do not have general purpose typographic programs.

When a publication is scheduled for production, : search of the appropriate part of the file is processed to retrieve the citations dealing with the de- 


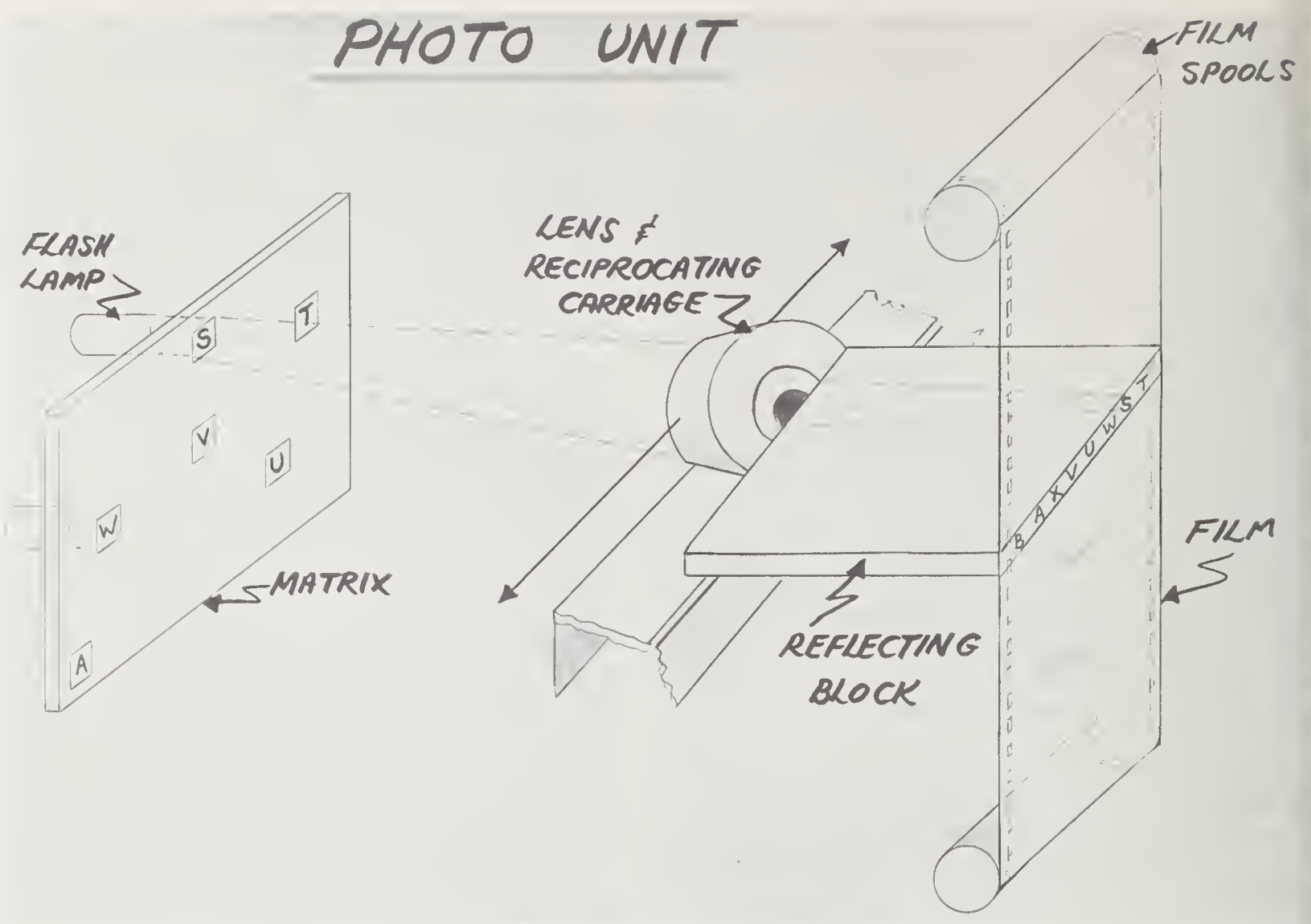

Figure 1. Components of the GRACE system.

sired subject area. These citations are then formatted into lines of GRACE characters, each line being the width of one column on the final output. In the case of Index Medicus, a search of the file is not necessary since all citations input during the previous month are selected for inclusion. A partial margin justification is accomplished by varying the inner word spacing on the lines. The citations are then expanded under the various headings which have been attached to it on input and the data are then sorted.

The page composition is the final step in the preparation of the input tape for GRACE. The citations are assembled into a 1-, 2-, or 3-column format, with the inner column space inserted. Page headings, running headings, subject headings, and page numbers are inserted by the program at this time. Once a complete page has been constructed in memory, it is recorded one line at a time onto the magnetic tape.

After processing on GRACE, the exposed film is processed by a Kodak Versamat processor. The developed film then is sent to a quality control station for inspection, is cut into page-size sheets, and packaged for delivery to the printer.

Starting with August 1964, all monthly issues of the Index Medicus have been processed on GRACE. In addition, the annual cumulations, each consisting of approximately 6,000 pages with references to about 160,000 articles, have been produced. The biweekly issues of the Current Catalog and all cumulations have also been produced. At present, recurring bibliographies produced include the Bibliography of Medical Reviews, Cerebrovascular Bibliography, Index to Dental Literature. International Nursing Index, Index to Rheumatology: Artificial Kidney, Fibrinolysis, Thrombolysis and Blood Clotting Bibliography, and Medical Education. Several others, such as Adrenal Cortex and Toxicity, are in various formative stages. The frequency of publication varies from biweekly for the NLM Current Catalog to quarterly for the Cerebrovascular Bibliography and the Index to Dental Literature. Most of these 
publications have cumulations produced as well. There are some obvious limitations to the GRACE equipment. For example :

1. The character set is limited. More than the 226 characters in this system would be required by a large general printing establishment. In addition, no graphic capability exists.

2. Speed is a limiting factor. By computer standards, 300 characters per second is quite slow.

3. Accuracy of character placement is imperfect. Close examination of our copy will reveal that it does not approach letterpress quality.
4. Programming is very complex, and a major investment in writing of programs is required.

In the 32-month period from August 1964 through March 1967, GR.ACE has been used to produce over 130,000 pages. Total production time is over 2,300 hours. We are presently using the equipment over 100 hours per month for production running not including setup time. Total usage is substantially more than this. A programming effort is presently underway which will allow for processing of publications on the Photon 901, the commercial version of GRACE, which will be used as backup to GRACE. 


\title{
Computer Typesetting Program at NBS \\ William R. Bozman
}

\author{
Inorganic Materials Division, \\ National Bureau of Standards
}

As I believe many of you already know, the National Bureau of Standards is very much interested in the problem of collecting and publishing standard reference data in a great variety of scientific and technical subjects. Much of this information will be processed through computers. In the past few years a large proportion of the output of computers has been published by using the computer printouts as camera copy for offset printing. This frequently has led to publications of substandard quality, having nonstandard symbols, inferior typography, and poor readability. Often these publications have been quite bulky, requiring more paper, more printing press and binding labor, more bookshelf space to store, and greater shipping costs.

However, in many cases this expedient has been necessary, mainly because of printing deadlines or of cost. It is hoped that some of these new developments we have been hearing about will remedy the situation so that the output of all computer-calculated or processed data can be published with all the special symbols and variations of typography necessary for good legibility, easy readability, and no more bulk than necessary.

So much for the output, now what about input?

Once these new developments in hardware and software have enabled us to publish from the computers at high speed, where will the bottleneck develop? I think the problem is already here. It is in keyboarding.

Although there are some computing jobs that require very little input keyboarding, such as the calculation of mathematical tables, the great bulk of our scientific and technical publications require a sizable amount of input keyboarding.

I am working on the computer programming for a job here that has been requiring a large amount of keyboarding - one of our people, Mrs. Eula M. Lawson, has spent about two years on it.

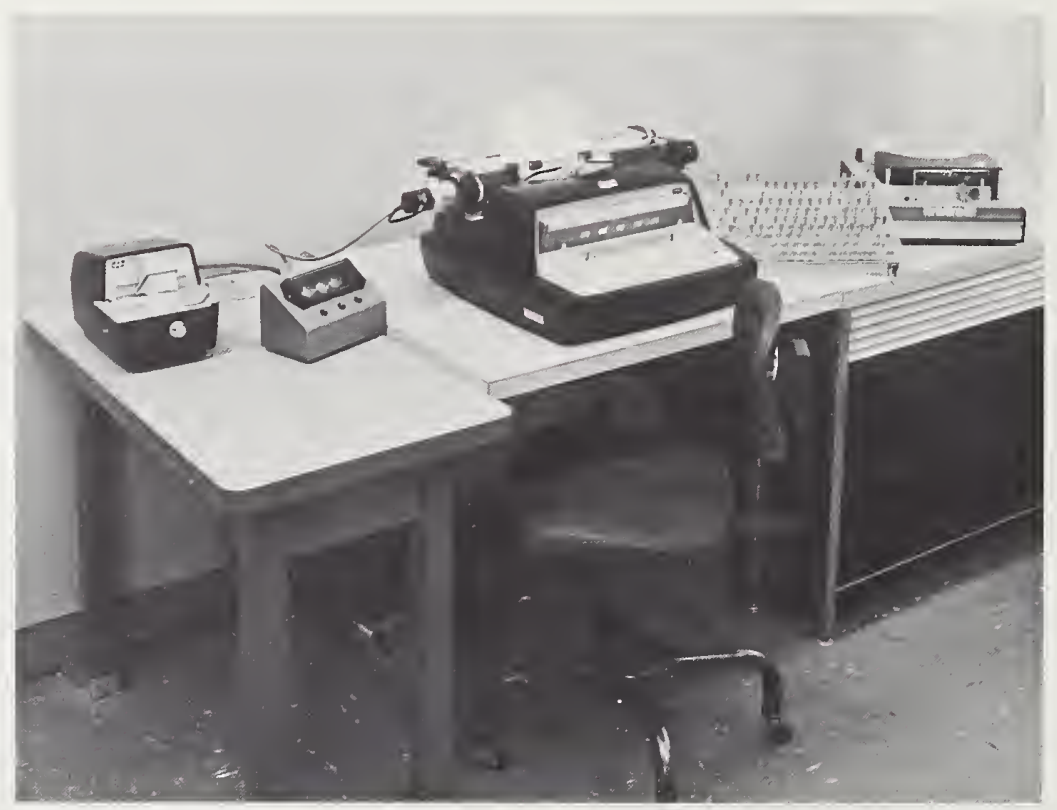

Figure 1. "Taxywriter," an electrie typewriter capable of printing special eoded eharaeters and punehing the eodes into paper tape. 
But before I describe that work I'd like to tell you about a keyboard which Blanton Duncan and Al Weissberg here at NBS, and others, have developed (fig. 1). This consists of an electric typewriter which has been modified so that special symbols can be typed in the insertion of any one of a set of small plastic handles containing a type character. These special typewriter symbols are in fairly widespread use; you have probably seen them. The thing that is special about this typewriter is that these "Typits," as they are called, are coded by pins placed in the sides so that the information can be read by small switches and can be punched into a paper tape at the same time that the symbol is being typed onto the hard copy.

Up to four pins can be placed in each side of a "Typit," giving an 8-level code. When a key is struck with a "Typit" in place, a precedence code is automatically punched, the code for the particu- lar symbol is read and punched, and a code returning to the normal mode is automatically punched.

Another feature of this typewriter is that the rotation of the platen is also punched into the paper tape. As shown in figure 2, the end of the platen has an encoder attached. This is particularly useful when typing mathematical or chemical formulas. The typist can make up the formula in whatever order seems most convenient, rotating the platen up or down, as needed. Since the information is all punched into the paper tape, the computer can reconstruct the formula line-by-line, if necessary, for the final typesetting.

Also shown in this slide is a small box containing three nixie tubes which are used to display the numerical code of the "Typit," when reading back a punched paper tape. When the tape reaches a place which calls for one of the special symbols, the coded number for that particular symbol is shown

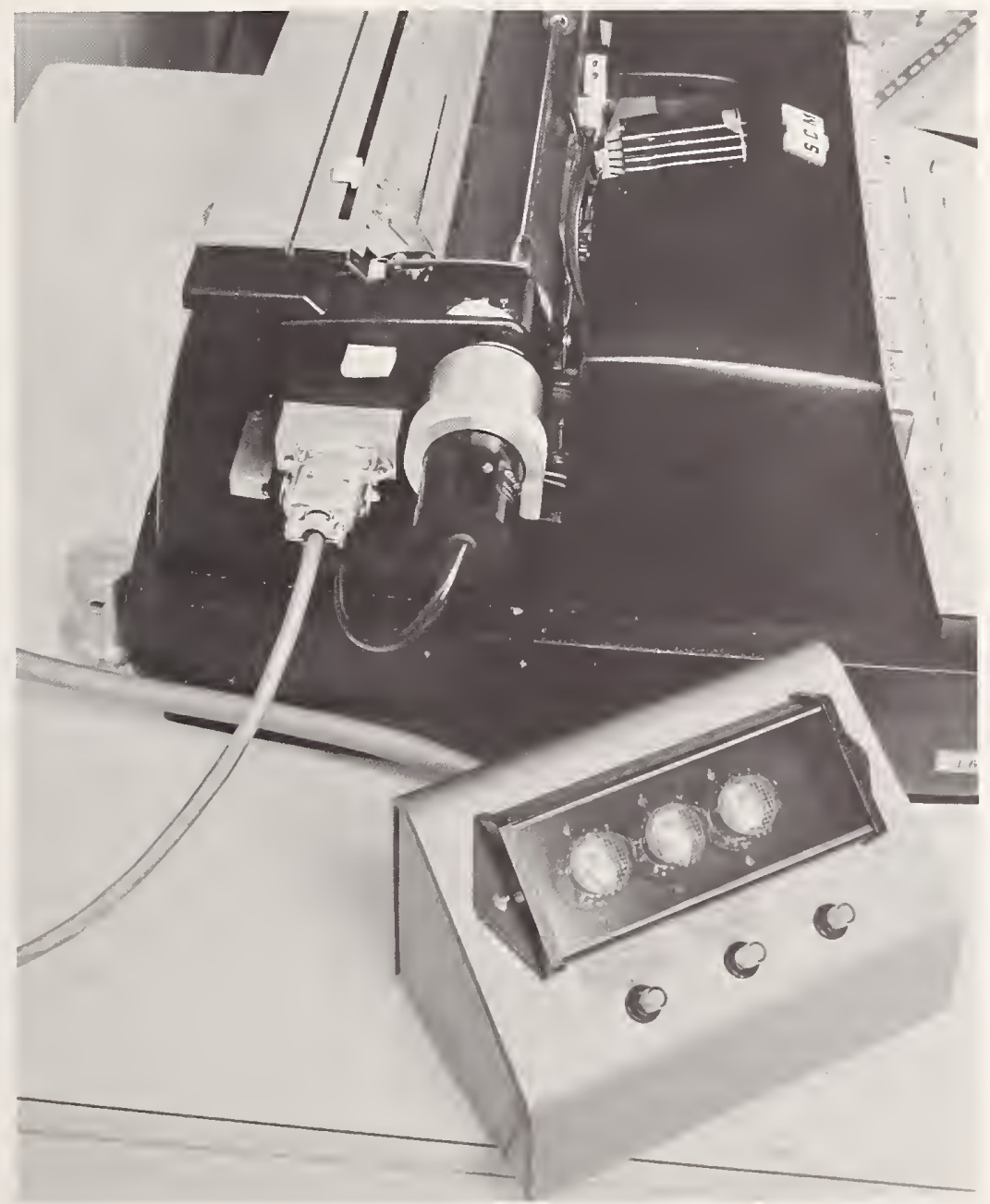

Figure 2. A elose-up of the Taxywriter showing the platen rotation scnsor and the Typit code display unit. 


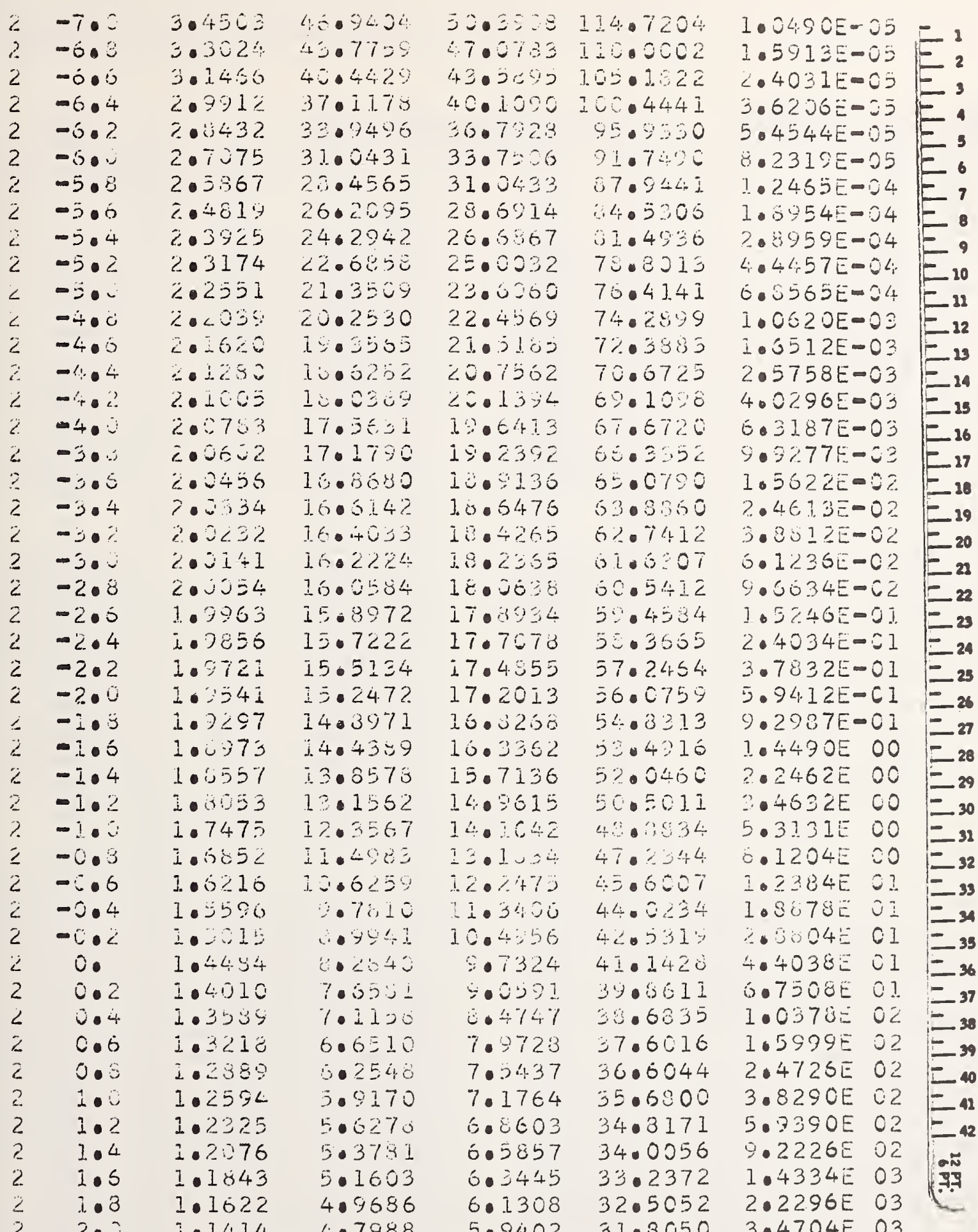

FIGURE 4. Sample of a eomputer produed page of data-one of several of poor quality. 
TABLE 1. Transition probabilities of copper

\section{Wavelength} A

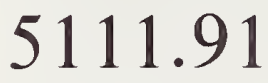

5144.12

5200.87

5352.67

5354.95

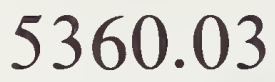

5376.87

5391.62

5432.05

5463.14
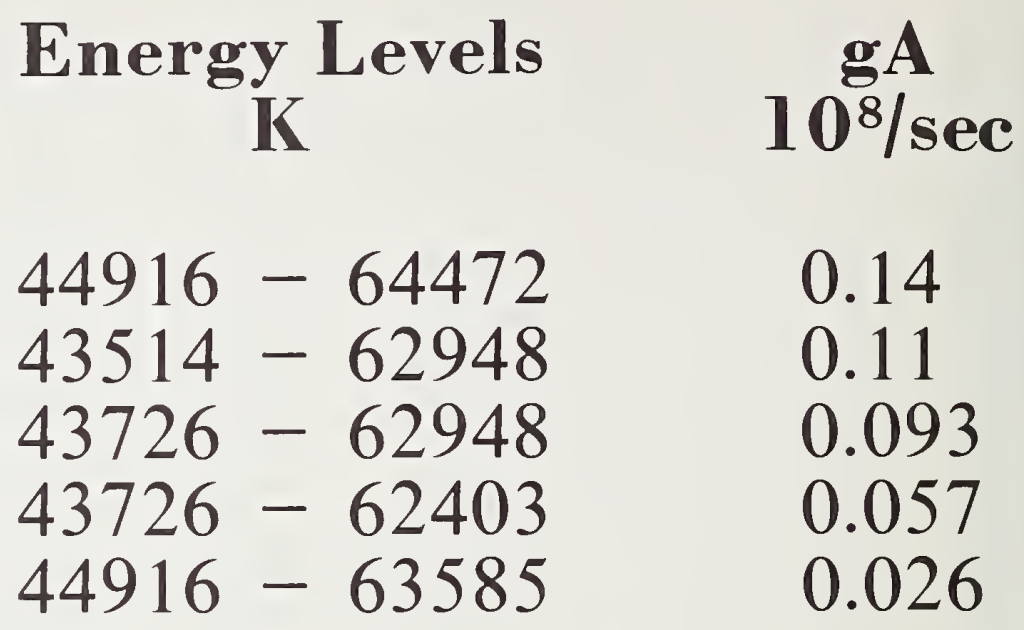

0.14

0.11

0.093

0.057

0.026

FIGURE 5. Sample of a phototypeset page-characters are sharp even when magnified.

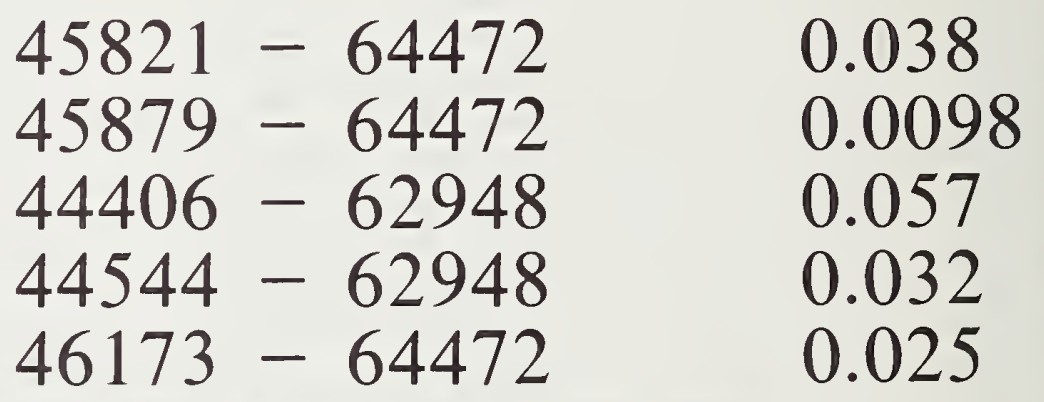

Original in 10-pt. type size.

on the nixies. 'The operator can then place the correct symbol in the typewriter, type that character, and start the automatic typing process again. I think that this method of keying-in special characters shows a lot of promise. It gives a hard copy with the actual symbol shown, it is easy to learn to use, and it is capable of handling a large number of special symbols.

Now I would like to tell you about some of the work with which I have been involved more directly. Figure 3 shows a sample of a printed page with a pica scale placed on the right hand edge to show the type size. This slide is fairly typical of the result when computel printout is used as camera copy for offset printing. It is fairly legible, although some broken and ragged figures are apparent. Sometimes, however, the result is quite poor, as shown in figure 4 . Here some of the figures are barely discernible, even though the page was printed in 12 point type size.

Figure 5 shows a portion of a page from one of our computer-prepared phototypesetting jobs of a few years ago. Not only could we use both upper and lower case alphabetic letters and any special characters we needed, but also the type is much more legible, in spite of the fact that it is set in 10-point type, two points smaller than the previous sample shown.

Figure 6 shows a poor example of using computer printout as camera-ready copy for publishing. In this case the information is there, but it is very difficult to use. This is a page from a set of tables that was being used by some of our people. It was brought to my attention by one of the users who was having trouble reading it and knew I was interested in trying to improve such things. I could go into a long explanation of what is wrong typographically with this page, but I think you can see for yourselves.

Now I would like to show you a sample of the input and of the output of the job that I am working on at the present time. Figure 7 shows a few entries from a forthcoming two-volume set of Crystal Data Determinative Tables, which will give information on over 25,000 different crystalline materials, both organic and inorganic. 


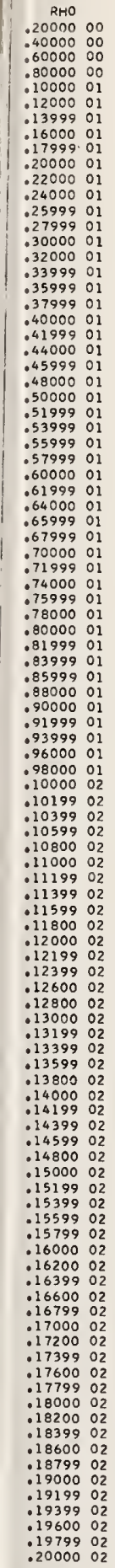

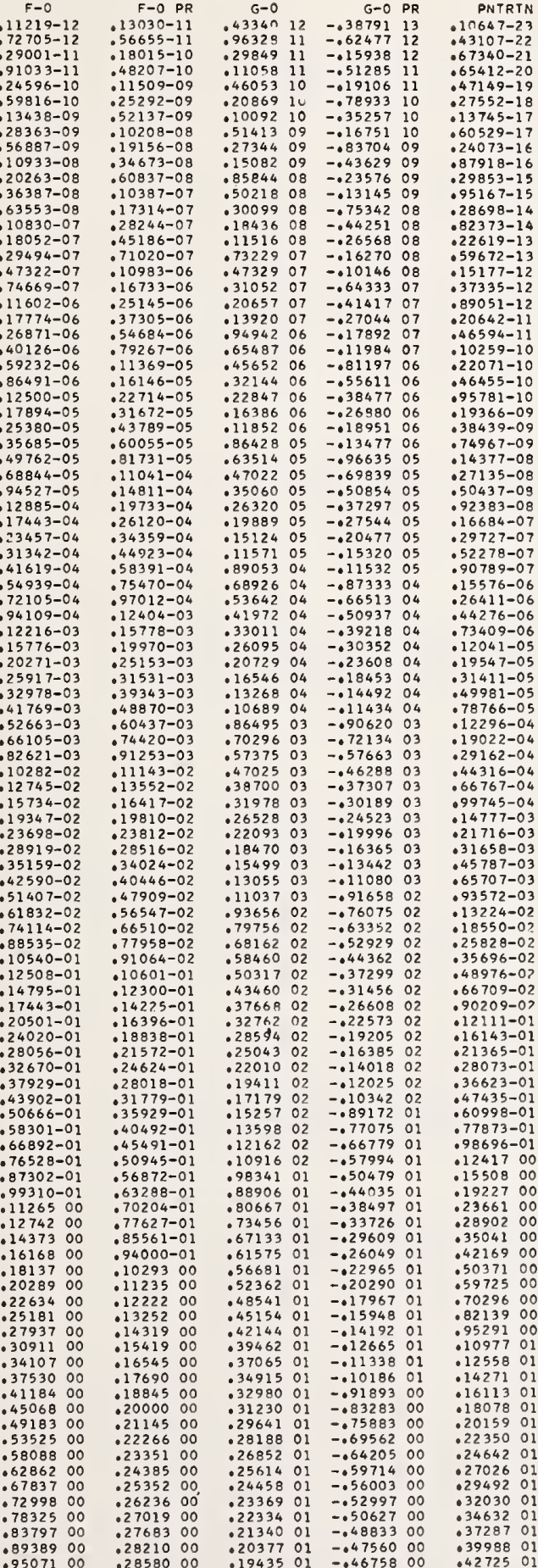
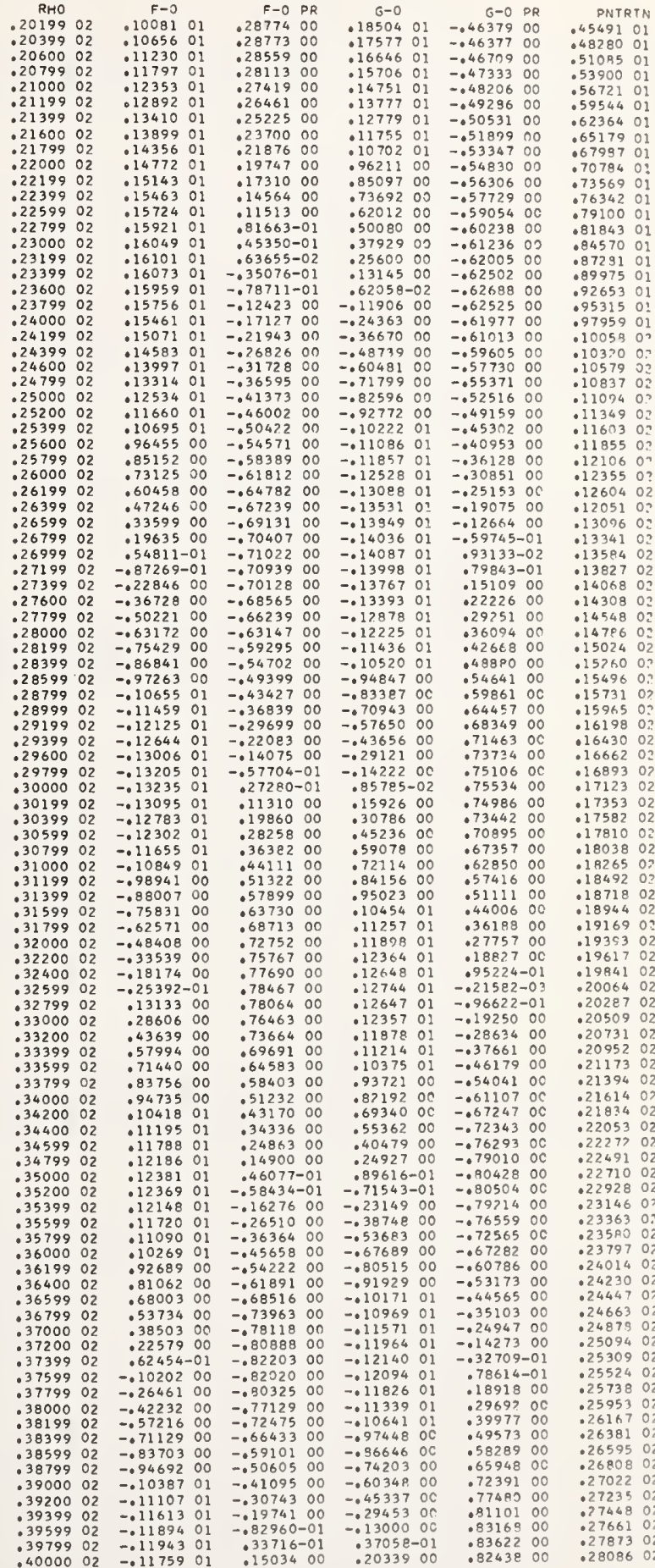

FIGURE 6. Sample of a computer produced page of data which is too crovded for good readability. 
***A,ED, NM,IN, 000450

Nitryl hydrogen sulfate $(1 \cdot 1 \cdot 2 \cdot 7)$

$\&$ Nitronium pyrosulfate

$\begin{array}{lllllllllll}\& \& \& .9621 & .6584 & 8.11 & 8.43 & 5.55 & \text { P } \bar{l} & 2 & \text { quant. } & 2.15 & 2.13\end{array}$

$108^{\circ} 24^{\prime} \quad 97^{\circ} 36^{\prime} 81^{\circ} 42^{\prime}$

Nitryl hydrogen pyrosulfate (nitronium pyrosulfate), $\mathrm{NO}_{2} \mathrm{HS}_{2} \mathrm{O}_{7}$ (Steeman \& MacGillavry, Acta Cryst. $\left.7,402,1954: 8.11 \pm 10,8.43 \pm 10,5.55 \pm 10 ; 71.6^{\circ} \pm 10,82.4 \pm 10,81.7^{\circ} \pm 10\right) \overline{1} 00 / 0 \overline{1} 0 / 001$.

Colorless. In parallelepipeds; acicular c or b. Very hygroscopic. [Dm 2.18, Dx. 2.09 in SR

XVIII, 487.]

***A,ED,NM,OR,000401

$\mathrm{C}_{8} \mathrm{H}_{20} \mathrm{CdCl}_{2} \mathrm{~N}_{4} \mathrm{~S}_{4}$

\&\&\&.9622 $\quad .9219 \quad 8.12 \quad 8.44 \quad 7.78 \quad \ldots .1$ none $1.81,20^{\circ} 1.73$

$117^{\circ} 22^{\prime} 91^{\circ} 36^{\prime} 98^{\circ} 43^{\prime}$

Tetrakis thAoacetamide cadmium chloride, $\mathrm{Cd}\left(\mathrm{SCNH}_{2} \mathrm{CH}_{3}\right)_{4} \mathrm{Cl}_{2}$ (Nardelli \& Chierici, Gazz. Chim. Ital. 87, 1478, 1957: 7.78, 8.12, 8.45; 79. $\left.8^{\circ}, 62.5^{\circ}, 88.4^{\circ}\right) 010 / 101 / 100$. Colorless,

yellow if impure. Short prismatic.

***A,ED, NM,IN,000402

Potassium zinc vanadate $(2 \cdot 2 \cdot 10 \cdot 28)$ 16-hydrate

$\begin{array}{lllllllllll}\& \& \& .9633 & .7851 & 10.76 & 11.17 & 8.77 & \mathrm{P} \overline{1} & 1 & \text { none } & \ldots & \ldots\end{array}$

$104^{\circ} 50^{\prime} \quad 109^{\circ} 29^{\prime} \quad 65^{\circ} 05^{\prime}$

Potassium zinc decavanadate 16-hydrate, $\mathrm{K}_{2} \mathrm{Zn}_{2} \mathrm{~V}_{10} \mathrm{O}_{28} \cdot 16 \mathrm{H}_{2} \mathrm{O}$ (Evans et al., Am. Mineralogist, $40,315,1955) 100 / 010 / 001$.

***A,ED,NM,OR,000403

$\mathrm{C}_{5} \mathrm{H}_{8} \mathrm{O}_{2}$

$\begin{array}{lllllllllll}\& \& \& .9636 & .6793 & 7.42 & 7.70 & 5.23 & \text { P } & 2 & \text { qual, } & 1.163 & 1.162\end{array}$

$105^{\circ} 30^{\prime} 96^{\circ} 92^{\circ} 18^{\prime}$

Tiglic acid, $\mathrm{C}_{5} \mathrm{H}_{8} \mathrm{O}_{2}$ (Porte \& Robertson, Nature, 176, 1116, 1955; J. Chem. Soc. ,17, 1959:

$\left.7.70 \pm 2,5.23 \pm 2,7.42 \pm 2 ; 96^{\circ} \pm 1,87.7^{\circ} \pm 10,74.5^{\circ} \pm 10\right) 00 \overline{1} / 100 / 0 \overline{1} 0$. Thick acicular.

***A,ED, MI,IN,000448

Sodium aluminum silicate $(1 \cdot 1 \cdot 3 \cdot 8)$

$\begin{array}{lllllllllll}\& \& \& .9636 & 9271 & 7.437 & 7.719 & 7.156 & \text { P } & 2 & \text { quant. } & 2.621 & 2.623\end{array}$

$107^{\circ} 22^{\prime} \quad 100^{\circ} 21^{\prime} \quad 115^{\circ} 05^{\prime}$

Albite (low temp. form) (sodium alumino-silicate), $\mathrm{NaAlSi}_{3} \mathrm{O}_{\underline{\underline{b}}}$ (Ferguson et al., Acta Cryst. 11, 331, 1958: 8.138, 12.789, 7.156; $\left.94^{\circ} 20^{\prime}, 116^{\circ} 34^{\prime}, 87^{\circ} 39^{\prime} ; C_{1} 1 ; Z 4\right)^{1 / 2}-1 / 20 / 1 \frac{1}{2} 1 / 20 / 001$. From Little Tree Mine, Ramona, San Diego County, California. Cleavage (110) and (001). Opt. pos.: 1.528, $1.532,1.538 ; 2 \mathrm{~V}_{\text {calc. }} 78^{\circ} 33^{\prime} ; 2 \mathrm{~V}_{\text {meas. }} 75^{\circ}, 80.5^{\circ}$ (Emmons, 1953$)$. Extinction on $(\overline{1} 10)+2112^{\circ}$, on $(001)+4^{\circ}$. Cp. 0.9647 .

***A,ED,NM,OR,000404

$\mathrm{C}_{12} \mathrm{H}_{36} \mathrm{CoN}_{14} \mathrm{O}_{12}$

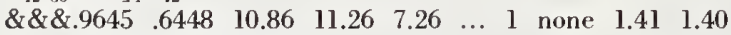

$102^{\circ} 36^{\prime} 106^{\circ} 30^{\prime} 110^{\circ} 54^{\prime}$

Hexakis (N-methylurea) cobalt(II) nitrate, $\mathrm{Co}\left[\mathrm{OC}\left(\mathrm{NH}_{2}\right) \mathrm{NHCH}_{3}\right]_{6}\left(\mathrm{NO}_{3}\right)_{2}$ (Nardelli \& Coghi, Ric. Sci. $\left.29,134,1959: 7.26,10.86,11.26 ; 110.9^{\circ}, 102.6^{\circ}, 106.5^{\circ}\right) 010 / 001 / 100$.

***A,ED,MI,IN,000449

Sodium aluminum silicate $(1 \cdot 1 \cdot 3 \cdot 8)$

(Taylor et al., Z. Krist. 87, 479, 1934): 8.14, 12.86, 7.17; $94^{\circ} 03^{\prime}, 116^{\circ} 29^{\prime}, 88^{\circ} 09^{\prime}$; Dm 2.619.

For ca. $\mathrm{Ab}_{45} \mathrm{An}_{55}$, after heat treatment, Cole et al. report an I-cell with 8.1648, 12.8585, $7.0973 \times 2 ; 93^{\circ} 33.7^{\prime}, 116^{\circ} 05.8^{\prime}, 89^{\circ} 47.1^{\prime}$. Cp. 0.9636 .

***A,ED,NM,OR,000405

$\mathrm{C}_{12} \mathrm{H}_{36} \mathrm{Br}_{2} \mathrm{~N}_{12} \mathrm{O}_{6} \mathrm{Zn}$

$\begin{array}{llllllllll}\& \& \& .9649 & .6697 & 10.46 & 10.84 & 7.26 & \ldots & 1 & \text { none } & 1.60 & 1.62\end{array}$

$102^{\circ} 54^{\prime} \quad 108^{\circ} 42^{\prime} 109^{\circ} 18^{\prime}$

Hexakis (N-methylurea) zinc bromide, $\mathrm{Zn}\left[\mathrm{OC}\left(\mathrm{NH}_{2}\right) \mathrm{NHCH}_{3}\right]_{6} \mathrm{Br}_{2}$ (Nardelli \& Coghi, Ric. Sci. 29, $\left.134,1959: 7.26,10.46,10.84 ; 109.3^{\circ}, 102.9^{\circ}, 108.7^{\circ}\right) 010 / 001 / 100$.

***A,ED, NM,IN,000461

Nickel molybdo silicate $(2 \cdot 1 \cdot 12 \cdot 40)$ 18-hydrate

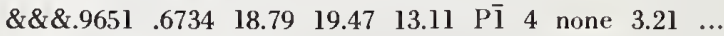

$92^{\circ} 02^{\prime} 107^{\circ} 22^{\prime} 87^{\circ} 29^{\prime}$

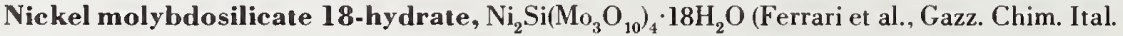
81, 47, 1951: 19.44, 13.11, 19.47; $92^{\circ} 02^{\prime}, 91^{\circ} 04^{\prime}, 112^{\circ} 42^{\prime}$; (a:b:c) gon $\left.=0.747: 1: 0.746\right)$

$\overline{1} 10 / 001 / 010$. Bright green. Isotypic with the tungstosilicates.

FIGURE 7. Input data as keyboarded for a computer data processing job. 
ANORTHIC

\begin{tabular}{|c|c|c|c|c|c|c|c|c|c|}
\hline$a / b$ & $\mathrm{c} / \mathrm{b}$ & $\begin{array}{l}\mathrm{a} \\
\alpha\end{array}$ & $\begin{array}{l}\mathrm{b} \\
\beta\end{array}$ & $\begin{array}{l}\mathrm{c} \\
\gamma\end{array}$ & Sp. gp. & Z & Structure & $\mathrm{Dm}$ & Dx \\
\hline 0.9967 & 0.6572 & $\begin{array}{l}14.33 \\
91^{\circ} 30^{\prime}\end{array}$ & $\begin{array}{l}14.38 \\
107^{\circ} 13^{\prime}\end{array}$ & $\begin{array}{l}9.450 \\
115^{\circ} 0^{\prime}\end{array}$ & $\ldots$ & 8 & none & 1.38 & 1.39 \\
\hline
\end{tabular}

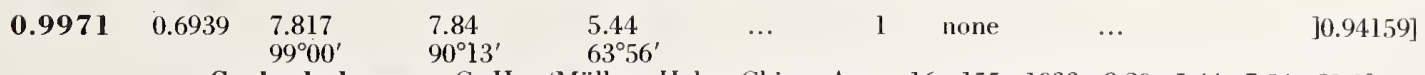

Cyclo-dodecane, $\mathrm{C}_{22} \mathrm{H}_{24}$ (Müller, Helv. Chim. Acta, 16, 155, 1933: 8.29, 5.44, 7.84; 81.0 , , $\left.81.7^{\circ}\right) 10 \overline{1} / 00 \overline{1} / 010$. At $20^{\circ}$. One of "the three most probable cells". Cp. 0.9975 . Cp. M - 1.6027. $\left.81.0^{\circ}\right) 00 \overline{1} / \overline{1} 00 / 010$. At $20^{\circ}$. One of "the most probable three cells". Very volatile. Erratu u u u u $\quad$ mmmmm r r r SB III, 748); $\gamma$ given as $80.0^{\circ}$. Another cell given is: 7.82 7.84, 5.44; $99^{\circ} 05^{\prime}, 98^{\circ} 18^{\prime}, 103^{\circ} 58^{\prime}$ (id., ibid.: 8.81, 5.44, 7.82; 81.7 $\left., 72.3^{\circ}, 61.5^{\circ}\right) 001 / 110 / 010$. Cp. 0.9971 . C.p. $\mathrm{M}-.6027$.

$\begin{array}{lll}8.62 & 8.64 & 5.65 \\ 95^{\circ} 13^{\prime} & 108^{\circ} 57^{\prime} & 63^{\circ} 14^{\prime}\end{array}$
6.65
1 none
1.74
1.77

bis-Ethylene thiourea cobalt thiocyanate, $\mathrm{C}_{4} \mathrm{H}_{12} \mathrm{CoN}_{6} \mathrm{~S}_{4}$ (Nardelli \& Chierici, azz. Chim. Ital.

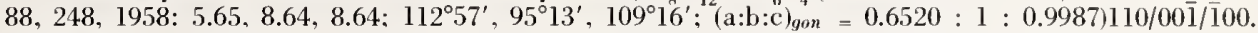
Reddish brown. Short prismatic. Pleochroic. Isostructural with $\mathrm{Mn}$ and $\mathrm{Ni}$ compouds.

$$
\begin{array}{lll}
8.68 & 8.69 & 5.64 \\
95^{\circ} 23^{\prime} & 108^{\circ} 41^{\prime} & 113^{\circ} 34^{\prime}
\end{array}
$$

1 none

1.77

1.76

bis-Ethylene thiourea nickel thiocyanate, $\mathrm{C}_{4} \mathrm{H}_{10} \mathrm{~N}_{\mathrm{NiS}}$ (Nardelli \& Chierici, azz. Chim. Ital. 88, 248, 1958: 5.64, 8.68, 8.69: 113 34', 95 $\left.23^{\prime}, 108^{\circ} 41^{\prime} ;(\mathrm{a}: \mathrm{b}: \mathrm{c})_{\text {gon }}=0.6493: 1: 1.0014\right) 010 / 001 / 100$. Greenish brown. Tabular. Pleochroic. Angles by goniometry; $\mathrm{d}(111)=4.50 \pm \mathrm{d}(100)=7.32 \pm 1, \mathrm{~T}(011)=$ $10.73 \pm 1$. Isostructural with $\mathrm{Mn}$ and Co compounds.

0.9989

$\begin{array}{llll}0.9869 & 9.18 & 9.19 & 9.07 \\ & 101^{\circ} 12^{\prime} & 110^{\circ} 30^{\prime} & 92^{\circ} 24^{\prime}\end{array}$

P̄̄ $\quad 2$ quant. $\quad 2.09$

]2.1147]

Phosphorus sulfide, $\mathrm{P}_{4} \mathrm{~S}_{10}$ (Vos \& Wiebenga, Acta Cryst. 8, 217, 1955: 9.07 $\pm 4,9.18 \pm 5,9.19 \pm 5$; $\left.92^{\circ} 24^{\prime} \pm 30,101^{\circ} 12^{\prime} \pm 30,110^{\circ} 30^{4}\right) 010 / 001 / 100$. Mp $286-290^{\circ}$.

1.0000

$\begin{array}{llll}0.5792 & 18.3 & 18.3 & 10.6 \\ & 96^{\circ} 38^{\prime} & 96^{\circ} 35^{\prime} & 113^{\circ} 21^{\prime}\end{array}$

Enigmatite (iron(II) titano-silicate), $\mathrm{Fe}_{7} \mathrm{TiSi}_{6} \mathrm{O}_{21}$ (Gossner \& Mussgnug, Zentr. Mineral. Geol. Paläont. A5, 1929)100/010/001. From Greenland. Angles from goniometry. With transformation $0 \overline{1} 0 / \overline{1} 00 / 00 \overline{1}$, interchange $\alpha$ and $\beta$. Formla from SB 1I, 579.

1.0000

$$
\begin{array}{lll}
6.85 & 6.85 & 6.47 \\
100^{\circ} 24^{\prime} & 100^{\circ} 24^{\prime} & 90^{\circ} 30^{\prime}
\end{array}
$$

Nitrogen selenide (Selenium nitride), NSe (Bärnighausen et al., Acta Cryst. 14, 1079, 1961 Bärnighausen et al., Acta Cryst. 14, 1079, 1961: 6.471, 6.85 $\pm 1,6.85 \pm 4 ; 90.5^{\circ} \pm 1,100.4^{\circ} \pm 1,100.4^{\circ} \pm 1$; Z 8)010/001/100, 001/010/100. Lath-shaped, el. a or b. Sometimes thick tabular. Twinned [100] or [010]. Red. Dm from Jander \& Doetsch (1960). Structure detn. in progress. Molecule N Se $_{4}$ suggested, hence probably P $\overline{1}$.

Copper(II) picolinate dihydrate ( $\alpha$ form), $\mathrm{C}_{12} \mathrm{H}_{16} \mathrm{CuN}_{2} \mathrm{O}_{4}$ (Cox et al., J. Chem. Soc. 775 , 936Cox et al., J. Chem. Soc. 775,1936$) 100 / 010 / 001$. d $(010)=8.87$. Very thin, six-sided plates. Deep blue: $\alpha<1.50, \gamma>1.76$. Not pyroooo00000000000000 eeeeeeeeeeeeeeeeeeeeeeeeeeeeeeee DDlectric. Dehydrates to lavender-blue poder on heating for a few hours at $110^{\circ}$ ( $\mathrm{Mp} \mathrm{dec} .298^{\circ}$ ). The $\beta$-form (blue needles) shows parallel extinction. Silver picolinate (fine needles) has same powder pattern (same structure).

Zine silicotungstate 18-hydrate, $\mathrm{Zn}_{2} \mathrm{Si}\left(\mathrm{W}_{3} \mathrm{O}, 18 \mathrm{H}_{0} \mathrm{O}\right.$ (Ferrari et al., Gazz. Chim. Ital. 81, 3 ,

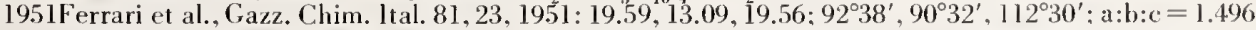
: : 1.495; this could be a multiple cell; $(\mathrm{a}: \mathrm{b}: \mathrm{c})_{\text {yon }}=(1.5404 / 2): 1:(1.5082 / 2) ;$ angles from gon.)1 10/001/010. The morphological study (Wyrouboff 1896; in Ferrari et al.) gave 0.4034: $1: 0.391$ l: $86^{\circ} 06^{\prime}, 91^{\circ} 26^{\prime}, 91^{\circ} 05^{\prime}$, in a setting that transforms to the Ferrari goniometric setting by $\overline{2} 00 / 110 / 00 \overline{2}$, giving: 0.7532 : 1 : $0.7302,93^{\circ} 06^{\prime}, 91^{\circ} 26^{\prime}, 111^{\circ} 02^{\prime}$ (J.D.H.D.); note discrepancies witl the above dala. Colorless. 
The figure shows part of a galley of the input as it is fed into the computer. A crystal entry starts with a special "flag" of three asterisks (***) followed by information to the computer as to which of six crystal systems the information is to be sorted into, whether it is to be "EDited" or not, whether a "MIneral" or Non Mineral, whether "ORganic" or "INorganic," and then a serial number for internal use. This line of information will not be printed in the book.

Following the "asterisk line" are one or more lines with supplementary names or formulas for the indexes, which will not be printed in the book except in the proper index.

The main entry for the book starts with three ampersands, (\&\&\&). The ampersands will not be printed; they are used only by the computer to identify this line of information which is to be tabulated under headings on each page of the book.

The triple asterisk and triple ampersand are the only "flags" used in the typing of the input data. All other symbols are typed exactly as they are to appear in the book. The line lengths are typed in whatever length is convenient to the typist. The final pages will be made up and justified by the computer.

As shown in figure 8, the computer sorts the information into six crystal systems, sorts into numerical order on the first number in the tabulated line (the number following the triple am- persand of the input), makes this number boldface, and tabulates each entry of the line under the proper heading. The computer then tabulates the next line, the three angles, and then assembles and justifies the remaining data lines.

The crystal names, which are typed in boldface, are extracted by the computer and alphabetized for an index. The chemical formula, which follows the boldface name, is also extracted by the computer. The formula has no imbedded spaces, so the first space signals the end of the formula. These formulas are sorted into their proper places in the organic and inorganic indexes by the computer.

In addition to the production of the book, which is my main objective at present, this large file of information will be used to perform demand searches by computer.

For example, if someone wants a list of all crystals with cell dimensions and angles between given limits and with densities heavier than a given value and containing a certain chemical element, or group of elements, the computer can make a search and print out a listing.

These demand searches may prove to be the most valuable use for compilations of data such as this. The real advantage of typing such data in machine-readable form is that it can be used for several things without retyping, e.g., publication of the complete set of data, publication of selected sets of the data, and further machine processing, corrections, and searches. 


\section{Typewriter-to-Computer Roster Publication and Maintenance}

\section{Arthur North*}

\section{U.S. Patent Office}

The title of this paper is intended to emphasize the interrelated ideas that routine typewritten data can be used to create and maintain a computer file; the average computer file can be published in graphic arts quality; published data can become a computer file-for retrieval, updating, extracting, and further publication.

More fundamentally stated, in an age when computers can be mass-produced like so many cookies, a means must be found of providing the requisite input: it is the thesis of this paper that natural-state, rough-draft, office-based typewritten data are the answer to this problem.

The Roster referred to in the title is a specific name-and-address file used in the Patent Office, for which a computer system has been designed using a standard electric typewriter as the input device, and yielding monthly computer listings and annual graphic arts publications as output (see fig. 1).

\section{Nature of the file}

The Attorney Roster file totals some 8,000 individual patent practitioners, plus approximately 600 law firms. Previously, these data had been stored in an 80,000 punch-card file which was used to print out $3 \times 5$ tub-file cards. The punch card file also formed the basis for periodical publications by the Government Printing Office-via tabulating machine paste-up-and was used to produce mailing labels as needed.

The rate-of-change for this file was typical of most name-and-address files-perhaps greater, for it contains much additional information. Roughly one quarter of the cards would require change in the course of a year. This meant some 20,000 cards to be keypunched-and verified. For some years the file had been growing, and as it grew the burden of maintaining it grew-both for the keypunch section and for the Attorney Roster Records Clerk in charge of the tub file. It was her responsibility to provide accurate change-data to the machine file. For each card to be keypunched, the Records

\footnotetext{
*Now with Documentation, Inc.
}

Clerk typed the new data on the pertinent $3 \times 5$ card, then forwarded it to the keypunch section. This operation-the typing-became the key to the new system.

\section{Need for Automation}

At the previous publication of the surname roster in 1963, a mailing of order-forms was made to all individuals listed therein, advising them of publication. Presumably the file was at optimum accuracy; it had been rigorously updated and made ready for publication. But over 300 of the 8,000 envelopes were returned as undeliverable; and generally no alternate address was available to remail these returned items-or, for that matter, to use in requesting updated address information.

Thus, with the approaching need for a new publication, it was decided to build a new file by getting completely new information from all registrants. The file would be designed for computer automation, and would be used as the basis for an automatically typeset roster. It was further planned to tighten up maintenance of the future sytem by completely bypassing the card keypunch operation, capturing instead the Records Clerk's $3 \times 5$ card typing as direct computer input. (See figure 1.)

\section{Human-Oriented File}

The punch card file, so typical of its ilk, was characterized by machine-oriented conventions such as significant $\times$-punches, list-assigned geographic sort codes, permanent file sequence numbers, and, of course, fixed-length data fields.

The new file, though designed to exploit the full capacity of the computer was unequirocally oriented toward the human being. Surname-not sequence number-would determine the file sort. Actual place names (or zipcodes) would be used to produce geographical directories. Data fields would be completely variable, accommodating the longest name. The law firm file would be extracted from individual records rather than being separately keysicroked.

Typical of the new approach was the Datil Sheet Form filled in by the individual patent practitioners. Whereas the old form was a small card 


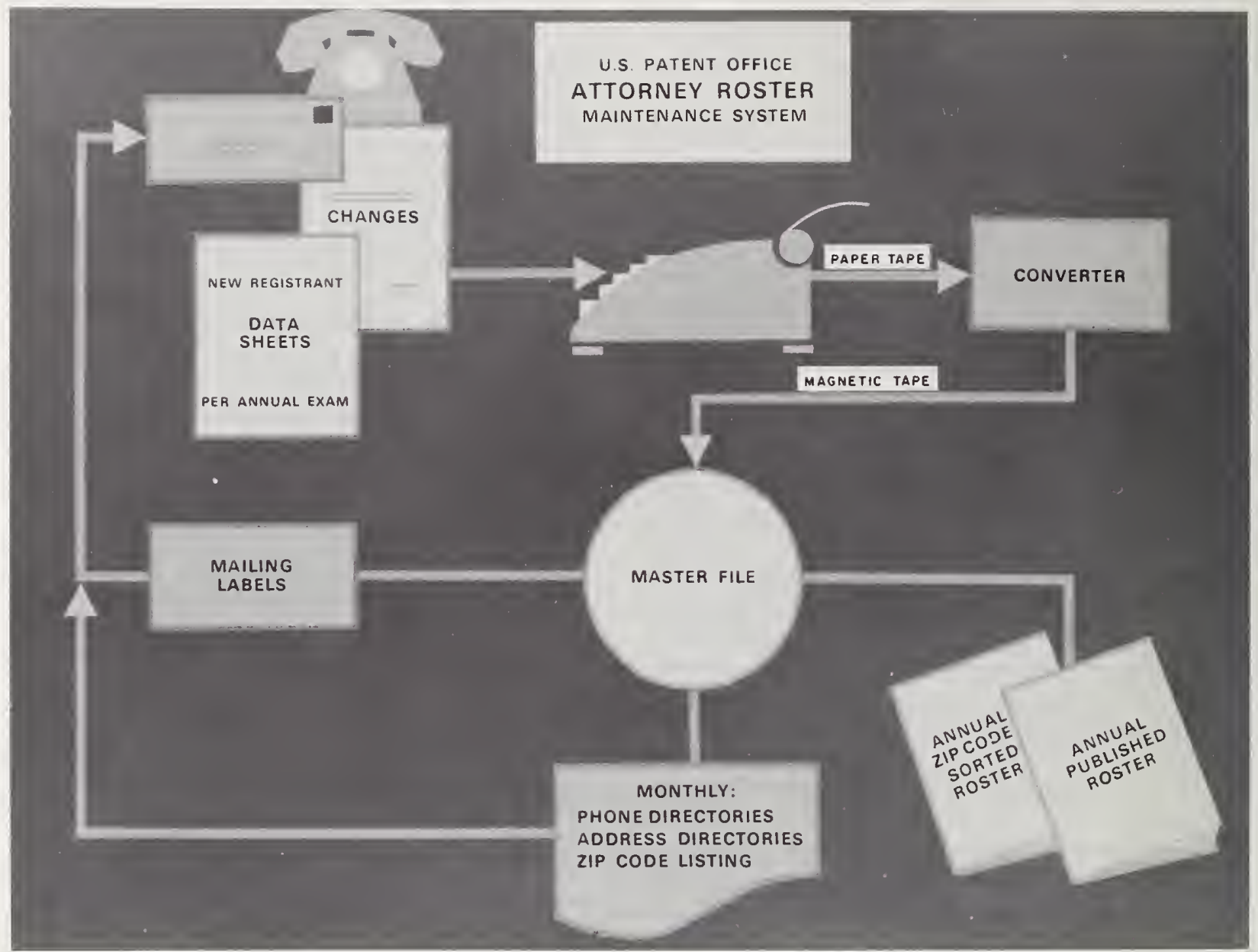

FIGURE 1. Chart showing typewriter-to-eomputer flow for roster publication and maintenanee.

designed for tub-file storage, cramped in its layout, and requiring extensive data-encoding prior to keypunching, the new form was $8 \times 101 / 2$ in, divided into logical sections and subsections, supplied with preprinted line-identity numbers for accurate reference, and ruled for standard typewriter indexing and tabbing (see fig. 2).

Further, the form would serve as a precise map to the computer record: the preprinted lineidentity numbers would be the field-identity numbers used in the computer version of the data. The computer record itself would be coded for upper and lower case, would provide at least one secondary mailing address, and would contain a high level of redundancy as a means of automatically verifying critical items-such as surname, bar membership, etc.

\section{Mailing of the Form}

With the new form designed, mailing labels were produced from the punch-card file, and forms mailed to each patent practitioner. In the period spent in assuring that-despite returned undeliverables- each practitioner received a copy, attention was turned to the next task, that of keystroking the new file.

\section{Initial Typing Procedures}

The usual procedure would have been to key- 


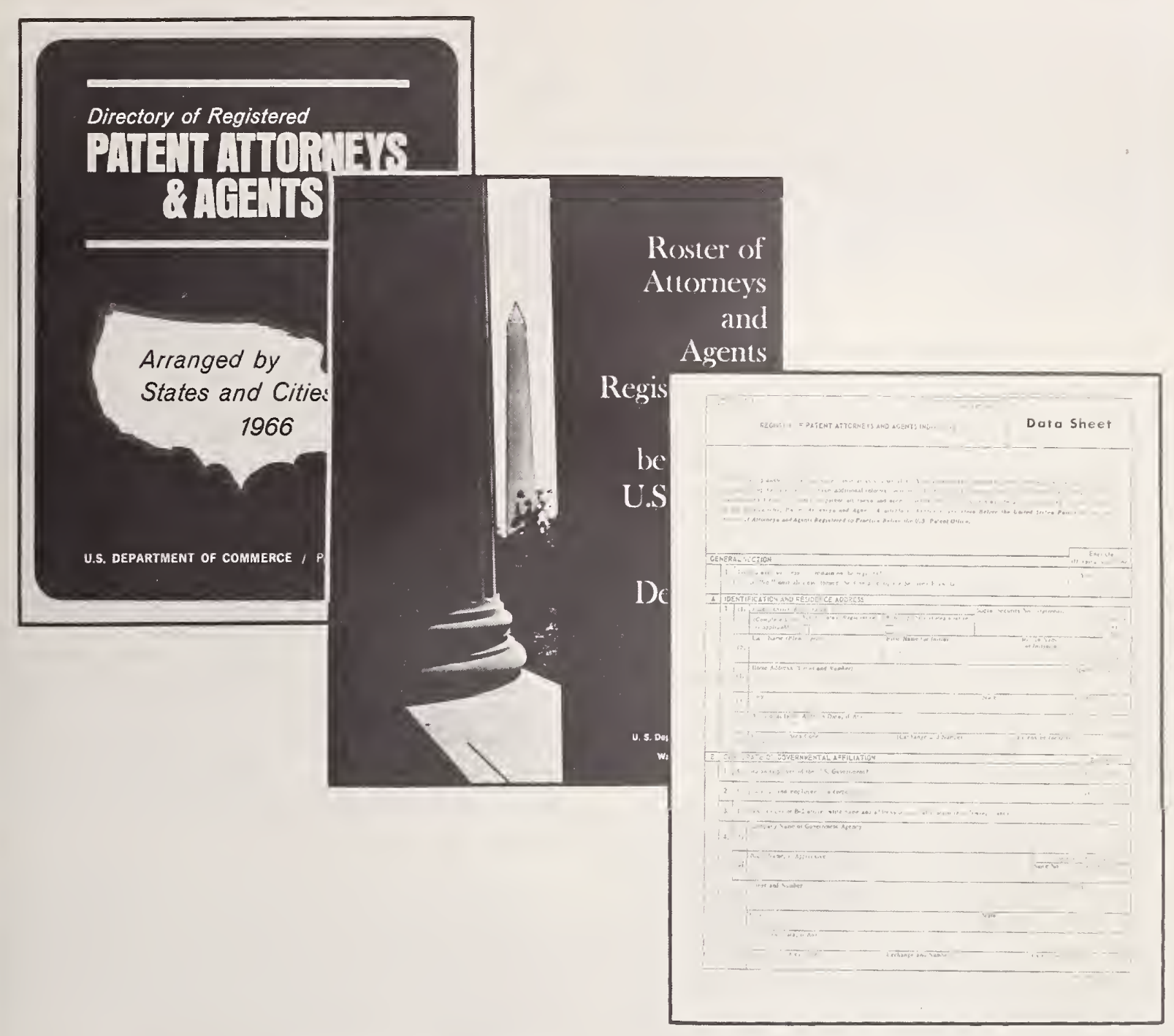

FIGURE 2. Data sheet form and patent office publications produced with the new system.

punch the returned forms on cardpunch machines. The estimated rolume of keystrokes was about $3,000,000$ - a sizable job, and one which woukd usually be split up among a number of keypunch operators.

It was felt, however, that much valuable automatic editing would be gained by having only one person keystroke the data-over a period of time. Specifically, that person should be the Records Clerk; she had been responsible for some years past for maintaining the tub file of $3 \times 5$ cards, amongst various other duties. She would use a machinelanguage producing typewriter, with fanfold to type a proof copy on, merely transcribing the data filled in on the returned forms.
Considering the locale of her work-a front office open to the public-and the other regular typing duties she had to perform, it was felt that the unit used, though producing machine language output, should have a standard keyboard, with no shift-interlock, should be quiet in operation, and of course, should produce hard copy.

These criteria were easier to specify than to fulfill. After trials with a half-clozen or more tapepunching typewiters, the final solution was a specially built unit, tailored to the actual production requirements of the system. $\Lambda$ standard IBMISelectric was used, to which a Litton punch was connected by cable. The punch was enclosed in a soundproof cabinet; the typewriter was used for 
routine typing when not employed in tape-punching the returned Data Sheets.

It might be noted parenthetically that, from the typist's viewpoint, the simplest solution would be to use optical scanning. The Olivetti-Underwood Praxis 48 typewriter, for example, is used by Documentation Incorporated to provide input to an REI Scanner. The font is a standard gothic, only slightly modified as to descenders; the scanner does not sense red, making forms typing possible. This approach entails the least disruption to the typist's routine.

\section{Building the File}

The Records Clerk typed data from the completed forms to a web of $8 \times 10$ fanfold, essentially on a random basis, and only when time could be spared from her other duties. No constraints of any kind were placed on the typist because she was producing computer input; on the contrary, the computer was used to make her task easier. Should she make an error in reading or typing, immediate correction procedures were available to her-prin cipally a line-delete, signaled by striking a " $q$ " immediately followed by a carriage return. Previously typed lines could be deleted by citing the form line-number. Whole records were deleted by preceding the stop code with a " $q$ ".

Newly punched data were converted to magnetic tape by use of the small, programmable Digi-Data converter; new mag tape data was merged to a master tape by surname field. When the file was essentially complete, sequence numbers were computer-added. Those names which had not sorted to proper alphabetical position, because of intervening spaces or shift codes, were assigned appropriate sequence numbers by change-card, and the whole file was resorted to acceptable alphabetical sequence.

\section{File Verifying}

Extensive automatic verification of the file data was achieved by a variety of techniques. As an example, extracts were made of principal lines plus the sequence number of the record: specifically, all corporate name lines were extracted and sorted; any variations on a given name were altered to conform to the standard. Similarly, all law firm citations were checked against each other. All city-and-state fields are uniform. A zipcodeand-place-name abstract was made, with the resultant file being sorted by zipcode: errors were easy to spot and correct, as with Des Moines appearing in the Philadelphia listing.

\section{Typesetting the File}

No typesetting codes were keystroked into the computer file. The basic alphanumeric set, with shift-up codes as needed (but no shift-down codes), plus end-of-line markers and a stop-code, were all that were typed.

An extract run created a tape containing nameand-address data, pīus corporate affiliation, if any, and an indication of the registrant's availability to represent new clients.

A line-measuring run ascertained runovers, planted hanging-indention em-quads as necessary, and provided for italics in the case of corporate affiliation.

A final pass translated the data to the machine language code required-teletypesetter code for use on Mergenthaler's automated line-casting machine.

\section{Publication Decisions}

It was decided to employ Linotype so that the typesetting routines thus developed could be used for other Patent Office linecasting work-which is considerable (fig. 2). One example is the thousandplus pages of six point type set annually citing patentees - another version of a roster file. A more impressive example is the 280,000 pages of patent specifications set on Linotype each year, at a typesetting cost exceeding three million dollars annually.

It had been planned to publish the geographical directory in zip code sequence, which would have provided more precise information to an individual looking for the nearest patent practitioner. This action was deferred, however, and, some months later, the standard geographical directory, updated, was published.

An internal publication is the phone directorylisting up to three numbers for a given individual, and citing his local Washington representative. This extract is the single most useful product of the new system in terms of internal Patent Office need. Its distribution has relieved the Records Clerk of the bulk of phone requests for information, thus providing her with additional time for more constructive work.

\section{Maintaining the File}

So, the file having been built, type set, and published, the job is not yet done-is, in fact, neverending, for it is maintained current by monthly computer update runs. The input is produced by the Records Clerk, typing change-data, as received, directly upon the pertinent data sheet. The 
updating is performed by the Machine Operations Branch. One file only is maintained-the master file. Monthly extracts are produced, having replaced the old tub-file cards. Full graphic arts publications can be produced on demand, with full confidence as to the accuracy of the date. An important aspect is that no additional personnel have been needed to implement this system.

\section{Summary}

In a specific application, we have seen that typing, typesetting, and computer file maintenance can be efficiently performed by one responsible and experienced operator-producing machine language directly from typewriter to computer, for file publication and maintenance. In the continuing maintenance of the file, the typewriter keystrokes formerly employed to communicate with the keypunch section now communicate directly with the computer. 


\title{
Implications of the Electronic Composition System for DSA Publications
}

\author{
William J. Beran, Chief Project Officer
}

\author{
DSA Electronic Composing Program, \\ Defense Supply Agency
}

As a prelude to this presentation, I would say that we have very little to offer in the way of pat answers or panaceas to the problems which inevitably arise with utilization of computer phototypesetting equipment. It has been our experience that easy solutions do not exist because each individual publication creates unique problems for which packaged, all-encompassing answers are not possible.

During these past few years, there have been many theories and forecasts concerning methods, equipment, and systems, which promise substantial benefits in the preparation of reproducibles for production printing. As pioneers in this field, we have found that these benefits do not always materialize and, if they do, it is always as a result of a major effort by personnel of varied backgrounds and skills.

The purpose of this presentation is to acquaint you with initial efforts to convert from such proven systems as computer printout, sequential card camera, and conventional typesetting to the Electronic Composition System at the Government Printing Office. Emphasis has been on commonsense planning, which offers increased quality at lower costs today and which will provide a foundation for more elaborate and sophisticated future programs.

The GPO equipment, which is designed to convert digital data on magnetic tape to film negative output of superior quality at speeds approaching 1,000 characters per second, is a really exciting and fascinating development. But this initial reaction is tempered with a searching and analytical study of the system.

Specifically, we can envisage potential problems in the following areas:

Transmission of data. In the near future, the bulk of DSA publications will originate in Battle
Creek, Mich. Wire transmission of data in the quantities required is not economically feasible. Movement of the magnetic tape files by mail or common carriers may adversely affect timeliness of publications.

Quality Control. At present, computer line printer processing is accomplished in-house under close surveillance of program managers who are most directly involved. Obvious errors, equipment malfunction, programming bugs are quickly detected and corrected by personnel familiar with files. We are concerned with tapes which may be lost in transit or garbled or broken during processing, especially when hundreds of miles separate the compiler from the processor.

Preparation of Input. Usage of this system in no way relieves us of our responsibility for maintenance of the file. Additionally, it is necessary to prepare edit/insert programs to insert the function codes required by the Master Typography Program. Debugging these programs is a major task when we are dependent for trial processing on equipment many miles distant.

But pessimists we are not. Though problems are inevitable, they are not insoluble and, given patience, fortitude, and close cooperation by GPO, we feel that substantial benefits will be possible.

In our day-to-day operation, it is clear that such advantages as may accrue from computer typesetting will depend on close cooperation between crafts which formerly had little in common.

It is not expected that printing technicians must become experts in EDP any more than the computer-oriented personnel will be required to become acclimated to the printing and publishing techniques. However, it is certain that a marriage of all of these skills will be necessary in order to obtain optimum benefits of this system. Many of 
the decisions which the programmer will face can only be answered by a technician possessing composition competence.

As an aside to the value of close liaison between these technicians, we can cite instances where suggestions by printing experts about what was primarily data processing operations resulted in substantial cost avoidances. Recently, Publications Division of DSA was furnished a 1,600-page computer printout for a publication for which there was a requirement of 28,000 copies. This publication consisted of the names and addresses of thousands of manufacturers. The format was designed to output the name, address, city and state, and zip code, each as a separate line. To printers familiar with typography and the costs of producing books, the inefficiency was apparent since each line of data occupied only a portion of that line. It was suggested that the printout be reprogrammed to run up the data and fill out each line. This seemingly insignificant idea reduced the size of the publication by 50 percent and resulted in a cost avoidance of $\$ 132,000$ a year. Certainly we do not infer that such suggestions will be a oneway street. Cataloging and technical data specialists and computer experts will have much to contribute to the basic objectives of increased quality at lower cost and the common experience of all will be required for an effective conversion to this totally new printing process.
Camera copy for the majority of DSA publications is generated on electronic data processing equipment. Hundreds of thousands of original pages and hundreds of millions of printed pages are produced annually to support the logistics mission of this Agency.

What, then, are the objections to a continuance of the use of the computer line printer output for this purpose and what specific advantages would accrue in conversion to a new process?

As stated previously, the basic reasons are twofold. First and foremost, we hope to achieve a reduction of printing costs and then, as a byprodnct of the system, the enhancement of the typographic quality of our publications.

It is in this area of economy that possibilities for improvements are most apparent and, indeed, the primary justification and purpose for utilization of electronic composition will have to be based on spending less of the taxpayers' money while achieving, at a minimum, an equal product. The GPO estimates that the average book generated on the line printer contains 40 percent more pages than the average book produced on typesetting equipment. Generally, we have found this to be an accurate statement.

But planning must always take into account that books are produced for people to read and that there is often a definite correlation between readability and efficiency of use. The use of bold

COST ANALYSIS OF PRINTING AND BINDING BASIC EDITION MASTER CROSS REFERENCE LISTS

COMPRESSION COMPARISON - COMPUTER LINE PRINTER AND ECS

\begin{tabular}{l|c|c|c|c|c}
\hline & & \multicolumn{2}{c|}{ COMPUTER LINE PR INTER } & \multicolumn{2}{c}{ ELECTRONIC COMPOS ING SYSTEM } \\
\cline { 3 - 6 } \multicolumn{1}{c|}{$\begin{array}{c}\text { SERVICES } \\
\text { NUMBER }\end{array}$} & OF COPIES & PAGES & $\begin{array}{c}\text { VOLUMES } \\
\text { (400 PAGES) }\end{array}$ & PAGES & $\begin{array}{c}\text { VOLUMES } \\
\text { (400 PAGES) }\end{array}$ \\
\hline $\begin{array}{l}\text { ARMY } \\
\text { REF TO FSN }\end{array}$ & 6,500 & 9,166 & 23 & 6,875 & 18 \\
\hline $\begin{array}{l}\text { NAVY } \\
\text { REF TO FSN }\end{array}$ & 7,500 & 12,500 & 32 & 9,375 & 24 \\
\hline $\begin{array}{l}\text { NAVY } \\
\text { REF TO FSN }\end{array}$ & 3,000 & 3,333 & 9 & 2,500 & 4 \\
\hline $\begin{array}{l}\text { MAR INE CORPS } \\
\text { REF TO FSN }\end{array}$ & 2,500 & 2,233 & 6 & 1,675 & 33 \\
\hline $\begin{array}{l}\text { AIR FORCE } \\
\text { FSN TO REF }\end{array}$ & 6,000 & 20,000 & 50 & 13,333 & 33 \\
\hline $\begin{array}{l}\text { "AIR FORCE } \\
\text { REF TO FSN }\end{array}$ & 5,000 & 20,000 & 50 & 13,333 & 119 \\
\hline \hline
\end{tabular}

PRINTING AND BINDING COST COMPARISON (ESTIMATED)

COPY FROM COMPUTER LINE PRINTER . . . . . \$ \$886,000

COPY FROM ELECTRONIC COMPOSING SYSTEM . . . . $\$ 628,000$

COST AVOIDANCE .... \$258,000

Figure 1. Analysis of printing eosts for master eross referenee list. 
SL-7-2 VCLUME 8

\begin{tabular}{|c|c|c|}
\hline REFERE:UCE & c & $\begin{array}{l}\text { MFR. } \\
\text { COOE }\end{array}$ \\
\hline 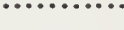 & & 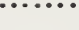 \\
\hline 7045654 & 2 & 00202 \\
\hline 7245655 & 2 & 00000 \\
\hline 7045655 & 2 & 17207 \\
\hline 7045660 & 2 & 00000 \\
\hline 7065660 & 2 & 19207 \\
\hline 7045063 & 2 & 00000 \\
\hline 7045653 & 2 & 19207 \\
\hline $70 \div 5666$ & 2 & 00000 \\
\hline 7065664 & 2 & 19207 \\
\hline 7045635 & 2 & 00000 \\
\hline 7045665 & 2 & 19207 \\
\hline $70 \div 5666$ & 2 & 00000 \\
\hline 7045067 & 2 & 00000 \\
\hline 7345667 & 2 & 19207 \\
\hline 7065669 & 2 & 00000 \\
\hline 7045670 & 2 & 00000 \\
\hline 7045672 & 2 & 00000 \\
\hline 7045672 & 2 & 19207 \\
\hline 7045673 & 2 & 00000 \\
\hline 7045673 & 2 & 19207 \\
\hline 7045693 & 2 & 00000 \\
\hline 7045693 & 2 & 19207 \\
\hline 7045674 & 2 & 00000 \\
\hline 7045694 & 2 & 19207 \\
\hline 7045395 & 2 & 00000 \\
\hline 7045695 & 2 & 19207 \\
\hline $70456 \geqslant 6$ & 2 & 00000 \\
\hline 7045696 & 2 & 19207 \\
\hline 7045697 & 2 & 00000 \\
\hline 7065697 & 2 & 19207 \\
\hline 7045698 & 2 & 00000 \\
\hline 7065699 & 2 & 19207 \\
\hline 7065697 & 2 & 00000 \\
\hline 7065699 & 2 & 17207 \\
\hline 704570 & 2 & 00000 \\
\hline 7045709 & 2 & 00000 \\
\hline 7045709 & 2 & 19207 \\
\hline 7045710 & 2 & 00000 \\
\hline $70<5710$ & 2 & 19207 \\
\hline 7065712 & 2 & 00000 \\
\hline 7045712 & 2 & 19207 \\
\hline 7045713 & 2 & 00000 \\
\hline 7045713 & 2 & 19207 \\
\hline 7045715 & 2 & 00000 \\
\hline 7045715 & 2 & 19207 \\
\hline 7045717 & 2 & 00000 \\
\hline 7045717 & 2 & 19207 \\
\hline 7045718 & 2 & 00000 \\
\hline 7045716 & 2 & 19207 \\
\hline 7045721 & 2 & 00000 \\
\hline 7045721 & 2 & 19207 \\
\hline 7045725 & 2 & 00000 \\
\hline 7045725 & 2 & 19207 \\
\hline 7045726 & 2 & 00000 \\
\hline 7045726 & 2 & 17207 \\
\hline 7045727 & 2 & 00000 \\
\hline 7045727 & 2 & 19207 \\
\hline 7045727 & 2 & 00000 \\
\hline 7045727 & 2 & 19207 \\
\hline 7045734 & 2 & 00000 \\
\hline $704573+$ & & 19207 \\
\hline 7045737 & 2 & 00000 \\
\hline 7045737 & 2 & 19207 \\
\hline 7045740 & 2 & 00000 \\
\hline 7045760 & 2 & 19207 \\
\hline $70457 \div 1$ & 2 & 03000 \\
\hline 7045741 & 2 & 19207 \\
\hline $70457+3$ & 2 & 00000 \\
\hline 7045743 & 2 & 19207 \\
\hline 7045745 & 2 & 00000 \\
\hline 7045745 & 2 & 19207 \\
\hline 7045745 & 2 & 00000 \\
\hline $70457+6$ & 2 & 19207 \\
\hline 7045767 & 2 & 00000 \\
\hline 7045747 & 2 & 19207 \\
\hline 7045745 & 2 & 00000 \\
\hline 7045743 & 2 & 19207 \\
\hline 7045755 & 2 & 00000 \\
\hline 7045755 & 2 & 19207 \\
\hline 7045756 & 2 & 00000 \\
\hline 7045756 & & 19207 \\
\hline 7045757 & 2 & 00000 \\
\hline 7065757 & 2 & 19207 \\
\hline 7045769 & 2 & 00000 \\
\hline 7045769 & 2 & 19207 \\
\hline 7045770 & 2 & 00000 \\
\hline 7045710 & 2 & 19207 \\
\hline 7045771 & 2 & 00000 \\
\hline 7045771 & 2 & 19207 \\
\hline 7045775 & 2 & 19207 \\
\hline 7045777 & 2 & 00000 \\
\hline 7045777 & 2 & 19207 \\
\hline $\begin{array}{l}7045774 \\
7045776\end{array}$ & 2 & $\begin{array}{l}00000 \\
00000\end{array}$ \\
\hline & & \\
\hline
\end{tabular}




\begin{tabular}{|c|c|c|c|c|c|c|c|c|c|c|c|c|}
\hline $\begin{array}{l}\text { Palerence } \\
\text { Pumber }\end{array}$ & $V C$ & $\begin{array}{l}\text { Hifir } \\
\text { Code }\end{array}$ & $\begin{array}{c}\text { Federa' } \\
\text { Stoch Number }\end{array}$ & $\begin{array}{c}\text { Relerence } \\
\text { Number }\end{array}$ & VC & $\begin{array}{l}\text { Mir } \\
\text { Code }\end{array}$ & $\begin{array}{c}\text { Federal } \\
\text { Stock Number }\end{array}$ & $\begin{array}{l}\text { Refirence } \\
\text { Number }\end{array}$ & VC & $\begin{array}{l}\text { Mfr. } \\
\text { Code }\end{array}$ & $\begin{array}{c}\text { rederal } \\
\text { Stock Number }\end{array}$ & $\begin{array}{l}\text { Refrerence } \\
\text { Number }\end{array}$ \\
\hline & 2 & & & & 2 & & 515 & & 2 & & & 4 \\
\hline & 2 & 1000 & & $=$ & 2 & 0000 & $40692-8939$ & 7699516 & 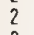 & 00000 & 406928999 & $76 \$ 3516$ \\
\hline 516 & 2 & 19207 & 8999 & 516 & 2 & 207 & $40-692.8993$ & 7639516 & 2 & 19207 & $25 \div 0-6928999$ & $7 6 \longdiv { 9 5 1 6 }$ \\
\hline 522 & 2 & 00000 & 05.7699522 & & 2 & 0000 & 005.7699522 & 7699522 & 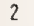 & 00000 & 100576995,22 & 6075522 \\
\hline 522 & 2 & 19207 & $1005-7 \overline{6} 9.9522$ & 99522 & 2 & 9207 & $1005-7693522$ & 7693522 & 2 & 19207 & $005769995 ? 2$ & 522 \\
\hline 7633524 & 2 & 00000 & 52069124897 & 7690524 & 2 & 00000 & 25206928897 & 7699524 & 2 & 00000 & 25206974839 & $769 \$ 524$ \\
\hline 7039524 & 2 & 19207 & $20-692.4897$ & 24 & 2 & 19207 & $2520-6924897$ & 7699524 & 2 & 19207 & 25206924897 & 769524 \\
\hline 525 & 2 & 00000 & 93525 & 25 & 2 & 0000 & $1005-7693525$ & 7639525 & 2 & 00000 & 99525 & $7 6 9 9 \longdiv { 2 5 }$ \\
\hline 525 & 2 & 9207 & 10057695525 & 7699525 & 2 & 19207 & $1005-7699525$ & 7693525 & 2 & 19207 & 99525 & $7699 \$ 25$ \\
\hline 7699526 & 2 & o60uo & 10057699526 & 7692526. & 2 & 00000 & 1005.763 .9526 & 7639526 & 2 & 00000 & 10057699526 & 69356 \\
\hline 526. & 2 & 19207 & 1005769.9526 & 93526 & 2 & 19207 & 10057639526 & 7693526 & 2 & 19207 & $1005-7693526$ & 769356 \\
\hline 530 & 2 & 00000 & 1005.7699530 & 30 . & 2 & 00000 & $1005-7699530$ & 76 & 2 & 00000 & -9530 & g6s \\
\hline 530 & 2 & 19207 & $1005 \cdot 769.9530$ & 99530. & 2 & 19207 & $1005 \cdot 769-9530$ & 7699530 & 2 & 19207 & 1005.7699530 & 7692530 \\
\hline 532 & 2 & 00000 & $1005-769-9532$ & 7699532 & 2 & 00000 & 1005.763 .9532 & 7699532 & 2 & 00000 & $1005-769-9532$ & 69953 \\
\hline 543. & 2 & 19207 & $1005-769.9532$ & 43. & 2 & 19207 & 1005.769 .9532 & 7699543 & 2 & 19207 & $1005.769-9532$ & 543 \\
\hline 7 & 2 & 00000 & 7566 & & 2 & 00000 & $1005-3467566$ & & 2 & 00000 & 7566 & 33. \\
\hline 7 & 2 & 19207 & 6.7566 & 33 & 2 & 19207 & 1005.3467566 & 7699533 & 2 & 19207 & -7566 & 669 \\
\hline 7 & 2 & 00000 & 6.7567 & 7 & 2 & 00000 & $1005 \cdot 346 \cdot 7567$ & 7699534 & 2 & 00000 & 6.7567 & 34 \\
\hline 7 & 2 & 00000 & 9000 & & 2 & 00000 & 9000 & 76 & 2 & 00 & 3000 & \\
\hline & 2 & 19207 & $1005-692-9000$ & $\ldots$ & 2 & 19207 & 2.9000 & & 2 & & $2-9000$ & 765 \\
\hline & 2 & 00000 & $1005-769-9538$ & 76 & 2 & 00000 & $9-9538$ & 765 & 2 & 00000 & 1005.7699538 & 76 \\
\hline 70 & 2 & 00000 & $2590-039.8955$ & 7 & 2 & 00000 & 8955 & 76 & 2 & 00000 & 9.8955 & 76 \\
\hline 7 & 2 & 19207 & 9.8955 & 7 & 2 & 19207 & $2590-039-8955$ & & 2 & 19 & 955 & 36 \\
\hline & 2 & 00000 & 2590 & 7 & 2 & 00000 & $2590-039.8956$ & 769 & 2 & 00000 & 8956 & 76 \\
\hline & 2 & 19207 & 9.8956 & 76 & 2 & 19207 & 2590 & 769 & 2 & 19207 & 9.8956 & 78 \\
\hline 7 & 2 & 00000 & 2590. & & 2 & 00000 & 2590. & 76 & 2 & 00000 & 3957 & \\
\hline & 2 & 19207 & 8957 & 76 & 2 & 19207 & $2590-0$ & & 2 & 19207 & 2590 & 36 \\
\hline & 2 & 00000 & .8958 & 76 & 2 & 00000 & 2590 & 76 & 2 & 00000 & .8958 & \\
\hline & 2 & 19207 & 9-8958 & 7 & 2 & 19207 & 2590 & 76 & 2 & 19207 & 9.8958 & 76 \\
\hline & 2 & 00000 & 9601 & 7 & 2 & 00000 & 530 & & 2 & 00000 & 601 & \\
\hline & 2 & 00000 & 2590 & & 2 & 00000 & 602 & 76 & 2 & 00000 & 9602 & \\
\hline & 2 & 19207 & 2590 & 70 & 2 & 19207 & 602 & 769 & 2 & 19207 & -9602 & \\
\hline & 2 & 00000 & 503 & 7 & 2 & 00000 & 603 & & 2 & 00000 & 9603 & \\
\hline & 2 & 19207 & 9603 & 7 & 2 & 19207 & 603 & & 2 & 19207 & 603 & \\
\hline & 2 & 00000 & 9606 & & 2 & 00000 & 6606 & 76 & 2 & 00000 & -9606 & \\
\hline & 2 & 19207 & 606 & ... & 2 & 19207 & 606 & 76 & 2 & 19207 & .9606 & \\
\hline & 2 & 00000 & & & 2 & 00000 & 609 & & 2 & 00000 & 9609 & \\
\hline & 2 & 19207 & 509 & & 2 & 19207 & 3609 & 76 & 2 & 19207 & 9609 & \\
\hline & 2 & 00000 & 473 & 76 & 2 & 00000 & 537 & 76 & 2 & 00000 & 537 & \\
\hline & 2 & 19207 & 4 & & 2 & 19207 & 537 & 76 & 2 & 19207 & & \\
\hline & 2 & 00000 & .4943 & & 2 & 00000 & 4943 & 76 & 2 & 00000 & 1943 & 96 \\
\hline & 2 & 00000 & -4945 & & 2 & 00000 & 4945 & 76 & 2 & 00000 & 9945 & 36 \\
\hline & 2 & 19207 & 312 & 7 & 2 & 19207 & 945 & 76 & 2 & 19207 & 945 & 36 \\
\hline & 2 & 00000 & 947 & & 2 & 00000 & 947 & & .2 & 00000 & 1947 & 76 \\
\hline & 2 & 00000 & 2590 & & 2 & 00000 & 3614 & 76 & 2 & 00000 & 614 & 60 \\
\hline & 2 & 00000 & 5330 & & 2 & 00000 & 545 & 76 & 2 & 00000 & 45 & 36 \\
\hline & 2 & 19207 & 545 & & 2 & 19207 & 545 & 70 & .2 & 19207 & 545 & 36 \\
\hline & 2 & 00000 & $6-3603$ & & 2 & 00000 & 603 & 76 & 2 & 00000 & 6603 & 86 \\
\hline & 2 & 00000 & 5330 & 76 & 2 & 00000 & 543 & 76 & 2 & 00000 & 543 & 3 \\
\hline & 2 & 19207 & & & 2 & 19207 & & 76 & 2 & 19207 & 43 & \\
\hline & 2 & 00000 & 3604 & & 2 & 00000 & 604 & 76 & 2 & 00000 & 3604 & b6 \\
\hline & 2 & 00000 & 6.3605 & & 2 & 00000 & 3605 & 76 & 2 & 00000 & & 36 \\
\hline & 2 & 00000 & & & & 00 & 540 & & $?$ & 00000 & & 76 \\
\hline & 2 & 18797 & 3450 & 77 & 2 & 18797 & 346 & & .2 & 18797 & 190 & 17 \\
\hline & 2 & 55719 & 5120 & & 2 & 55719 & 35 & & 2 & 55719 & & \\
\hline & 2 & 77554 & 5 & & 2 & 77 & 18 & & .2 & 77 & & 87 \\
\hline & 2 & 76854 & 5562 & & 2 & 76854 & 59 & & 2 & 76854 & 562 & $\$ 7$ \\
\hline & 2 & 80765 & 5930 & 7 & 2 & & & & .2 & 80765 & & 67 \\
\hline & 2 & 81349 & 318 & & 2 & 81 & 18 & & 2 & & & 67 \\
\hline & 2 & 0569 & & & 2 & 05 & & 7 & . 2 & 0 & & \\
\hline & 2 & 38512 & 7520 & & 2 & 38 & & 77. & .2 & 38512 & -8553 & 87 \\
\hline $\begin{array}{l}77 \cdot 8 \cdot 111-01710 \text {. } \\
8430\end{array}$ & $?$ & 10001 & $3110-10$ & $\begin{array}{l}77 \cdot 8 \cdot 111 \cdot 01710 \\
8430\end{array}$ & & 10001 & 2364 & $\int_{0}^{11.01710 .}$ & 2 & 10001 & 2364 & $\begin{array}{l}7 \cdot B \cdot 111 \cdot 0 \\
8430\end{array}$ \\
\hline $\begin{array}{l}77 \cdot B \cdot 115 \cdot 07401 . \\
0000\end{array}$ & 2 & 10001 & 3991 & $\begin{array}{l}77 \cdot 8 \cdot 115 \cdot 07401 . \\
0000\end{array}$ & 2 & 10001 & 991 & 15.07401. & 2 & 10001 & $3110 \cdot 155-8991$ & $\begin{array}{r}7.8 \\
00\end{array}$ \\
\hline 01532 & 2 & 10001 & $3110-151-8232$ & 77. & 2 & 10001 & $3110-151.8232$ & $32-$ & 2 & 10001 & $3110-151 \cdot 8232$ & \\
\hline & & & & & & & & & & & & \\
\hline $\begin{array}{l}77 \cdot 8 \cdot 231 \cdot 05002 \text {. } \\
0000\end{array}$ & 2 & 000 & 63 & $\begin{array}{l}77 \cdot \mathrm{B} \cdot 231 \cdot 05002 \\
0000\end{array}$ & 2 & 10001 & 663 & $\begin{array}{l}77.8 .231 .05002 . \\
0000\end{array}$ & 2 & 0001 & 53 & $\begin{array}{l}77.8 .231 \cdot 050 p 2 . \\
0000\end{array}$ \\
\hline $\begin{array}{l}77.8 .991 .15134 . \\
0000\end{array}$ & 2 & $1000 !$ & 3110 & $\begin{array}{l}77 \cdot 8 \cdot 991 \cdot 15134 \\
0000\end{array}$ & 2 & 10001 & $3110 \cdot 186 \cdot 5031$ & $\begin{array}{l}77 \cdot \mathrm{B}-991 \cdot 15134 \\
0000\end{array}$ & 2 & 0001 & 5031 & $\begin{array}{c}7.0 .991 .15 \\
0000\end{array}$ \\
\hline 17. & 2 & 05690 & 295 & $77 \cdot 1$ & 2 & 5690 & 295 & 77.1 & 2 & 05690 & & 67.1 \\
\hline & 2 & 0011 & 371 & & 2 & 11 & 371 & & 2 & & & 67.1 \\
\hline & 2 & 74193 & 453 & & 2 & 93 & 453 & & 2 & & & 77.102 .1 \\
\hline $\begin{array}{c}77.112-24 \cdot 15 A 110 \\
\text { VAC. } 400 \cdot 58\end{array}$ & 2 & 74193 & & $\begin{array}{c}77.112 \cdot 24 \cdot 15 A 110 \\
\text { VAC. } 400 \cdot 58\end{array}$ & $?$ & 74193 & 587 & $\begin{array}{r}77.112 .24 \\
\text { VAC. } 400\end{array}$ & 2 & $74: 93$ & $5925-826.6587$ & $\begin{array}{l}7.112 .24,15 A 110 \\
\text { VAC. } 400.58\end{array}$ \\
\hline 77.1 & 2 & 81541 & 390 & 77.1 & 2 & 1541 & 390 & 77 & & & & $2.31 \ldots$ \\
\hline & 2 & 74193 & 389 & & 2 & 93 & 389 & & 2 & 74193 & 389 & 2.56 \\
\hline 77. & 2 & 9.9923 & 2984 & 77. & 2 & 94923 & 984 & & 2 & 94923 & & 67.112726. \\
\hline & 2 & 05620 & 8123 & 77.1 & 2 & 05690 & & 77 & 2 & 05690 & 8123 & $77.12 \ldots \ldots$ \\
\hline 77.206 & 2 & 35301 & 2737 & $77 \cdot 2$ & 2 & 35301 & 29 & & & 353 & 2737 & 77.206 \\
\hline $77 \cdot 22$ & 2 & 35301 & -8795 & 77.22. & 2 & 35301 & 3795 & 77 & 2 & 35301 & 8795 & 67.22. \\
\hline & 2 & & $142 \cdot 1741$ & 77.22 & & & & 77.22 & 2 & 64104 & .1741 & 77.22 \\
\hline & 2 & 71995 & $142-1741$ & $77-22$ & 2 & 71995 & 1741 & 77.2 & 2 & 71995 & & 77.22 . \\
\hline 77.29 & 2 & 05348 & $\hat{-6} 787$ & 77.2921 & 2 & 09348 & 6787 & 77.292 & 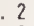 & 09348 & 5.6787 & 67.292195 \\
\hline $77 \cdot 3$ & 2 & 05690 & 3.0296 & & 2 & 05690 & 8.0296 & 77.3 & 2 & 05690 & 88.0296 & 67.3 \\
\hline & 2 & 83259 & 1354 & $77 \cdot 545 \cdot 2$ & & 8325 & & 77.5 & 2 & 83250 & 30.1354 & 77.5 \\
\hline & 2 & 75377 & 2504 & $77.981 \cdot 15$ & & 753 & & $77 \cdot 98$ & 2 & 75377 & & 77. \\
\hline & & 86577 & 38 & 77 & & & & $\begin{array}{l}77 A \\
77 \AA\end{array}$ & & 86577 & & \\
\hline & & & & & & & & & & & & \\
\hline
\end{tabular}


COST ANALYSIS OF PRINTING AND BIND ING CATALOGING HANDBOOK H4-1

FSC FOR MANUFACTURERS, U.S. AND CANADA - NAME TO CODE

AND MONTHLY SUPPLEMENTS THERETO

PRESENT METHOD (COMPUTER LINE PRINTER CAMERA COPY)

NO. OF COPIES PR INTED

TOTAL NO. OF PAGES

PRINTING AND PRINTED ANNUALLY

BIND ING COSTS

30,000

3,300

$\$ 125,000$
PROPOSED METHOD IELECTRONIC COMPOSITION SYSTEM FROM PROPERLY CODED FILES SCREENED AREAS IN VUGRAPHS IND ICATE COMPRESSION OF DATA)
NO. OF COPIES PRINTED
ESTIMATED NO. OF PAGES PRINTED ANNUALLY
30,000
1,500
ESTIMATED PRINTING AND B IND ING COSTS
$\$ 60,000$

ESTIMATED COST AVOIDANCE

$\$ 65,000$

FIGURE 4. Analysis of printing costs for cataloging handbook.

face or italic type in various sizes to accentuate important data; leaders which direct the eye from column to column; and rules that effectively delineate columns of data contribute significantly toward usability of the book.

These benefits, however, are of such a nebulous nature that it is difficult, if not impossible, to determine actual savings in dollars.
It is significant to note that the kind of work that will yield the greatest benefit is the repetitive type of publication, such as directories, catalogs, handbooks, etc., which are primarily the type of books published by the Defense Supply Agency.

The figure above and those which follow illustrate money and space saving possibilities using the electronic composing system. 
P 0 BOK $4 \overline{Z 147}$

LUS ANGELES CAL IF

- bewler eVoINEERING Co

SRIDGEPORT CONN

NOW BEWLEY ENGINEERING CORP SOUTHPOR I CONN

BEWLEY ENGINEERING CORP

KIINGS HWY WEST

SOUTHPORT CONN

FORMERLY BEWLEY ENGINEERING CO BRIJGEPORT CONN

BEY ELECTRIC

TROY LANE P D BOX 54B

L INCOLN PARK $N$

BEYER MACHINE CO INC

JACKSON MICH

BIACH INDUSTRIES INC

210 S AVE E

CRAVFORO N J

BIAS BUFF AND WHEEL CO

CONOVER N C

FORMERLY IN JERSEY CITY N J

- BIAS BUFF AVD HHEEL CO INC

JERSEY CITY N J NON IN CONOVER N C

BIBH MFG CO

237 MAIN ST PO BOX 37

MACON GA

ZIP CODE 31262

BIBER L R CO INC NEW YORK N $Y$

BICKETT L M CO

FIRST ST WATERTOHN WIS

BICKFORD BROS CO BUFFALU N Y

BICKFORO BROS CO ROCHESTER N $Y$

- bickfuro h ano co LAKEPORT N H

NOW ACME SERVICE INT.

LAKEPOR T N H

BICKING S AUSTIN PAPER MFG CO DOWVINGTON PA

BICKLEY FURINACES INC

SSO STATE RO

PHILADELPHIA PA

FORMERLY REMMEY RICHARO C SON CO PHILADELPHIA PA

BICKNELL ALFREO ASSOCIATES

CAMBRIDGE MASS

BICKNELL MFG CO

2 LIME ST

ROCKLANO MAINE

BICO INC BURAANK CAL IF

BIDOLE CO

2BI7 BRECKENRIDGE INDUSTRIAL

COURT

ST LJUIS MO

ZIP CODE 63144

FORMERLY BIDOLE PUTIY CO

ST LOUIS MO

BIUOLE ENGINEERING CO

$P$ O BOX 98

WARRENDALE PA

- Biodle james g co PHILAOEL PHIA PA NOW IN PLYMOUTH MEETING PA

BIDDLE JAIAES G CO PLYMOUTH MEETIVG PA FORMERLY IN PHILADELPHIA PA

- bidole putty co ST LOUIS MO NOH BIODLE CO ST LOUIS MO

BIEDERMAN A PRECISION IVSTRUMENT LABORATORIES

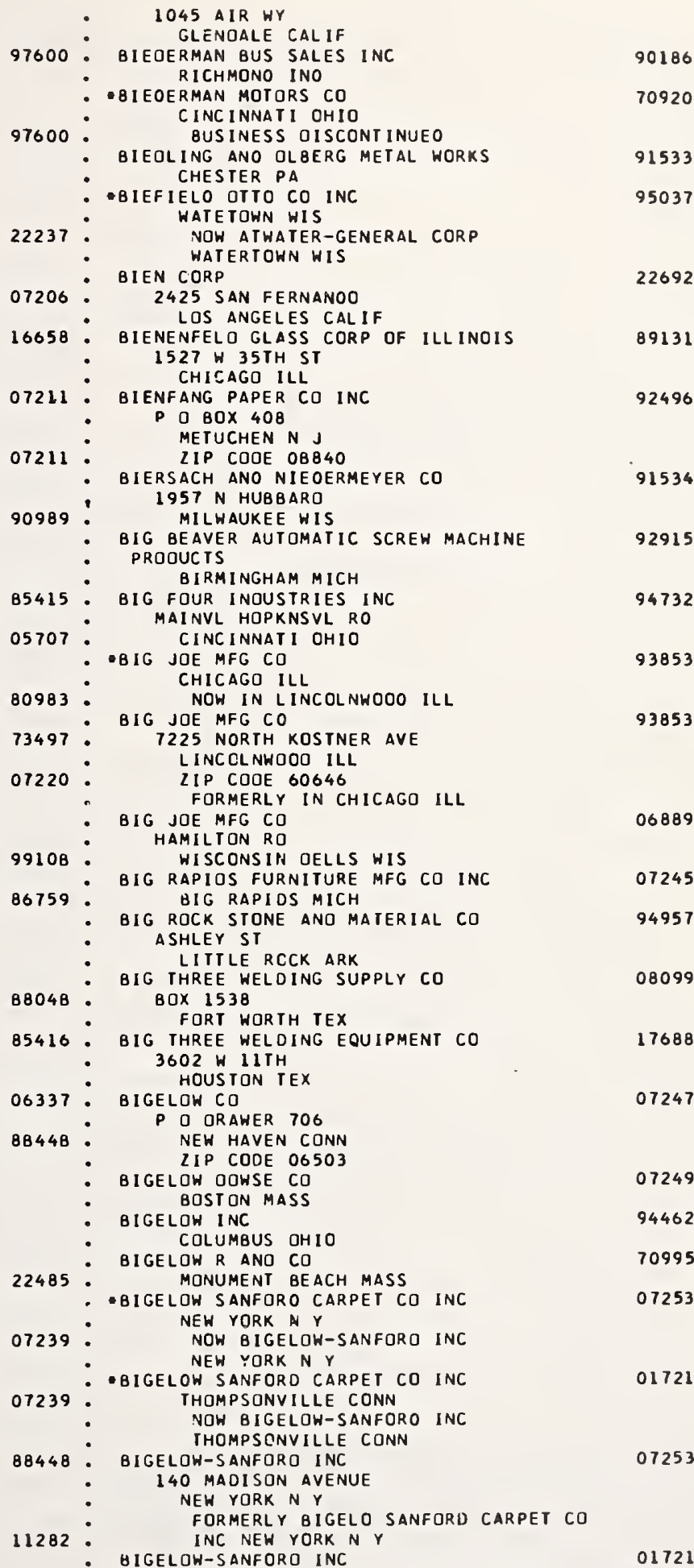

Figure 5. Present page design of handbook. 
97600

BEWLEY ENGINEERING CORP KINGS HWY WEST SOUTHPORT FORMERLY BEWLEY ENGINEERING CO BRIDGEPORT CONN

BEY ELECTRIC TROY LANE P O BOB 548 LINCOLN PARK N J BEYER MACHINE CO INC JACKSON MICH

BIACH INDUSTRIES INC 210 S AVE E CRANFORO N J

BIAS BUFF ANO WHEEL CO CONOVER N C FORMERLY IN JERSEY CITY N I

"BIAS BUFF AND WHEEL CO INC JERSEY CITY N

NOW IN CONOVER N C

BIBB MFG CO 237 MAIN ST PO BOX 37 MACON

BIBER L R CO INC NEW YORK $N$ Y

BICKETT L M CO FIRST ST WATERTOWN WIS

BICKFORD BROS CD BUFFALO N $Y$

BICKFORD BROS CO ROCHESTER N $Y$

"BICKFORD H AND CO LAKEPORT N H

NOW ACME SERVICE INC LAKEPORT N H

BICKING S AUSTIN PAPER MFG CO OOWNINGTON PA

BICKLEY FURNACES INC 550 STATE RO PHILADELPFIIA PA

FORMER Y REMMEY RICHARD C SDN CO PHILADELPHIA PA

BICKNELL ALFRED ASSOCIATES CAMBRIOGE MASS

BICKNELL MFG CD 2 LIME ST ROCKLAND MAINE

BICD INC BURBANK CALIF

BIDOLE CO 2817 BRECKENRIOGE INOUSTRIAL COURT

ST LOUIS MO 63144

FORMERLY BIOOLE PUTTY CO ST LOUIS MO

BIDDLE ENGINEERING CO P 0 BOX 98 WARRENOALE PA

"BIDDLE JAMES G CO PHILADEPHIA PA

NOW IN PLYMOUTH MEETING PA

BIOOLE JAMES G CO PLYMOUTH MEETING PA

FORMERLY IN PHILAOELPHIA PA

"BIDDLE PUTTY CO ST LOUIS MO

NOW BIDDLE CO ST LOUIS MO

BIEOERMAN A PRECISION INSTRUMENT LABORATORIES

1045 AIR WY GLENOALE CALIF

PIEDERMAN BUS SALES INC RICHMOND IND

"BIEDERMAN MOTORS CO CINCINNATI DHIO

BUSINESS OISCONTINUEO

BIEDLING AND OLBERG METAL WORKS CHESTER PA

"BIEFIELO OTTO CD INC WATETOWN WIS

NOW ATWATER-GENERAL CORP WATERTOWN WIS

BIEN CORP 2425 SAN FERNANOO LOS ANGELES CALIF

BIEN CORP 2425 SAN FERNANDO LOS ANGELES CALIF

BIENFANG PAPER C 9 INC $P$ O BOX 408 METUCHEN N J $08840 \quad 92496$

BIEASACH ANO NIEDERMEYER CO 1957 N HUBBARO MILWAUKEE WI 91534

BIG BEAVER AUTOMATIC SCREW MACHINE PRODUCTS

BIRMINGHAM MICH

BIG FOUR INDUSTAIES INC MAINVL HOPKNSVL RD CINCINNATI OHI 949732

"BIG IOE MFG CO CHICAGO ILL

NOW IN LINCOLNWOOO ILL

BIG IOE MFG CO 7225 NORTH KOSTNER AVE LINCOLNW000 ILL 6064

FORMERLY IN CHICAGO ILL

BIG JOE MFG CO HAMILTON RO WISCONSIN OELLS WIS

BIG RAPIDS FUANITURE MFG CO INC BIG RAPIOS MICH

BIG ROCK STONE ANO MATERIAL CO ASHLEY ST LITTLE ROCK ARK

BIG THREE WELDING SUPPLY CO BOX 1538 FORT WORTH TEX

BIG THREE WELDING EQUIPMENT CO 3602 W 11 TH HOUSTON TEX

BIGELOW CO P O ORAWER 706 NEW HAVEN CONN 06503

BIGELOW DDWSE CO BOSTON MASS

BIGELOW INC COLUMBUS OHIO

BIGELOW R AVD RO MONUMENT BEACH MASS

NOW BIGELOW-SANFDRO INC NEW YORK N Y

"BIGELNW SANFORN RARPET TO INR. THOMPSONV'ILE CONN

NOW BIGELOW-SANFORO INC THOMPSONVILLE CONN

BIGELOW-SANEORD INR, IAN MAO'SAN AVENIIE NFW YORK N Y 07253

FORMERLY BIGELO SANFORD CATKPET CO INC NEW YORK $N Y$

BIGELOW-SANFORD INC

BETHLCAEM STEEL CO SHIPBUILOURE DIVISION SPARAOWS POINT PIT

SPARROWS POINT BAO

BETHLEHEM STEEL CORP 25 BROABWAY NEW YORK $N Y$

BETHLEHEM STEEL FORP BETHLEHEM OFFICE BETHLEHEM PA

BETHLEHEM STEEL CORP WULMEGTON OFFICE WLLALETON OEL

BETHLEMFA SUPPLY CO 600 ALGOA UER LONG BEACH CALIE

BETHLEHEM SUPPLY CO TULSA OKLA

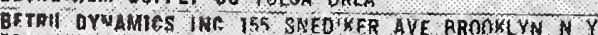

FORMERLY OU BEST STAMPING ANO WFG BROOKLYN NY Y

DETI MARR MFG CO HOPKINS MIKN
97600

22237

07206

07211

07211

90989

85415

80983

73497

07220

99108

86759

88048

85416

88448

22485

07239

88448

11282

90186

0920

91533

95037

92915

93853

93853

06889

07245

94957

08099

17688

07247

07249

94462

07253

01721

01721

70984

80398

80406

80405

94016

91530

19024

80462

80462
MAME

BETYER COIL AND TRANSFORMER CO zOO1 W UNION GOODLAND IND

ALTTER CONTALNERS MFG CO INC 2644 WEST MAOISON CHICAGO II

94617

betTER finisHes aNo coATING SO ANAHEIM Gail NOW BFC ONVISION OF ESSEX CHEMICAL GORP LA MIRADA CALIF

BETTER FINISHES AND COATINGS CO NEWARK NO

NEW BFC OIVISION OF ESSEX CHEMICAL CORP CLIFTON HI

BETTER MONKEY GRIP CO DALLAS TEX

BETIER PACKAGES INC 256 GANAL ST SHELTON CONH

BETTER STEEL PROOUCTS IHC 604 COMMERCLAL STREET

ALBERT LEA MINN

BETIERBILT EMGINEERING AND MFL CO THC

NORTH HOLLYWOOO CALIF

"BETTER-BILT MFG CO OE SOTO MO

BUSINESS OISCONTINUEO

BETTERLY WILLIAM A THC WILKES BARRE PA

BETTGER IMOUSTRIES LTO STRATFORD ONTARIO CANADA

BETTHNGER CORP 59 SUMMER MILFORD MASS

BETIS COAP HOUSTON TEA

BETTS ANO BETTS CORP 100 POMPERAUS RO WOOOBURY GONN

BETTS MACHINE CO 1800 PENAA AVE W WARREES PA

BETIS SPAIRG CO SAR FRAKCISCO CALIF

BETTY MACHIHE CO MASHOTLL TENA

BETTYS MFG CO 4207 S E HGL AVEULE PORTLAMO OREG

BETZ CORP HAMHONO INO

BEIZ FRANK S CO CLEVELANO OHIO

BETZ LABORATORIES TTO MONTREAL OUEBBEC CANADA

BETZ PIEACE CO 2965 E 55 CLEVELANO OHIO \$412\%

-BETZ W H AND L O PHILAOELPH'A PA

UNKHOWN TO LOCAL POSTAL AUTHORITES

BEUGLER MFG CO 4318 W 2 NO ST LOS ANGELES CALIF

BEVA LABQRATORY TRENTON N I

BEVCO CO INE THE 10520 BHE BERO ST LOUIS MO G3LL2?

BEYERLY BUILOULG MATERIAT CO 9270 ALON DR

BEVERLY HILLS CALIT

BEVERLY ELECTRENIES 8413 BEVRIY BEVERLY HILLS CALIF

BEVERLY INSTRUMENT CO THC 008 WAREEN ST BEVERLY A

FORMERL Y BRTOGE ELECTRONICS CO INC BEYERLY N

BEVERLY MFG CO 10 ROLANO STREET BOSTOA MASS

BEVERLY MFG CO 9118 S MAIN ST IOS ANGELES CALIF

BEYERLY SHEAR MFG CO 3004 W IIITH ST CHICAGO ILC 60655

17200

1729

BSA10

03095

07163

19756

9878

BALR ALAN U INC SEXTON GEOAGETOWN RO

BALT TMORE MO 21230

BEVIL AHO CO PORTLANO OREG

BEVII ELECTROHIE' INC 43 NEWARK WAY MAPLEWOOD NI

FORMERLY AAGL ER INDUSIREES EUZAEETH N

FORMERLY AKGLLER NDOSTRIES NEWARK N

BEVIK AYO WILOX LINE 60 95 SKINNER EAST HAMPTON CONN

BEVINS BROS MFE CO BEVIN RO $Z$ HAMPTON COHK OET24

BEVLES CO INC BOX 366 ALPENA MICH

BESSIRE AKD CO INC $101 \mathrm{E}$ SOUTH ITOLARAPOOLIS INO

GESSIBE GO THE 4103 WEST PLAY STREEI RICHKGONO VA

BESSOME E A TORP SALEM MASS

BEST CHAIN MFG CO LYMWOOD CALIF

BEST OEVICES CO INC 10921 BRTGGS RD CLEVELAMO OHTO

TASST AMO OOHOVAM CHICASO $I L$

NOW BEST ANO OONOVAN CANCHNATI OHIO

BEST ANO OOHAYAK CORMER FOWLER MANITOU STS

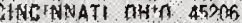

FORMERIY BEST ANO DONOVAN CHICAGO 111

GEST FOODS DIVISIOK OF CORH PRODUCTS CO TO E STAYE ST.

HEW. YORK N Y 1002 .

FORMERLY BEST FOODS WC NEW YORK NY

"BEST TONA JNS NEW YSRK IY Y

NOW BEST FOOOS OHVISION OF CORA PROOUCTS CO NEW YORK N Y

BEST GASKET CO 10 F $15 T$ T LOS AYGEELS CALF

BEST L CO SHEW YORA N Y

BEST MFE CO ING IRVINGTOA NI

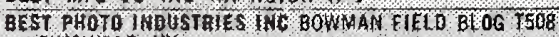

LOUISVILLE $K Y$

BEST PROBUCTS CO $2620 \mathrm{~W}$ ADO' SON STREET CHICAGO IIL GES18

0.264

BEST RICHARO PENCLL CO INC 213 MOUATAIK AVE SPAINGFIILO N

BEST STAMP AND MFE TQ 3214 TROOST AVENUE

KANSAS CITY MO 64109

BEST TOOL AND ENELNEERTHE CO DETROTT MICK

96863

36557

0078

16503

7096

13224

05411

70913

22907

93996.

06131

16356

Q5S12

$70 \% 8$

70990

98973

O3iा०

85413

02070

06216

10757

21766

07201

67335

85414

14575

BEST UNIYERSAL LOCK CO IHC PO BOX 103 INDTAMAPOLIS INO

BEST $W$ H ENGHEERING CO INC WEW YORK \& Y

BESTCO ROAP 3465 H 63 H HARRISBURE PA
00639

92713

96670

07063

19754

97325

19755

07073

07078

07078

91765

9765

96998

07087

7027

15534

11403

65407

90215

99266

70019

70976

85408

Figure 6. Proposed page design of handbook. 


\title{
Conversion to Linotron
}

\author{
Victor G. Kehler, Chief
}

\section{Advanced Systems Planning Team, Department of the Air Force}

The Air Force is committed to electronic composition. Further, we are committed to the use of the Mergenthaler Linotype Company Linotron.

On March 10, 1964, the Congressional Joint Committee on Printing (JCP) authorized our acquisition of a Lexical-Graphical ComposerPrinter (LGCP) system for installation at Wright-Patterson Air Force Base, Dayton, Ohio. This approval carried with it the restriction that the Air Force and Government Printing Office systems would be basically compatible. Although the two systems are not identically configured, the instruction tape produced by either system will drive either agency's phototypesetter (Linotron).

The Joint Committee on Printing controls all Government printing. Several necessary definitions are:

Printing

The processes of composition, platemaking, presswork and binding.

Composition_...-_._. Typesetting or final copy prepared by any method and used in the production of printing or a printing plate.

Departmental printing.-. All printing for general use in a department regardless of the place of origin. Shall not be produced or procured as field printing unless authorized by the JCP.

Field printing._._._.. All printing, the need for which originates and which is for use primarily in the geographical area of origin.

Thus, the Air Force approach must be to process departmental publications via the GPO. Field publications and certain departmental requirements waived to the field will be processed on the Air Force Logistics Command LGCP.

An LGCP system has three free-standing components, as shown in figure 1 . The Video Graphics Copier converts illustrations to video tape. The Format Processor accepts full-text coded magnetic tape, effects composition, and produces an instruction tape. The Photocomposer accepts the instruction and video tapes as input, is driven by the instruction tape to select and position data characters onto the output and to insert the graphics from the video tape when necessary, and creates fully composed pages in the form of film positives.

Programmed applications, totalling about 421,000 pages annually, are Air Force Supply Catalogs, selected Technical Orders, Master Equipment Lists, and some miscellaneous publications. We anticipate that this page volume will require about 1,686 LGCP hours annually, half of the available time. The timing is based on an average speed of 250 pages an hour, and staffing of one shift five days a week. Although the LGCP maximum speed is 600 pages an hour, we will be using varying sizes and styles of print and inserting graphics material; hence the 250-page yardstick.

The anticipated benefits from LGCP production of Stock Lists, Technical Orders, and Master Equipment Lists are a cost avoidance of $\$ 1,214,000$ and a reduction in bulk of 175,000 page negatives. Total page reduction, considering the number of copies produced, should be about 607 million. A 60 percent increase in page density should result from LGCP processing of Stock Lists, and an average increase of 50 percent for Technical Orders. See figure 2 for "before and after" examples.

The LGCP was contracted for during 1964, with a production lead time of about 2 years. In order to provide the Air Force Logistics Command with phototypsetting experience, a Mergenthaler Linofilm was installed during July 1964. An Electronic Printing Office was formed, consisting of computer personnel and printing technicians. Current staffing is 16 people-14 technical and 2 secretaries. With the assistance of Mergenthaler personnel, two general purpose programs, Autoset and Autofile, were developed for the IBM 7080. In addition, since some of the print tapes produced by current management data processing systems were processed through Linofilm to gain phototypesetting experience, specialized edit-insert programs were developed (fig. 3). Due to the unique data structuring, or record layout, of each such print tape, separate edit-insert programs were written to strip headings and add typesetting codes instead of developing a general purpose program. 


\section{SYSTEM COMPONENTS}

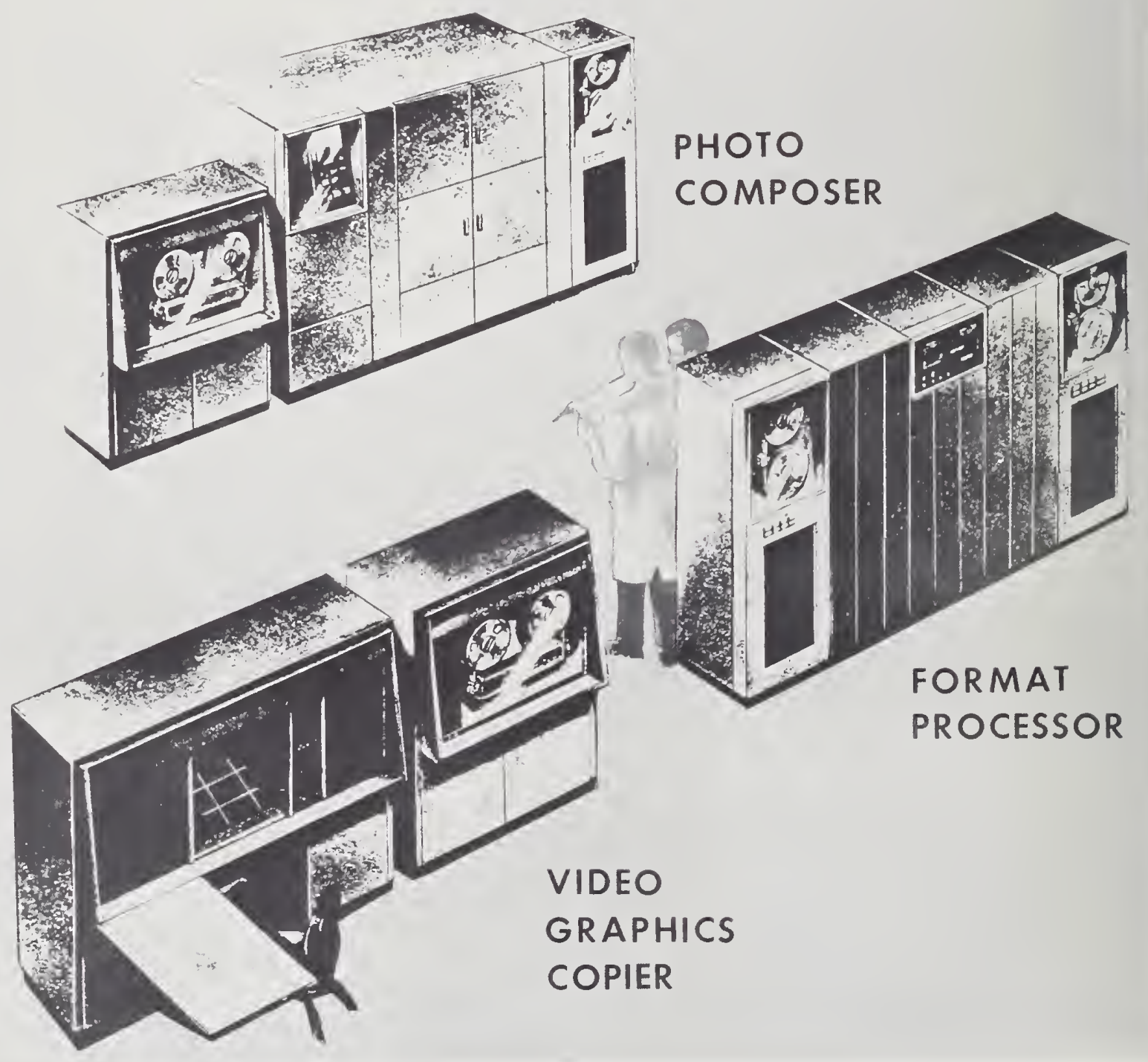

Figure 1. LGCP system components. 


\section{FORMAT COMPARISON}

\section{STOCK LISTS}

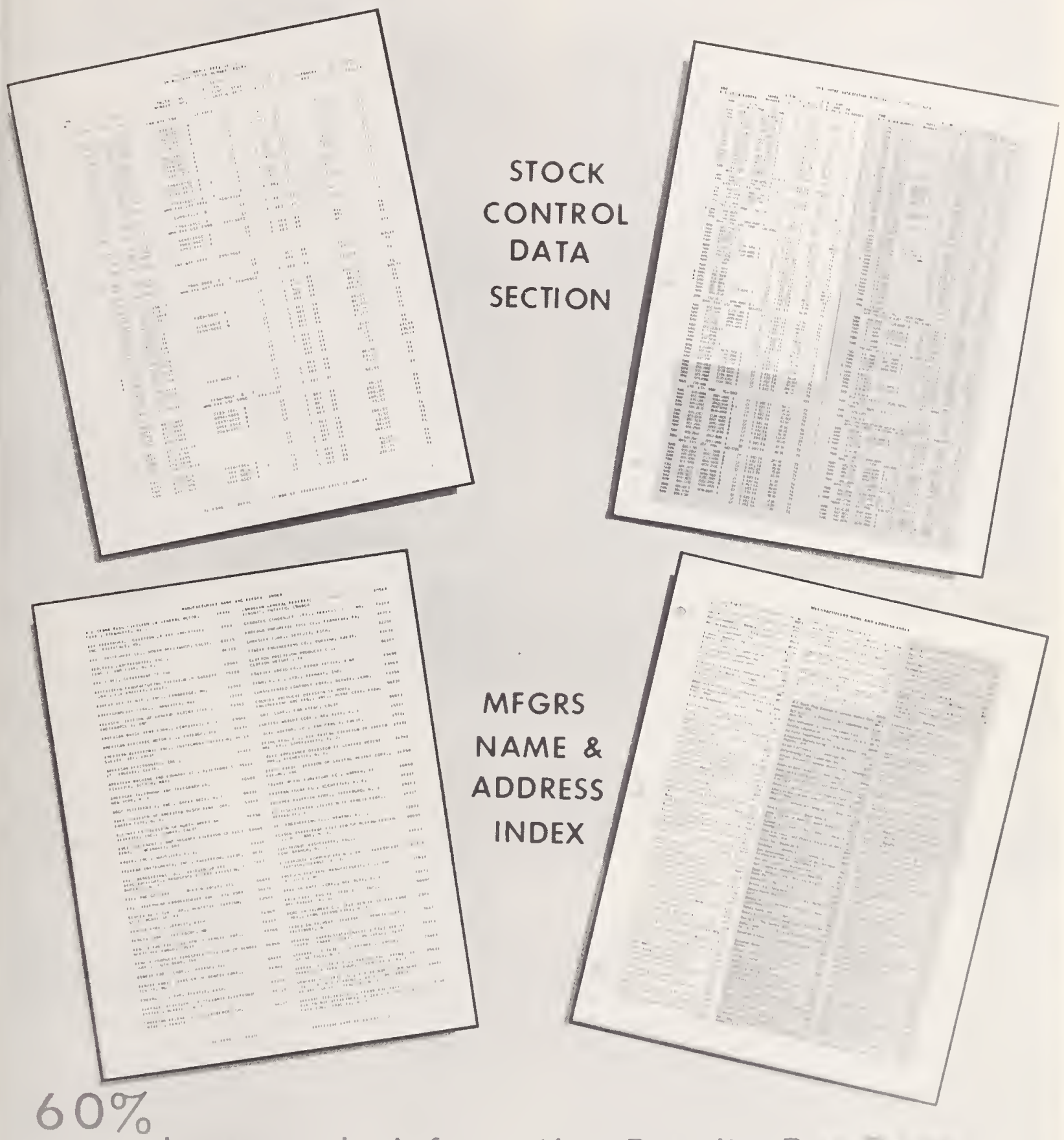

Increase in Information Density Per Proge

Figure 2. Format comparison showing inerease in information density per page. 


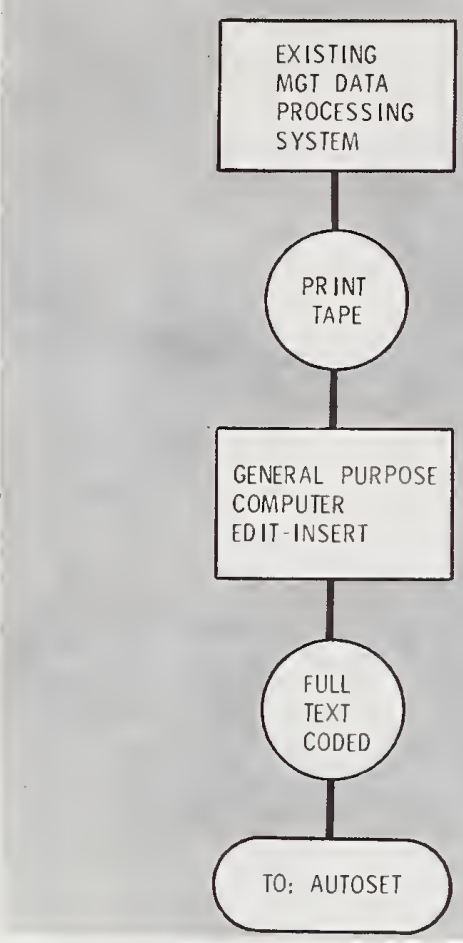

FIgURE 3. Flow chart showing route of mechanizcd source data.

The coded tape so produced can be input to the Autoset composition program.

When dealing with nonmechanized source data, the original manuscript is keyboarded with typesetting codes onto paper tape (fig. 4). This operation parallels the edit-insert program, and the paper tape, after conversion to magnetic tape, can be input to Autoset.

Autofile (fig. 5) is a file maintenance program designed to update publications which had been previously converted to magnetic tape and produced via photocomposition. This program would not be needed if all the phototypesetter input came from computer print tapes, since the file maintenance would be done by the management supporting data processing system. However, Autofile or its equivalent is vital to any phototypesetting system dealing with the automated composition of material which is now printed from manuscript copy. The updated information is keyboarded, prefixed with verb-type instructions such as "Add," "Change," "Advance," etc. The master is updated, a new master written, proof list prepared, and a full text-coded tape for input to Autoset or the LGCP Format Processor created. A restriction is

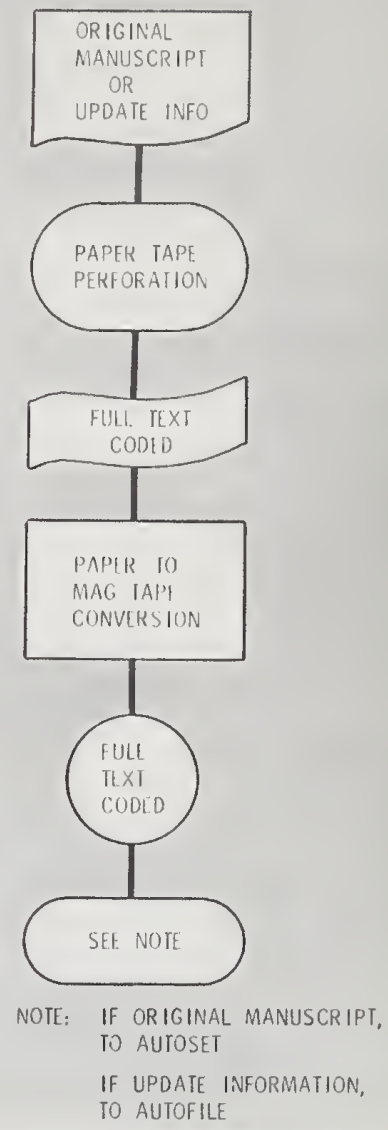

Figure 4. Flow chart of nonmechanized sourcc data.

that each sentence is a record; thus, if one wishes to change a word in a sentence, the entire sentence must be keyboarded.

The proof listing is double-lined; that is, the text appears on the first line and the typesetting codes on the second line. Since each tape record equals one sentence, and since the computer printer is limited to 132 characters per line, the proof listing usually shows several sets of double-line textcode data per sentence. Single spacing is used between the text and code lines; double spacing between sets. Further, each sentence is numbered sequentially, and that number indicated on the proof list. This number is used for identification purposes when correcting or updating. The sequential number, of course, will not appear on the "fulltext-coded" tape to be input to the Autoset program.

Autoset, figure 6, is a composition program designed to convert text and codes into an instruction tape to drive the Linofilm. Thus, it bears the same 


\section{AUTOFILE}

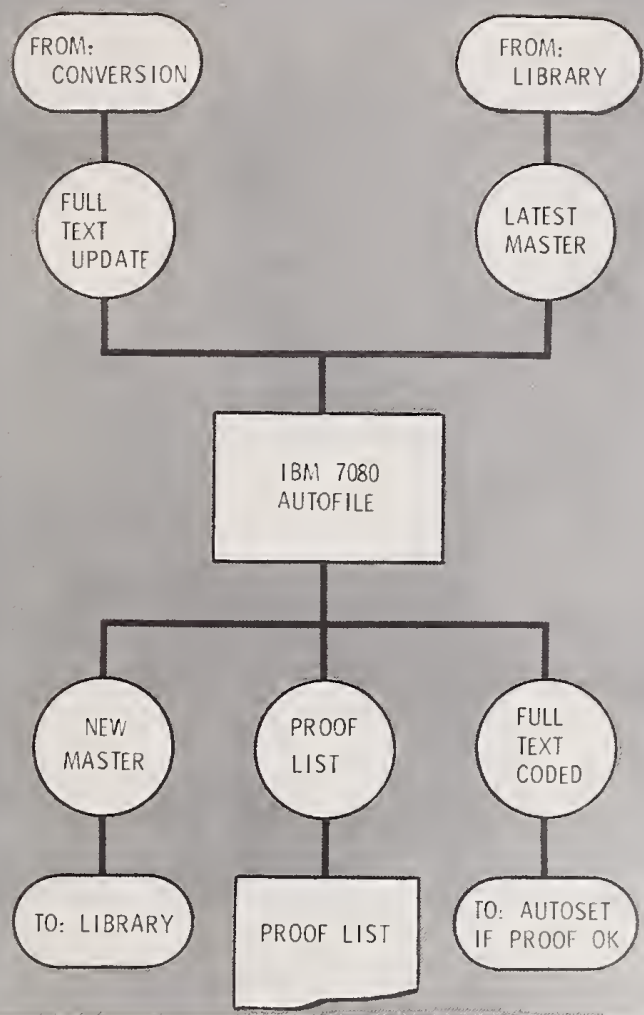

FIgURE 5. Autofile flow chart.

relationship to Linofilm that the Format Processor bears to the LGCP. The input tape emanates from the edit-insert program, from Autofile, or from the paper-to-magnetic-tape conversion of manuscript source data. Autoset uses a parameter tape to establish working factors such as line length, output format, etc., for the particular job being processed. The program converts the text tape data characters to grid codes which identify the corresponding character on the specified Linofilm grid. Justification is accomplished by matching the accumulated width values of the Linofilm characters against the predetermined line length, and adjusting inter-word spaces when necessary. Capabilities include centered lines, left justification, right justification, or left and right justification. The output instruction tape is converted to 15 -level paper tape to drive the Linofilm. At this time we have no definite plans to acquire magnetic tape Linofilm input capability.

An example of Linofilm production is the Master Equipment Management Index, figure 7. Current procedure is to treat a computer printout as camera-ready copy. The average number of pages so produced is about 4,500. Each page contains about 15 references. Linofilm increased page density to 20 references, and reduced total pages to about $3,300-$ a saving of about 25 percent. To use Linofilm, the print tape was processed through a specialized edit insert Univac 1107 program in about 3 minutes, the IBM 7080 Autoset program in about 25 minutes, and then through the Linofitm. Since this was a simulation exercise, the complete listing was not produced on the Linofilm. The average per-page processing time for those pages actually produced was 8.32 minutes. The entire product (3,300 pages) would have taken over 400 hours or almost three months on a one-shift fiveday-week basis. Compare this time to the LGCP rate of 250 pages per hour, or about 13 hours! The Linofilm has been so exercised using print tapes from the RCA 301, Univac 1107, and IBM 7080, and also using some nonmechanized source data.

We are not restricting the use of LGCP to the AFLC alone. All other Major Air Commands are surveying their unique printing requirements to identify potential LGCP applications. The AFLC will train other Air Force users in this respect.

Now, at the departmental level, we will be using the Government Printing Office facilities. Source data for printing is in one of two forms; either manuscript copy or computer printout listings. We are breaking our workload into these two categories, and are dealing with the latter type first.

The mechanized source data, that is, computer printouts, are comparatively easy to divert to Linotron. During the initial conversion, no change will be made to existing computer programs. This allows some backup, since we will have the capability to produce the final product in either Iinotron or computer printout mode. The print tape now produced by management supporting data systems is tabular data, contained in fixed fields. By the use of parameter cards, the print tape can be input directly to the Master Typography Program of the GPO IBM 360. The M'TP serves the same function as the $\mathrm{AFI}$, Format Processor; it creates an instruction tape to drive the phototypesetter. We realize that this approach will not give us upper and lower case distinction, bnt we will still enjoy some economic benefits.

For example, Part Five of Lir Force Manual $300-4$ is now produced by a computer, and the IBM 1401 printout treated as camera-ready copy (figure 8 ). By using the print tape as imput to the M'TP and designating a turn page mode, we can achieve a 40 percent reduction in the number of pages. 'This particular' part of AFM 300-4 is produced monthly in 10,000 copies. It a verages 220 pages, and should reduce to about 130 pages. Althongh it is tabular material, we are able to nse 


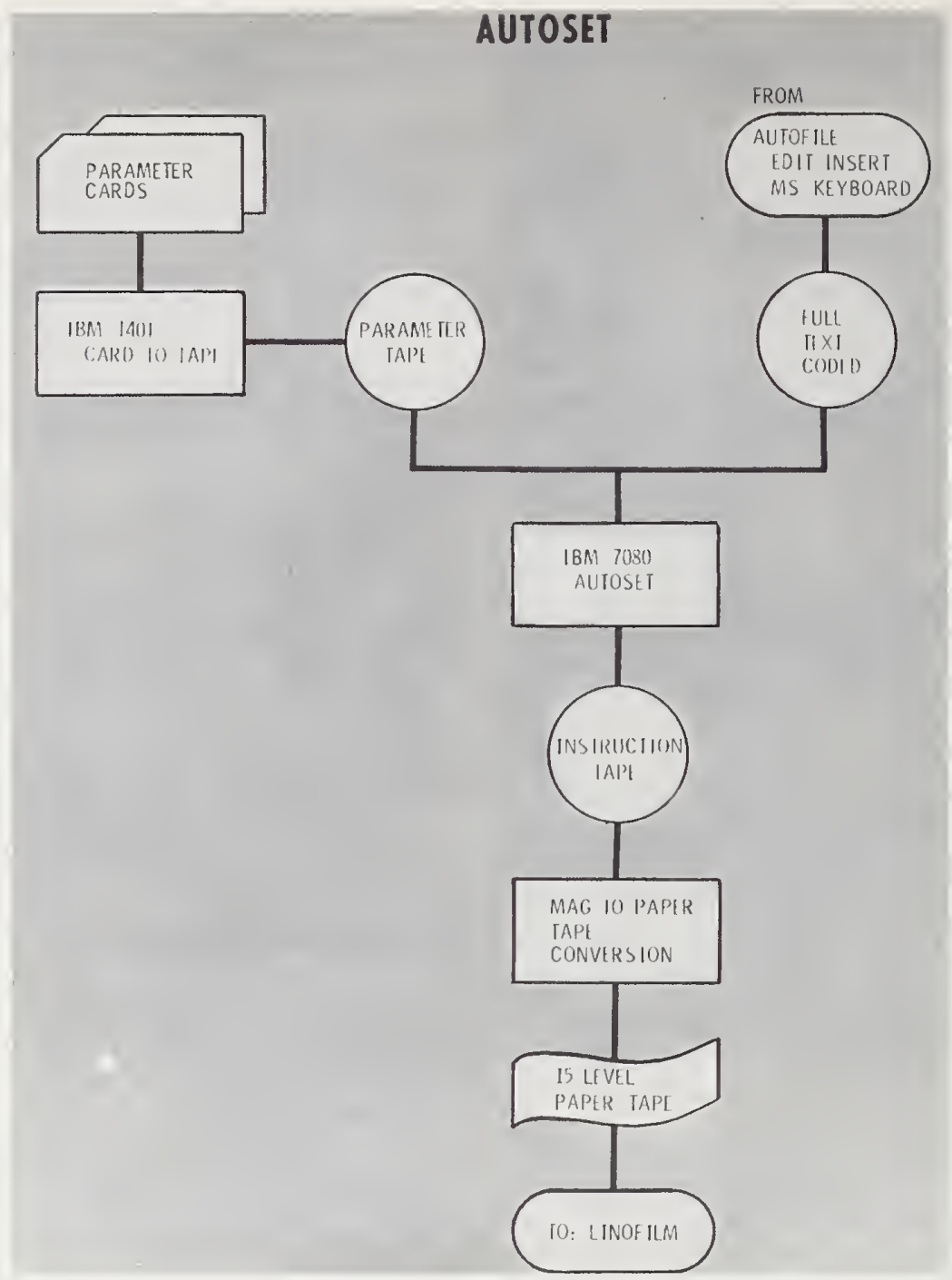

Figure 6. Autoset flow chart.

the turn page mode and to reduce the number of pages because the Linotron typographic quality allows the compression of data characters within the tabular fields without loss of readability. Later, after we have most of the computer-generated copy converted to Linotron, we will analyze this class of work to determine the "how" of obtaining upper-lower case distinction.

We are taking a real close look at the conversion of nonmechanized publications to Linotron. These now emanate from various offices within the Air Staff. Typed manuscript copy is forwarded to the Publishing Division where it is edited and prepared for the printer (fig. 9). For Linotron, we want a magnetic tape containing full text plus the function codes necessary to designate size, style and position of the data, shown in figure 10.

The various offices produce different kinds of typewritten products: general correspondence, reports, publication manuscripts. We want to capture the manuscript, in computer-compatible media, at the source. Automatic typewriters, which use paper or magnetic tape, seem to be an answer. The typing workload would be reduced, since a rough draft of any correspondence once captured on tape can be corrected many times, each time salvaging the "good" portion of the previous master, until the final product is acceptable. If the same automatic typewriter could produce computer-compatible magnetic tape, we would have an ideal machine to serve the dual correspondence-publication typing requirement.

However, until our study concerning requirements for automatic typewriters is complete, we will probably centralize the keyboarding of manu- 


\section{MASTER EQUIPMENT MANAGEMENT INDEX}

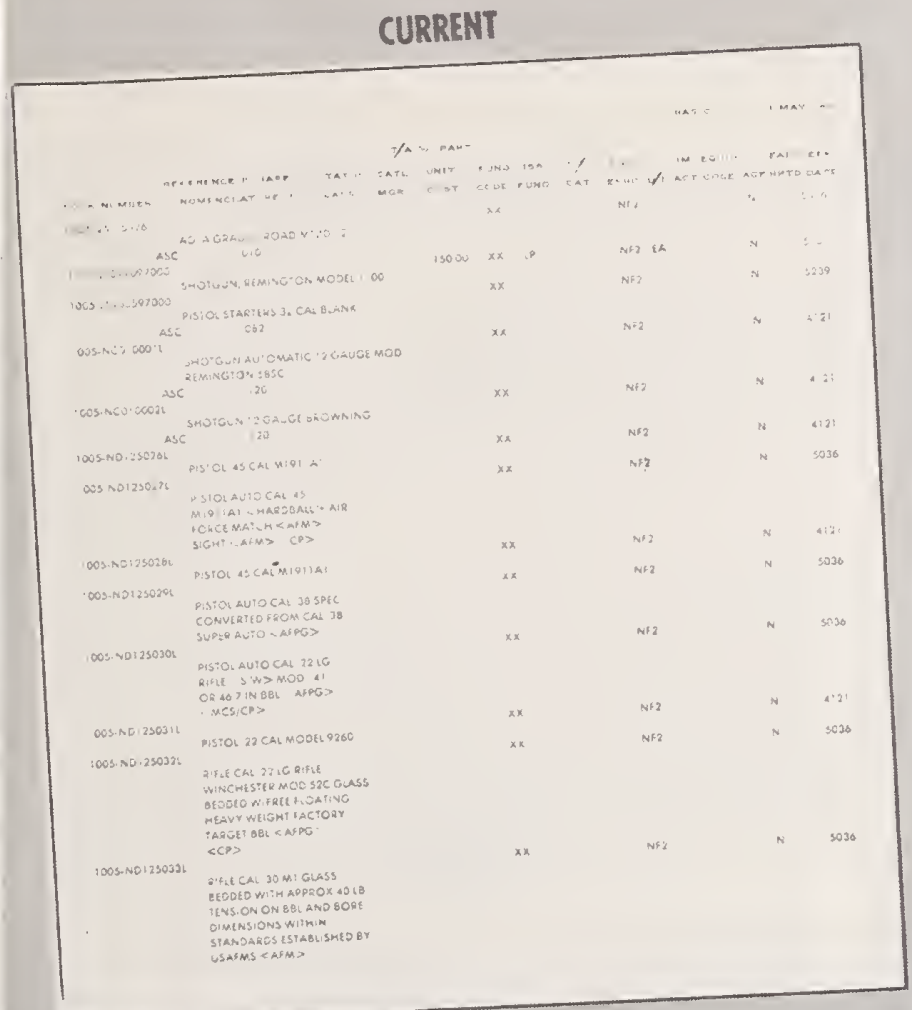

4500 PAGES

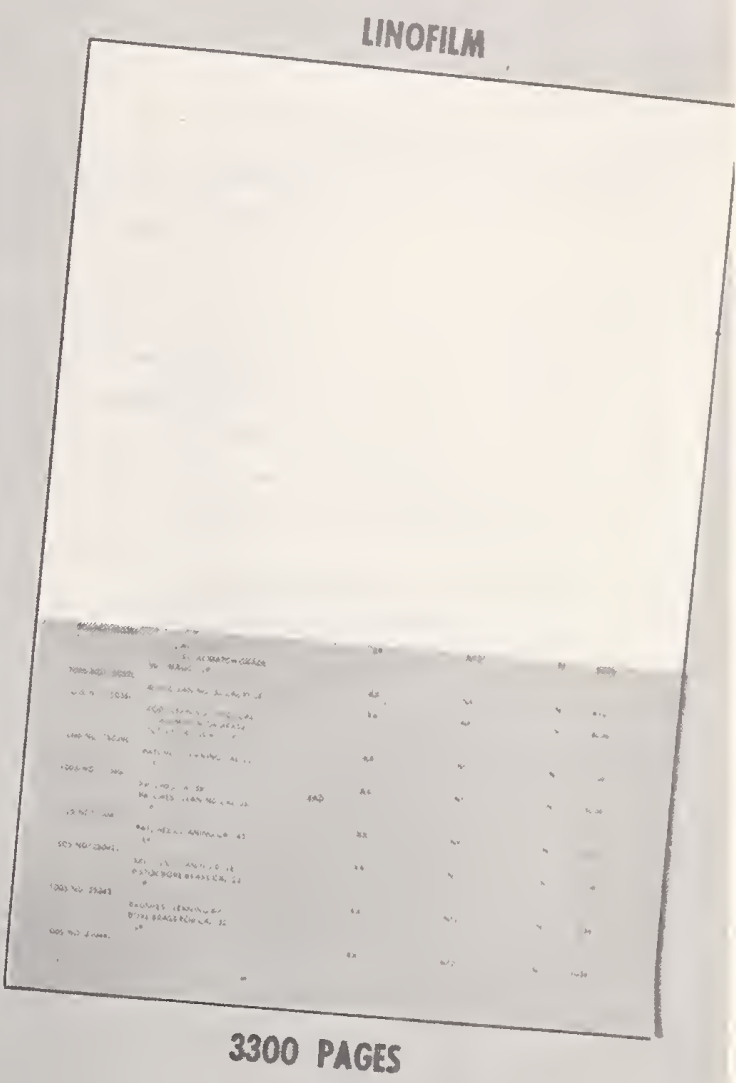

3300 PAGES

\section{$25 \%$ SAVINGS}

FIGURE 7. Comparison of current and Linofilm production of the master equipment management index showing a 25 percent savings obtained by using the Linofilm.

scripts destined for Linotron production. This will be done by acquiring keyboard-to-computer-compatible-magnetic-tape devices. Manuscript copy will continue to be typed by the originator and forwarded to the Publishing Division. Here it will be edited, the function codes inserted, and full keyboarding accomplished. Eventually, the originator will be sending us magnetic tape in addition to the manuscript.

Our future plans, after the automated publishing system is operational, include the development of an automated indexing system. We should be able to develop a computer program to screen the typesetting-coded tapes, isolate key words by paragraph and publication number, and create a crossindex showing the key word and all its references. This would prove invaluable in keeping our publications current and accurate. For example, if we were about to revise a particular publication, a search of the index should indicate, by paragraph and publication number, all other publications affected by the proposed revision. Thus, we could identify every change necessary due to a change in one publication.

In summary:

a. We are using the Air Force Logistics Command as our pilot on photocomposition. A Mergenthaler Linofilm is being used now, and a LexicalGraphical Composer-Printer will soon be installed. With the LGCP we will achieve automatic full-page composition comprised of both text and illustrations.

b. At the departmental level, we will use the GPO Linotron. Initially, copy now produced by management data systems will be Linotron-processed by diverting the print tape to the GPO. Later, manuscript copy will be converted to coded magnetic tape for the Linotron. Eventually, copy will be captured on magnetic tape at the originating level. 


\section{AFM 300-4 PART V}

PRODUCED MONTHLY 10,000 COPIES

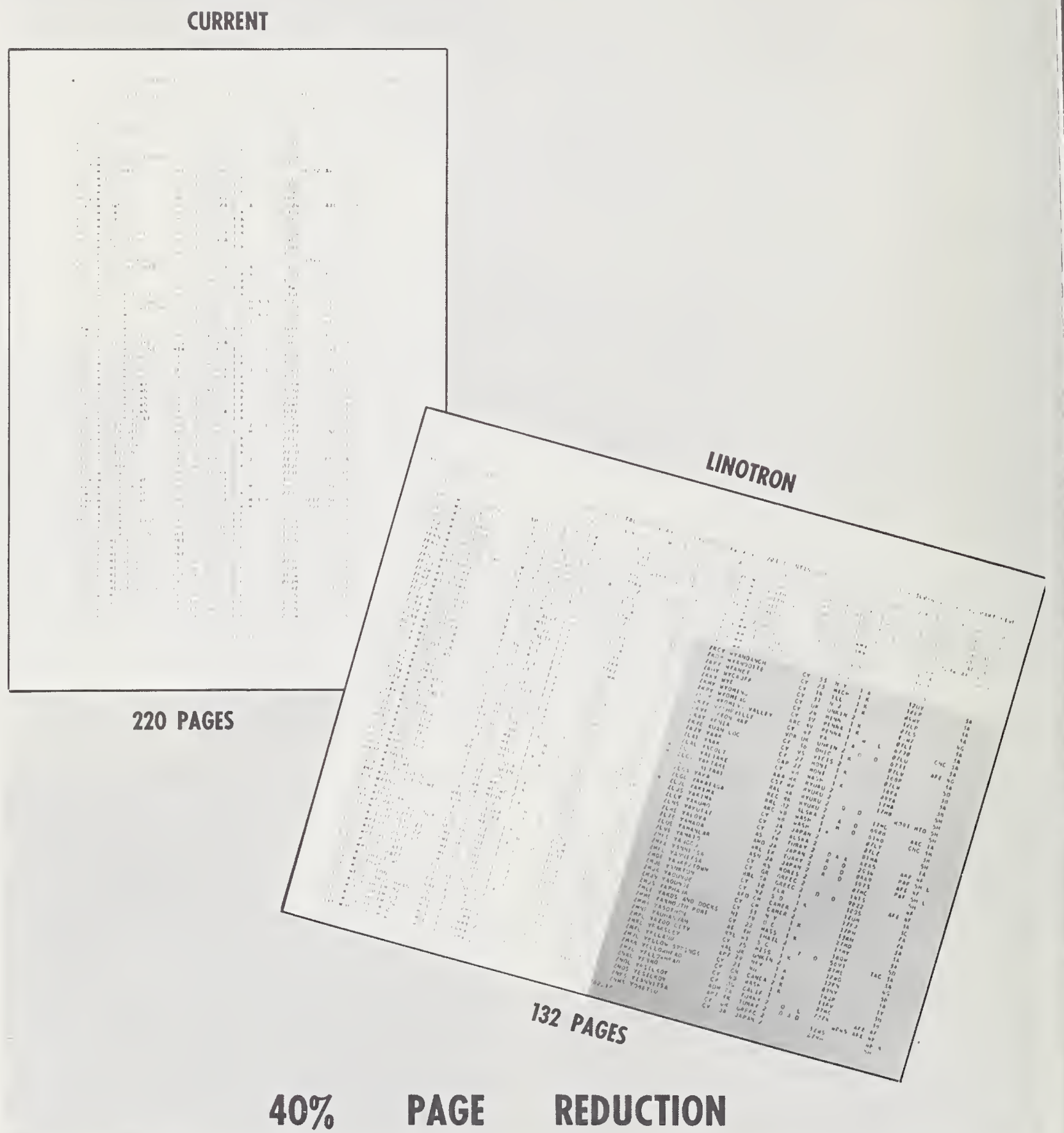

FIGURE 8. A 40 percent reduction in number of pages is achieved with Air Force Manual s00-4 using the Linotron. 
AFR. 100-7

AIR FORCE REGUIATION

NO. $100-7$
DEPARTMENT OF THE AIR FORCE

Washington, 16 December 1966

Communications-Electronics Activities

COMMNICATIONS PUBLICATIONS (JANAPS, ACPS, and AMSPS)

This regulation tells how the Air Force distributes JANAPs, ACPs, and AMSPs.

$k \rightarrow i_{1}$

1. Terms Explained. For the purpose of this regulation, the following terms apply:

a. ACPs (Allied Communications Publications). Publications prepared in conjunction with other allied nations. The Joint Chiefs of Staff (JCS) have approved ACPs for United States use.

$r ?$

b. AMSPs (Allied Military Security Publications). Cryptographic publications adopted for use by NATO: AMSPs will gradually replace cryptographic publications with ACP titles.

c. Changes, Formal, printed, serially numbered modifications of JANAPs, ACP, AMSPs, and supplements.

d. JANAPs (Joint Army, Navy, Air Force Publications). US publications prepared under the direction of the Joint Chiefs of Staff for joint-service use.

e. Memorandum Corrections. Memorandums containing part or all of important approved changes that have not been formally issued. These memorandums are issued inf requently.

This regulation supersedes AFR 100-7. 18 September 1962

OPR: AF'OCCON

DISTRIBUTION: $S$

Figure 9. Example of a typical manuscript page edited and marked for the printer. 
IIO2 AIR FORCE REGULATION TIC2 NO. 100-7

\section{FIOI AFR 100-7}

II03DEPARTMENT OF THE AIR FORCE

RI03 Washington, 16 December 1966

JIOY Communications-Electronics Activities

IIO5 COMMUICATIONS PUBLICATIONS (JANAPS, ACPS, and AMSPS)

7106 This regulation tells how the Air Force distributes JANAPs, ACPs, and AMSPs.

$$
\text { IIII }
$$

KI07 1. Terms Explained. $V$ For the purpose of this regulation, the following terms apply:

rIO8 a. ${ }^{\top T 2}$ ACPs (Allied Communications Publications). ${ }^{\top}{ }^{\top}$ Publications prepared in conjunction with other allied nations. The Joint Chiefs of Staff (JCS) have approved ACPs for United States use. AP

b. ${ }^{\sim \top 2}$ AMSPs (Allied Military Security Publications). ${ }^{2}{ }^{\top}$ Cryptographic publications adopted for use by NATO; AMSPs will gradually replace cryptographic publications with ACP titles. IP

c. "Changes? Formal, printed, serially numbered modifications of JANAPs, ACP, AMSPs, and supplements. If $P$

d. JANAPs (Joint Army, Navy, Air Force Publications). $)^{\top 1}$ US publications prepared under the direction of the Joint Chiefs of Staff for joint-service use. IP

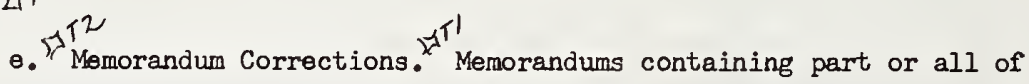
important approved changes that have not been formally issued. These memorandums are issued infrequently. तो

112

YI09 This regulation supersedes AFR 100-7, 18 September 1962

MI 10 OPR: AFOCCON MP

DISTRIBUTION: SAP

FIGURE 10. The same page as in figure 9 marked with special codes for reproduction using the Linotron. 